\title{
Atherosclerotic plaque stability : identification and validation of key regulators
}

Citation for published version (APA):

Schapira, K. B. (2007). Atherosclerotic plaque stability : identification and validation of key regulators. [Doctoral Thesis, Maastricht University]. Datawyse / Universitaire Pers Maastricht. https://doi.org/10.26481/dis.20070906ks

Document status and date:

Published: 01/01/2007

DOI:

$10.26481 /$ dis.20070906ks

Document Version:

Publisher's PDF, also known as Version of record

\section{Please check the document version of this publication:}

- A submitted manuscript is the version of the article upon submission and before peer-review. There can be important differences between the submitted version and the official published version of record.

People interested in the research are advised to contact the author for the final version of the publication, or visit the DOI to the publisher's website.

- The final author version and the galley proof are versions of the publication after peer review.

- The final published version features the final layout of the paper including the volume, issue and page numbers.

Link to publication

\footnotetext{
General rights rights.

- You may freely distribute the URL identifying the publication in the public portal. please follow below link for the End User Agreement:

www.umlib.nl/taverne-license

Take down policy

If you believe that this document breaches copyright please contact us at:

repository@maastrichtuniversity.nl

providing details and we will investigate your claim.
}

Copyright and moral rights for the publications made accessible in the public portal are retained by the authors and/or other copyright owners and it is a condition of accessing publications that users recognise and abide by the legal requirements associated with these

- Users may download and print one copy of any publication from the public portal for the purpose of private study or research.

- You may not further distribute the material or use it for any profit-making activity or commercial gain

If the publication is distributed under the terms of Article $25 \mathrm{fa}$ of the Dutch Copyright Act, indicated by the "Taverne" license above, 


\section{Atherosclerotic plaque stability: identification and validation of key regulators}


Cover illustration: Human coronary artery atherosclerotic plaque. Image kindly provided by Dr. Andrzej Loesch, Phd, DSc.

\section{ISBN 9789052786445}

(c) Copyright Kitty Schapira, Maastricht 2007 


\title{
Atherosclerotic plaque stability: identification and validation of key regulators
}

\author{
Proefschrift
}
ter verkrijging van de graad van doctor aan de Universiteit Maastricht, op gezag van de Rector Magnificus, Prof. mr. G.P.M.F. Mols
volgens het besluit van het College van Decanen, in het openbaar te verdedigen op
donderdag 6 september 2007 om 14:00 uur

door

Kitty Brigitte Schapira

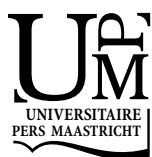




\section{Promotor}

Prof. dr. M.J.A.P. Daemen

\section{Copromotor}

Dr. S. Heeneman

\section{Beoordelingscommissie}

Prof. dr. C. Bruggeman (Voorzitter)

Prof. dr. E.A.L. Biessen

Prof. dr. W. Buurman

Prof. dr. A. Tedgui (INSERM, Paris)

Prof. dr. H. ten Cate gratefully acknowledged. 


\section{Contents}

Chapter 1 General introduction 9

$\begin{array}{lll}\text { Chapter } 2 & \text { Animal models to study plaque vulnerability } & 15\end{array}$

Chapter 3 Gene profiling in atherosclerosis reveals a key role for 33 small inducible cytokines: validation using a novel monocyte chemoattractant protein monoclonal antibody

Chapter 4 Anti-angiogenesis treatment with anginex or endostatin inhibits early lesion development in collar-induced atherosclerotic plaques of ApoE-/- mice

Chapter 5 Genetic deletion or antibody blockade of $\alpha 1 \beta 1$ integrin induces a stable plaque phenotype in ApoE-/- mice

Chapter 6 TWEAK inhibition reduces fibrosis and alters the macrophage phenotype in atherosclerotic plaques of ApoE-/mice

Chapter 7 General discussion

Summary

Samenvatting

Full colour figures

Acknowledgements

Curriculum Vitae

Publications 
oSMA alpha smooth muscle actin

$\mathrm{Ab} \quad$ antibody

AHA American Heart Association

ApoE-/- apolipoprotein E knockout

BMP bone morphogenic protein

BSA bovine serum albumin

CD40L CD40 ligand

cDNA complimentary DNA

CHX cycloheximide

DAPI 4',6-diamidino-2-phenylindole

DiI 1,1'-dioctadecyl-3,3,3', 3'-tetramethylindocarbocyanine perchlorate

DNA deoxyribonucleic acid

EC endothelial cell

ECM extracellular matrix

ELISA enzyme-linked immunosorbent assay

EST expressed sequence tag

FACS fluorescence-activated cell sorting

FasL Fas ligand

FGF fibroblast growth factor

HDL high density lipoprotein

HE hematoxylin and eosin

HMGB1 high mobility group box 1

IFN $\gamma \quad$ interferon gamma

IL interleukin

IVUS intravascular ultrasound

LDL low density lipoprotein

LDLR-/- low density lipoprotein receptor knockout

$\mathrm{mAb}$ monoclonal antibody

MAPP microarray pathway profiles

MCP monocyte chemoattractant protein

MGP matrix Gla protein

MI myocardial infarction

MMP matrix metalloproteinase

MRI magnetic resonance imaging

MSB martius, scarlet and blue

NC normal chow

NFкB nuclear factor kappa B 


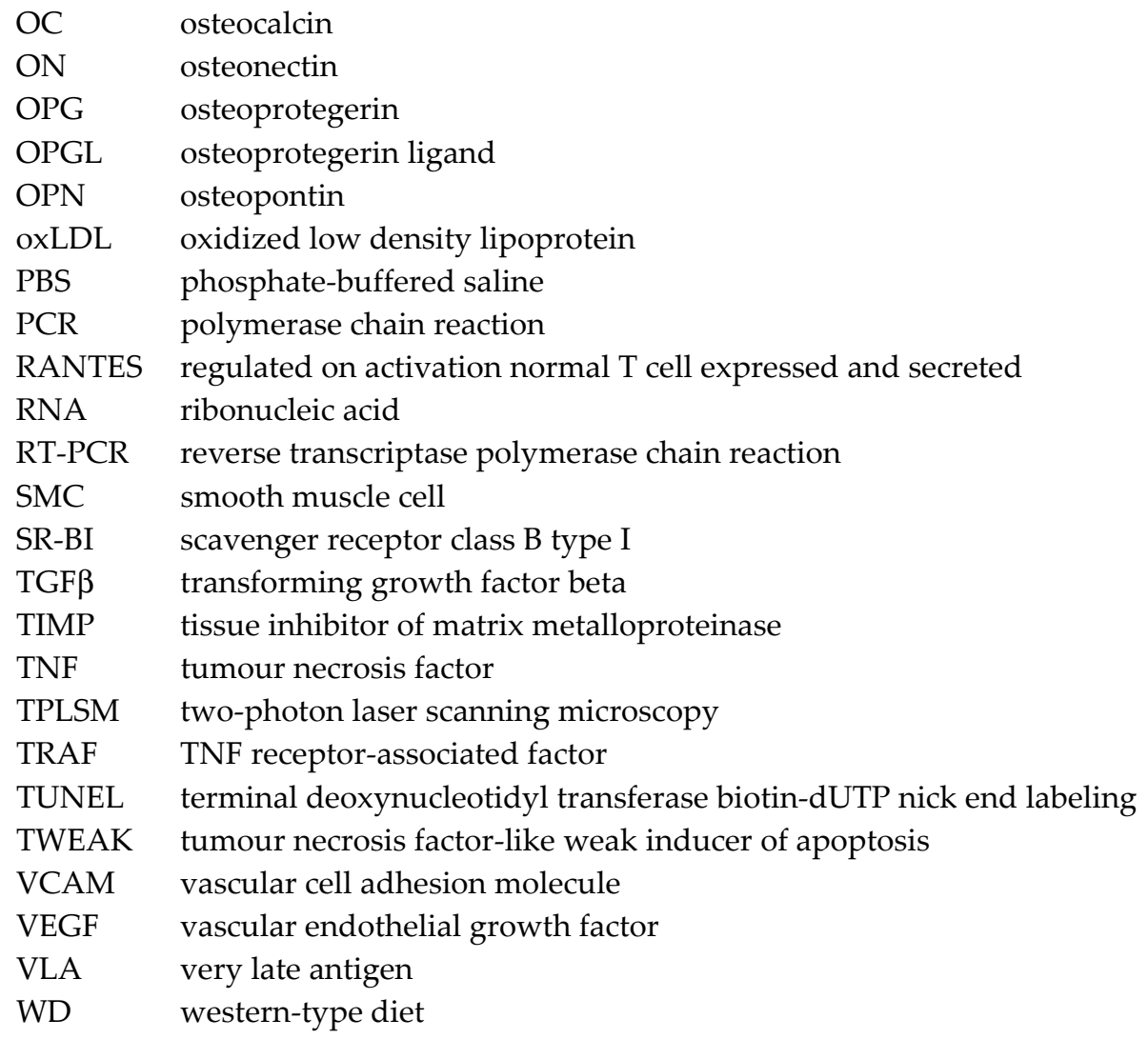




\section{CHAPTER 1}

s.ing

General introduction
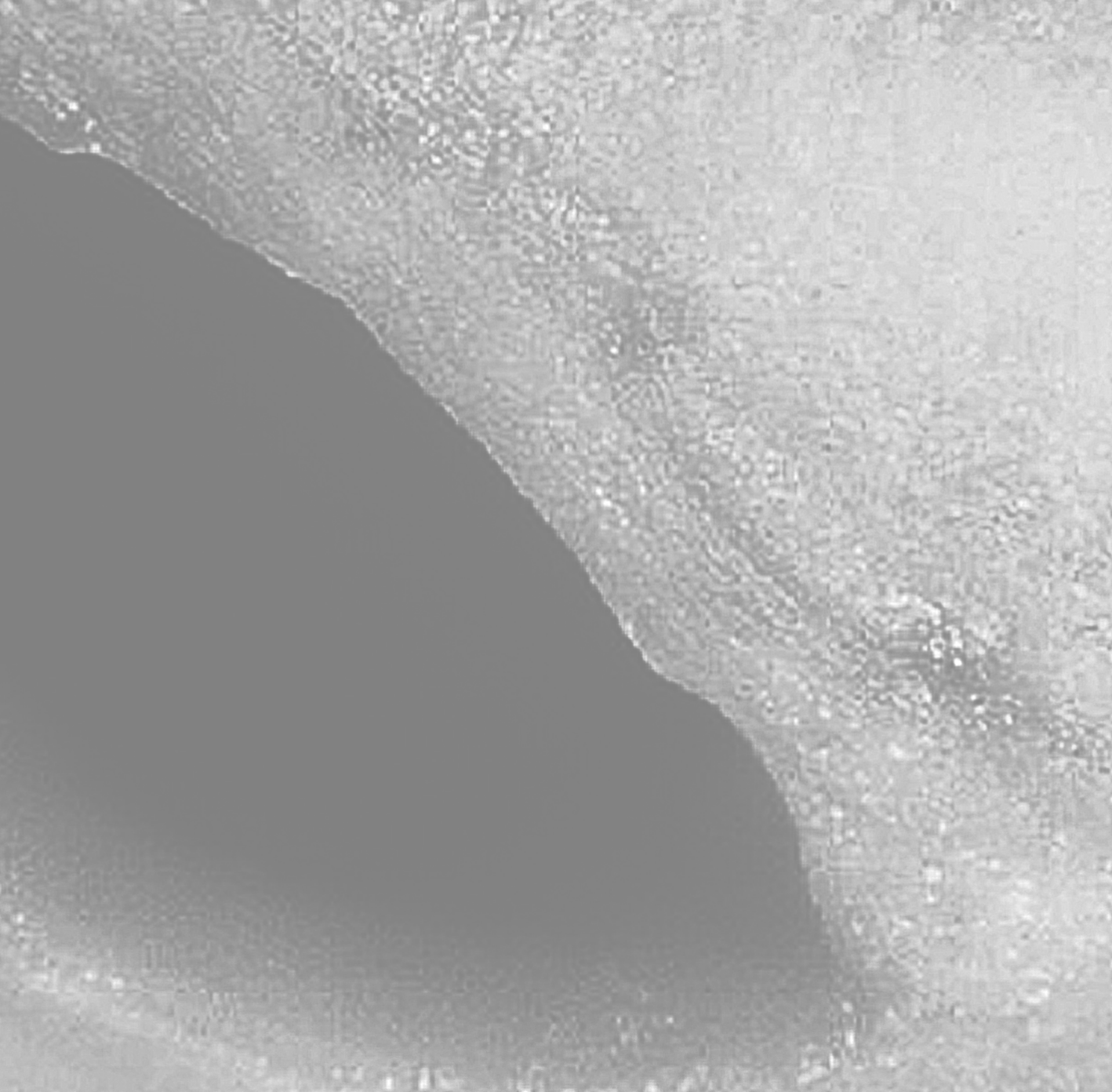


\section{Clinical Relevance}

Cardiovascular disease is the leading cause of death and disability in western society and is increasing rapidly in the developing world. ${ }^{1}$ An underlying cause of cardiovascular disease is atherosclerosis, a disease of the large and medium-sized arteries characterized by fatty deposits that develop in the inner lining of the vessel wall. Atherosclerosis is a progressive disease that begins as early as infancy and becomes clinically relevant in the adult affecting different organ systems depending on the artery affected. ${ }^{2}$ Luminal narrowing of an artery due to lesion progression can impair blood flow to target organs, especially during exertion when metabolic activity and oxygen demand are increased. In the coronary and cerebral circulation this can lead to angina pectoris or transient ischemic attack, respectively. The renal arteries, lower extremities and abdominal aorta are also frequently affected by atherosclerosis resulting in renal failure, claudication, and limb-threatening ischemia. ${ }^{3}$ Common acute manifestations of atherosclerosis are myocardial infarction or stroke as a result of complete vessel occlusion caused by the formation of a thrombus over an underlying atherosclerotic plaque.

\section{Pathogenesis of Atherosclerosis}

A widely accepted hypothesis of the initiation of atherosclerosis is the response to injury theory, which proposes that endothelial dysfunction in the arterial wall causes an inflammatory and fibroproliferative response. ${ }^{4}$ Endothelial dysfunction can be caused by various factors such as hyperlipidemia, hyperglycemia, infectious agents, and toxins. ${ }^{5}$ The injured site is characterized by increased adhesion and permeability of endothelial cells (EC) leading to an accumulation of lipoproteins in the intima of the vascular wall. An inflammatory response ensues as chemokines released by ECs recruit circulating monocytes and $\mathrm{T}$ lymphocytes that infiltrate the intima. ${ }^{6}$ Extravasated monocytes differentiate into macrophages as they take up modified lipids such as oxidized low density lipoprotein (oxLDL) thereby forming the characteristic foam cells of early lesions. The inflammatory response is perpetuated as macrophages release cytokines and growth factors that activate vascular smooth muscle cells (SMC) residing in the media to proliferate and migrate to the intima. SMCs synthesize components of extracellular matrix (ECM) such as collagen resulting in the formation of a fibrous cap that covers the lesion. Progression to advanced lesions occurs as macrophage foam cells release their lipid content leading to the development of a necrotic core. When lesions are disrupted and the fibrous cap loses its integrity, the highly thrombogenic necrotic core is exposed and comes in contact with blood prompting the formation of a thrombus that overlies the plaque. If the thrombus is large enough, this can lead to complete occlusion of the vessel resulting in an acute clinical event. Fibrotic lesions or those with a thick fi- 
brous cap are generally considered stable, whereas those with a thin fibrous cap, large lipid core, and inflammation in the shoulder region are considered unstable and at risk for thrombus formation. ${ }^{7}$

\section{Hypothesis}

Because atherosclerosis is a complex multifactorial disease, identification of potential mediators at various stages is key in gaining insight into the atherogenic process. Once mediators are identified, they can be manipulated in animal models of atherosclerosis such that their effects are either inhibited or enhanced in an attempt to promote stability in lesions. We hypothesized that in a mouse model of atherosclerosis, the apolipoprotein E-deficient mouse (ApoE-/-), the various stages of atherogenesis are accompanied by a specific expression patterns of genes. To test this hypothesis, we used microarray technology to analyze gene expression in the various stages of atherosclerosis in ApoE-/- mice. The gene expression profile during plaque progression revealed upregulation of genes involved in inflammation, namely the small inducible cytokines, as well as genes involved in matrix degradation. We further hypothesized that inhibition of the small inducible cytokines would reduce atherosclerosis and lead to a stable plaque phenotype.

Besides gene expression profiling using microarray technology, novel mediators involved in atherosclerosis as well as new potential targets of intervention may be found in the literature. Examples are very late antigen-1 (VLA-1) and tumour necrosis factor-like weak inducer of apoptosis (TWEAK), which have previously been shown to play a role in fibrosis and inflammation. Given that atherosclerosis is an inflammatory disease, the role of VLA- 1 and TWEAK was investigated in the present thesis in ApoE-/- mice. We hypothesized that inhibition of VLA-1 and TWEAK would reduce atherosclerosis and induce a stable plaque phenotype.

Processes that promote atherosclerotic development and progression such as angiogenesis may also be targeted in an attempt to induce stable lesions. We hypothesized that inhibiting angiogenesis would reduce atherosclerosis in an ApoE-/mouse model.

\section{Outline of this Thesis}

In this thesis, we identify and describe the role of several mediators of atherosclerosis in ApoE-/- mice. First, in chapter 2, the various animal models of atherosclerosis, particularly those used in the study of unstable lesions are reviewed and evaluated. In chapter 3, we identify the gene expression profile during atherosclerotic plaque progression in ApoE-/- mice and reveal a role for small inducible cytokines such as monocyte chemoattractant protein-1 (MCP-1). In chapter 4, we describe the effects of 
treatment with the angiogenesis inhibitors anginex and endostatin on atherosclerotic plaque development in the ApoE-/- mouse model of collar-induced atherosclerosis. In chapter 5, the role of VLA-1 is described in atherosclerotic development in ApoE-/- mice. Similarly, in chapter 6, the role of the multifactorial cytokine TWEAK is described in atherosclerotic development in ApoE-/- mice. Lastly, in chapter 7, the findings in this thesis are discussed and future directions are given. 


\section{References}

1. Yusuf S, Reddy S, Ounpuu S, Anand S. Global burden of cardiovascular diseases: part I: general considerations, the epidemiologic transition, risk factors, and impact of urbanization. Circulation. 2001;104:2746-2753.

2. Stary HC. Lipid and macrophage accumulations in arteries of children and the development of atherosclerosis. Am J Clin Nutr. 2000;72:1297S-1306S.

3. Silva JA, White CJ. Plaque instability in peripheral vessels. Prog Cardiovasc Dis. 2002;44:429-436.

4. Ross R, Glomset JA. Atherosclerosis and the arterial smooth muscle cell: Proliferation of smooth muscle is a key event in the genesis of the lesions of atherosclerosis. Science. 1973;180:1332-1339.

5. Hadi HA, Carr CS, Al Suwaidi J. Endothelial dysfunction: cardiovascular risk factors, therapy, and outcome. Vasc Health Risk Manag. 2005;1:183-198.

6. Hansson GK. Inflammation, atherosclerosis, and coronary artery disease. $N$ Engl J Med. 2005;352:1685-1695.

7. Virmani R, Burke AP, Farb A, Kolodgie FD. Pathology of the unstable plaque. Prog Cardiovasc Dis. 2002;44:349-356. 


\section{CHAPTER 2}

\section{Animal models to study plaque}

vulnerability

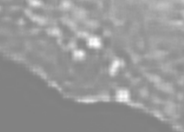

Kitty Schapira, Sylvia Heeneman, Mat J.A.P. Daemen

Current Pharmaceutical Design 2007;13(10):1013-1020

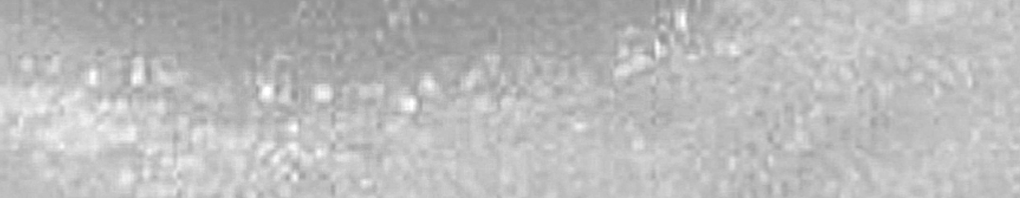




\begin{abstract}
The need to identify and characterize vulnerable atherosclerotic lesions in humans has lead to the development of various animal models of plaque vulnerability. In this review, current concepts of the vulnerable plaque as it leads to an acute coronary event are described, such as plaque rupture, erosion, intraplaque hemorrhage, and neovascularization. Recently developed animal models that have attempted to reproduce these concepts are described and evaluated based on their suitability in the study of vulnerable plaques. Although certain features of plaque vulnerability have been reported in animal models, a model encompassing all aspects of the vulnerable plaque is lacking.
\end{abstract}




\section{Definition of a Vulnerable Plaque}

The definition of a "vulnerable" plaque varies among literature and is constantly being revised as clinicians and investigators gain more insight into the pathobiology of atherosclerosis and the conditions that lead to acute coronary events and stroke. Until about 10 years ago it was thought that atherosclerosis was a process in which lesions progressed to the point of complete arterial stenosis thereby leading to an acute coronary event. ${ }^{1}$ It is now accepted that most clinical manifestations of atherosclerosis such as acute myocardial infarction (MI), unstable angina, and sudden cardiac death result from the development of an occlusive thrombus over an underlying plaque. ${ }^{2}$ Vulnerable plaques are most often described as prone to thrombus formation and have a high probability of progressing rapidly to the point of becoming culprit lesions. ${ }^{3}$

There are various ways in which plaques can lead to thrombus formation, the most common being plaque rupture. ${ }^{4}$ Virmani et al. ${ }^{5}$ defined plaque rupture as a fibroatheroma with a disruption in the cap where the overlying thrombus is continuous with the lipid core. Until recently it was thought that all acute coronary events were the result of plaque rupture, however an occlusive thrombus can also be caused by plaque erosion. ${ }^{6}$ This term defines plaques with a thrombus in which there is no evidence of rupture and the endothelium is absent at the site of erosion. ${ }^{5}$ A less common, but documented cause of atherothrombosis is the calcific nodule, which is described as erupting through the fibrous cap into the lumen resulting in the formation of a thrombus. ${ }^{5}$

Because the etiology of coronary thrombi is diverse, it is important to characterize vulnerable plaques. When plaques prone to rupture were first defined as vulnerable, they were described as having thin fibrous caps, large lipid cores, and macrophage accumulation. ${ }^{7}$ In a comprehensive classification scheme for atherosclerotic lesions, Virmani et al. referred to lesions that are most likely to rupture as thin fibrous cap atheromas. ${ }^{5}$ Such plaques are characterized by a thin fibrous cap, a large lipid core, and an inflammatory infiltrate. However, it is important to emphasize that not all plaques responsible for acute coronary syndromes possess this phenotype, as demonstrated by post-mortem studies. ${ }^{5,8,9}$ It also appears necessary to take into consideration the coagulability of the patient's blood as well as the susceptibility of the myocardium to develop fatal arrhythmia since these factors contribute to acute coronary syndromes. ${ }^{3}$

Several recent reviews have argued that the concept of the "vulnerable plaque" is overly simplistic and implies that such plaques can predict future clinical events., ${ }^{3,10-13}$ Characterization of vulnerable plaques has been based on retrospective histological studies of plaques containing a thrombus and, therefore, do not describe plaques just prior to thrombus formation. Currently, the life of a lesion and the circumstances that ultimately lead to acute clinical events are unknown simply because of the inability to recognize lesions that become clinically relevant. Imaging 
techniques have been able to identify features of atherosclerotic plaques, however longitudinal studies following the life of a plaque are limited. One recent study did however, follow subjects over an 18-month period using magnetic resonance imaging (MRI) to investigate whether intraplaque hemorrhage in carotid artery lesions stimulates plaque progression. ${ }^{14}$ Indeed, it was found that hemorrhage into carotid lesions was associated with atherosclerotic plaque progression. Another imaging technique, intravascular ultrasound (IVUS), has shown promise as it can distinguish between stable and unstable lesions. ${ }^{15}$ In a two-year follow-up study, the progression of non-stenotic atheromatous ruptured plaques in patients presenting with acute coronary syndromes was assessed using IVUS. It was found that $50 \%$ of ruptures healed spontaneously within the two years of follow-up. ${ }^{16}$ This study provides useful information for the treatment of patients with acute coronary syndromes, however serial prospective studies using IVUS on the natural history of plaques leading to rupture and thrombosis have not yet been published.

In this review, the term vulnerable plaque will refer to the "concept of such plaques and not their histologic basis", as recommended by Schaar et al.,13 and will be used synonymously with "unstable plaque", "high-risk plaque", and "thrombusprone plaque".

\section{Mechanisms of Plaque Vulnerability}

When a plaque ruptures, the fibrous cap is disrupted exposing the thrombogenic lipid core, which comes in contact with circulating blood leading to thrombus formation and ultimately to an acute clinical event. Thin fibrous caps are associated with a reduced smooth muscle cell (SMC) and extracellular matrix (ECM) content. ${ }^{5}$ Because SMCs produce collagen, a major ECM component of atherosclerotic plaques, one of the mechanisms proposed to contribute to plaque vulnerability is fibrous cap thinning as a result of SMC apoptosis. ${ }^{17,18}$ The death of SMCs was shown to be induced by their direct interaction with macrophages. ${ }^{19}$ It has been suggested that SMCs in human atherosclerotic plaques exhibit reduced proliferation, undergo earlier senescence, and demonstrate higher levels of apoptosis. ${ }^{20}$ It has also been proposed that activated mast cells may contribute to plaque rupture through the secretion of mediators such as chymase, which inhibit SMC-mediated collagen synthesis. $^{21}$

In addition to collagen synthesis, the stability of an atherosclerotic plaque depends on collagen degradation. ${ }^{22}$ Expression of matrix degrading enzymes have been shown in atherosclerotic plaques such as matrix metalloproteinases (MMP) ${ }^{23}$ and cathepsins $\mathrm{K}$ and $\mathrm{S},{ }^{24,25}$ and contribute to plaque vulnerability by reducing the collagen content in plaques and degrading the fibrous cap. ${ }^{23}$ In addition, tissue inhibitors of MMPs (TIMP) and cystatin C (an endogenous inhibitor of cathepsins) are also expressed in atherosclerotic lesions and mediate plaque stability by regulating 
their respective proteinases. ${ }^{26-28}$ The factors contributing to fibrous cap thinning, as well as other mechanisms of plaque vulnerability discussed below, are summarized in table 1.

Table 1. Factors contributing to plaque vulnerability.

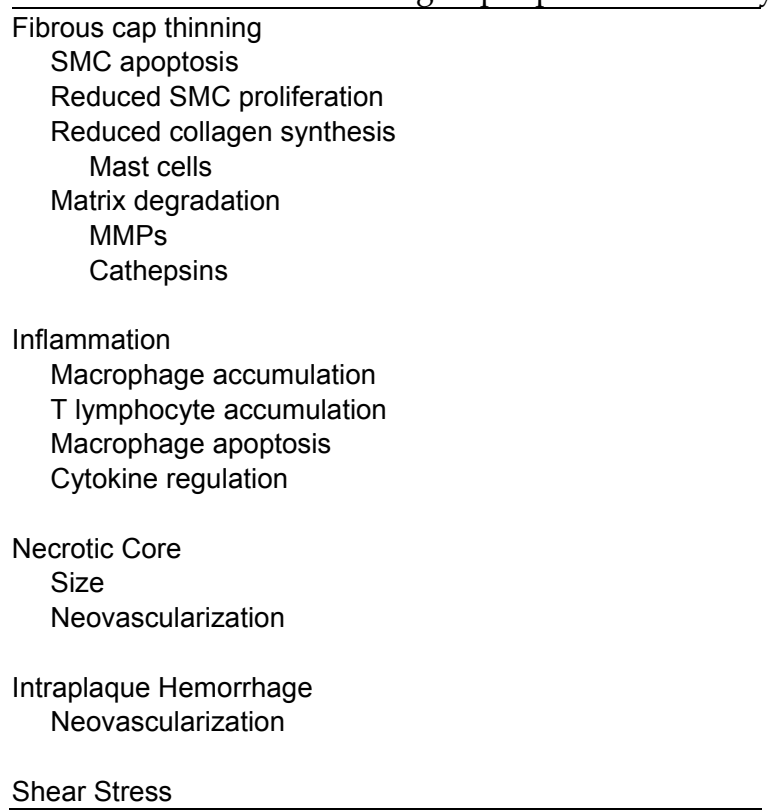

Primary sources of matrix degrading enzymes and their inhibitors are monocytederived macrophages. ${ }^{29} \mathrm{An}$ inflamed plaque with a high macrophage infiltrate may contribute to plaque instability by synthesis and secretion of MMPs. In addition, macrophages release cytokines and chemotactic factors that attract more macrophages and $\mathrm{T}$ lymphocytes into the lesion, thereby increasing inflammation. ${ }^{30}$ Macrophage-derived foam cells, which take up extracellular lipids that have accumulated in the intima ultimately die, release their contents and lead to the development of the necrotic core. An influx of inflammatory cells such as macrophages and $\mathrm{T}$ lymphocytes has been shown to increase at sites of plaque rupture in humans. ${ }^{31}$ Besides the accumulation of inflammatory cells, apoptosis of macrophages has also been shown to contribute to plaque vulnerability. In advanced lesions, apoptotic macrophages are more abundant than in early lesions, which has been attributed to defective clearance by phagocytes. ${ }^{32}$ Defective phagocytosis of apop- 
totic macrophages promotes secondary necrosis of these cells and enhances the inflammatory response, in turn contributing to plaque instability. ${ }^{32}$

The initiation of atherosclerotic lesion formation involving the accumulation of macrophages and lipids often occurs at bifurcations and the inner curvature of vessels where there is disturbed blood flow or low shear stress. ${ }^{33}$ Low shear stress promotes the accumulation of lipids and stimulates the expression of leukocyte adhesion molecules, cytokines, and growth factors that induce the proliferation of monocyte-derived macrophages. ${ }^{34}$ Local shear stress conditions may not only induce plaque initiation, but is thought to play a role in plaque progression and vulnerability. As plaques develop, the local shear stress environment is altered such that the disturbed blood flow becomes exacerbated downstream of the plaque, in turn promoting the progression of the plaque. ${ }^{35}$ In addition, shear stress surrounding a growing plaque increases the tensile stress in the shoulder region making it prone to fissures and thrombosis. ${ }^{36}$

Another factor that may contribute to plaque vulnerability is intraplaque hemorrhage (figure 1A and B), which has been shown to occur in vulnerable plaques and is thought to mediate the progression of asymptomatic plaques into unstable lesions. ${ }^{37}$ Intraplaque hemorrhage involves the rapid accumulation of erythrocytes in the plaque, accompanied by macrophage infiltration. Erythrocyte membranes are a rich source of free cholesterol, which contributes to the enlargement of the necrotic core. ${ }^{37}$ Recently, it was suggested that a likely source of erythrocytes in lesions are leaky, immature vessels within the plaque. ${ }^{38}$ The role of neovascularization in plaque progression has previously been described ${ }^{39}$ and shown to be increased in lesions of patients with acute coronary syndromes. ${ }^{40}$ Microvessels in atherosclerotic plaques are thought to arise from hypoxic conditions that may occur when the vessel wall exceeds a critical thickness beyond which the supply of oxygen and nutrients from the lumen are restricted. ${ }^{41}$ Microvessels may therefore extend from the adventitial vasa vasorum through the media into the base of a lesion, or from the lumen through the fibrous cap. ${ }^{40}$

Rupture in itself may contribute to plaque vulnerability in that ruptures associated with non-occlusive thrombi as shown in figure $1 \mathrm{C}$ and D are known to occur at the subclinical level, which are thought to play a role in plaque progression. ${ }^{42}$ Analysis of human atherosclerotic plaques has revealed previously healed ruptures, suggesting that plaques may rupture without resulting in acute coronary syndromes. ${ }^{43}$ A detailed pathological study provided further evidence that silent ruptures may be a form of wound healing and plaque progression. ${ }^{42}$ It was also reported in this study that previous plaque ruptures were common in arteries with an acute rupture suggesting that silent ruptures are a marker of plaque vulnerability. A recent study demonstrated that previous successive thrombotic events appear to occur in patients with acute coronary occlusion. ${ }^{44}$ In this study, the composition of thrombi in patients presenting with acute MI were analyzed. It was found that in over half of the cases, thrombi were days or even weeks old and had a layered com- 


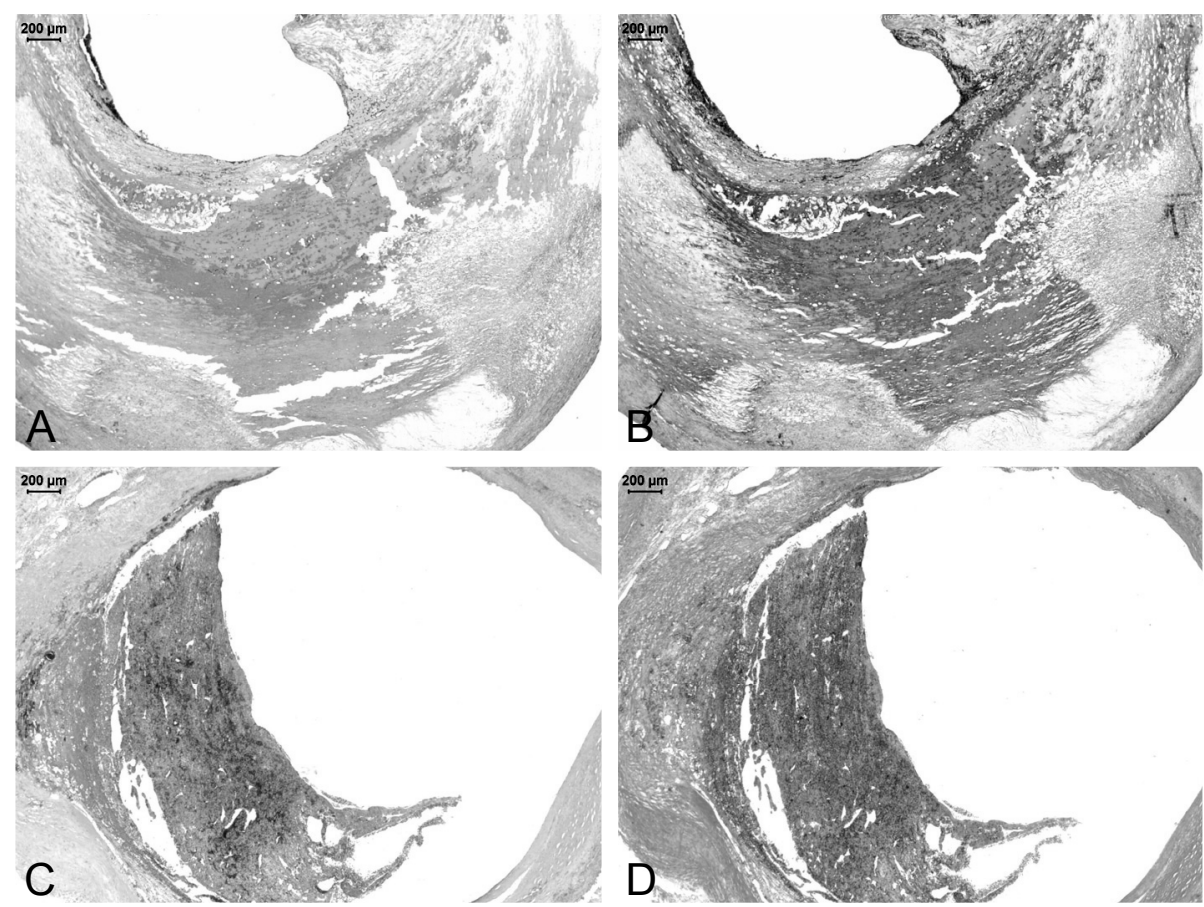

Figure 1. Human atherosclerotic lesions with intraplaque hemorrhage or non-occlusive luminal thrombus. (A) Hematoxylin and eosin (HE)-stained section of a carotid artery atherosclerotic plaque with intraplaque hemorrhage. (B) Martius, scarlet and blue (MSB)-stained section of the same plaque as in A, with fibrin deposition shown in red. (C) HE-stained section of a carotid artery atherosclerotic plaque associated with a nonocclusive luminal thrombus. (D) MSB-stained section of the same plaque as in $\mathrm{C}$ showing fibrin deposits in red and components of fresh thrombus (erythrocytes) shown in yellow. For full colour figure see page 129.

position suggesting episodic growth of thrombi prior to their becoming occlusive and symptomatic.

\section{Animal Models to Study Vulnerable Plaques}

The quest to better understand the mechanisms leading to human atherosclerotic plaque rupture and thrombus formation have lead to the emergence of a variety of animal models of plaque vulnerability. Models have been developed primarily in mice, rats, and rabbits in which plaque rupture was either induced ${ }^{45-49}$ or occurred spontaneously. ${ }^{50-54}$ These models have been described extensively in recent reviews $s^{55-58}$ and will therefore not be repeated in the present review.

In the past few years, several reports of new models of plaque rupture and vulnerability have been published, most of which have made use of apolipoprotein $\mathrm{E}$ 
knockout (ApoE-/-) mice. Frequent occurrences of acutely ruptured plaques were observed in the brachiocephalic artery of ApoE-/- mice after short periods of highfat feeding. ${ }^{59}$ It was found that the incidence of ruptured plaques significantly increased after 8 weeks. Ruptures were defined as disruptions in the fibrous cap accompanied by hemorrhage intruding into the lesion. An earlier study by the same group reported similar ruptures in plaques located in the brachiocephalic artery of ApoE-/- mice after prolonged periods (up to 14 months) of fat feeding, ${ }^{53}$ however this extended time period does not make intervention studies in such a model feasible. Ruptured plaques were also reported in aortic root lesions of ApoE-/- mice treated with biphosphonates, ${ }^{60}$ which reduce bone resorption and inhibit arterial calcification, lipid accumulation, and fibrosis. ${ }^{61}$ Ruptures were observed in inflamed plaques in the aortic root and were associated with mural thrombosis, however the definition of plaque rupture was not given in this study.

Another model tested the contribution of angiotensin II to plaque vulnerability. ${ }^{62}$ Hypertensive ApoE-/- mice were generated in which angiotensin II production was either endogenously increased (2K1C renovascular hypertension model) or remained normal. It was found that high angiotensin II production resulted in vulnerable plaques characterized by a thin fibrous cap, large lipid core, and increased macrophage content. Another study unexpectedly observed intralaminar hemorrhage in upper aortic regions in ApoE-/- mice that received angiotensin II and which were also naturally deficient in macrophage colony stimulating factor. ${ }^{63}$ Angiotensin II administration in ApoE-/- and low density lipoprotein receptor knockout (LDLR-/-) mice has been associated with abdominal aortic aneurysm formation. ${ }^{64,65}$ Rupture and thrombosis of aortic aneurysms has been reported in these mice, which involves weakening of the media and adventitia. ${ }^{66}$

Although evidence of plaque rupture in mouse models is sparse, atherosclerotic lesions in mice do develop intraplaque hemorrhage, an example of which is shown in figure 2. ApoE-/- mice in which atherosclerotic lesions develop rapidly in carotid arteries by placement of a perivascular collar were employed in two recent studies of plaque vulnerability in which intraplaque hemorrhage was observed. In one of the studies, the proinflammatory cytokine interleukin (IL)-18 was overexpressed by intravenous injection of an adenoviral vector carrying the IL-18 transgene in mice with advanced collar-induced lesions. ${ }^{67}$ Plaque morphology was analyzed and it was found that IL-18 overexpression resulted in a reduced intimal collagen content, thinner fibrous caps, and the cap/core ratio significantly decreased. Intralesional bleeding as detected by iron deposition was reported in $19 \%$ of the plaques exhibiting this vulnerable phenotype, however plaque rupture or erosion were not observed. In the other collar-induced lesion model, Fas ligand (FasL) was transferred directly to fibrous caps by transluminal injection of recombinant adenovirus carrying FasL. ${ }^{68}$ Because the Fas/FasL pathway of apoptosis has been implicated in plaque vulnerability, this study investigated whether FasL overexpression could induce rupture-related events. As quickly as one day after gene transfer, a signifi- 
cant increase in apoptosis in the fibrous cap was found. After two weeks, 35\% of plaques exhibited intraplaque hemorrhage, as detected by the presence of iron deposits, and plaque ruptures that were not associated with thrombus formation. In a similar model, an extravascular device resembling a tapered collar was placed around carotid arteries in ApoE-/-mice so as to induce vulnerable lesions (thin fibrous cap, large lipid core) upstream and stable lesions downstream of the device. ${ }^{69}$ Mice were treated with angiotensin II and were shown to have intraplaque hemorrhage in $75 \%$ of lesions.

A recent study investigated the effects of radiation on atherosclerotic development in ApoE-/- mice and found intraplaque hemorrhage in carotid artery lesions. ${ }^{70}$ Intraplaque hemorrhage was common in irradiated mice, especially 34 weeks after irradiation ( $\sim 85 \%$ of mice), and these lesions were associated with a vulnerable inflammatory phenotype. Plaque neovascularization was, however, not determined. The use of radiation to induce vulnerable plaques has previously been applied in a rabbit model. ${ }^{71}$ Plaque development was induced in iliac arteries by balloon denudation followed by placement on a hypercholesterolemic diet. Animals were then irradiated so as to induce a vulnerable phenotype consisting of macrophage-rich, SMC-poor lesions that expressed MMPs. Intraplaque hemorrhage was, however, not reported in this model.

Small animal models of atherosclerosis associated with typical end-stage events such as MI, cardiac dysfunction, or premature death are limited. Rat models such as atherosclerosis-prone JCR:LA-corpulent rats $^{72}$ and Dahl salt-sensitive hypertensive rats that overexpress human cholesteryl ester transfer protein ${ }^{52}$ have been shown to develop MI. Recently, a murine model exhibiting end-stage features of cardiovascular disease has been generated in ApoE-/- mice in which the gene for the high den-
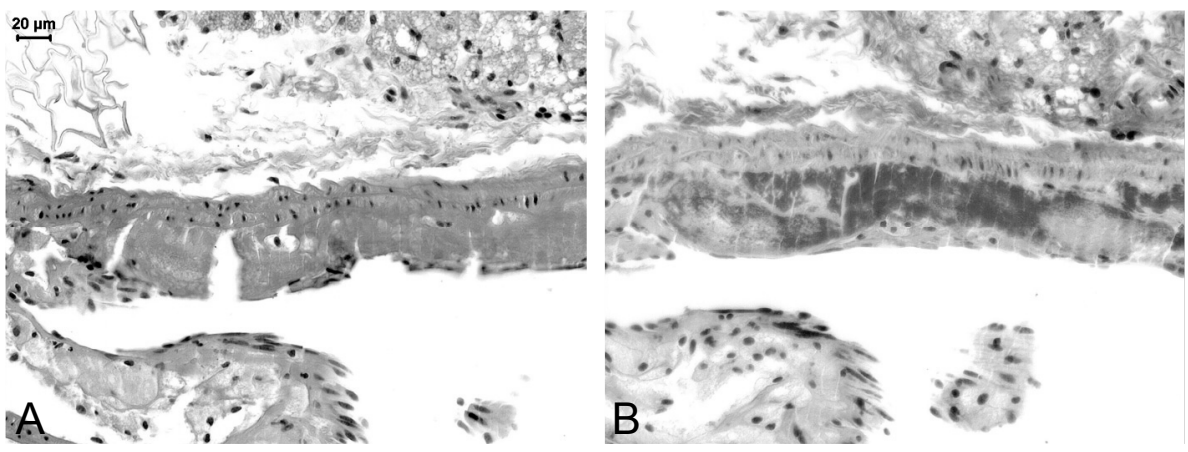

Figure 2. Mouse atherosclerotic lesion with intraplaque hemorrhage. (A) HE-stained section of an aortic arch atherosclerotic plaque with intraplaque hemorrhage. (B) MSB-stained section of the same plaque as in A showing fibrin deposition in red. For full colour figure see page 130. 
sity lipoprotein (HDL) receptor SR-BI (scavenger receptor class B, type I) was deleted. ${ }^{73}$ When fed a normal chow diet, these mice become hypercholesterolemic and develop atherosclerotic lesions, coronary artery occlusions, MI, cardiac dysfunction, and spontaneous death. The same group later developed a similar model in which the features of cardiovascular disease observed in ApoE/SR-BI double knockout mice was induced with a high-fat diet in SR-BI-deficient, hypomorphic ApoER61 mice. ${ }^{74}$ In addition to events related to coronary artery occlusion, these mice also developed intraplaque hemorrhage in aortic root lesions.

Recent models of plaque vulnerability continue to make use of small animals, particularly mice, however most do not result in features of human end-stage atherosclerosis. Characteristics of human vulnerable plaque such as plaque disruption, neovascularization, intraplaque hemorrhage, and occlusive thrombus formation occur rather infrequently in mouse models.

\section{Do Animal Models of Plaque Vulnerability Exist?}

The first commonly used animal models of atherosclerosis were cholesterol-fed rabbits, pigs, and non-human primates. Rabbits are beneficial in that they are easy to manipulate and develop lesions in a relatively short period of time on a high cholesterol diet. ${ }^{75}$ Their disadvantages lie in the development of exceptionally high plasma cholesterol levels that differ from humans, and lesions do not develop beyond macrophage-rich lesions resembling human fatty streaks. ${ }^{76}$ Pigs and primates develop lesions that are more similar to those in humans, ${ }^{76}$ however their size, rate of reproduction, and the time required for the formation of lesions make them costly models. The development of genetically engineered mice that lack genes crucial to lipid metabolism, such as ApoE and the LDL receptor has therefore been a major advancement in animal models of atherosclerosis. The ApoE-/- mouse in particular develops lesions of all stages of atherosclerosis throughout the arterial tree in a reproducible manner. ${ }^{77}$ Lesions in ApoE-/- mice resemble those in humans if only in that they progress from fatty streaks to advanced fibroinflammatory lesions containing a thick fibrous cap and often develop necrotic cores, cholesterol clefts, and

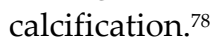

These animal models have been instrumental in studying atherogenesis and elucidating the role of a multitude of mediators involved in the process. Where they fall short is their lack of resemblance to human end-stage atherosclerosis. Until recently, the accepted paradigm for human end-stage atherosclerosis focused on a "big bang" scenario in which acute clinical events result from acute occlusive thrombus formation associated with disruptions in an underlying plaque. Occlusive thrombi leading to acute events were attributed to either plaque rupture, endothelial erosion, or the presence of protruding calcified nodules. Vulnerable plaques considered to be at high risk for rupture have often been characterized as having a 
thin fibrous cap, a large lipid core, and an inflammatory infiltrate, however, it is now known that not all plaques associated with occlusive thrombi possess this phenotype. Recent studies suggest a more subtle manner of occlusive thrombus formation and the development of vulnerable plaques. Rittersma et al. ${ }^{44}$ recently showed that plaque instability in the form of successive silent thrombi frequently occurs days or weeks prior to occlusive thrombus formation, which suggests that plaque disruption may not be the final determining factor in an acute clinical event. In addition, intraplaque hemorrhage and plaque angiogenesis have been reported to play a role in plaque destabilization. ${ }^{37,38}$ As such, it has been difficult to define vulnerable plaques and pinpoint the specific biological conditions that trigger occlusive thrombus formation.

Atherosclerotic plaque rupture, by its very nature, is difficult to study in humans. ${ }^{57}$ Advances in imaging techniques have been able to distinguish plaque characteristics, however, because the occurrence and time point of rupture are unpredictable, it remains difficult to identify vulnerable lesions. What are needed are animal models in which the pathophysiology of vulnerable plaques that lead to rupture can be studied. Plaque ruptures have been reported in lesions of the brachiocephalic artery in ApoE-/- mice after both long and short periods of high-fat feeding. ${ }^{33,59}$ However, ruptures were not associated with an occlusive thrombus. Although sudden death occurred in more than half of the mice that were fed a high fat diet for a long period of time (up to 59 weeks), this was not attributed to plaque rupture. ${ }^{53}$ Ruptured lesions have also been reported in the aorta of ApoE-/- mice treated with biphosphonates, but again, were not associated with an occlusive thrombus. ${ }^{60}$ Luminal thrombi rarely occur in mice and are unorganized and nonocclusive, and it is known that the regulation of coagulation differs in mice and humans. ${ }^{79}$ Because blood coagulability in humans is now considered to be an important contributing factor in thrombus formation, ${ }^{3}$ mouse models fail to emulate the human condition in this respect.

Another important factor that may contribute to plaque vulnerability is intraplaque hemorrhage, which has been observed in mouse plaques, albeit infrequently. ${ }^{67,68,80}$ The source of intraplaque hemorrhage in humans is thought to occur via microvessels that are present in advanced lesions. These vessels mediate plaque progression by allowing for the rapid accumulation of cholesterol-rich erythrocyte membranes inside the plaque that contribute to enlargement of the lipid core. ${ }^{37} \mathrm{Al}-$ though intraplaque hemorrhage was observed in mouse studies mentioned above, plaque neovascularization was either not reported or not determined. ${ }^{67,68,70}$ Studies by Moulton et al. ${ }^{81,82}$ in ApoE-/- mice investigated the role of angiogenesis and atherosclerosis by the use of angiogenic inhibitors, which significantly reduced plaque area and progression. However, the occurrence of intimal vessels was relatively low and whether or not they had a direct effect on plaque development was inconclusive. Administration of vascular endothelial growth factor (VEGF), a major inducer of angiogenesis, was shown to promote atherosclerosis in mice deficient in 
ApoE and ApoB100,83 however other studies suggest that VEGF may not play an angiogenesis-specific role in plaque development. Antibodies directed against Flk-1, the major receptor for VEGF-mediated angiogenesis, reduced plaque growth, but this was not attributable to reduced plaque neovascularization. ${ }^{84}$ Similarly, adenoviral transfer of various VEGF isoforms in LDLR/ApoB48 double knockout mice had no effect on plaque growth or neovascularization. ${ }^{85}$ The role of plaque neovascularization in mouse atherosclerosis, intraplaque hemorrhage, and plaque vulnerability remains unclear. The new concept of angiogenesis as a contributor to plaque vulnerability has, therefore, not been reproduced in mouse or other animal models.

Attempts to better mimic human cardiovascular disease have recently been made in mouse models in which acute coronary events occur. In particular, high fat diet-fed SR-BI-deficient hypomorphic ApoER61 mice are hypercholesterolemic and develop intraplaque hemorrhage, MI, cardiac dysfunction, and premature death. ${ }^{74}$ In this model, hypomorphic ApoER61 mice express reduced levels of an ApoE4-like murine ApoE isoform, which has structural and lipoprotein binding characteristics that resemble the human ApoE4 isoform. ${ }^{74}$ Human ApoE4 is associated with higher LDL cholesterol levels and an increased risk of cardiovascular disease. ${ }^{86}$ Other mouse models of atherosclerosis have been developed to resemble the human condition by the introduction of human genes. For example, in ApoE2 knockin and ApoE3Leiden mice, lipid profiles are comparable to humans, and as such they continue to be used in atherosclerosis studies, however they do not result in human end-stage coronary events.

\section{Conclusions and Future Directions}

Currently, there is no standard animal model of vulnerable plaque. Much focus has been placed on mouse models, however mice do not develop atherosclerosis without genetic manipulation. Genetically altered mice that have been shown to develop plaque rupture have either required mechanical intervention to induce rupture or if they occurred spontaneously, were not associated with end-stage atherosclerosis such as occlusive thrombi, MI, or death. Focus has also been placed on rupture of atherosclerotic plaques, however recent studies have revealed other causes of occlusive thrombus formation such as endothelial erosion and the presence of calcific nodules - phenomena that are yet to be described in animal models. The goal of most studies of vulnerable plaque has been to induce lesions with a thin fibrous cap, large lipid core, and an inflammatory infiltrate, however the phenotype of culprit lesions associated with occlusive thrombi in humans has been shown to be varied and do not necessarily possess these characteristics. Furthermore, the relatively new concept of angiogenesis as a marker of vulnerable plaque and a source of intraplaque hemorrhage remains to be reproduced in animal models. Lesions in mouse 
models in particular lack angiogenesis, and whatever intraplaque hemorrhage that has been reported has not been attributed to neovascularization.

Animal models have been invaluable in elucidating the pathobiology and complex processes of atherosclerosis, but their use in studying vulnerable plaques and end-stage atherosclerosis remains limited. An ideal animal model would possess lesions that are histologically identical to human lesions, and their lipid metabolism and coagulation would also resemble that in humans. Lesions in animal models should also have the same propensity to disrupt as in humans and result in occlusive thrombus formation. ${ }^{57}$ This may be too much to ask of an animal model. We should perhaps focus our attention on unraveling the mechanisms of occlusive thrombus formation as related to plaque disruptions in humans by longitudinal imaging studies or identification of genes differentially expressed in human lesions, as performed by Faber et al. ${ }^{87}$ We may also have to accept that only specific aspects of the mechanisms of plaque vulnerability can be reproduced in animal models and that we may never be able to study the entire picture in one model. 


\section{References}

1. Falk E, Shah PK, Fuster V. Coronary plaque disruption. Circulation. 1995;92:657-671.

2. Shah PK. Insights into the molecular mechanisms of plaque rupture and thrombosis. Indian Heart J. 2005;57:21-30.

3. Naghavi M, Libby P, Falk E, Casscells SW, Litovsky S, Rumberger J, et al. From vulnerable plaque to vulnerable patient: a call for new definitions and risk assessment strategies: Part I. Circulation. 2003;108:1664-1672.

4. Fuster V, Moreno PR, Fayad ZA, Corti R, Badimon JJ. Atherothrombosis and high-risk plaque: part I: evolving concepts. J Am Coll Cardiol. 2005;46:937-954.

5. Virmani R, Kolodgie FD, Burke AP, Farb A, Schwartz SM. Lessons from sudden coronary death: a comprehensive morphological classification scheme for atherosclerotic lesions. Arterioscler Thromb Vasc Biol. 2000;20:1262-1275.

6. Farb A, Burke AP, Tang AL, Liang TY, Mannan P, Smialek J, et al. Coronary plaque erosion without rupture into a lipid core. A frequent cause of coronary thrombosis in sudden coronary death. Circulation. 1996;93:1354-1363.

7. Muller JE, Tofler GH, Stone PH. Circadian variation and triggers of onset of acute cardiovascular disease. Circulation. 1989;79:733-743.

8. Davies MJ. Anatomic features in victims of sudden coronary death. Coronary artery pathology. Circulation. 1992;85:I19-24.

9. Davies MJ. Stability and instability: two faces of coronary atherosclerosis. The Paul Dudley White Lecture 1995. Circulation. 1996;94:2013-2020.

10. Kereiakes DJ. The Emperor's clothes: in search of the vulnerable plaque. Circulation. 2003;107:2076-2077.

11. Casscells W, Naghavi M, Willerson JT. Vulnerable atherosclerotic plaque: a multifocal disease. Circulation. 2003;107:2072-2075.

12. Maseri A, Fuster V. Is there a vulnerable plaque? Circulation. 2003;107:2068-2071.

13. Schaar JA, Muller JE, Falk E, Virmani R, Fuster V, Serruys PW, et al. Terminology for high-risk and vulnerable coronary artery plaques. Report of a meeting on the vulnerable plaque, June 17 and 18, 2003, Santorini, Greece. Eur Heart J. 2004;25:1077-1082.

14. Takaya N, Yuan C, Chu B, Saam T, Polissar NL, Jarvik GP, et al. Presence of intraplaque hemorrhage stimulates progression of carotid atherosclerotic plaques: a high-resolution magnetic resonance imaging study. Circulation. 2005;111:2768-2775.

15. Rudd JH, Davies JR, Weissberg PL. Imaging of atherosclerosis -- can we predict plaque rupture? Trends Cardiovasc Med. 2005;15:17-24.

16. Rioufol G, Gilard M, Finet G, Ginon I, Boschat J, Andre-Fouet X. Evolution of spontaneous atherosclerotic plaque rupture with medical therapy: long-term follow-up with intravascular ultrasound. Circulation. 2004;110:2875-2880.

17. Bauriedel G, Hutter R, Welsch U, Bach R, Sievert H, Luderitz B. Role of smooth muscle cell death in advanced coronary primary lesions: implications for plaque instability. Cardiovasc Res. 1999;41:480-488.

18. Bennett MR. Apoptosis of vascular smooth muscle cells in vascular remodelling and atherosclerotic plaque rupture. Cardiovasc Res. 1999;41:361-368.

19. Boyle JJ, Bowyer DE, Weissberg PL, Bennett MR. Human blood-derived macrophages induce apoptosis in human plaque-derived vascular smooth muscle cells by Fas-ligand/Fas interactions. Arterioscler Thromb Vasc Biol. 2001;21:1402-1407.

20. Bennett MR, Macdonald K, Chan SW, Boyle JJ, Weissberg PL. Cooperative interactions between $\mathrm{RB}$ and p53 regulate cell proliferation, cell senescence, and apoptosis in human vascular smooth muscle cells from atherosclerotic plaques. Circ Res. 1998;82:704-712.

21. Leskinen MJ, Kovanen PT, Lindstedt KA. Regulation of smooth muscle cell growth, function and death in vitro by activated mast cells--a potential mechanism for the weakening and rupture of atherosclerotic plaques. Biochem Pharmacol. 2003;66:1493-1498. 
22. Heeneman S, Cleutjens JP, Faber BC, Creemers EE, van Suylen RJ, Lutgens E, et al. The dynamic extracellular matrix: intervention strategies during heart failure and atherosclerosis. J Pathol. 2003;200:516-525.

23. Galis ZS, Khatri JJ. Matrix metalloproteinases in vascular remodeling and atherogenesis: the good, the bad, and the ugly. Circ Res. 2002;90:251-262.

24. Lutgens E, Lutgens SP, Faber BC, Heeneman S, Gijbels MM, de Winther MP, et al. Disruption of the cathepsin $\mathrm{K}$ gene reduces atherosclerosis progression and induces plaque fibrosis but accelerates macrophage foam cell formation. Circulation. 2006;113:98-107.

25. Sukhova GK, Shi GP, Simon DI, Chapman HA, Libby P. Expression of the elastolytic cathepsins $\mathrm{S}$ and $\mathrm{K}$ in human atheroma and regulation of their production in smooth muscle cells. J Clin Invest. 1998;102:576-583.

26. Bengtsson E, To F, Hakansson K, Grubb A, Branen L, Nilsson J, et al. Lack of the cysteine protease inhibitor cystatin $\mathrm{C}$ promotes atherosclerosis in apolipoprotein E-deficient mice. Arterioscler Thromb Vasc Biol. 2005;25:2151-2156.

27. Sukhova GK, Wang B, Libby P, Pan JH, Zhang Y, Grubb A, et al. Cystatin C deficiency increases elastic lamina degradation and aortic dilatation in apolipoprotein E-null mice. Circ Res. 2005;96:368-375.

28. Watanabe N, Ikeda U. Matrix metalloproteinases and atherosclerosis. Curr Atheroscler Rep. 2004;6:112-120.

29. Galis ZS, Sukhova GK, Kranzhofer R, Clark S, Libby P. Macrophage foam cells from experimental atheroma constitutively produce matrix-degrading proteinases. Proc Natl Acad Sci U S A. 1995;92:402-406.

30. Hansson GK. Inflammation, atherosclerosis, and coronary artery disease. $N$ Engl J Med. 2005;352:1685-1695.

31. Moreno PR, Falk E, Palacios IF, Newell JB, Fuster V, Fallon JT. Macrophage infiltration in acute coronary syndromes. Implications for plaque rupture. Circulation. 1994;90:775-778.

32. Tabas I. Consequences and therapeutic implications of macrophage apoptosis in atherosclerosis: the importance of lesion stage and phagocytic efficiency. Arterioscler Thromb Vasc Biol. 2005;25:2255-2264.

33. Cheng C, de Crom R, van Haperen R, Helderman F, Gourabi BM, van Damme LC, et al. The role of shear stress in atherosclerosis: action through gene expression and inflammation? Cell Biochem Biophys. 2004;41:279-294.

34. Malek AM, Alper SL, Izumo S. Hemodynamic shear stress and its role in atherosclerosis. JAMA. 1999;282:2035-2042.

35. Feldman CL, Stone PH. Intravascular hemodynamic factors responsible for progression of coronary atherosclerosis and development of vulnerable plaque. Curr Opin Cardiol. 2000;15:430-440.

36. Slager CJ, Wentzel JJ, Gijsen FJ, Thury A, van der Wal AC, Schaar JA, et al. The role of shear stress in the destabilization of vulnerable plaques and related therapeutic implications. Nat Clin Pract Cardiovasc Med. 2005;2:456-464.

37. Kolodgie FD, Gold HK, Burke AP, Fowler DR, Kruth HS, Weber DK, et al. Intraplaque hemorrhage and progression of coronary atheroma. N Engl J Med. 2003;349:2316-2325.

38. Virmani R, Kolodgie FD, Burke AP, Finn AV, Gold HK, Tulenko TN, et al. Atherosclerotic plaque progression and vulnerability to rupture: angiogenesis as a source of intraplaque hemorrhage. Arterioscler Thromb Vasc Biol. 2005;25:2054-2061.

39. Jeziorska M, Woolley DE. Neovascularization in early atherosclerotic lesions of human carotid arteries: its potential contribution to plaque development. Hum Pathol. 1999;30:919-925.

40. Moreno PR, Purushothaman KR, Fuster V, Echeverri D, Truszczynska H, Sharma SK, et al. Plaque neovascularization is increased in ruptured atherosclerotic lesions of human aorta: implications for plaque vulnerability. Circulation. 2004;110:2032-2038.

41. Khurana R, Simons M, Martin JF, Zachary IC. Role of angiogenesis in cardiovascular disease: a critical appraisal. Circulation. 2005;112:1813-1824.

42. Burke AP, Kolodgie FD, Farb A, Weber DK, Malcom GT, Smialek J, et al. Healed plaque ruptures and sudden coronary death: evidence that subclinical rupture has a role in plaque progression. Circulation. 2001;103:934-940. 
43. Mann J, Davies MJ. Mechanisms of progression in native coronary artery disease: role of healed plaque disruption. Heart. 1999;82:265-268.

44. Rittersma SZ, van der Wal AC, Koch KT, Piek JJ, Henriques JP, Mulder KJ, et al. Plaque instability frequently occurs days or weeks before occlusive coronary thrombosis: a pathological thrombectomy study in primary percutaneous coronary intervention. Circulation. 2005;111:11601165.

45. Abela GS, Picon PD, Friedl SE, Gebara OC, Miyamoto A, Federman M, et al. Triggering of plaque disruption and arterial thrombosis in an atherosclerotic rabbit model. Circulation. 1995;91:776-784.

46. Nakamura M, Abe S, Kinukawa N. Aortic medial necrosis with or without thrombosis in rabbits treated with Russell's viper venom and angiotensin II. Atherosclerosis. 1997;128:149-156.

47. Reddick RL, Zhang SH, Maeda N. Aortic atherosclerotic plaque injury in apolipoprotein E deficient mice. Atherosclerosis. 1998;140:297-305.

48. Eitzman DT, Westrick RJ, Xu Z, Tyson J, Ginsburg D. Hyperlipidemia promotes thrombosis after injury to atherosclerotic vessels in apolipoprotein E-deficient mice. Arterioscler Thromb Vasc Biol. 2000;20:1831-1834.

49. von der Thusen JH, van Vlijmen BJ, Hoeben RC, Kockx MM, Havekes LM, van Berkel TJ, et al. Induction of atherosclerotic plaque rupture in apolipoprotein E-/- mice after adenovirusmediated transfer of p53. Circulation. 2002;105:2064-2070.

50. Calara F, Silvestre M, Casanada F, Yuan N, Napoli C, Palinski W. Spontaneous plaque rupture and secondary thrombosis in apolipoprotein E-deficient and LDL receptor-deficient mice. J Pathol. 2001;195:257-263.

51. Rosenfeld ME, Polinsky P, Virmani R, Kauser K, Rubanyi G, Schwartz SM. Advanced atherosclerotic lesions in the innominate artery of the ApoE knockout mouse. Arterioscler Thromb Vasc Biol. 2000;20:2587-2592.

52. Herrera VL, Makrides SC, Xie HX, Adari H, Krauss RM, Ryan US, et al. Spontaneous combined hyperlipidemia, coronary heart disease and decreased survival in Dahl salt-sensitive hypertensive rats transgenic for human cholesteryl ester transfer protein. Nat Med. 1999;5:1383-1389.

53. Williams H, Johnson JL, Carson KG, Jackson CL. Characteristics of intact and ruptured atherosclerotic plaques in brachiocephalic arteries of apolipoprotein E knockout mice. Arterioscler Thromb Vasc Biol. 2002;22:788-792.

54. Johnson JL, Jackson CL. Atherosclerotic plaque rupture in the apolipoprotein E knockout mouse. Atherosclerosis. 2001;154:399-406.

55. Rekhter M. Vulnerable atherosclerotic plaque: emerging challenge for animal models. Curr Opin Cardiol. 2002;17:626-632.

56. Rekhter MD. How to evaluate plaque vulnerability in animal models of atherosclerosis? Cardiovasc Res. 2002;54:36-41.

57. Cullen P, Baetta R, Bellosta S, Bernini F, Chinetti G, Cignarella A, et al. Rupture of the atherosclerotic plaque: does a good animal model exist? Arterioscler Thromb Vasc Biol. 2003;23:535-542.

58. Lowe HC, Jang IK, Khachigian LM. Animal models of vulnerable plaque. Clinical context and current status. Thromb Haemost. 2003;90:774-780.

59. Johnson J, Carson K, Williams H, Karanam S, Newby A, Angelini G, et al. Plaque rupture after short periods of fat feeding in the apolipoprotein E-knockout mouse: model characterization and effects of pravastatin treatment. Circulation. 2005;111:1422-1430.

60. Shimshi M, Abe E, Fisher EA, Zaidi M, Fallon JT. Bisphosphonates induce inflammation and rupture of atherosclerotic plaques in apolipoprotein-E null mice. Biochem Biophys Res Commun. 2005;328:790-793.

61. Ylitalo R. Bisphosphonates and atherosclerosis. Gen Pharmacol. 2000;35:287-296.

62. Mazzolai L, Duchosal MA, Korber M, Bouzourene K, Aubert JF, Hao H, et al. Endogenous angiotensin II induces atherosclerotic plaque vulnerability and elicits a Th1 response in ApoE-/mice. Hypertension. 2004;44:277-282.

63. Babamusta F, Rateri DL, Moorleghen JJ, Howatt DA, Li XA, Daugherty A. Angiotensin II infusion induces site-specific intra-laminar hemorrhage in macrophage colony-stimulating factordeficient mice. Atherosclerosis. 2006;186:282-290. 
64. Daugherty A, Manning MW, Cassis LA. Angiotensin II promotes atherosclerotic lesions and aneurysms in apolipoprotein E-deficient mice. J Clin Invest. 2000;105:1605-1612.

65. Daugherty A, Cassis L. Chronic angiotensin II infusion promotes atherogenesis in low density lipoprotein receptor -/- mice. Ann N Y Acad Sci. 1999;892:108-118.

66. Daugherty A, Manning MW, Cassis LA. Antagonism of AT2 receptors augments angiotensin IIinduced abdominal aortic aneurysms and atherosclerosis. Br J Pharmacol. 2001;134:865-870.

67. de Nooijer R, von der Thusen JH, Verkleij CJ, Kuiper J, Jukema JW, van der Wall EE, et al. Overexpression of IL-18 decreases intimal collagen content and promotes a vulnerable plaque phenotype in apolipoprotein-E-deficient mice. Arterioscler Thromb Vasc Biol. 2004;24:2313-2319.

68. Zadelaar AS, Thusen JH, LS MB, Hoeben RC, Kockx MM, Versnel MA, et al. Increased vulnerability of pre-existing atherosclerosis in ApoE-deficient mice following adenovirus-mediated Fas ligand gene transfer. Atherosclerosis. 2005;183:244-250.

69. Cheng C, Tempel D, van Haperen R, van der Baan A, Grosveld F, Daemen MJ, et al. Atherosclerotic lesion size and vulnerability are determined by patterns of fluid shear stress. Circulation. 2006;113:2744-2753.

70. Stewart FA, Heeneman S, Te Poele J, Kruse J, Russell NS, Gijbels M, et al. Ionizing Radiation Accelerates the Development of Atherosclerotic Lesions in ApoE-/- Mice and Predisposes to an Inflammatory Plaque Phenotype Prone to Hemorrhage. Am J Pathol. 2006;168:649-658.

71. Pakala R, Leborgne L, Cheneau E, Chan RC, Yazdi H, Fournadjiev J, et al. Radiation-induced atherosclerotic plaque progression in a hypercholesterolemic rabbit: a prospective vulnerable plaque model? Cardiovasc Radiat Med. 2003;4:146-151.

72. Russell JC, Graham SE, Richardson M. Cardiovascular disease in the JCR:LA-cp rat. Mol Cell Biochem. 1998;188:113-126.

73. Braun A, Trigatti BL, Post MJ, Sato K, Simons M, Edelberg JM, et al. Loss of SR-BI expression leads to the early onset of occlusive atherosclerotic coronary artery disease, spontaneous myocardial infarctions, severe cardiac dysfunction, and premature death in apolipoprotein Edeficient mice. Circ Res. 2002;90:270-276.

74. Zhang S, Picard MH, Vasile E, Zhu Y, Raffai RL, Weisgraber KH, et al. Diet-induced occlusive coronary atherosclerosis, myocardial infarction, cardiac dysfunction, and premature death in scavenger receptor class B type I-deficient, hypomorphic apolipoprotein ER61 mice. Circulation. 2005;111:3457-3464.

75. Yanni AE. The laboratory rabbit: an animal model of atherosclerosis research. Lab Anim. 2004;38:246-256.

76. Jawien J, Nastalek P, Korbut R. Mouse models of experimental atherosclerosis. J Physiol Pharmacol. 2004;55:503-517.

77. Nakashima Y, Plump AS, Raines EW, Breslow JL, Ross R. ApoE-deficient mice develop lesions of all phases of atherosclerosis throughout the arterial tree. Arterioscler Thromb. 1994;14:133-140.

78. Smith JD, Breslow JL. The emergence of mouse models of atherosclerosis and their relevance to clinical research. J Intern Med. 1997;242:99-109.

79. Carmeliet P, Moons L, Collen D. Mouse models of angiogenesis, arterial stenosis, atherosclerosis and hemostasis. Cardiovasc Res. 1998;39:8-33.

80. Lutgens E, Gijbels M, Smook M, Heeringa P, Gotwals P, Koteliansky VE, et al. Transforming growth factor-beta mediates balance between inflammation and fibrosis during plaque progression. Arterioscler Thromb Vasc Biol. 2002;22:975-982.

81. Moulton KS, Heller E, Konerding MA, Flynn E, Palinski W, Folkman J. Angiogenesis inhibitors endostatin or TNP-470 reduce intimal neovascularization and plaque growth in apolipoprotein E-deficient mice. Circulation. 1999;99:1726-1732.

82. Moulton KS, Vakili K, Zurakowski D, Soliman M, Butterfield C, Sylvin E, et al. Inhibition of plaque neovascularization reduces macrophage accumulation and progression of advanced atherosclerosis. Proc Natl Acad Sci USA. 2003;100:4736-4741.

83. Celletti FL, Waugh JM, Amabile PG, Brendolan A, Hilfiker PR, Dake MD. Vascular endothelial growth factor enhances atherosclerotic plaque progression. Nat Med. 2001;7:425-429.

84. Luttun A, Tjwa M, Moons L, Wu Y, Angelillo-Scherrer A, Liao F, et al. Revascularization of ischemic tissues by PIGF treatment, and inhibition of tumor angiogenesis, arthritis and atherosclerosis by anti-Flt1. Nat Med. 2002;8:831-840. 
85. Leppanen P, Koota S, Kholova I, Koponen J, Fieber C, Eriksson U, et al. Gene transfers of vascular endothelial growth factor-A, vascular endothelial growth factor-B, vascular endothelial growth factor- $C$, and vascular endothelial growth factor-D have no effects on atherosclerosis in hypercholesterolemic low-density lipoprotein-receptor/apolipoprotein B48-deficient mice. Circulation. 2005;112:1347-1352.

86. Saito H, Dhanasekaran P, Baldwin F, Weisgraber KH, Phillips MC, Lund-Katz S. Effects of polymorphism on the lipid interaction of human apolipoprotein E. J Biol Chem. 2003;278:4072340729.

87. Faber BC, Cleutjens KB, Niessen RL, Aarts PL, Boon W, Greenberg AS, et al. Identification of genes potentially involved in rupture of human atherosclerotic plaques. Circ Res. 2001;89:547554. 


\section{CHAPTER 3}

\section{Gene profiling in atherosclerosis reveals a}

key role for small inducible cytokines:

validation using a novel monocyte chemoattractant protein monoclonal antibody

Esther Lutgens*, Birgit Faber*, Kitty Schapira*, Chris T.A. Evelo, Rachel van Haaften, Sylvia Heeneman, Kitty B.J.M. Cleutjens, Ann Pascale Bijnens, Linda Beckers, J. Gordon Porter, Charles R. Mackay, Paul Rennert, Veronique Bailly, Matthew Jarpe, Brian Dolinski, Victor Koteliansky, Tony de Fougerolles, Mat J.A.P. Daemen

Circulation 2005;111(25):3443-3452

* The first three authors have contributed equally

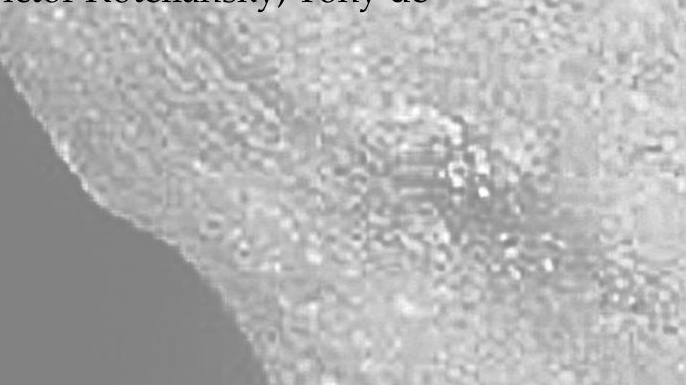




\begin{abstract}
Pathological aspects of atherosclerosis are well described, but gene profiles during atherosclerotic plaque progression are largely unidentified. Microarray analysis was performed on mRNA of aortic arches of ApoE-/- mice fed normal chow (NC) or western-type diet (WD) for 3, 4.5, and 6 months. Out of 10176 reporters, 387 were differentially $(>2 \times)$ expressed in at least one group compared to a common reference (ApoE-/-, 3-month NC group). The number of differentially expressed genes increased during plaque progression. Time-related expression clustering and functional grouping of differentially expressed genes suggested important functions for genes involved in inflammation (especially the small inducible cytokines monocyte chemoattractant protein [MCP]-1, MCP-5, macrophage inflammatory protein [MIP]$1 \alpha$, MIP-1 $\beta$, MIP-2, and fractalkine), and matrix degradation (cathepsin S, matrix metalloproteinase [MMP]-2, and MMP-12). Validation experiments focused on the gene cluster of small inducible cytokines. Real-time PCR revealed a plaque progression-dependent increase in mRNA levels of MCP-1, MCP-5, MIP-1 $\alpha$, and MIP-1 $\beta$. ELISA for MCP-1 and MCP-5 showed similar results. Immunohistochemistry for MCP-1, MCP-5, and MIP-1 $\alpha$ located their expression to plaque macrophages. An inhibiting antibody for MCP-1 and MCP-5 (11K2) was designed and administered to ApoE-/- mice for 12 weeks starting at 5 or 17 weeks of age. $11 \mathrm{~K} 2$ treatment reduced plaque area and macrophage and CD45+ cell content and increased collagen content, thereby inducing a stable plaque phenotype. Gene profiling of atherosclerotic plaque progression in ApoE-/- mice revealed upregulation of the gene cluster of small inducible cytokines. Further expression and in vivo validation studies showed that this gene cluster mediates plaque progression and stability.
\end{abstract}




\section{Introduction}

Although clinical consequences and pathological aspects of atherosclerosis are well described, understanding of the precise molecular mechanisms of atherosclerotic plaque initiation and progression has been a daunting task for years. However, since the 1990s, new techniques have emerged to study gene expression profiles in complex disease systems in high-output fashion. In atherosclerosis, numerous highoutput gene expression studies have been performed in atherosclerosis-related cell types, revealing differential expression of mediators of inflammation, lipid metabolism, signaling molecules, and extracellular matrix (ECM)-related genes, as well as many unknown genes. ${ }^{1-5}$ Although these studies are technically easy to perform, genetic information obtained from cell culture experiments may not accurately reflect the molecular events that take place in an atherosclerotic lesion. A more desirable approach is the use of whole-mount (atherosclerotic) vascular tissue.

In the first whole-mount experiments, gene expression profiles of smooth muscle cell (SMC)-rich components of the vascular wall (aorta, vena cava, and neointima) were compared on a systematic basis. Comparisons between these different SMC origins revealed consistent differential expression of genes encoding matrix proteins (collagens) or proteins involved in G-protein signaling (RGS5). ${ }^{6,7}$

In another set of experiments, gene expression profiles of whole-mount human atherosclerotic plaques ${ }^{8,9}$ or macrophages obtained from atherosclerotic plaques by laser microdissection microscopy ${ }^{10}$ were compared with nondiseased arterial wall. These studies revealed differential expression of a wide array of genes, the majority of which were involved in foam cell formation, inflammation, apoptosis, and thrombosis..$^{8-10}$

Most acute clinical complications of atherosclerosis result from rupture of an atherosclerotic plaque and superimposed thrombosis. ${ }^{11,12}$ Identification of genes correlated with atherosclerotic plaque rupture is crucial to understand and intervene in the disease process. In a recent study we were able to identify genes that were differentially expressed between stable and ruptured human atherosclerotic plaques using the suppression subtractive hybridization technique. ${ }^{13}$ Although some clones represented known genes, such as perilipin, the majority of genes found in this study coded for unknown genes, one of them was named vasculin. ${ }^{13,14}$ In a microarray study that compared coronary atherectomy specimens from patients with stable and patients with unstable angina, differential gene expression was predominantly observed in the clusters for thrombosis and inflammation. ${ }^{15}$

The aim of the present study was to obtain a detailed portrait of murine gene expression in the different stages of atherosclerosis. For this purpose we chose microarray analysis (mouse unigene 1, 10176 reporters, Incyte Corporation). To limit the effects of genetic heterogeneity and environmental influence, the experiment was performed in a well-established mouse model of atherosclerosis, the ApoE-/mouse. A similar study was performed several years ago, but on a much smaller 
scale, with limited time points and conditions. ${ }^{16}$ In this study, mRNA of entire aortas of ApoE-/- mice fed a western-type diet for 10 or 20 weeks was hybridized on gene filter arrays containing 588 genes. Multiple gene clusters containing $>200$ genes based on expression levels were found. ${ }^{16}$ In a recent publication, transcripts of aortic tissue of atherosclerosis-resistant $(\mathrm{C} 3 \mathrm{H} / \mathrm{HeJ})$ and atherosclerosis-prone (C57B16) mice were analyzed at baseline, during aging, and during exposure to an atherogenic stimulus (high fat diet) and validated in atherosclerotic lesions of ApoE-/mice, revealing that $\mathrm{C} 57 \mathrm{Bl} 6$ mice have an atherosclerosis-prone transcription profile. ${ }^{17}$

In our study, gene expression patterns of atherosclerotic aortic arches of ApoE/- mice that were fed normal chow or a western-type diet $(0.21 \%$ cholesterol $)$ for 3 , 4.5 , and 6 months were determined. Time-related expression pattern clustering and functional grouping of differentially expressed genes revealed an important role of genes involved in inflammation and in protein/matrix degradation. Expression studies further highlighted regulation of the small inducible cytokines during disease development in this murine model. The role of the chemokines MCP-1 and MCP-5 was validated using a novel monoclonal antibody, which was shown to attenuate atherosclerotic plaque development and progression and induce plaque stabilization in the ApoE-deficient mouse.

\section{Materials and Methods}

\section{Microarray}

\section{Mice and Experimental Protocols}

All animal experiments were performed in accordance with animal care institutional guidelines. Male ApoE-/- mice were purchased from Iffa Credo (France). Mice were fed either NC or WD $(0.21 \%$ cholesterol, Hope Farms) starting at 5 weeks of age. Mice were sacrificed at the age of 3 months (ApoE-/-, NC, n=35; ApoE-/-, WD, $\mathrm{n}=13$ ), 4.5 months (ApoE-/-, NC, n=14; ApoE-/-, WD, n=14) or 6 months (ApoE-/-, $\mathrm{NC}, \mathrm{n}=16$; ApoE-/-, WD, n=16).

After the experimental period, mice were euthanized after an 8-hour fast, and blood $( \pm 1 \mathrm{ml})$ was drawn from the caval vein for lipoprotein analysis. Mice were used for either RNA or protein extraction ( $n=10$ to 31 per group) or histological analysis ( $n=4$ per group). For RNA or protein extraction, the aortic arches including their main branch points (brachiocephalic artery, left carotid artery, and left subclavian artery) (figure 1) were cleaned from fatty tissue and adventitial tissue, excised, rinsed in ice-cold phosphate-buffered saline (PBS), snap-frozen in liquid nitrogen, and stored at $-70^{\circ} \mathrm{C}$ until further use. For histological analysis, mice were perfused with PBS containing 1\% nitroprusside followed by perfusion with $1 \%$ paraformaldehyde as described previously. ${ }^{18}$ The aortic root and the entire aortic 


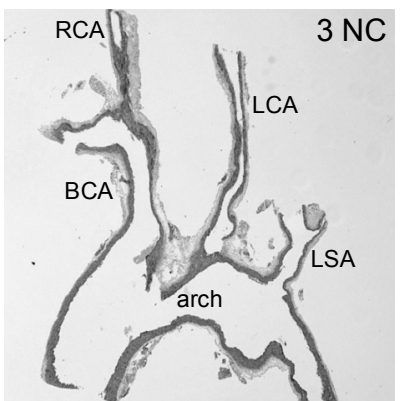

Plaque area: $26 \pm 21 \mu \mathrm{m}^{2 *}$

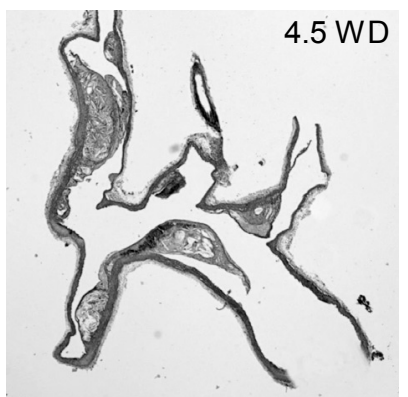

Plaque area: $668 \pm 142 \mu \mathrm{m}^{2 *}$

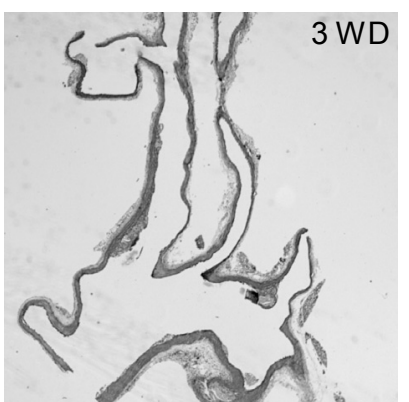

Plaque area: $106 \pm 26 \mu \mathrm{m}^{2 *}$

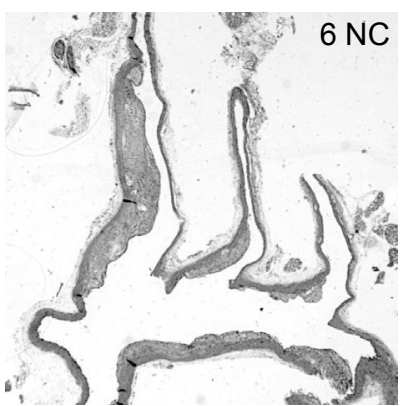

Plaque area: $712 \pm 24 \mu \mathrm{m}^{2 *}$

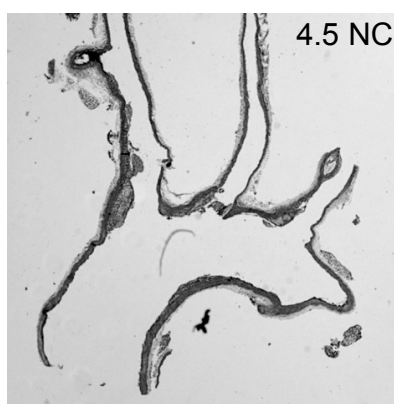

Plaque area: $162 \pm 42 \mu \mathrm{m}^{2 *}$

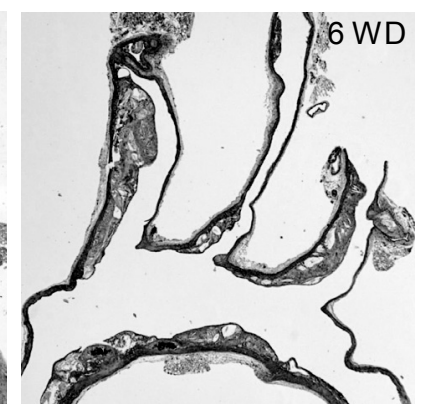

Plaque area: $1807 \pm 188 \mu \mathrm{m}^{2 *}$

Figure 1. HE-stained sections of aortic arches (arch) of ApoE-/- mice including the brachiocephalic artery (BCA), right common carotid artery (RCA), left common carotid artery (LCA), and left subclavian artery (LSA). ${ }^{*}$ Per $10^{3} \mu \mathrm{m}^{2}$. For full colour figure see page 130.

arch including its main branchpoints were cleaned of fatty tissue and fixed overnight in $1 \%$ paraformaldehyde. ${ }^{18}$ After they were processed, aortic arches were embedded longitudinally, and twenty $4 \mu \mathrm{m}$ sections that represented the central portion of the aortic arch were cut. For frozen sections $(6 \mu \mathrm{m})$, aortic roots were embedded in OCT compound (Tissue-Tek, Sakura Finetek) and stored at $-70^{\circ} \mathrm{C}$.

\section{RNA Isolation and Microarray Analysis}

Total RNA was isolated with the use of the RNeasy kit (Qiagen). Per isolation, 3 aortic arches of ApoE-/- mice were pooled. The mean yield per isolation was $5 \mu \mathrm{g}$ total RNA. For microarray analysis, mRNA was amplified with a T7-based technique. ${ }^{19}$

\section{Microarray Processing}

Regulation of gene expression was analyzed with the commercially available complimentary DNA (cDNA) mouse UniGEM array of Incyte Genomics. This array con- 
tains 10176 reporters representing 9556 genes and 580 controls. Polymerase chain reation (PCR) analysis confirmed the identity of 8848 reporters.

Cy3-dUTP or Cy5-dUTP (Amersham) was incorporated during reverse transcription of polyadenylated [poly(A)1] RNA, primed by a dT(16) oligomer, resulting in Cy3- and Cy5-labeled samples. ${ }^{20}$ Samples from the experimental groups were labeled with the Cy3 fluorescent dye, and the common reference group was labeled with the Cy5 fluorescent dye.

\section{Microarray Hybridization}

cDNA was processed as described previously. ${ }^{20}$ Briefly, cDNA was applied to the microarray under a cover slip, and the slide was placed in a hybridization chamber that was subsequently incubated for approximately 8 to 12 hours in a water bath at $62^{\circ} \mathrm{C}$. Subsequently, the slides were washed for 1 minute and dried by centrifugation at 500 RPM.

All samples from the experimental group (3, 4.5, and 6 month NC and WD ApoE-/- mice) were hybridized to a cDNA chip and compared to the cohybridized common reference. All hybridizations were performed in duplicate; in total $2 \times 5$ chips were hybridized.

\section{(Statistical) Analysis of Microarray Data}

Chips were scanned to detect hybridization signals. Scanned image output files were visually examined for major chip defects and hybridization artifacts and subsequently analyzed with Incyte's GemTools ${ }^{\mathrm{TM}}$ software. Genes were analyzed if both of the readings had a signal-to-background ratio of $\geq 2.5$, a signal intensity of $>250 \mathrm{U}$ for one or both dyes, and a spot size of $\geq 40 \%$ of the spotted area. Twentyfive percent of all arrays contained 1 of 10176 reporters that failed the minimal area requirement to be included. The mean number of reporters that had a signal below the minimal signal-to-backgroud level was 278.7 \pm 41.6 . The threshold of differential expression was set at $>2$-fold upregulation or downregulation.

Subsequently, time-related expression pattern clustering was performed using an algorithm. The different groups representing the different stages of atherosclerosis were put in sequential order on the basis of plaque area, as follows: 3 month WD diet, 4.5 month NC, 4.5 month WD, 6 month NC, and 6 month WD (figure 1 and table 1). Every gene at each time point was given a number representing $>2$-fold upregulation (1), no change $(0)$ or $>2$-fold downregulation $(-1)$ compared with the cohybridized common reference.

Functional grouping of differentially expressed genes was performed with the use of the visualization tool GenMAPP (Gene MicroArray Pathway Profiler; http://www.genmapp.org). This is a generally accessible program for viewing and analyzing microarray data on microarray pathway profiles (MAPP) representing biological pathways or any other functional grouping of genes. ${ }^{21}$ All MAPPs generated from the Gene Ontology database (http://www.geneontology.org) as well as 
Table 1. Time-related expression clustering of gene expression profiles of atherosclerotic aortic arches of ApoE-/- mice of 3, 4.5, and 6 months of age, fed a western-type diet (3WD, 4.5WD, 6WD) or normal chow diet $(4.5 \mathrm{NC}, 6 \mathrm{NC})$. Dark grey $(-1)$ : $>2$-fold downregulation compared with common reference; light grey (1): $>2$-fold upregulation compared with common reference; white (0): $>-2<2$ fold upregulation compared with common reference.

\begin{tabular}{|c|c|c|c|c|c|c|c|}
\hline $\begin{array}{c}3 \\
\text { WD }\end{array}$ & $\begin{array}{l}4.5 \\
\text { NC }\end{array}$ & $\begin{array}{l}4.5 \\
\text { WD }\end{array}$ & $\begin{array}{c}6 \\
\mathrm{NC}\end{array}$ & $\begin{array}{c}6 \\
\text { WD }\end{array}$ & $\begin{array}{c}\# \\
\text { Genes }\end{array}$ & Example & Incyte ID \\
\hline \multicolumn{8}{|c|}{ Genes downregulated in early atherosclerosis } \\
\hline-1 & 0 & 0 & 0 & 0 & 58 & Placental growth factor & uh10a05 \\
\hline \multicolumn{8}{|c|}{ Genes downregulated in advanced atherosclerosis } \\
\hline 0 & 0 & -1 & -1 & -1 & 1 & Integral membrane protein 2 & vc21b11 \\
\hline 0 & 0 & -1 & 0 & -1 & 3 & Carbonic anhydrase 3 & $\mathrm{mm16a05}$ \\
\hline 0 & 0 & -1 & 0 & 0 & 1 & Regulator of G-protein signaling 2 & $\mathrm{mv} 53 \mathrm{~b} 07$ \\
\hline 0 & 0 & 0 & -1 & -1 & 7 & Glutathione S-transferase, alpha 4 & $\mathrm{ml} 84 \mathrm{~g} 10$ \\
\hline 0 & 0 & 0 & -1 & 0 & 2 & Pancreatitis-associated protein & vo87h09 \\
\hline 0 & 0 & 0 & 0 & -1 & 47 & Kruppel like factor 15 & $\mathrm{mj} 86 \mathrm{e} 04$ \\
\hline \multicolumn{8}{|c|}{ Genes downregulated during atherosclerosis } \\
\hline-1 & 0 & 0 & -1 & -1 & 1 & Solute carrier family 27 (fatty acid transport) & $\operatorname{ma79d07}$ \\
\hline-1 & 0 & 0 & -1 & 0 & 1 & Serine proteinase inhibitor, clade B & ub62h11 \\
\hline-1 & 0 & 0 & 0 & -1 & 1 & Lectin, galactose binding & vn42h06 \\
\hline-1 & 0 & -1 & -1 & -1 & 1 & Protease, serine 16 & mu26b07 \\
\hline 0 & -1 & -1 & -1 & 0 & 1 & ESTs & vw59h01 \\
\hline 0 & -1 & 0 & -1 & -1 & 1 & Retinol binding protein & ve71cf1 \\
\hline 0 & -1 & 0 & -1 & 0 & 1 & Amine $\mathrm{N}$-sulfotransferase & mi98h07 \\
\hline \multicolumn{8}{|c|}{ Genes upregulated in early atherosclerosis } \\
\hline 1 & 0 & 0 & 0 & 0 & 26 & $\begin{array}{l}\text { MCP-3 } \\
\text { RANTES }\end{array}$ & $\begin{array}{l}\text { vu25f10 } \\
\text { ve78c12 }\end{array}$ \\
\hline 0 & 1 & 0 & 0 & 0 & 1 & FMS-like tyrosine kinase 1 & $\mathrm{mm09f03}$ \\
\hline \multicolumn{8}{|c|}{ Genes upregulated in advanced atherosclerosis } \\
\hline 0 & 0 & 0 & 0 & 1 & 111 & $\begin{array}{l}\text { Matrix metalloproteinase } 2 \\
\text { Cathepsin } \mathrm{H} \\
\text { Mouse complement factor } \mathrm{H}\end{array}$ & 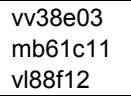 \\
\hline 0 & 0 & 0 & 1 & 0 & 5 & Jun oncogene & vk45c10 \\
\hline 0 & 0 & 0 & 1 & 1 & 55 & $\begin{array}{l}\text { MIP-1 } \beta \\
\text { MIP-1 } \alpha \\
\text { Cathepsin B }\end{array}$ & $\begin{array}{l}\mathrm{ml} 14 \mathrm{~h} 12 \\
\mathrm{vb} 44 \mathrm{~h} 05 \\
\mathrm{mg} 64 \mathrm{~b} 10\end{array}$ \\
\hline 0 & 0 & 1 & 0 & 0 & 8 & Apolipoprotein A1 & vp25g01 \\
\hline 0 & 0 & 1 & 0 & 1 & 8 & IL-8 like & vp23f01 \\
\hline 0 & 0 & 1 & 1 & 1 & 15 & Fractalkine & mb59d08 \\
\hline \multicolumn{8}{|c|}{ Genes upregulated in atherosclerosis } \\
\hline 0 & 1 & 0 & 1 & 0 & 1 & Hemoglobin & $\mathrm{mm09g04}$ \\
\hline 0 & 1 & 0 & 1 & 1 & 3 & Cathepsin D & $\mathrm{mb} 64 \mathrm{c} 01$ \\
\hline 0 & 1 & 1 & 1 & 1 & 10 & Cathepsin L & vl60h02 \\
\hline 1 & 0 & 0 & 0 & 1 & 2 & $M C P-1$ & $\mathrm{mp} 63 \mathrm{c} 06$ \\
\hline 1 & 0 & 0 & 1 & 1 & 4 & MCP-2 & mu45A04 \\
\hline 1 & 0 & 1 & 0 & 0 & 3 & ESTs & mn30b09 \\
\hline 1 & 0 & 1 & 0 & 1 & 2 & Heat shock protein 70 & mq49f01 \\
\hline 1 & 1 & 1 & 0 & 0 & 1 & Fatty acid synthase & vv71a07 \\
\hline 1 & 1 & 1 & 1 & 1 & 3 & Cathepsin S & $\mathrm{mr05a08}$ \\
\hline \multicolumn{8}{|c|}{ Genes up and downregulated in atherosclerosis } \\
\hline 1 & -1 & -1 & 1 & 0 & 2 & Immunoglobulin heavy chain 1 & $\mathrm{mt} 85 \mathrm{~d} 12$ \\
\hline 1 & -1 & 0 & 0 & 0 & 1 & $C C L 21 b$ & ma74f01 \\
\hline
\end{tabular}


local MAPPs generated by the G-protein Coupled Receptor Database (http://www.gpcr.org), the KEGG database (http://www.genome.ad.jp/kegg), and MAPPs specifically designed for GenMAPP were used. Gene expression data were imported into the program and dynamically linked to the MAPPs with the tool MAPP Finder.

\section{Validation}

\section{Quantitative Reverse Transcriptase PCR}

The SMART PCR cDNA synthesis kit (BD Biosciences) was used for the preparation of double-stranded cDNA from $1 \mu \mathrm{g}$ template RNA (used from a pool of $n=3$ aortic arches per group). cDNA was diluted to a total volume of $50 \mu 1$. Primers and FAMTAMRA-labeled probes for mouse MCP-1, MCP-5, MIP- $1 \alpha$ and MIP-1 $\beta$ were developed. Samples were amplified in duplicate with the use of the Taqman universal PCR master mix and the 7700 sequence detector (Applied Biosystems) using $300 \mathrm{nmol} / \mathrm{L}$ of primer and $200 \mathrm{nmol} / \mathrm{L}$ of probe. Data were analyzed with the use of Sequence Detection Software (Applied Biosystems). Relative expression of mRNA was calculated by the comparative CT method. To standardize for the amount of input RNA, the endogenous cyclophilin gene was included.

\section{ELISA}

Samples of aortic arch were homogenized in tissue protein extract buffer (Pierce) with the use of a Medimachine (BD Biosciences) fitted with 50 $\mu \mathrm{m}$ units. Protein extracts of two pools of $n=3$ aortic arches of ApoE-/- mice per group (3, 4.5, and 6 month NC or WD) were filtered with $30 \mu \mathrm{m}$ filters and subjected to an enzymelinked immunosorbent assay (ELISA) for MCP-1 and MCP-5 (R\&D Systems).

\section{Immunohistochemistry}

Immunohistochemistry was performed on frozen sections of aortic roots (MCP-1 and MCP-5) or paraffin-embedded aortic arch sections (MIP-1 $\alpha$ ) with the use of standard procedures. In short, sections were fixed for 15 minutes in $4 \%$ paraformaldehyde and incubated with anti-MCP-1 antibody (goat polyclonal, 1:30, R\&D Systems), anti-MCP-5 antibody (goat polyclonal, 1:50, R\&D Systems), and anti-MIP-1 $\alpha$ antibody (rabbit polyclonal, 1:100, RDI) or the respective control IgG (negative control). Subsequently, a suitable biotinylated secondary antibody was applied, followed by incubation with an $\mathrm{ABC}^{\mathrm{AP}}$ kit (DAKO). Immunostaining was visualized with an alkaline phosphatase-I kit (Vectastain). 


\section{Intervention Study}

\section{Generation of 11K2 Monoclonal Antibody}

Murine hybridomas were generated from RBF mice immunized with human MCP-1 (Garvan Institute) to provide neutralizing monoclonal antibodies. One monoclonal antibody (11K2) was selected for its high affinity for human MCP-1 (14 pmol/L) and its convenient cross-reactivity to the murine homologues (MCP-1 and MCP-5) allowing studies in murine disease models. The $11 \mathrm{~K} 2$ hybridoma cell line was suspension adapted and grown in reactors, and the antibody was purified by chromatography on protein A Sepharose and SP Sepharose.

\section{ELISA}

The wells of a 96-well plate (Maxisorb Nunc) were coated with synthetic murine MCP-1, MCP-3, or MCP-5 (Chemicon). Residual non-specific binding sites were blocked with bovine serum albumin (BSA). The binding of 11K2 was detected with the use of horseradish peroxidase-conjugated goat anti-murine IgG (Jackson Immunoresearch), and the colorimetric reaction was done with TMB.

\section{Kinexa Assay}

The Fab fragment of $11 \mathrm{~K} 2$ was generated by papain digestion of the antibody and purified from the Fc fragment by chromatography on protein A Sepharose. The affinity of $11 \mathrm{~K} 2$ for murine MCPs was measured with a Kinexa instrument (Sapidyne Instruments). $11 \mathrm{~K} 2 \mathrm{Fab}$ at $20 \mathrm{pmol} / \mathrm{L}$ was incubated in PBS, $0.02 \%$ azide, $0.1 \% \mathrm{BSA}$, with various concentrations of murine MCP-1 (Chemicon Inc.) or MCP-5 (Peprotech Inc.). The mixtures were allowed to reach equilibrium for 3 hours at room temperature and applied to a column of huMCP-1-coated polymethylmethacrylate beads $(98 \mu \mathrm{m})$. Free Fab bound to the column and was detected with Cy-5-labeled goat anti-mouse $F\left(a b^{\prime}\right) 2$. Under these conditions, the signal measured is proportional to the concentration of free Fab applied to the column. The data were fit to a quadratic curve as described previously.22

\section{Chemotaxis Assays}

Chemotaxis towards murine MCP-1 (BioSource), MCP-3, or MCP-5 (Cell Sciences) was measured with the ChemoTx system (Neuro Probe, Inc.). Murine monocytes, WEHI-274.1 (ATCC) or THP-1 cells were separated from the chemokines and the antibody by a filter with $5 \mu \mathrm{m}$ pores. The effectiveness of $11 \mathrm{~K} 2$ in inhibiting monocyte chemotaxis was determined after 4 hours. Migration was quantified using Cell Titer dye (Promega). 


\section{Mouse Experiments}

Male ApoE-/- mice (Iffa Credo) were injected intraperitoneally with the $11 \mathrm{~K} 2$ antibody $(200 \mu \mathrm{g} /$ week) or an isotype control antibody (IgG1, MOPC-21) twice a week for 12 weeks. Treatment started at the age of 5 weeks (early treatment: $n=15$ for $11 \mathrm{~K} 2$, $\mathrm{n}=15$ for control) or 17 weeks (delayed treatment: $\mathrm{n}=15$ for $11 K 2, \mathrm{n}=15$ for control).

Tissue processing was performed as described above, and atherosclerotic lesions were analyzed as described previously. ${ }^{18,23}$ In short, atherosclerotic plaques were subdivided into initial lesions (pathological intimal thickening, intimal xanthoma) and advanced lesions (fibrous cap atheroma) according to the classification by Virmani et al. ${ }^{24}$ Morphometric analysis with the use of computerized morphometry (Leica Quantimet 570), included measuring plaque area (hematoxylin and eosin $[\mathrm{HE}])$, collagen content (Sirius Red), $\alpha$-smooth muscle actin content ( $\alpha \mathrm{SMA}$, mouse monoclonal 1:3000, Sigma), macrophage content (Mac3, rat monoclonal,1:30, Pharmingen), and CD45+ cell content (CD45, rat monoclonal 1:30, Pharmingen).

\section{Evaluation of Possible Side Effects}

To evaluate possible side effects of $11 \mathrm{~K} 2$ treatment, fluorescence-activated cell sorting (FACS) analysis (FACSCalibur, BD Biosciences) with T lymphocyte-specific antibodies was performed on peripheral blood leukocytes, spleen, and lymph nodes of $\mathrm{n}=611 \mathrm{~K} 2$ and $\mathrm{n}=6$ control treated mice of both treatment groups. Antibodies used

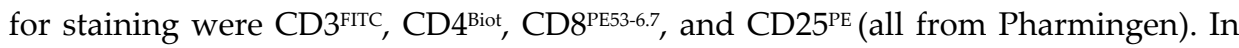
addition, $>20$ organs were excised and evaluated macroscopically and microscopically on $4 \mu \mathrm{m}$ sections stained with HE.

\section{Lipid Profile}

For the assessment of lipid profiles, standard enzymatic techniques were used, automated on the Cobas Fara centrifugal analyzer (Hoffmann-La Roche). Total plasma cholesterol and high density lipoprotein (HDL) were measured with the use of kits 0736635 and 543004 (Hoffmann-La Roche), total glycerol using kit 33740A/337-10B (Sigma), and free glycerol using kit 0148270 (Hoffmann-La Roche). Precipath (standardized serum) was used as an internal standard. Low density lipoprotein (LDL) was calculated as follows: total cholesterol - [(total glycerol - free glycerol)/2.2 - HDL)].

\section{Statistical Analysis}

All microarrays were analyzed and validated with the use of Gemtools. In the intervention study, data were compared with a non-parametric Mann-Whitney U test. 


\section{Results}

\section{Microarray}

\section{Analysis}

In total, 387 of 10176 reporters were expressed >2-fold (compared with the cohybridized reference: ApoE-/- mice, 3 month NC) in one or more of the experimental groups analyzed. The majority of the differentially expressed genes were upregulated in one or more experimental groups (258 genes upregulated, 127 downregulated, 2 upregulated and downregulated in different experimental groups). Of those genes, 289 were known and 98 were expressed sequence tags (ESTs) (including RIKEN database).

Differential expression levels relative to the cohybridized reference ranged from 2 to 17.5 and from -2 to -11 .1. Five genes showed a $>10$-fold increase, 15 genes $>5$ to $<10$-fold, and 240 genes $>2$ to $<5$-fold. For the downregulated genes, these numbers were 3,18 , and 109 .

Genes that showed the highest relative expression levels were serine protease inhibitor 2-2 (10.5-fold upregulation), CD68 (11.0-fold upregulation), cathepsin S (12.6-fold upregulation), lectin galactose binding soluble 3 (12.4-fold upregulation), and apoptosis inhibitory 6 (17.5-fold upregulation). Genes with the lowest relative expression levels were 3 ESTs (all -10.1-fold downregulation).

\section{Time-Related Gene Expression Changes During Atherogenesis}

For the detection of time-related expression clustering, we developed the algorithm described in the methods section. In theory, $3^{5}=243$ clusters could be formed, however only 33 different clusters were observed. From these 33 clusters the majority of genes were found in clusters containing genes upregulated in advanced atherosclerosis. Among those genes, many were linked to inflammation and proteolysis (table $1)$.

\section{Functional Grouping of Differentially Expressed Genes}

Functional groups that contained most of the differentially expressed genes were those involved in inflammation (acute phase response, chemotaxis, cytokines) and protein/matrix degradation (protein degradation, proteolysis and peptidolysis, catabolism) (table 2). 
Table 2. Functional grouping of genes using gene ontology databases and time-related expression profiles of genes differentially expressed in aortic arches of ApoE-deficient mice.

\begin{tabular}{|c|c|c|c|}
\hline Category & Gene Name & Clone ID & Cluster* \\
\hline \multirow[t]{16}{*}{ Lipid metabolism } & apolipoprotein A-I & 107774 & $0,0,1,0,0$ \\
\hline & apolipoprotein C-IV & 404046 & $0,0,0,0,0$ \\
\hline & apolipoprotein E & 521479 & $0,0,0,0,0$ \\
\hline & apolipoprotein $\mathrm{H}$ & 1350386 & $0,0,0,0,0$ \\
\hline & apolipoprotein B editing complex 1 & 618120 & $0,0,0,0,1$ \\
\hline & apolipoprotein B editing complex 2 & 482571 & $0,-1,-1,-1,-1$ \\
\hline & fatty acid synthase & 1227828 & $1,1,1,0,0$ \\
\hline & solute carrier family 27 (fatty acid transporter), 2 & 521620 & $-1,0,0,-1,-1$ \\
\hline & fatty acid binding protein 1 & 1277312 & $0,0,1,01$ \\
\hline & fatty acid binding protein 4 & 523460 & $0,0,0,0,-1$ \\
\hline & fatty acid binding protein 5 & 990152 & $0,0,0,0,0$ \\
\hline & fatty acid synthase & 1227828 & $1,1,1,0,0$ \\
\hline & LDL receptor related protein 1 & 407600 & $0,0,0,0,1$ \\
\hline & phospholipid transfer protein & 1001588 & $0,1,1,1,1$ \\
\hline & phospholipase D3 & 933757 & $0,0,0,1,1$ \\
\hline & glycosylphosphatidylinosytol specific phospholipase D1 & 333314 & $0,0,0,0,0$ \\
\hline \multirow{37}{*}{$\begin{array}{l}\text { Matrix turnover } \\
\text { (protein degradation) }\end{array}$} & elastin & 372899 & $0,0,0,0,1$ \\
\hline & fibulin 5 & 819734 & $0,0,0,0,1$ \\
\hline & glypican 1 & 1065141 & $-1,0,0,0,0$ \\
\hline & procollagen, type I alpha 1 & 402270 & $0,0,1,1,1$ \\
\hline & procollagen, type II alpha 1 & 669703 & $0,0,0,0,1$ \\
\hline & procollagen, type XVIII alpha 1 & 720629 & $0,0,0,0,1$ \\
\hline & matrix Gla protein & 407582 & $0,0,1,1,1$ \\
\hline & cartilage oligomeric matrix protein & 335946 & $0,0,0,1,1$ \\
\hline & osteoprotegerin & 851484 & $0,0,0,1,1$ \\
\hline & thrombospondin 1 & 1383744 & $0,0,0,0,1$ \\
\hline & transglutaminase 2 , C polypeptide & 536592 & $0,0,0,0,1$ \\
\hline & transglutaminase 3 , E polypeptide & 317794 & $-1,0,0,0,0$ \\
\hline & cathepsin B & 437755 & $0,0,0,1,1$ \\
\hline & cathepsin D & 334176 & $0,1,0,1,1$ \\
\hline & cathepsin $\mathrm{H}$ & 333908 & $0,0,0,0,1$ \\
\hline & cathepsin L & 976659 & $0,1,1,1,1$ \\
\hline & cathepsin S & 596534 & $1,1,1,1,1$ \\
\hline & cathepsin Z & 539055 & $0,0,0,0,1$ \\
\hline & MMP-2 & 1224700 & $0,0,0,0,1$ \\
\hline & MMP-12 & 1037661 & $0,0,0,1,1$ \\
\hline & TIMP & 622732 & $0,0,0,1,0$ \\
\hline & TIMP-3 & 580753 & $0,0,0,0,1$ \\
\hline & cysteine protease 1 & 403755 & $0,0,1,1,1$ \\
\hline & serine protease 16 & 640501 & $-1,0,-1,-1,-1$ \\
\hline & chitinase 3 -like 1 & 313884 & $0,0,0,0,1$ \\
\hline & serine proteinase inhibitor, clade $B$ & 1382373 & $-1,0,0,-1,0$ \\
\hline & serine proteinase inhibitor, clade $\mathrm{E}$ & 1002830 & $0,0,0,0,1$ \\
\hline & serine proteinase inhibitor, clade $\mathrm{F}$ & 333193 & $0,0,0,0,0$ \\
\hline & serine proteinase inhibitor, clade $\mathrm{H}$ & 1077734 & $0,0,0,0,0$ \\
\hline & serine protease inhibitor $1-1$ & 1077714 & $0,0,1,0,1$ \\
\hline & serine protease inhibitor $1-2$ & 367239 & $0,0,0,0,0$ \\
\hline & serine protease inhibitor $1-3$ & 334942 & $0,0,1,1,1$ \\
\hline & serine protease inhibitor $1-5$ & 331065 & $0,0,1,0,1$ \\
\hline & serine protease inhibitor 2 related sequence 1 & 1077424 & $0,0,0,0,0$ \\
\hline & serine protease inhibitor $2-2$ & 1077628 & $0,1,1,1,1$ \\
\hline & secretory leukocyte protease inhibitor & 1367229 & $-1,-1,-1,-1,-1$ \\
\hline & extracellular proteinase inhibitor & 1195775 & $0,0,0,1,1$ \\
\hline \multirow[t]{4}{*}{ Cytoskeleton } & myosin VI & 872172 & $-1,0,0,0,0$ \\
\hline & melanoma X-actin & 1005837 & $0,0,0,0,1$ \\
\hline & actin, gamma, cytoplasmic & 1005899 & $0,0,0,0,1$ \\
\hline & alpha actin cardiac & 536543 & $0,0,0,0,0$ \\
\hline
\end{tabular}




\begin{tabular}{|c|c|c|c|}
\hline Category & Gene Name & Clone ID & Cluster* \\
\hline & laminin $\gamma 2$ & 335886 & $-1,0,0,0,0$ \\
\hline \multirow[t]{6}{*}{ Growth factors } & endothelin 1 & 1040154 & $0,0,0,0,1$ \\
\hline & insulin-like growth factor 1 & 1001007 & $0,0,0,1,1$ \\
\hline & insulin-like growth factor binding protein 2 & 1277469 & $0,0,0,0,1$ \\
\hline & insulin-like growth factor binding protein 4 & 597004 & $0,0,0,1,1$ \\
\hline & placental growth factor & 1617488 & $-1,0,0,0,0$ \\
\hline & latent TGF $\beta$ binding protein 2 & 1396864 & $0,0,0,0,1$ \\
\hline \multirow{39}{*}{$\begin{array}{l}\text { Immune system } \\
\text { and inflammation }\end{array}$} & complement component 1q alpha polypeptide & 597157 & $0,0,0,1,1$ \\
\hline & complement component 1q beta polypeptide & 1430527 & $0,0,0,1,1$ \\
\hline & complement component 1q c polypeptide & 426010 & $0,0,0,1,1$ \\
\hline & complement component 4 & 1227418 & $0,0,1,1,1$ \\
\hline & complement factor $\mathrm{H}$-related protein & 681810 & $0,0,0,0,1$ \\
\hline & Fc receptor, IgG high affinity & 576062 & $0,0,0,1,1$ \\
\hline & Fc receptor, IgG low affinity III & 516594 & $0,0,0,1,1$ \\
\hline & Fc receptor, IgE high affinity & 316763 & $0,0,0,1,1$ \\
\hline & Fc receptor, IgE low affinity II & 717625 & $1,0,0,0,0$ \\
\hline & immunoglobulin heavy chain 1 & 636695 & $1,-1,-1,1,0$ \\
\hline & immunoglobulin heavy chain 3 & 1448206 & $1,-1,-1,1,-1$ \\
\hline & immunoglobulin heavy chain 6 & 1179412 & $1,-1,-1,0,-1$ \\
\hline & immunoglobulin gamma constant & 635556 & $1,-1,-1,1,0$ \\
\hline & immunoglobulin kappa chain variable 28 & 597591 & $1,-1,-1,0,-1$ \\
\hline & immunoglobulin kappa chain variable 20 & 2749406 & $1,-1,-1,0,-1$ \\
\hline & immunoglobulin joining chain & 1277614 & $0,0,0,0,0$ \\
\hline & IG alpha chain $\mathrm{C}$ region & 875880 & $-1,-1,-1,-1,-1$ \\
\hline & immunoglobulin-associated beta & 720992 & $1,0,0,0,0$ \\
\hline & delta-immunoglobulin & 831907 & $1,0,0,0,0$ \\
\hline & histocompatibility $2, \mathrm{Q}$ region locus 7 & 596447 & $0,0,0,0,1$ \\
\hline & small inducible cytokine D1 (fractalkine) & 333711 & $0,0,1,1,1$ \\
\hline & small inducible cytokine A2 (MCP-1) & 573898 & $1,0,0,0,1$ \\
\hline & small inducible cytokine A3 (MIP-1a) & 751833 & $0,0,0,1,1$ \\
\hline & small inducible cytokine A4 (MIP-1 $\beta$ ) & 621095 & $0,0,0,1,1$ \\
\hline & small inducible cytokine A5 (RANTES) & 832342 & $1,0,0,0,0$ \\
\hline & small inducible cytokine $A 6$ & 1077529 & $0,0,1,0,1$ \\
\hline & small inducible cytokine A7 (MCP-3) & 1181707 & $1,0,0,0,0$ \\
\hline & small inducible cytokine A8 (MCP-2) & 620243 & $1,0,0,1,1$ \\
\hline & small inducible cytokine A21a (CCL21a) & 335077 & $1,-1,0,0,0$ \\
\hline & small inducible cytokine A21b (CCL21b) & 316441 & $1,-1,0,-1,-1$ \\
\hline & IL11 receptor alpha chain 1 & 366999 & $0,0,0,0,1$ \\
\hline & IL11 receptor alpha chain 2 & 1349690 & $0,0,0,0,1$ \\
\hline & IL12b & 750641 & $-1,0,0,0,0$ \\
\hline & IL1 receptor accessory protein & 678770 & $-1,0,0,0,0$ \\
\hline & IL2 receptor gamma chain 2 & 721711 & $-1,0,0,0,0$ \\
\hline & TNF superfamily member 11 & 618692 & $0,0,0,1,1$ \\
\hline & serum amyloid $A 3$ & 126951 & $0,0,0,0,1$ \\
\hline & heat shock protein $70 \mathrm{kDa} 1$ & 779196 & $1,0,1,0,1$ \\
\hline & heat shock protein $70 \mathrm{kDa} 3$ & 582093 & $1,0,1,0,1$ \\
\hline \multirow[t]{5}{*}{ Cell adhesion } & VCAM-1 & 635211 & $0,0,0,0,1$ \\
\hline & syndecan 1 & 1077399 & $0,0,0,0,1$ \\
\hline & p-selectin & 876033 & $0,0,0,0,1$ \\
\hline & cadherin 13 & 482972 & $0,0,0,0,1$ \\
\hline & glycosylation dependent cell adhesion molecule 1 & 749605 & $1,0,0,0,0$ \\
\hline \multirow{9}{*}{$\begin{array}{l}\text { Phosphatases, kinases } \\
\text { esterases }\end{array}$} & 6-phosphofructo-2-kinase/fructose-2,6-biphosphatase 1 & 1511542 & $0,0,-1,0,-1$ \\
\hline & proline-serine-threonine phosphatase-interacting protein 1 & 1349888 & $0,0,0,0,1$ \\
\hline & MAPKKKK 1 & 318867 & $0,0,0,1,1$ \\
\hline & spleen tyrosine kinase & 642318 & $1,0,0,1,1$ \\
\hline & serum/glucocorticoid regulated kinase & 1383570 & $-1,0,0,0,0$ \\
\hline & esterase 31 & 747188 & $0,0,0,0,0$ \\
\hline & protein tyrosine phosphatase, non-receptor type 11 & 332650 & $0,0,0,1,0$ \\
\hline & lymphocyte protein tyrosine kinase & 1148872 & $0,0,0,0,0$ \\
\hline & creatine kinase & 520908 & $0,0,0,0,-1$ \\
\hline
\end{tabular}




\begin{tabular}{llll}
\hline Category & Gene Name & Clone ID & Cluster* \\
\hline & protein tyrosine phosphatase, receptor type, V polypeptide- & \multirow{2}{*}{$\begin{array}{l}\text { * } \\
\text { associated }\end{array}$} & \multirow{2}{*}{$0,0,0,0$} \\
\hline Apoptosis & apoptosis inhibitory 6 & 764624 & $0,1,1,1,1$ \\
& cell death-inducing DNA fragmentation factor & 333124 & $0,0,0,0,-1$ \\
\hline Differentiation & growth differentiation factor 15 & 8204034 & $0,0,0,0,1$ \\
\hline Transcription factors & paired-like homeodomain transcription factor 3 & 482871 & $-1,0,0,0,0$ \\
\hline Cell cycle & growth arrest and DNA-inducible 45 alpha & 961868 & $0,1,0,1,1$ \\
& cyclin dependent kinase inhibitor 1 C & 1038618 & $0,0,0,1,0$ \\
\hline lon channels/receptors & potassium intermediate/small conductance calcium acti- & \multirow{2}{*}{642677} & $0,0,0,0,1$ \\
& vated channel & 1092732 & $0,0,0,0,1$ \\
& nuclear receptor subfamily 2 group H member 2 & 641865 & $0,0,0,1,0$ \\
& nuclear receptor subfamily 4 group A member 1 & 1148775 & $0,0,0,1,1$ \\
\hline Oxidative stress & colony stimulating factor 2 receptor & 334351 & $0,0,0,0,1$ \\
\hline Coagulation & metallothionein 2 & 537284 & $0,0,0,0,1$ \\
& GAS 6 & 318749 & $0,0,0,0,0$ \\
\hline
\end{tabular}

*Gene expression in aortic arches of ApoE-deficient mice fed a western-type diet (WD) for 3 months (m), normal chow diet (NC) for $4.5 \mathrm{~m}$, WD for $4.5 \mathrm{~m}$, NC for $6 \mathrm{~m}$, or WD for $6 \mathrm{~m}$. -1 represents downregulation, 0 no modulation, and 1 upregulation when gene expression was compared with the common reference (ApoE-deficient mice fed a NC diet for 3 months).

Of special interest within these large gene maps were the subfamilies of small inducible cytokines and the cathepsins. Numerous members of both subfamilies were expressed throughout atherogenesis. Members of the small inducible cytokines included MCP-1, MCP-3, MCP-5, RANTES (regulated on activation normal T cell expressed and secreted), fractalkine, MIP-1 $\alpha$, MIP-1 $\beta$, MIP-2, IL-8-like, and small inducible cytokine $21 \mathrm{a}$ and $21 \mathrm{~b}$. The expression of the majority of the small inducible cytokines was slightly elevated in early atherosclerosis and increased to expression levels above the 2-fold threshold level in advanced atherosclerotic plaques (figure 2A), except for small inducible cytokine 21a and 21b (CCL21a and b) and RANTES, which appeared to be downregulated in advanced atherosclerosis. Members of the cathepsin subfamily included cathepsin B, D, H, L, S, and Z. Relative expression levels of all members increased steadily during plaque progression (figure 2B). Further validation experiments were confined to the small inducible cytokine family.

\section{Validation of Expression Profiles of Small Inducible Cytokines in Atherosclerosis}

Real-time PCR for MCP-1, MCP-5, MIP- $1 \alpha$, and MIP-1 $\beta$ on aortic arches of ApoE-/mice of different age and diet confirmed the increased expression in atherosclerosis (figure 3A). ELISA on aortic arch lysates showed that expression of MCP-1 and MCP-5 protein was highest in advanced atherosclerotic plaques (figure 3B). Immunohistochemistry for MCP-1, MCP-5 and MIP-1 $\alpha$ showed highest expression levels in macrophage foam cells of advanced atherosclerotic plaques (figure 3C-E). 


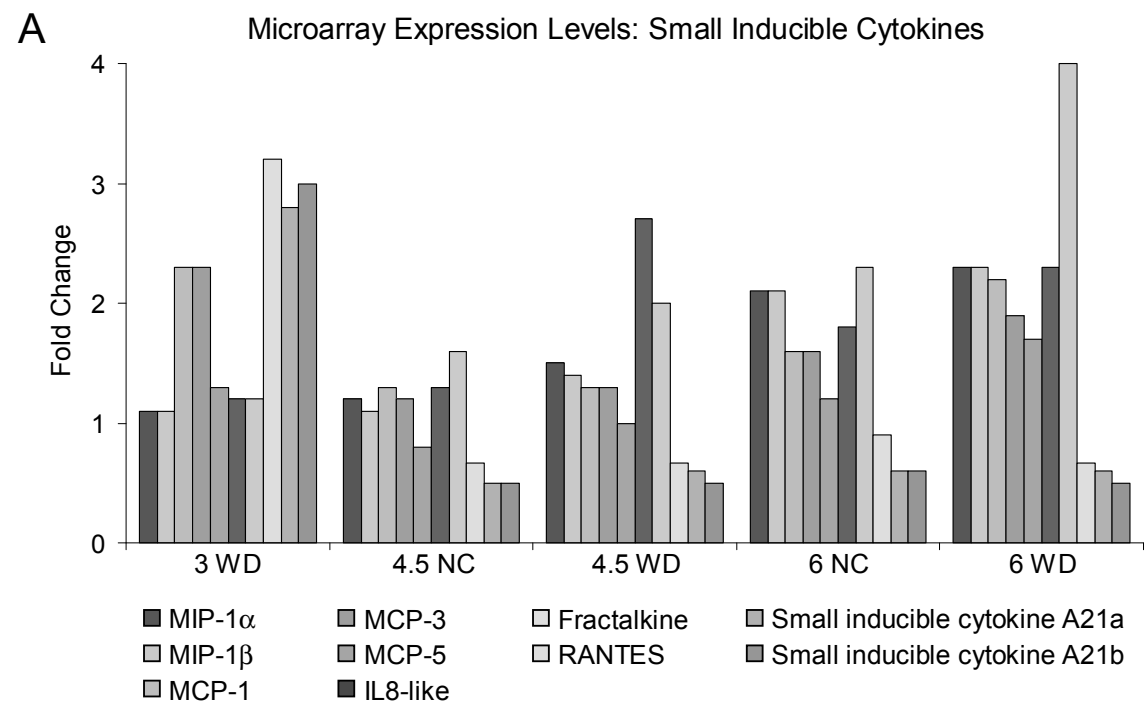

B Microarray Expression Levels: Cathepsins

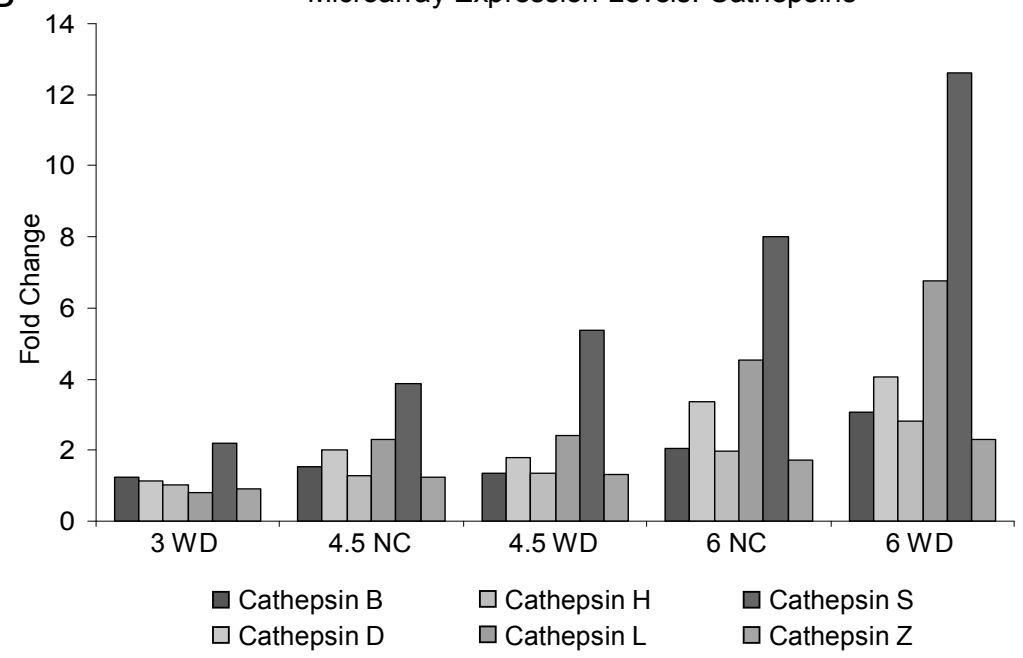

Figure 2. Microarray expression levels of members of the two most abundant clusters: the small inducible cytokines (A) and the cathepsins (B). For full colour figure see page 131. 

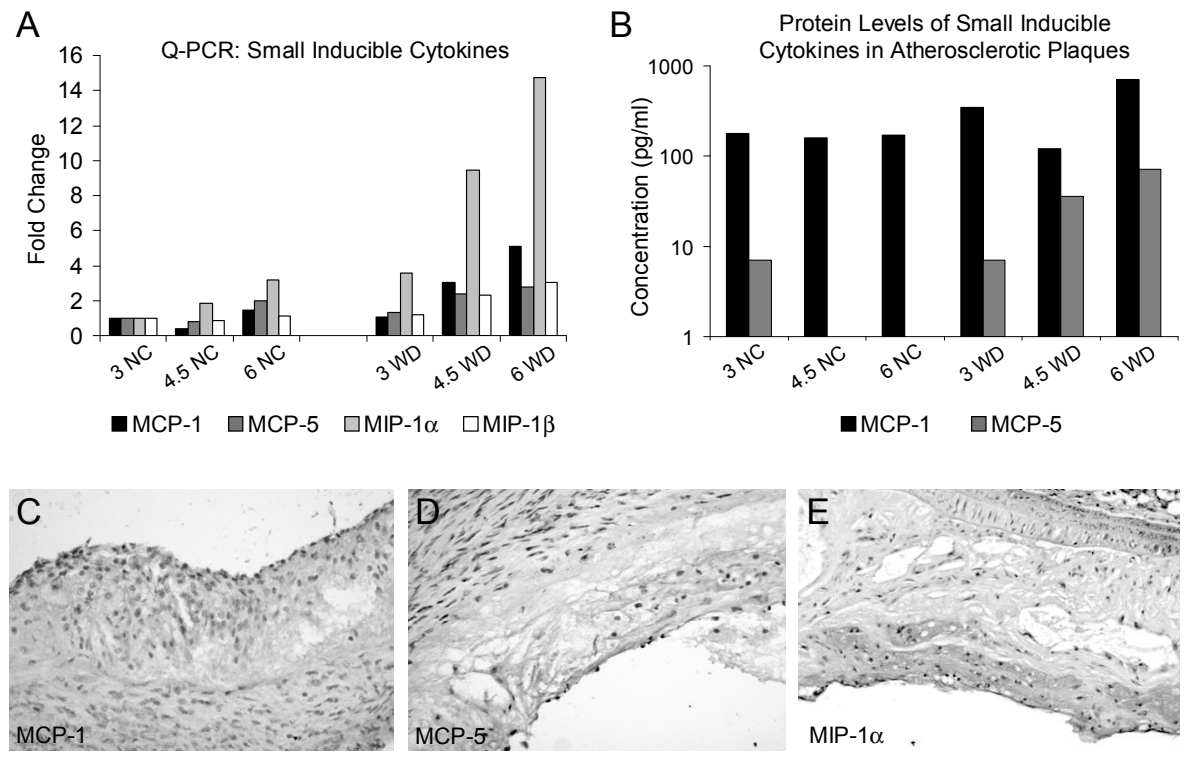

Figure 3. Validation experiments. (A) Quantitative PCR and (B) ELISA show that both RNA and protein levels of several members of the small inducible cytokine family (MCP-1, MCP-5, MIP-1 $\alpha$ and MIP-1 $\beta$ ) increase with disease progression. Immunohistochemistry for (C) MCP-1, (D) MCP-5 and (E) MIP-1 $\alpha$ show that these proteins are predominantly expressed in macrophages of advanced atherosclerotic lesions (magnification 400X). For full colour figure see page 132 .

\section{Role of Small Inducible Cytokines in Atherosclerosis: Mouse Study}

\section{K2: Specificity and Function}

The binding specificity of $11 \mathrm{~K} 2$ was measured by ELISA (figure 4A). 11K2 demonstrated half-saturable binding at approximately $1.5 \mathrm{ng} / \mathrm{ml}(10 \mathrm{nmol} / \mathrm{L})$ for both MCP1 and MCP-5. In contrast, no specific binding of 11K2 to murine MCP-2 and MCP-3 could be detected up to $10 \mu \mathrm{g} / \mathrm{ml}$ (figure $4 \mathrm{~A}$ ).

The Fab form of $11 \mathrm{~K} 2$ was used to obtain a measure of the intrinsic affinity for murine MCP-1 and MCP-5. With the use of Kinexa assay, 11K2 Fab was found to bind to solution phase murine MCP-1 with an affinity of $0.3 \mathrm{nmol} / \mathrm{L}$, whereas its affinity for murine MCP-5 was $1.4 \mathrm{nmol} / \mathrm{L}$ (figure $4 \mathrm{~B}$ ). As determined by ELISA, no binding was observed for murine MCP-2.

The ability of $11 \mathrm{~K} 2$ to block monocyte chemotaxis was analyzed by cell migration assays. Different ratios of $11 \mathrm{~K} 2$ and murine MCP-1 or MCP-5 were tested for the inhibition of murine monocyte migration across a filter barrier over a 4-hour test period. For both murine MCP-1 and MCP-5, a 50\% reduction in migration was observed with approximately 20 -fold excess of monoclonal antibody (figure 4C). 
A

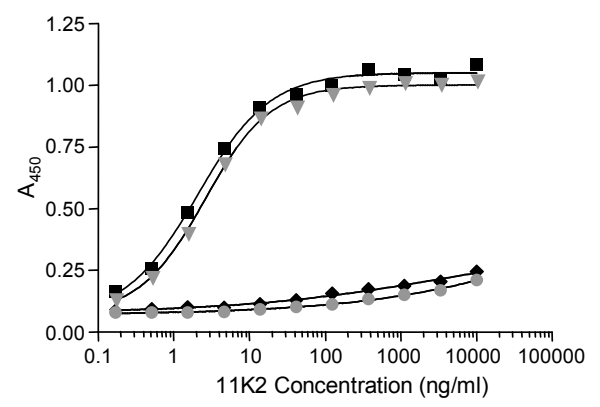

C

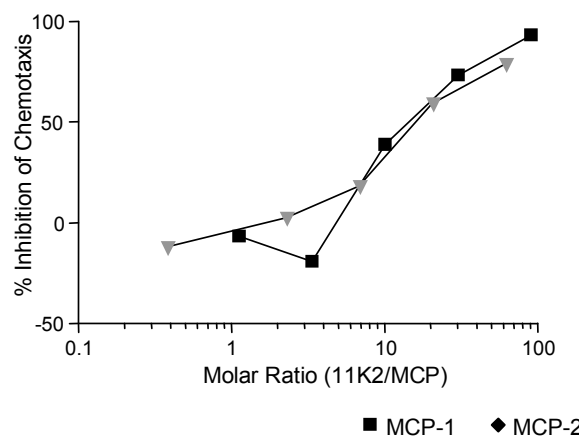

B

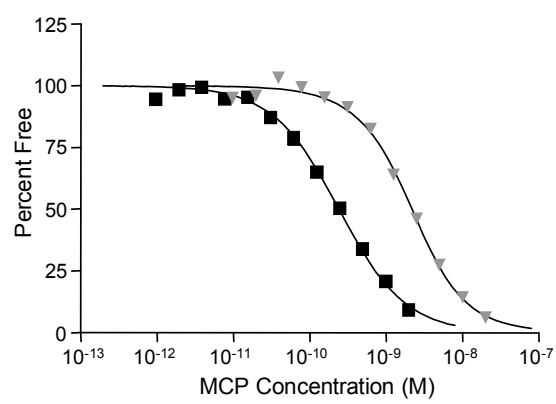

D

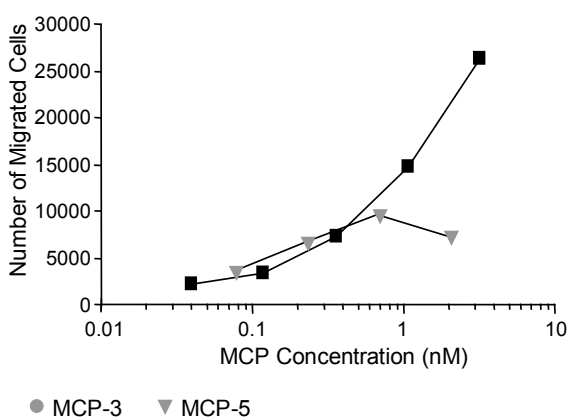

Figure $4.11 \mathrm{~K} 2$ is a binding antagonist of murine MCP-1 and MCP-5. (A) Binding of $11 \mathrm{~K} 2$ to surface coated murine MCP-1, MCP-2, MCP-3, and MCP- 5 measured by ELISA. (B) Measure of free $11 \mathrm{~K} 2 \mathrm{Fab}$ in mixtures of $11 \mathrm{~K} 2 \mathrm{Fab}$ and MCP-1 or MCP-5 at various concentrations. (C) $11 \mathrm{~K} 2$ blocks the chemotaxis of a murine monocytic cell line induced by murine MCP-1 and MCP-5. (D) Both MCP-1 and MCP-5 are strong chemotactic agents for monocytes.

\section{Role of MCP-1 and MCP-5 in Monocyte Recruitment}

In an in vitro experiment using THP- 1 cells, we showed that both MCP-1 and MCP5 are strong mediators of monocyte recruitment (figure $4 \mathrm{D}$ ). These results indicate an important role for both MCP-1 and MCP-5 in monocyte recruitment in atherosclerotic plaques.

\section{Mice}

In the early treatment group ( 5 to 17 weeks of age), survival rates were $100 \%$. In the delayed treatment group (17 to 29 weeks of age), survival rates were $93.3 \%$ for the $11 \mathrm{~K} 2$ treated group and $93.3 \%$ for the control treated group. Macroscopic and microscopic analysis on hematoxylin-eosin-stained sections of $>20$ organs revealed no abnormalities. No differences in total cholesterol, triglycerides, HDL, and LDL were observed between 11K2 and control treated ApoE-/- mice (data not shown). 
FACS analysis on peripheral blood leukocytes, spleen, and lymph nodes revealed no differences in the number of CD3+ cells or in the activation status of $\mathrm{T}$ cells (CD4+/CD8+ ratio, CD25+ T-cells) between 11K2 and control treated ApoE-/mice (data not shown).

\section{Plaque Development and Phenotype}

In the early treatment group (treatment age 5 to 17 weeks), $11 \mathrm{~K} 2$ treatment decreased total atherosclerotic plaque area per aortic arch (figure 5A). After this treatment regimen, only initial lesions were present in the aortic arch of $11 \mathrm{~K} 2$ and control treated ApoE-/- mice. Although the number of initial lesions per aortic arch did not change after $11 \mathrm{~K} 2$ treatment $(2.1 \pm 0.2$ lesions per aortic arch for $11 \mathrm{~K} 2$ vs. $2.2 \pm 0.4$ for control), these initial lesions were remarkably smaller in $11 \mathrm{~K} 2$ treated mice than in control treated mice $\left(8.803 \pm 1.314 \mu \mathrm{m}^{2}\right.$ for $11 \mathrm{~K} 2$ vs. $12.921 \pm 1.258 \mu^{2}$ for control, $\mathrm{P}<0.05)$. This indicates that $11 \mathrm{~K} 2$ treatment does not impair lesion initiation, but does inhibit lesion growth.

In the delayed treatment group (treatment from age 17 to 29 weeks), we also observed a significant decrease in total plaque area per aortic arch after $11 \mathrm{~K} 2$ treat-

A

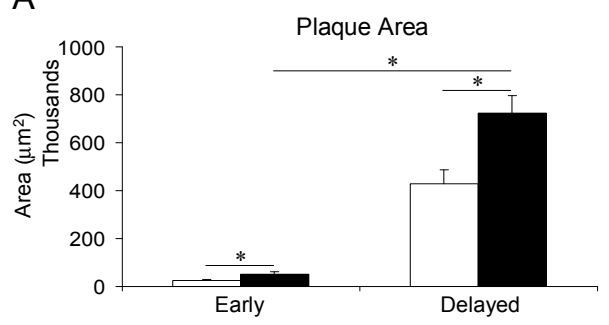

C

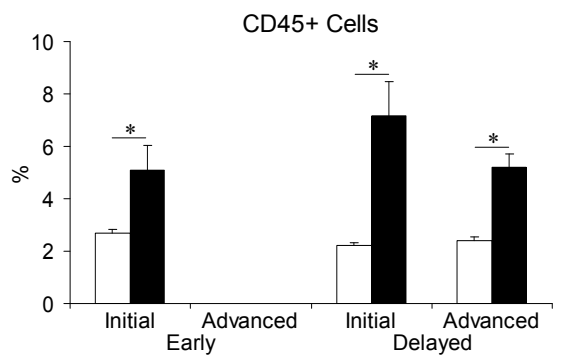

B

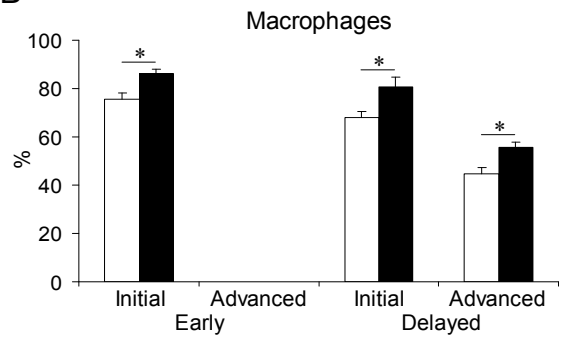

D

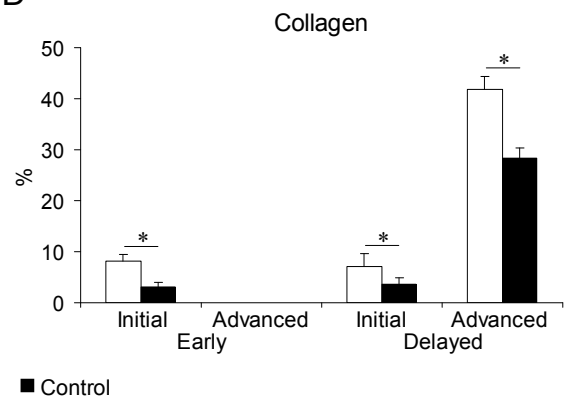

Figure 5. Plaque characteristics of ApoE-/- mice treated with 11K2 or control antibody. (A) 11K2 treatment significantly decreased total plaque area per aortic arch. (B) Macrophage and (C) CD45+ cell content significantly decreased in initial and advanced lesions after $11 \mathrm{~K} 2$ treatment. (D) Collagen content significantly increased in initial and advanced lesions after $11 \mathrm{~K} 2$ treatment. 


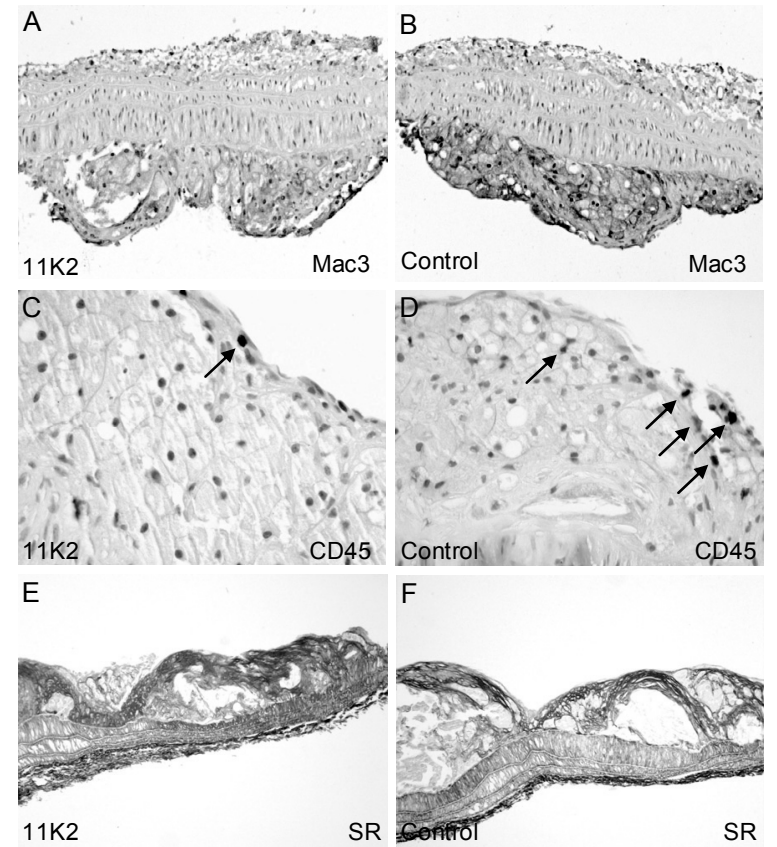

Figure 6. The relative amount of Mac3+ macrophages (200X) is decreased after (A) $11 \mathrm{~K} 2$ treatment compared with (B) control treatment. CD45 staining (400X) of advanced atherosclerotic lesions (shoulder region) revealed that $(C) 11 \mathrm{~K} 2$ treatment decreased the percentage of CD45+ leukocytes (indicated by arrows) compared with (D) control treatment. Sirius Red (SR) staining (100X) of advanced atherosclerotic plaques revealed an increase in collagen content after (E) $11 \mathrm{~K} 2$ treatment compared with (F) control treatment. For full colour figure see page 132 .

ment (figure 5A). Although individual initial and advanced plaque area did not change after $11 \mathrm{~K} 2$ treatment, the total number of advanced plaques per aortic arch significantly decreased $(2.6 \pm 0.3$ for $11 \mathrm{~K} 2$ vs. $4.0 \pm 0.2$ for control, $\mathrm{P}<0.05)$, whereas the number of initial lesions increased $(1.9 \pm 0.3$ for $11 \mathrm{~K} 2$ vs. $1.1 \pm 0.2$ for control, $\mathrm{P}<0.05)$. This indicates that the decrease in total plaque area is due to inhibition of disease progression: initial lesions partly fail to progress into advanced atherosclerotic plaques.

A third observation that stresses the effect of $11 \mathrm{~K} 2$ treatment on lesion progression is that the increase in plaque area was retarded from 14.1-fold from week 17 to week 29 in the control group to only 8.3-fold in the 11K2 treated group (figure 5A).

Analysis of plaque composition showed that early and advanced atherosclerotic plaques of ApoE-/- mice treated with the $11 \mathrm{~K} 2$ antibody were particularly low in inflammation. Both initial and advanced atherosclerotic lesions of early and delayed treatment groups showed a profound reduction in macrophage and CD45+ cell content (figure 5B, C, 6A-D). Moreover, plaques exhibited increased fibrosis after 11K2 treatment, as shown by their collagen content (figure 5D, 6E-F). $\alpha$ SMA content had increased in initial plaques after $11 \mathrm{~K} 2$ treatment (early treatment, $4.4 \pm 1.2 \%$ for $11 \mathrm{~K} 2$ vs. $0.7 \pm 0.3 \%$ for control, $\mathrm{P}<0.05$; delayed treatment, $3.3 \pm 1.0 \%$ for $11 \mathrm{~K} 2$ vs. $0.2 \pm 0.1 \%$ for control, $\mathrm{P}<0.05)$. 
These data show that $11 \mathrm{~K} 2$ treatment not only inhibits atherosclerotic plaque progression, but also induces a plaque phenotype that is low in inflammation and high in fibrosis, which are characteristics of a stable atherosclerotic plaque.

\section{Discussion}

In the present study, we obtained a detailed gene expression profile of murine atherosclerosis. We showed that each stage of atherosclerosis is characterized by a unique but complex expression pattern of genes. Time-related expression clustering and functional grouping of genes shed some light on these complex patterns.

The uniqueness of gene expression profiles during atherosclerosis is reflected by the outcome of a similar experiment performed with wild-type mice. In that study we analyzed gene profiles of aortic arches of C57B16 mice of similar ages and diets similar to those of the present study. Remarkably, only 107 genes were differentially expressed, most of them selectively in C57B16, and only a few unannotated clusters could be identified (data not shown).

The two largest clusters/functional gene groups identified during atherogenesis were those of inflammation and proteolysis. Within these two groups, two gene families in particular were modulated during atherogenesis: the small inducible cytokines and the cathepsins. Broad-range inhibitors of both families may therefore be considered valuable targets for the treatment of atherosclerosis, especially because inhibition of individual genes showed promising results.

Small inducible cytokines or chemokines are members of a superfamily of small secreted proteins ( 8 to $16 \mathrm{kDa}$ ) that mediate migration and activation of inflammatory cells into the tissue..$^{25}$ Members of the CC chemokine subfamily (MCP-1, MCP-2, MCP-5, MIP-1 $\alpha$, MIP-1 $\beta$, MIP-3 $\alpha$, MIP-3 $\beta$, RANTES, eotaxin, TECK, and CCL21 $a+b)$ predominantly chemoattract monocytes and $\mathrm{T}$ lymphocytes, but not neutrophils. Members of the CXC family (IL-8, SDF-1, MIP-2, and CXCL16) particularly induce the migration of neutrophils and not monocytes. Fractalkine, the only CX3C chemokine described, not only functions as a chemoattractant, but also acts as an adhesion molecule. The XCL chemokine lymphotactin induces T lymphocyte trafficking. ${ }^{25}$

Most of the chemokines reported are present in human atherosclerotic plaques. ${ }^{26}$ Moreover, a subset of the chemokine family has been tested in atherosclerotic animal models and proved an important role for this family in the pathogenesis of atherosclerosis. Atherosclerotic mice that functionally lack MCP-127,28, RANTES ${ }^{29}$, or the chemokine receptors CCR2 ${ }^{30,31}$, CXCR2, ${ }^{32}$ and CX3CR1 ${ }^{33,34}$ reduced atherosclerosis. Moreover, inhibition of most of these chemokines reduced the inflammatory cell content in the lesion and induced an increase in ECM content, characteristics of a stable atherosclerotic plaque. An exception is the chemokine receptor CCR5, which failed to affect atherosclerosis. ${ }^{35}$ The recently discovered interferon 
(IFN)- $\gamma$-regulated chemokine CXCL16 was also found to be expressed in atherosclerosis. ${ }^{36}$

In the present study we found that even more members of the small inducible cytokine family were present in atherosclerotic lesions. Besides upregulation of MCP-1 and fractalkine, we also found upregulation of MCP-3, MCP-5, MIP-1 $\alpha$, MIP-1 $\beta$ and IL-8-like. Interestingly, in contrast to an earlier report, ${ }^{29}$ we found downregulation of RANTES and of CCL21a and CCL21b, especially in the more advanced stages of atherosclerosis. Our microarray results stress the importance of the entire gene family of small inducible cytokines in atherosclerosis.

In a subsequent in vivo experiment, we designed a unique inhibitor $(11 \mathrm{~K} 2)$ for the small inducible cytokines MCP-1 and MCP-5. MCP-1 and MCP-5 both bind to the CCR-2 receptor. ${ }^{37}$ Administration of $11 \mathrm{~K} 2$ to ApoE-/- mice in a prevention and a regression setting revealed that inhibition of MCP-1 and MCP-5 resulted in reduction of atherosclerosis. Moreover, atherosclerotic plaques were low in inflammation and contained increased amounts of ECM. Inhibition of MCP-1 and MCP-5 induced a stable atherosclerotic plaque phenotype.

Although our antibody did not distinguish between the individual effects of MCP-1 and MCP-5, we showed that both MCP-1 and MCP-5 are potent monocyte chemoattractants in vitro, suggesting an important role for both MCP-1 and MCP-5 in monocyte recruitment in atherosclerotic plaques in vivo. Unfortunately, we could not perform comparative experiments in vivo because we would need a humanized anti-murine MCP-1 and/or MCP-5 monoclonal antibody for comparison with $11 \mathrm{~K} 2$, neither of which exist at present. The only available monoclonal antibody specifically against MCP-1 is a hamster anti-rodent antibody (clone 2H5). ${ }^{38}$ Hamster monoclonal antibodies are notoriously antigenic in mice and are therefore not suitable for long-term in vivo experiments.

Although our mouse data are very promising, caution should be exercised in regard to the use of $11 \mathrm{~K} 2$ as treatment of human atherosclerosis. Atherosclerosis is a slowly progressive disease, and therefore long-term treatment is required. One of the problems with long-term application of antibodies is the development of "antidrug" antibodies. Moreover, antibodies are large proteins, and the risk of nonspecific binding to other epitopes is present. MCP-1 and MCP-5 are also involved in combating infections, therefore safety of long-term $11 \mathrm{~K} 2$ treatment might be questionable. However, FACS analysis in our mice did not reveal any signs of immunosuppression after a 3-month treatment period. Recently, antibody therapy in small groups of patients using antibodies against tumour necrosis factor (TNF)- $\alpha$, CD40 ligand (CD40L) and interleukin (IL)-12 for Crohn's disease, rheumatoid arthritis, and systemic lupus erythematosus proved effective with only limited side effects. ${ }^{39,40,41}$

For the cluster subfamily of cathepsins, which are important cysteine proteases, we observed that cathepsin B, D, H, L, S, and Z were highly expressed during atherogenesis. Cathepsin $S$ was one of the most highly expressed genes of our mi- 
croarray in all stages of atherosclerosis. Cathepsin B, D, L, S, and K were previously reported to be expressed in atherosclerotic plaques. ${ }^{42,43}$ Mice deficient in cathepsin $S$ and the LDL receptor showed a decrease in plaque area, plaque macrophage, SMC, and $\mathrm{T}$ lymphocyte content, ${ }^{44}$ indicating an important role of cathepsin $\mathrm{S}$ in atherosclerotic plaque progression.

Besides the two most abundant functional clusters, functional gene groups like blood coagulation (e.g., Gas6), cholesterol metabolism (e.g., fatty acid binding protein), embryogenesis, and morphogenesis (homeobox genes, dickkopf homolog 3) were also significantly activated, reflecting the highly complex nature of atherosclerotic plaque development and progression.

Microarrays are becoming more and more integral in unraveling pathways of complex diseases. Although they are powerful, caution must be exercised in regard to the experimental design and interpretation of results. Before multiple microarray measurements can be integrated into a single analysis, measurements of individual arrays must be normalized. ${ }^{45}$ In our study we used a pool of cDNA derived from ApoE-/- mice fed NC for 3 months that was used as a reference for all microarrays. In each microarray experiment, there is a significant amount of "biological noise" that can distort the interpretation of the expression data. ${ }^{45}$ To avoid misinterpretation, microarrays were performed in duplicate, and the expression of a subset of genes were validated using real-time PCR, ELISA, and immunohistochemistry.

Despite our careful analysis and validation experiments, the use of entire aortic arches in the analysis implies that both intima and media may contribute to the observed differences in gene expression. However, validation experiments for our candidate genes did not show expression in the media.

Moreover, in our current setup, differential gene expression of individual cell types in the plaque (SMCs, macrophages, endothelial cells, and T lymphocytes) could only be distinguished after validation. A method successfully used to identify gene expression profiles of individual plaque cell types, macrophages in this case, is microdissection of individual cells by laser capture microscopy. ${ }^{10,46}$

Here we show that the use of DNA microarray analysis yielded a detailed database that will improve insight into the pathogenesis of atherosclerosis and will be helpful to identify new diagnostic markers and therapeutic targets to monitor and intervene in atherosclerotic plaque progression.

\section{Acknowledgements}

E.L. is a postdoctoral fellow of the Dr. E. Dekker program of the Dutch Heart Foundation (2000T41). We thank Teresa Cachero, Fang Qian, Joseph Amatucci, and Konrad Miatkowski (Biogen Idec, Inc.) for reagent purification and characterization. 


\section{References}

1. Zhang QJ, Goddard M, Shanahan C, Shapiro L, Bennett M. Differential gene expression in vascular smooth muscle cells in primary atherosclerosis and in stent stenosis in humans. Arterioscler Thromb Vasc Biol. 2002;22:2030-2036.

2. Feng Y, Yang JH, Huang H, Kennedy SP, Turi TG, Thompson JF, et al. Transcriptional profile of mechanically induced genes in human vascular smooth muscle cells. Circ Res. 1999;85:1118-1123.

3. de Vries CJ, van Achterberg TA, Horrevoets AJ, ten Cate JW, Pannekoek H. Differential display identification of 40 genes with altered expression in activated human smooth muscle cells. Local expression in atherosclerotic lesions of smags, smooth muscle activation-specific genes. J Biol Chem. 2000;275:23939-23947.

4. Shiffman D, Mikita T, Tai JT, Wade DP, Porter JG, Seilhamer JJ, et al. Large scale gene expression analysis of cholesterol-loaded macrophages. J Biol Chem. 2000;275:37324-37332.

5. Herman MP, Sukhova GK, Libby P, Gerdes N, Tang N, Horton DB, et al. Expression of neutrophil collagenase (matrix metalloproteinase-8) in human atheroma: a novel collagenolytic pathway suggested by transcriptional profiling. Circulation. 2001;104:1899-1904.

6. Adams LD, Geary RL, McManus B, Schwartz SM. A comparison of aorta and vena cava medial message expression by cDNA array analysis identifies a set of 68 consistently differentially expressed genes, all in aortic media. Circ Res. 2000;87:623-631.

7. Geary RL, Wong JM, Rossini A, Schwartz SM, Adams LD. Expression profiling identifies 147 genes contributing to a unique primate neointimal smooth muscle cell phenotype. Arterioscler Thromb Vasc Biol. 2002;22:2010-2016.

8. Martinet W, Schrijvers DM, De Meyer GR, Thielemans J, Knaapen MW, Herman AG, et al. Gene expression profiling of apoptosis-related genes in human atherosclerosis: upregulation of deathassociated protein kinase. Arterioscler Thromb Vasc Biol. 2002;22:2023-2029.

9. Tyson KL, Weissberg PL, Shanahan CM. Heterogeneity of gene expression in human atheroma unmasked using cDNA representational difference analysis. Physiol Genomics. 2002;9:121-130.

10. Tuomisto TT, Korkeela A, Rutanen J, Viita H, Brasen JH, Riekkinen MS, et al. Gene expression in macrophage-rich inflammatory cell infiltrates in human atherosclerotic lesions as studied by laser microdissection and DNA array: overexpression of HMG-CoA reductase, colony stimulating factor receptors, CD11A/CD18 integrins, and interleukin receptors. Arterioscler Thromb Vasc Biol. 2003;23:2235-2240.

11. Ross R. Atherosclerosis--an inflammatory disease. N Engl J Med. 1999;340:115-126.

12. Lusis AJ. Atherosclerosis. Nature. 2000;407:233-241.

13. Faber BC, Cleutjens KB, Niessen RL, Aarts PL, Boon W, Greenberg AS, et al. Identification of genes potentially involved in rupture of human atherosclerotic plaques. Circ Res. 2001;89:547554 .

14. Bijnens AP, Gils A, Jutten B, Faber BC, Heeneman S, Kitslaar PJ, et al. Vasculin, a novel vascular protein differentially expressed in human atherogenesis. Blood. 2003;102:2803-2810.

15. Randi AM, Biguzzi E, Falciani F, Merlini P, Blakemore S, Bramucci E, et al. Identification of differentially expressed genes in coronary atherosclerotic plaques from patients with stable or unstable angina by cDNA array analysis. J Thromb Haemost. 2003;1:829-835.

16. Wuttge DM, Sirsjo A, Eriksson P, Stemme S. Gene expression in atherosclerotic lesion of ApoE deficient mice. Mol Med. 2001;7:383-392.

17. Tabibiazar R, Wagner RA, Spin JM, Ashley EA, Narasimhan B, Rubin EM, et al. Mouse strainspecific differences in vascular wall gene expression and their relationship to vascular disease. Arterioscler Thromb Vasc Biol. 2005;25:302-308.

18. Lutgens E, Gorelik L, Daemen MJ, de Muinck ED, Grewal IS, Koteliansky VE, et al. Requirement for CD154 in the progression of atherosclerosis. Nat Med. 1999;5:1313-1316.

19. Pabon C, Modrusan Z, Ruvolo MV, Coleman IM, Daniel S, Yue H, et al. Optimized T7 amplification system for microarray analysis. Biotechniques. 2001;31:874-879.

20. DeRisi JL, Iyer VR, Brown PO. Exploring the metabolic and genetic control of gene expression on a genomic scale. Science. 1997;278:680-686. 
21. Dahlquist KD, Salomonis N, Vranizan K, Lawlor SC, Conklin BR. GenMAPP, a new tool for viewing and analyzing microarray data on biological pathways. Nat Genet. 2002;31:19-20.

22. Hulme EC, Birdsall NJM. Strategy and tactics in receptor-binding studies. In: Hulme EC, ed. Receptor Ligand Interactions: A Practical Approach. 1992:63-176.

23. Lutgens E, Gijbels M, Smook M, Heeringa P, Gotwals P, Koteliansky VE, et al. Transforming growth factor-beta mediates balance between inflammation and fibrosis during plaque progression. Arterioscler Thromb Vasc Biol. 2002;22:975-982.

24. Virmani R, Kolodgie FD, Burke AP, Farb A, Schwartz SM. Lessons from sudden coronary death: a comprehensive morphological classification scheme for atherosclerotic lesions. Arterioscler Thromb Vasc Biol. 2000;20:1262-1275.

25. Rossi D, Zlotnik A. The biology of chemokines and their receptors. Annu Rev Immunol. 2000;18:217-242.

26. Sheikine Y, Hansson GK. Chemokines and atherosclerosis. Ann Med. 2004;36:98-118.

27. Ni W, Egashira K, Kitamoto S, Kataoka C, Koyanagi M, Inoue S, et al. New anti-monocyte chemoattractant protein-1 gene therapy attenuates atherosclerosis in apolipoprotein E-knockout mice. Circulation. 2001;103:2096-2101.

28. Inoue S, Egashira K, Ni W, Kitamoto S, Usui M, Otani K, et al. Anti-monocyte chemoattractant protein-1 gene therapy limits progression and destabilization of established atherosclerosis in apolipoprotein E- knockout mice. Circulation. 2002;106:2700-2706.

29. Veillard NR, Kwak B, Pelli G, Mulhaupt F, James RW, Proudfoot AE, et al. Antagonism of RANTES receptors reduces atherosclerotic plaque formation in mice. Circ Res. 2004;94:253-261.

30. Boring L, Gosling J, Cleary M, Charo IF. Decreased lesion formation in CCR2-/- mice reveals a role for chemokines in the initiation of atherosclerosis. Nature. 1998;394:894-897.

31. Guo J, Van Eck M, Twisk J, Maeda N, Benson GM, Groot PH, et al. Transplantation of monocyte CC-chemokine receptor 2-deficient bone marrow into ApoE3-Leiden mice inhibits atherogenesis. Arterioscler Thromb Vasc Biol. 2003;23:447-453.

32. Boisvert WA, Santiago R, Curtiss LK, Terkeltaub RA. A leukocyte homologue of the IL-8 receptor CXCR-2 mediates the accumulation of macrophages in atherosclerotic lesions of LDL receptor- deficient mice. J Clin Invest. 1998;101:353-363.

33. Combadiere C, Potteaux S, Gao JL, Esposito B, Casanova S, Lee EJ, et al. Decreased atherosclerotic lesion formation in CX3CR1/apolipoprotein $\mathrm{E}$ double knockout mice. Circulation. 2003;107:1009-1016.

34. Lesnik P, Haskell CA, Charo IF. Decreased atherosclerosis in CX3CR1-/- mice reveals a role for fractalkine in atherogenesis. J Clin Invest. 2003;111:333-340.

35. Kuziel WA, Dawson TC, Quinones M, Garavito E, Chenaux G, Ahuja SS, et al. CCR5 deficiency is not protective in the early stages of atherogenesis in apoE knockout mice. Atherosclerosis. 2003;167:25-32.

36. Wuttge DM, Zhou X, Sheikine Y, Wagsater D, Stemme V, Hedin U, et al. CXCL16/SR-PSOX is an interferon-gamma-regulated chemokine and scavenger receptor expressed in atherosclerotic lesions. Arterioscler Thromb Vasc Biol. 2004;24:750-755.

37. Sarafi MN, Garcia-Zepeda EA, MacLean JA, Charo IF, Luster AD. Murine monocyte chemoattractant protein (MCP)-5: a novel CC chemokine that is a structural and functional homologue of human MCP-1. J Exp Med. 1997;185:99-109.

38. Luo Y, Laning J, Hayashi M, Hancock PR, Rollins B, Dorf ME. Serologic analysis of the mouse beta chemokine JE/monocyte chemoattractant protein-1. J Immunol. 1994;153:3708-3716.

39. Mannon PJ, Fuss IJ, Mayer L, Elson CO, Sandborn WJ, Present D, et al. Anti-interleukin-12 antibody for active Crohn's disease. N Engl J Med. 2004;351:2069-2079.

40. St Clair EW, van der Heijde DM, Smolen JS, Maini RN, Bathon JM, Emery P, et al. Combination of infliximab and methotrexate therapy for early rheumatoid arthritis: a randomized, controlled trial. Arthritis Rheum. 2004;50:3432-3443.

41. Grammer AC, Slota R, Fischer R, Gur H, Girschick H, Yarboro C, et al. Abnormal germinal center reactions in systemic lupus erythematosus demonstrated by blockade of CD154-CD40 interactions. J Clin Invest. 2003;112:1506-1520. 
42. Jormsjo S, Wuttge DM, Sirsjo A, Whatling C, Hamsten A, Stemme S, et al. Differential expression of cysteine and aspartic proteases during progression of atherosclerosis in apolipoprotein E-deficient mice. Am J Pathol. 2002;161:939-945.

43. Sukhova GK, Shi GP, Simon DI, Chapman HA, Libby P. Expression of the elastolytic cathepsins $\mathrm{S}$ and $\mathrm{K}$ in human atheroma and regulation of their production in smooth muscle cells. J Clin Invest. 1998;102:576-583.

44. Sukhova GK, Zhang Y, Pan JH, Wada Y, Yamamoto T, Naito M, et al. Deficiency of cathepsin S reduces atherosclerosis in LDL receptor- deficient mice. J Clin Invest. 2003;111:897-906.

45. Butte A. The use and analysis of microarray data. Nat Rev Drug Discov. 2002;1:951-960.

46. Trogan E, Choudhury RP, Dansky HM, Rong JX, Breslow JL, Fisher EA. Laser capture microdissection analysis of gene expression in macrophages from atherosclerotic lesions of apolipoprotein E-deficient mice. Proc Natl Acad Sci U.S.A. 2002;99:2234-2239. 


\section{CHAPTER 4}

\section{Anti-angiogenesis treatment with anginex}

or endostatin inhibits early lesion development in collar-induced atherosclerotic lesions of ApoE-/- mice

Kitty Schapira, Sylvia Heeneman, Marjo M.P.C. Donners, Daisy W.J. van der Schaft, Victor L. Thijssen, Kevin H. Mayo, Mat J.A.P. Daemen, Arjan W. Griffioen

In preparation 


\begin{abstract}
Neovascularization has been implicated in the development and progression of atherosclerotic plaques and is thought to contribute to their destabilization. The effects of the angiogenesis inhibitor endostatin and a novel anti-angiogenic peptide called anginex were investigated in collar-induced atherosclerotic lesions of ApoE-/mice. Anginex, endostatin or control treatment was administered via osmotic mini pumps either prior to lesion development (early treatment), or thereafter (delayed treatment). Analysis revealed smaller lesions in carotid arteries after early anginex and endostatin treatment compared to controls, whereas no effect was found on advanced lesions following delayed treatment. Plaque phenotype was not affected by anginex or endostatin treatment. Quantitative real-time PCR analysis revealed a trend toward a reduced expression of angiogenic factors in carotid arteries of mice receiving anginex treatment compared to controls. Furthermore, neovascularization was not observed in lesions as determined by immunohistochemical analysis. Treatment with anginex or endostatin appears to reduce early, but not advanced, lesions in an angiogenesis-independent manner in collar-induced atherosclerotic plaques of ApoE-/- mice.
\end{abstract}




\section{Introduction}

Under normal, non-diseased conditions, the adventitial layer of arteries contains vasa vasorum that function to nurture the outer component of the vessel wall, while the intima is supplied with nutrients from the lumen. ${ }^{1}$ Under pathological conditions, when the vessel wall exceeds a critical thickness beyond which oxygen can no longer diffuse from the lumen, the vasa vasorum proliferate, producing a network of microvasculature to facilitate transport of nutrients. ${ }^{2}$ Neovascularization has been shown to occur in atherosclerotic plaques and is thought to contribute to their development and progression. ${ }^{3}$

Neovascularization in atherosclerosis has been found to be increased in lesions of patients with acute coronary syndromes ${ }^{4}$ and has been implicated in plaque instability. ${ }^{5}$ The formation of immature microvessels in lesions may lead to intraplaque hemorrhage, which contributes to lipid core expansion and inflammation by the accumulation of free cholesterol from erythrocyte membranes and leukocyte infiltration, respectively. ${ }^{6}$

Inhibiting angiogenesis in atherosclerotic plaques may reduce plaque progression and increase their stability. It has been demonstrated that the angiogenesis inhibitors endostatin or TNP-470 (a fumagillin analogue) reduce intimal neovascularization and plaque growth in ApoE-/- mice. ${ }^{7}$ Treatment with the proangiogenic factor vascular endothelial growth factor (VEGF) increased plaque area in ApoE/ApoB double knockout mice. ${ }^{8}$ It was later shown by the same group that the angiogenesis inhibitor angiostatin blocked VEGF-mediated neointima progression in rabbits. ${ }^{9}$ VEGF overexpression in collar-induced atherosclerotic plaques of ApoE-/- mice was also reported to increase plaque growth and promote leukocyte recruitment. ${ }^{10} \mathrm{Con}-$ versely, inhibition of the VEGF receptor Flt-1 or transfection with soluble Flt-1 reduced plaque growth in ApoE-/- mice ${ }^{11}$ and inhibited neointimal formation and inflammation in hypercholesterolemic mice,,$^{12}$ respectively.

The designed peptide anginex, also exhibits strong anti-angiogenic properties such as inhibition of endothelial cell (EC) adhesion and migration, ultimately reducing proliferation and increasing apoptosis. ${ }^{13}$ Anginex has been shown to reduce angiogenesis and tumour growth in mouse tumour models,,$^{14}$ however its effects in atherosclerosis have not yet been studied. In the present study, we investigated the effects of anginex or endostatin treatment on atherosclerotic plaque development in a collar-induced mouse model of atherosclerosis. We hypothesized that anginex or endostatin treatment would reduce plaque development and progression, as well as decrease plaque angiogenesis. 


\section{Materials and Methods}

Mice

Male ApoE-/- mice on a 100\% C57B16 background were used (Charles River). Mice were treated in an early and delayed treatment setting with anginex $(8 \mathrm{mg} / \mathrm{kg} /$ day $)$, endostatin (5 mg/kg/day) or phosphate-buffered saline (PBS) administered via mini osmotic pumps (Alzet, model 2004, Durect Corporation) inserted subcutaneously. In the early treatment setting, mice (anginex $n=12$, endostatin $n=5, P B S n=11$; mice 14 weeks of age) were fed a high fat diet $(0.21 \%$ cholesterol) for 2 weeks after which silastic collars were placed around the left and right carotid arteries as described previously. ${ }^{15}$ Mini pumps were also inserted at this time to begin treatment prior to atherosclerotic lesion development. After 4 weeks, approximately $1.0 \mathrm{ml}$ of blood was drawn from the caval vein for lipoprotein analysis, mice were sacrificed, and tissues were harvested. In the delayed treatment setting, mice (anginex $n=12$, endostatin $n=5$, PBS $n=12$; mice 14 weeks of age) were fed a high fat diet for 2 weeks after which collars were placed. After 4 weeks when atherosclerotic plaques had developed, mini pumps were inserted to begin treatment. After 4 weeks, mice were processed as in the early treatment group. Animal experiments were approved by the institutional committee for the care and welfare of laboratory animals of Maastricht University.

\section{Tissue Harvesting}

The left carotid artery was first removed and either snap-frozen in liquid nitrogen for isolation of RNA or frozen in OCT compound (Tissue-Tek, Sakura Finetek) for histological analysis. The arterial tree was perfused with PBS containing $0.1 \mathrm{mg} / \mathrm{ml}$ sodium nitroprusside (Sigma) followed by $1 \%$ phosphate-buffered paraformaldehyde. The right carotid artery and the rest of the aortic tree were excised and preserved for 24 hours at $4^{\circ} \mathrm{C}$ in phosphate-buffered paraformaldehyde, after which they were placed in $70 \%$ alcohol.

\section{Histology and Morphometry}

Right carotid arteries including intact collars were embedded in paraffin. Transverse sections were cut in the caudal direction relative to the carotid bifurcation and mounted in order on a parallel series of slides as described previously. ${ }^{15}$ Sections were stained with hematoxylin and eosin (HE) and those exhibiting maximal stenosis were used to measure plaque area. Sections adjacent to those with maximal stenosis were stained with Sirius Red to determine relative collagen content. Morphometric analysis was performed with the use of computerized morphometry (Quantimet 570, Leica). 


\section{Immunohistochemistry}

Paraffin sections adjacent to those with maximal stenosis were immunolabeled with Mac3 rat monoclonal antibody (1:30, Pharmingen) to detect macrophages and determine macrophage content relative to plaque area. Neovascularization in lesions was determined by anti-CD31 antibody (1:200, Pharmingen) staining for the detection of ECs. Staining was enhanced by incubating with a fluorescein-labeled tyramide amplification reagent (1:50, Tyramide Signal Amplification Fluorescence Systems Kit, Perkin Elmer).

\section{RNA Isolation, cNDA Synthesis and Quantitative Real-Time PCR}

RNA was isolated from left carotid arteries of mice of the delayed treatment group using an RNA isolation kit (RNeasy Mini Kit, Qiagen). Frozen carotid arteries of mice were pooled (anginex, $\mathrm{n}=4$ and control, $\mathrm{n}=6$ ) to ensure sufficient quality of RNA. The iScript cDNA Synthesis Kit (Biorad) was used to convert 500ng of RNA into cDNA. Quantitative real-time PCR was performed as previously described. ${ }^{16}$ Briefly, tissues were analyzed for the following angiogenic factors: VEGF-A, B, C, and $\mathrm{D}$, basic fibroblast growth factor (bFGF), and angiopoietin (Ang)-1, 2, and 3 with primers (Eurogentec) specific for mouse transcripts. The delta-delta CT method was used to compare the relative RNA expression levels between anginex and control treated tissues.

\section{Statistical Analysis}

Statistical analysis was performed using the Kruskall-Wallis test to compare differences between the three independent groups (anginex, endostatin, and control treatment). Data are expressed as mean $\pm \mathrm{SEM}$ and differences were considered statistically significant at $\mathrm{P}<0.05$.

\section{Results}

\section{Atherosclerotic Plaque Area and Composition}

Both anginex and endostatin treatment reduced plaque area relative to controls in collar-induced atherosclerotic lesions of the early treatment group (figure 1). In the delayed treatment group, anginex or endostatin treatment did not have an affect on lesion area compared with controls. In addition, the two angiogenesis inhibitors did not have an affect on plaque phenotype. As shown in figure 2, there was no change in collagen content or macrophage content compared to controls with either early or delayed treatment. 
A

Early Treatment

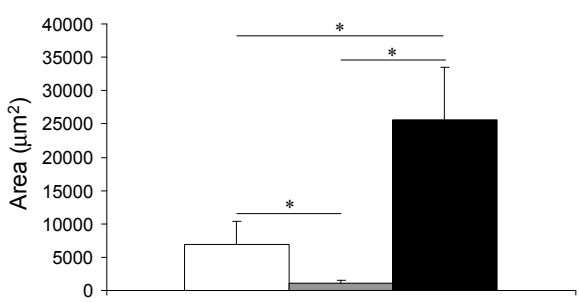

$\square$ Anginex
B

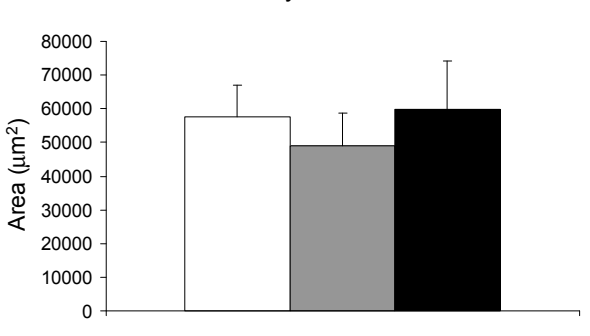

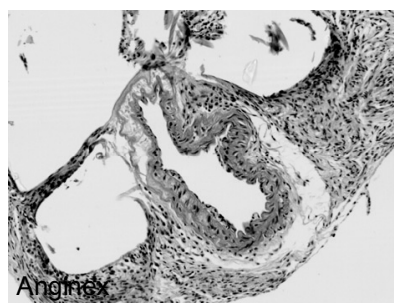
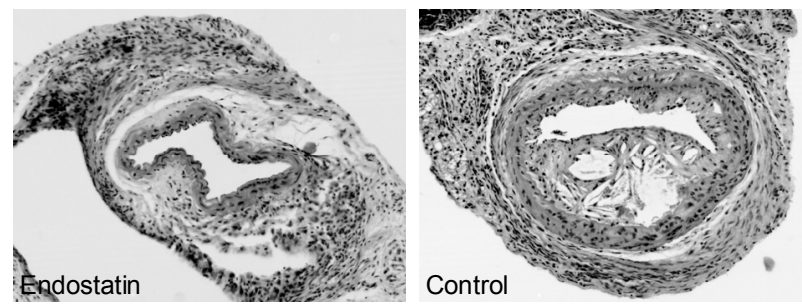

Figure 1. Reduced plaque area with early anginex or endostatin treatment. (A) Plaques of anginex or endostatin-treated mice of the early treatment group were smaller compared with controls. (B) No difference in plaque area between anginex or endostatin treatment compared with controls. ${ }^{*} \mathrm{P}<0.05$. Images are representative of carotid artery plaques of the early treatment group. For full colour figure see page 133 .

\section{Plaque Angiogenesis}

Quantitative real-time PCR analysis was performed on carotid arteries of anginex treated and control mice to determine RNA expression levels of factors involved in angiogenesis. Because tissue samples from mice in a given treatment group had to be pooled to ensure sufficient quality of RNA, statistical analysis could not be performed. However, there was an apparent decrease in the expression of angiogenic factors in tissues of mice treated with anginex compared with controls (figure 3). CD31 immunohistochemical staining revealed positive staining of luminal ECs, however microvessels were not evident within the plaque itself (figure 4). 

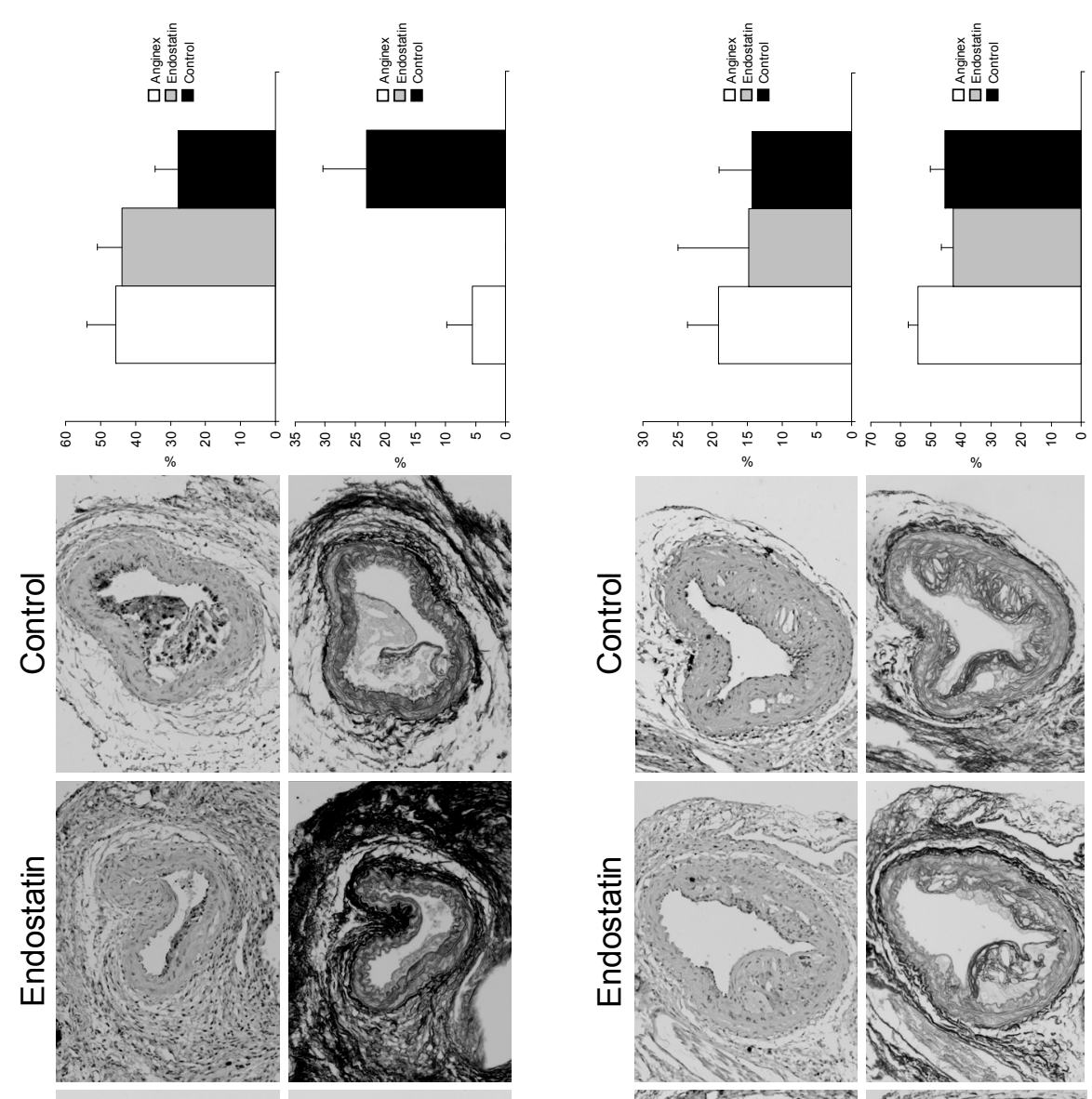

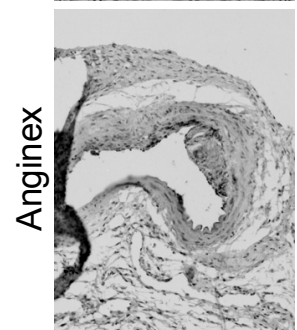

Q

$\leftarrow$
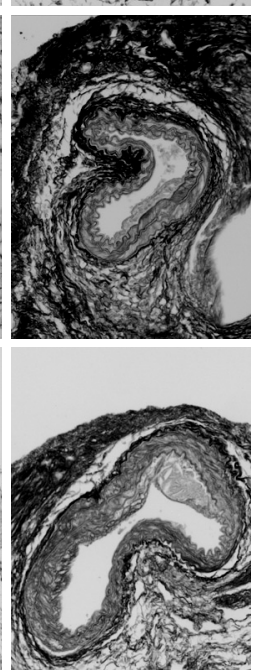

采

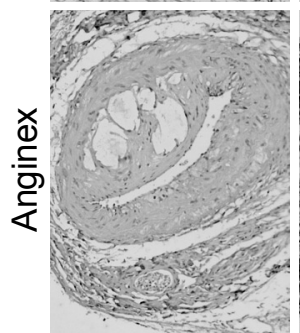

$\stackrel{Q}{E}$

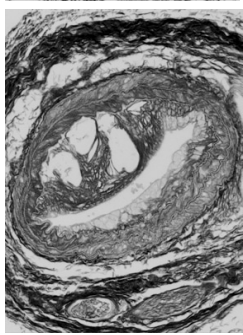

ज

$m$

Figure 2. No change in plaque composition with anginex or endostatin treatment. There was no change in macrophage content $(\mathrm{m} \phi)$ or collagen content (SR, indicating Sirius Red staining) in either of the (A) early or (B) delayed treatment groups compared with controls. For full colour figure see page 134 . 


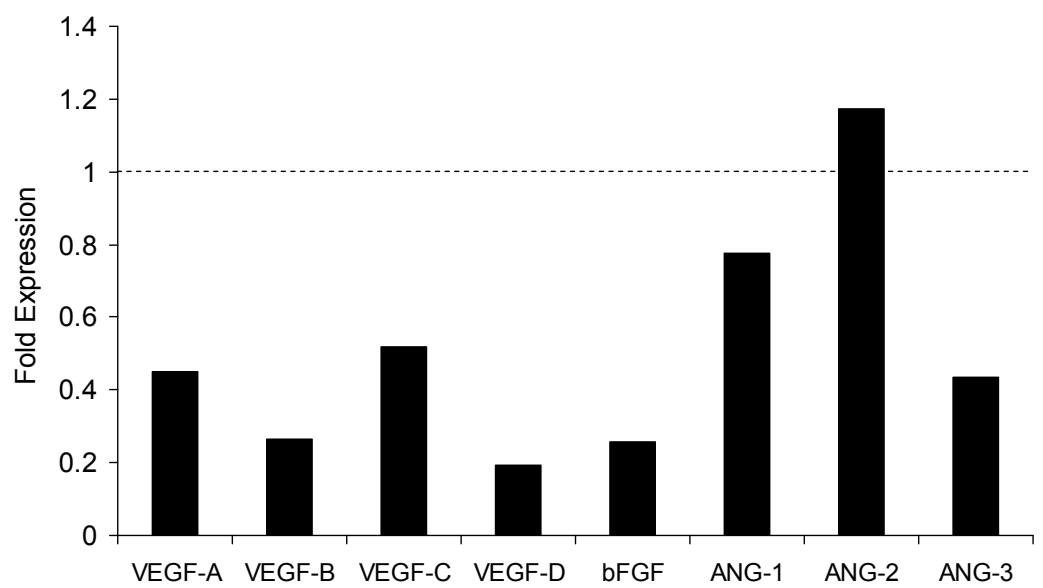

Figure 3. Fold RNA expression of angiogenic factors in carotid arteries of mice treated with anginex relative to controls.

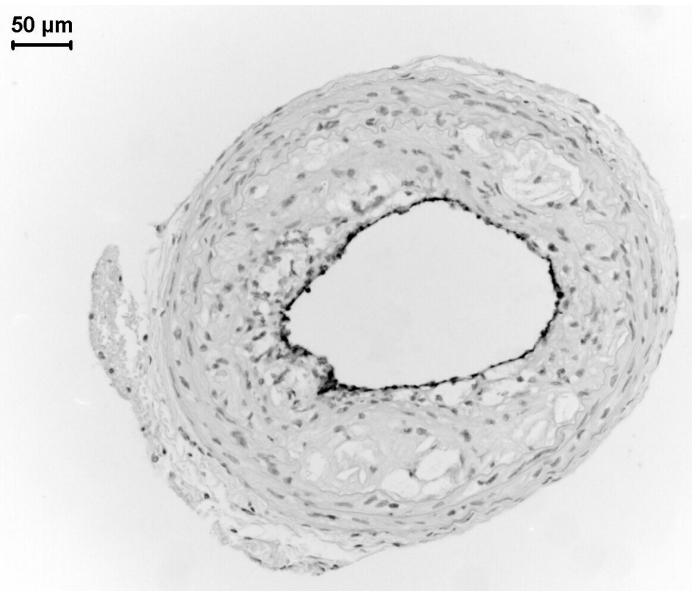

Figure 4. CD31 immunostaining of a carotid artery atherosclerotic plaque reveals positively stained luminal ECs. For full colour figure see page 135 . 


\section{Discussion}

In this study we investigated the effects of the designed anti-angiogenesis peptide anginex in murine atherosclerotic plaque development. We found that anginex reduced plaque area in early atherosclerotic lesions, but did not affect advanced lesions. Similar results were found with endostatin treatment. Treatment with anginex and endostatin did not alter the composition of plaques as determined by collagen and macrophage content. This is in contrast to a previous study that reported reduced plaque growth in advanced, but not early, stages of atherosclerosis in ApoE-/- mice upon treatment with endostatin or the angiogenesis inhibitor TNP470.7 Although angiogenesis is commonly reported to be a feature of advanced stages of atherosclerosis, studies have observed neovascularization in early human atherosclerotic lesions. ${ }^{3}$ In addition, in the study by Moulton et al. ${ }^{7}$ plaque area was determined in the aortic sinus after prolonged treatment (16 weeks) with antiangiogenesis agents, whereas in the present study plaque area was measured in collar-induced lesions of carotid arteries after four weeks of treatment. Atherogenesis in ApoE-/- mice as a result of perivascular collar placement is rapid and induced, thereby differing from lesion development at other aortic sites. It would be interesting to determine the effects of anginex treatment on lesions of the aortic sinus and aortic arch - two sites in ApoE-/- mice that are commonly examined for plaque development.

Neovascularization in atherosclerotic lesions was not observed in the present study, be it early or late stage. Previous studies have shown the presence of microvessels in atherosclerotic plaques of ApoE-/- mice, however these were lesions located in the aorta or aortic sinus, ${ }^{7,17}$ not in collar-induced lesions as in the present study. Recently, it was found that focal overexpression of VEGF-A in collar-induced advanced atherosclerotic plaques of ApoE-/- mice led to an increase in plaque size and induced an unstable phenotype characterized by an increased macrophage and lipid content, and decreased collagen content. Surprisingly, VEGF-A overexpression did not induce plaque angiogenesis as microvessels were not observed in lesions, which suggests that the effects exerted by VEGF-A are independent of angiogenesis. ${ }^{10}$ It appears that neovascularization in atherosclerotic plaques of ApoE-/- mice, particularly those induced by collar placement, is a rare event, even with administration of proangiogenic factors.

Although we observed a trend toward reduced RNA expression of proangiogenic factors with anginex treatment, which would suggest that angiogenesis was inhibited, results are preliminary and inconclusive. Furthermore, reduced plaque growth and development upon treatment with anti-angiogenesis agents is often correlated with a reduced leukocyte infiltrate, ${ }^{10,17}$ however we did not find differences in macrophage content in lesions of mice treated with anginex or endostatin compared to controls. Interestingly, this is in contrast to the effects of anginex treatment in tumours in which it has been found that anginex increases the leuko- 
cyte infiltrate. While anginex inhibits tumour growth and microvessel density, the number of infiltrated leukocytes is increased as a result of the upregulation of endothelial adhesion molecules. ${ }^{18}$ These and our findings suggest not only that angiogenesis inhibitors such as anginex exert different effects in different tissues, but also that their effects on neovascularization and leukocyte infiltration occur independently of one another.

Given these findings, it is possible that the reduced plaque area observed in initial plaques may have occurred by an angiogenesis-independent mechanism. In fact, in all of the studies mentioned above in which the effects of positive (VEGF-A) or negative (endostatin, TNP-470, and VEGFR-1 inhibitors) regulators of angiogenesis on lesion development were investigated, changes in plaque growth and phenotype could not be attributed to plaque neovascularization.

In conclusion, anginex and endostatin treatment reduces early, but not advanced lesions in collar-induced atherosclerotic plaques of ApoE-/- mice. Preliminary results indicate that treatment with these angiogenesis inhibitors downregulates proangiogenic factors, suggesting that angiogenesis was inhibited. However, neovascularization could not be detected in lesions, therefore, lesion sizes may have been reduced by an angiogenesis-independent mechanism. 


\section{References}

1. Moreno PR, Purushothaman KR, Sirol M, Levy AP, Fuster V. Neovascularization in human atherosclerosis. Circulation. 2006;113:2245-2252.

2. Khurana R, Simons M, Martin JF, Zachary IC. Role of angiogenesis in cardiovascular disease: a critical appraisal. Circulation. 2005;112:1813-1824.

3. Jeziorska M, Woolley DE. Neovascularization in early atherosclerotic lesions of human carotid arteries: its potential contribution to plaque development. Hum Pathol. 1999;30:919-925.

4. Moreno PR, Purushothaman KR, Fuster V, Echeverri D, Truszczynska H, Sharma SK, et al. Plaque neovascularization is increased in ruptured atherosclerotic lesions of human aorta: implications for plaque vulnerability. Circulation. 2004;110:2032-2038.

5. Kolodgie FD, Gold HK, Burke AP, Fowler DR, Kruth HS, Weber DK, et al. Intraplaque hemorrhage and progression of coronary atheroma. N Engl J Med. 2003;349:2316-2325.

6. Virmani R, Kolodgie FD, Burke AP, Finn AV, Gold HK, Tulenko TN, et al. Atherosclerotic plaque progression and vulnerability to rupture: angiogenesis as a source of intraplaque hemorrhage. Arterioscler Thromb Vasc Biol. 2005;25:2054-2061.

7. Moulton KS, Heller E, Konerding MA, Flynn E, Palinski W, Folkman J. Angiogenesis inhibitors endostatin or TNP-470 reduce intimal neovascularization and plaque growth in apolipoprotein E-deficient mice. Circulation. 1999;99:1726-1732.

8. Celletti FL, Waugh JM, Amabile PG, Brendolan A, Hilfiker PR, Dake MD. Vascular endothelial growth factor enhances atherosclerotic plaque progression. Nat Med. 2001;7:425-429.

9. Celletti FL, Waugh JM, Amabile PG, Kao EY, Boroumand S, Dake MD. Inhibition of vascular endothelial growth factor-mediated neointima progression with angiostatin or paclitaxel. J Vasc Interv Radiol. 2002;13:703-707.

10. Lucerna M, Zernecke A, de Nooijer R, de Jager SC, Bot I, van der Lans C, et al. Vascular endothelial growth factor-A induces plaque expansion in ApoE knock-out mice by promoting de novo leukocyte recruitment. Blood. 2007;109:122-129.

11. Luttun A, Tjwa M, Moons L, Wu Y, Angelillo-Scherrer A, Liao F, et al. Revascularization of ischemic tissues by PIGF treatment, and inhibition of tumor angiogenesis, arthritis and atherosclerosis by anti-Flt1. Nat Med. 2002;8:831-840.

12. Zhao Q, Egashira $\mathrm{K}$, Hiasa $\mathrm{K}$, Ishibashi $\mathrm{M}$, Inoue S, Ohtani $\mathrm{K}$, et al. Essential role of vascular endothelial growth factor and Flt-1 signals in neointimal formation after periadventitial injury. Arterioscler Thromb Vasc Biol. 2004;24:2284-2289.

13. Griffioen AW, van der Schaft DW, Barendsz-Janson AF, Cox A, Struijker Boudier HA, Hillen HF, et al. Anginex, a designed peptide that inhibits angiogenesis. Biochem J. 2001;354:233-242.

14. van der Schaft DW, Dings RP, de Lussanet QG, van Eijk LI, Nap AW, Beets-Tan RG, et al. The designer anti-angiogenic peptide anginex targets tumor endothelial cells and inhibits tumor growth in animal models. FASEB J. 2002;16:1991-1993.

15. von der Thusen JH, van Berkel TJ, Biessen EA. Induction of rapid atherogenesis by perivascular carotid collar placement in apolipoprotein E-deficient and low-density lipoprotein receptordeficient mice. Circulation. 2001;103:1164-1170.

16. Thijssen VL, Brandwijk RJ, Dings RP, Griffioen AW. Angiogenesis gene expression profiling in xenograft models to study cellular interactions. Exp Cell Res. 2004;299:286-293.

17. Moulton KS, Vakili K, Zurakowski D, Soliman M, Butterfield C, Sylvin E, et al. Inhibition of plaque neovascularization reduces macrophage accumulation and progression of advanced atherosclerosis. Proc Natl Acad Sci U S A. 2003;100:4736-4741.

18. Dirkx AE, oude Egbrink MG, Castermans K, van der Schaft DW, Thijssen VL, Dings RP, et al. Anti-angiogenesis therapy can overcome endothelial cell anergy and promote leukocyteendothelium interactions and infiltration in tumors. FASEB J. 2006;20:621-630. 


\section{CHAPTER 5}

Genetic deletion or antibody blockade of $\alpha 1 \beta 1$ integrin induces a stable plaque phenotype in ApoE-/-mice

Kitty Schapira*, Esther Lutgens*, Antonin de Fougerolles, Andrew Sprague, Anouk Roemen, Humphrey Gardner, Victor Koteliansky, Mat J.A.P. Daemen, Sylvia Heeneman

Arteriosclerosis, Thrombosis and Vascular Biology 2005;25(9):1917-1924

${ }^{*}$ The first two authors have contributed equally 


\begin{abstract}
Adhesive interactions between cells and the extracellular matrix play an important role in inflammatory diseases like atherosclerosis. We investigated the role of the collagen-binding integrin $\alpha 1 \beta 1$ in atherosclerosis. ApoE-/- mice were $\alpha 1$-deficient or received early and delayed anti- $\alpha 1$ antibody treatment. Deficiency in $\alpha 1$ integrin reduced the area of atherosclerotic plaques and altered plaque composition by reducing inflammation and increasing extracellular matrix. In advanced plaques, $\alpha 1-$ deficient mice had a reduced macrophage and CD3+ cell content, collagen and smooth muscle cell content increased, lipid core sizes decreased, and cartilaginous metaplasia occurred. Anti- $\alpha 1$ antibody treatment reduced the macrophage content in initial plaques after early and delayed treatment, decreased the CD3+ cell content in advanced plaques after delayed treatment, and increased the collagen content in initial and advanced plaques after delayed treatment. Migration assays performed on $\alpha 1$-deficient macrophages on collagen I and IV substrata revealed that $\alpha 1$ deficient cells can migrate on collagen I, but not IV. Anti- $\alpha 1$ antibody treatment of ApoE-/- macrophages also inhibited migration of cells on collagen IV. Our results suggest that $\alpha 1 \beta 1$ integrin is involved in atherosclerosis by mediating the migration of leukocytes to lesions by adhesion to collagen IV. Blocking this integrin reduces atherosclerosis and induces a more stable plaque phenotype.
\end{abstract}




\section{Introduction}

Inflammatory responses, as in atherosclerosis, involve adhesive interactions between cells and the extracellular matrix (ECM) that are necessary for cell attachment, extravasation and migration into tissues, proliferation, and differentiation. Major receptors for ECM ligands are integrins, which are transmembrane heterodimers consisting of an $\alpha$ and $\beta$ subunit. The role of several integrins has previously been studied in atherosclerotic development. Integrin $\alpha 4 \beta 1$ has been shown to be expressed on smooth muscle cells (SMC) during pathological neointimal thickening and is involved in SMC differentiation. ${ }^{1}$

Furthermore, $\alpha 4 \beta 1$ integrin mediates adhesion of monocytes to the vascular endothelium and anti- $\alpha 4$ antibody treatment decreases leukocyte entry in mice fed an atherogenic diet, ${ }^{2}$ as well as attenuates neointimal growth following carotid injury in ApoE-/- mice. ${ }^{3}$ Agonists against $\alpha \mathrm{V} \beta 3$ integrin were also shown to reduce neointima formation after injury ${ }^{4}$ and it has been suggested that this integrin regulates the maturation of macrophages into foam cells. ${ }^{5}$ Yet another model of endothelial injury has revealed that $\alpha 2 \beta 1$ integrin mediates the adhesion of platelets to collagen in the vessel wall and $\alpha 2 \beta 1$-deficient mice exhibit delayed thrombus formation following injury to the carotid artery. ${ }^{6}$

The role of $\alpha 1 \beta 1$ integrin in atherosclerosis has not yet been investigated, but has been shown to mediate inflammation in several other illnesses. Integrin $\alpha 1 \beta 1$ is a major collagen receptor that is highly expressed on activated monocytes ${ }^{7}$ and $\mathrm{T}$ lymphocytes, including those found in atherosclerotic plaques. ${ }^{8}$ The role of $\alpha 1 \beta 1$ integrin has been studied in various models of inflammatory diseases including hypersensitivity and arthritis, ${ }^{9}$ kidney fibrosis, ${ }^{10}$ and colitis ${ }^{11}$ in which it has been shown that a deficiency or blocking of this integrin using anti- $\alpha 1$ antibodies attenuates the inflammatory response as seen by a reduced leukocyte infiltrate. These studies suggest a role for $\alpha 1 \beta 1$ integrin in the migration of leukocytes to sites of inflammation.

Besides its expression on immune cells, $\alpha 1 \beta 1$ integrin is also expressed on mesenchymal cells, most notably SMCs and fibroblasts. Human aortic SMCs have been reported to express $\alpha 1 \beta 1$ integrin, which is involved in SMC differentiation. ${ }^{12}$ It has been demonstrated that $\alpha 1$-deficient fibroblasts cannot adhere to or migrate on collagen $\mathrm{IV}^{13}$ and are deficient in collagen-dependent proliferation. ${ }^{14} \mathrm{~A}$ major function attributed to $\alpha 1 \beta 1$ integrin is the regulation of feedback inhibition of collagen synthesis. This was shown by enhanced collagen-dependent downregulation of collagen synthesis upon receptor stimulation, ${ }^{15}$ and a later study reported an increase in collagen synthesis in the dermis of $\alpha 1$-deficient mice. ${ }^{16}$

Given that $\alpha 1 \beta 1$ integrin regulates collagen synthesis and mediates the migration of activated leukocytes during inflammation, we wanted to investigate its role in atherosclerosis. To examine the role of $\alpha 1 \beta 1$ integrin in plaque inflammation and development, we used a murine model of atherosclerosis in which $\alpha 1$ integrin was 
either knocked out or mice were treated with an $\alpha 1$-blocking antibody. Here we report that a deficiency or blocking of $\alpha 1$ integrin attenuates atherosclerosis and induces a more stable plaque phenotype.

\section{Materials and Methods}

Mice

To study the role of $\alpha 1$ integrin in atherosclerosis, $\alpha 1-/-/ A p o E-/-$ mice were used. ApoE-/- mice on a C57Bl6 background were obtained from Jackson Laboratories and were backcrossed 10 times with $\alpha 1-/-$ mice, originally on a Balb/c background ${ }^{13}$ to generate male and female $\alpha 1-/-/ A p o E-/-$ (homozygous, $n=13$ ), $\alpha 1+/-/ A p o E-/-$ (heterozygous, $n=8$ ) and $\alpha 1+/+/$ ApoE-/- (wild type, $W T, n=12$ ) mice. Mice were fed normal chow for 27 weeks after which they were sacrificed following an 8-hour fast. Approximately 0.5 to $1.0 \mathrm{ml}$ of blood was drawn from the vena cava for lipoprotein analysis. To study effects of antibody ( $\mathrm{Ab}$ ) blockade of $\alpha 1$ integrin, ApoE-/- mice on a C57Bl6 background were used, obtained from Iffa Credo, and fed normal chow. Mice were injected intraperitoneally twice a week with $200 \mu \mathrm{g}^{9}$ of a murinized version of a hamster anti-rodent $\alpha 1$-blocking $\mathrm{Ab}(\mathrm{muHa} 31 / 8)$ or murine IgG isotype control Ab (MOPC-21) (Biogen Idec, Inc.). Mice received treatment for 12 weeks beginning at either 5 weeks of age when no atherosclerotic lesions are present in the aortic arch (early treatment: anti- $\alpha 1 \mathrm{Ab}, \mathrm{n}=13$; control, $\mathrm{n}=14$ ) or 17 weeks of age when advanced lesions begin to appear in the aortic arch (delayed treatment: anti$\alpha 1 \mathrm{Ab}, \mathrm{n}=11$; control, $\mathrm{n}=14$ ). Animal experiments were approved by the institutional committee for the care and welfare of laboratory animals of Maastricht University.

\section{Antibody Infiltration}

To determine whether antibody infiltrated plaques, Ha31/8 mAb was labeled with Alexa488 using a protein labeling kit (Molecular Probes), and $200 \mu \mathrm{g}$ were injected intraperitoneally into 53-week-old ApoE-/- mice three times in the period of one week. Control mice did not receive any antibody. Following treatment, mice were sacrificed and the arterial tree was briefly perfused with phosphate-buffered saline (PBS). Aortic arches were snap-frozen in OCT compound (Tissue Tek, Sakura Finetek) for histological analysis and carotid arteries and abdominal aortas were placed in PBS until analysis by two-photon laser scanning microscopy (TPLSM). Aortic arch cryosections were fixed in acetone, counterstained with hematoxylin, mounted with Prolong Anti-Fade (Molecular Probes), and viewed with a fluorescence microscope. For analysis by TPLSM, carotid arteries and abdominal aortas were placed in perfusion chambers, and glass micropipettes were inserted into their ends so they could be kept taut during imaging and facilitate perfusion with PBS. 


\section{Lipid Profiles}

Lipid profiles were assessed as described previously. ${ }^{17}$

\section{Histology and Morphometry}

Histological and morphometrical analyses were performed as described previously. ${ }^{17}$ To confirm the presence of cartilaginous metaplasia observed in plaques of $\alpha 1$-deficient mice, aortic arch sections were stained with alcian blue and toluidine blue.

\section{Immunohistochemistry}

Aortic arch sections were immunostained with Mac3 rat monoclonal Ab (mAb) (1:30, Pharmingen) to detect macrophages, CD3 rabbit polyclonal Ab (1:200, Dako) to detect $\mathrm{T}$ lymphocytes, and $\alpha \mathrm{SMA}^{\mathrm{FITC}} \mathrm{mAb}(1: 500$, Sigma) as a marker for $\alpha$-smooth muscle actin ( $\alpha \mathrm{SMA})$-positive vascular SMCs. To determine $\alpha 1$ integrin expression in macrophages in atherosclerotic plaques of aortic arches, double immunohistochemistry was performed using Alexa488-conjugated Ha31/8 anti- $\alpha 1 \mathrm{mAb}$ (Biogen Idec, Inc.) and CD11 $\mathrm{b}^{\mathrm{PE}}$ (1:200, Pharmingen). To identify characteristics of cartilaginous metaplasia, sections were stained with antibodies against collagen II (goat polyclonal, 1:75, Santa Cruz Biotechnology, Inc.), osteocalcin (OC) (rabbit polyclonal, 1:50, ANAWA Trading SA), osteonectin (ON) (rabbit polyclonal, 1:2000, Zymed Laboratories, Inc.), osteopontin (OPN) (goat polyclonal, 1:25), bone morphogenetic protein (BMP)-2 (mouse monoclonal, 1:20, Genetics Institute, Inc.), BMP-4 (goat polyclonal, 1:25, Santa Cruz), matrix Gla protein (MGP) (mouse monoclonal, 1:25), osteoprotegerin (OPG, 1:100), and osteoprotegerin ligand (OPGL, 1:75). To determine collagen IV expression in atherosclerotic plaques, mouse aortic arch and human carotid artery paraffin sections were stained with antibody against collagen IV (rabbit polyclonal anti-mouse 1:300, anti-human 1:50).

\section{Cell Isolation}

Bone marrow-derived macrophages were isolated from the femur and tibia of $\alpha 1-/-$ /ApoE-/- and $\alpha 1+/+/$ ApoE-/- mice. Cells were cultured in standard RPMI containing L-glutamine, HEPES, $10 \%$ fetal calf serum, $100 \mathrm{IU} / \mathrm{ml}$ penicillin/streptomycin, and 15\% L929 cell-conditioned medium.

\section{Migration Assay}

Cell migration was assayed using 24-well Transwell migration chambers (Costar) with a pore size of $8 \mu \mathrm{m}$. Membranes were coated with $110 \mu \mathrm{g} / \mathrm{ml}$ of type I collagen (isolated as previously described) ${ }^{18}$ or $50 \mu \mathrm{g} / \mathrm{ml}$ of type IV collagen (BD Biosciences) and incubated at $37^{\circ} \mathrm{C}$ for 1 hour until complete gel formation. Membranes were allowed to air dry, then $10^{6}$ cells suspended in serum-free medium were added to each chamber. Cells isolated from WT mice were incubated with $100 \mu \mathrm{g} / \mathrm{ml}$ of $\alpha 1$ - 
blocking $\mathrm{Ab}$ or control $\mathrm{Ab}$ for 30 minutes prior to addition to chambers. Complete medium including 100ng/ml MCP-1 (R\&D Systems, Inc.) was added to lower chambers and migration was carried out at $37^{\circ} \mathrm{C}$ for 4 and 12 hours. Non-migrated cells were removed from membranes and migrated cells within the membrane were fixed with methanol and stained with toluidine blue. Membranes were cut out of inserts and mounted onto slides in immersion oil. The number of migrated cells were counted on five randomly chosen microscopic fields of each membrane.

\section{FACS Analysis}

Fluorescence-activated cell sorting (FACS) analysis (FACSCalibur, Beckton Dickinson) was performed on cells isolated from peripheral blood, spleen, and lymph nodes, as well as peritoneal macrophages from antibody-treated mice (anti- $\alpha 1 \mathrm{Ab}$, $\mathrm{n}=6$; control $\mathrm{Ab}, \mathrm{n}=6$ of both early and delayed treatment groups). Cells were labeled with $\mathrm{T}$ lymphocyte-specific antibodies: $\mathrm{CD} 3^{\mathrm{FTTC}}, \mathrm{CD} 4^{\mathrm{Cy}}$-Chrome, $\mathrm{CD} 8^{\mathrm{PE}}$, and $\mathrm{CD} 25^{\mathrm{PE}}$, as well as antibodies to detect macrophages: Gr1 ${ }^{\mathrm{FITC}}$ and $\mathrm{Mac1}^{\mathrm{PE}}$ (all from Pharmingen).

\section{Statistical Analysis}

Statistical analyses were performed using a non-parametric Mann-Whitney U test. Data are expressed as mean \pm SEM and differences were considered statistically significant at $\mathrm{P}<0.05$.

\section{Results}

\section{$\alpha 1$ Deficiency}

Mice

Body weight did not differ in $\alpha 1$-deficient mice compared with controls and plasma total cholesterol, triglycerides, LDL, and HDL levels did not differ between $\alpha 1-/-$ and $\alpha 1+/+$ mice, but were elevated in $\alpha 1+/$ - relative to $\alpha 1+/+$ mice (table 1 ). Autopsy of organs revealed no abnormalities or pathologies.

\section{Expression of $\alpha 1$ Integrin}

Expression of $\alpha 1$ integrin was present on SMCs and slightly on T lymphocytes (data not shown). Expression was also detected on macrophages in atherosclerotic plaques. Figure 1 shows $\mathrm{CD} 11 \mathrm{~b}+$ macrophages in atherosclerotic plaques that stained positive for $\alpha 1$ integrin. 
Table 1. Plasma lipid profile and body weight of $\alpha 1$-deficient, antibody-treated, and control mice.

\begin{tabular}{|c|c|c|c|c|c|c|}
\hline Mice & $\mathrm{n}$ & $\begin{array}{c}\text { Average } \\
\text { body weight } \\
(\mathrm{g})\end{array}$ & $\begin{array}{c}\text { Plasma total } \\
\text { cholesterol } \\
(\mathrm{mM})\end{array}$ & $\begin{array}{l}\text { Plasma total } \\
\text { triglycerides } \\
(\mu \mathrm{M})\end{array}$ & $\begin{array}{c}\text { Plasma total } \\
\text { HDL } \\
(\mathrm{mM}) \\
\end{array}$ & $\begin{array}{c}\text { Plasma total } \\
\text { LDL } \\
(\mathrm{mM}) \\
\end{array}$ \\
\hline$\alpha 1-/-/ A p o E-/-$ & 10 & 26 & $9.79 \pm 0.79$ & $1703.5 \pm 112$ & $0.38 \pm 0.1$ & $8.6 \pm 0.7$ \\
\hline$\alpha 1+/-/ A p o E-/-$ & 9 & 26 & $14.9 \pm 1.2^{*}$ & $2433.5 \pm 166^{*}$ & $0.81 \pm 0.1^{*}$ & $12.9 \pm 1.1^{*}$ \\
\hline$\alpha 1+/+/$ ApoE-/- & 12 & 27 & $10.7 \pm 1.1$ & $1690.4 \pm 195$ & $0.33 \pm 0.1$ & $9.6 \pm 1.0$ \\
\hline \multicolumn{7}{|l|}{ Early treatment } \\
\hline anti- $\alpha 1 \mathrm{Ab}$ & 13 & 28 & $10.9 \pm 0.6$ & $1088.6 \pm 106$ & $0.44 \pm 0.1^{\dagger}$ & $10.1 \pm 0.6$ \\
\hline control $\mathrm{Ab}$ & 14 & 28 & $9.4 \pm 0.6$ & $859.2 \pm 121$ & $0.28 \pm 0.1$ & $8.8 \pm 0.5$ \\
\hline \multicolumn{7}{|l|}{ Delayed treatment } \\
\hline anti- $\alpha 1 \mathrm{Ab}$ & 11 & 30 & $11.2 \pm 0.6$ & $1227.9 \pm 117$ & $0.32 \pm 0.03$ & $10.4 \pm 0.6$ \\
\hline control $A b$ & 14 & 30 & $11.3 \pm 0.6$ & $1419.8 \pm 110$ & $0.31 \pm 0.03$ & $10.5 \pm 0.6$ \\
\hline
\end{tabular}

* $\mathrm{P}<0.05, \alpha 1+/-/$ ApoE-/- vs. $\alpha 1+/+/$ ApoE-/-

$+\mathrm{P}<0.05$, early treatment, anti- $\alpha 1 \mathrm{Ab}$ vs. control $\mathrm{Ab}$
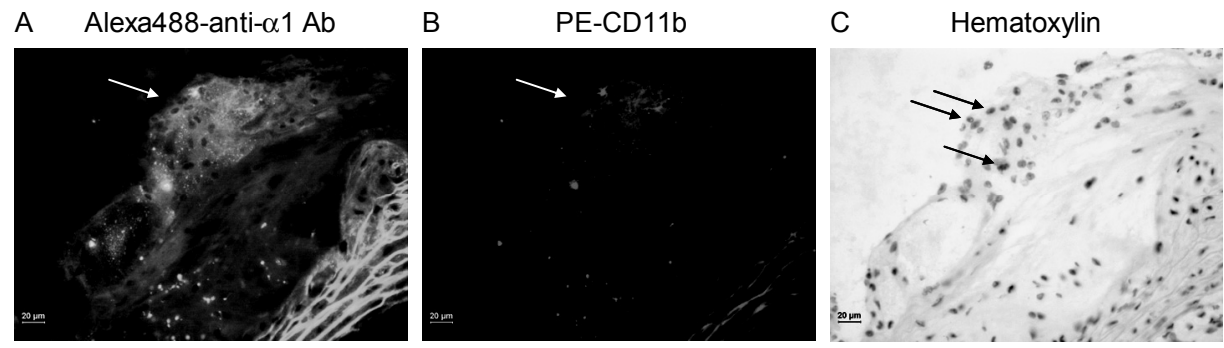

Figure 1. Fluorescence immunohistochemical staining showing expression of (A) $\alpha 1$ integrin (Alexa488-labeled anti- $\alpha 1 \mathrm{Ab}$, green, indicated by arrow) in (B) macrophages (PE-CD11b, red, indicated by arrow) in an advanced atherosclerotic plaque in the aortic arch of an ApoE-/- mouse. (C) Hematoxylin counterstaining of the same plaque showing macrophages (indicated by arrows). For full colour figure see page 135. 
A

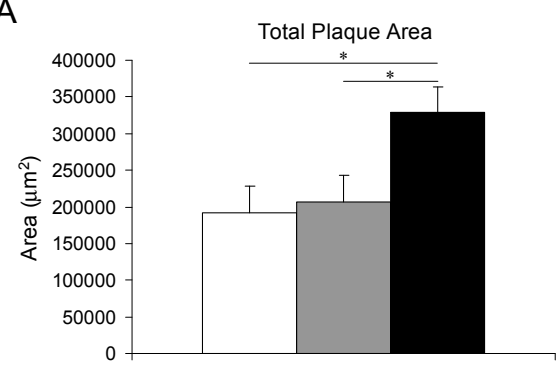

B

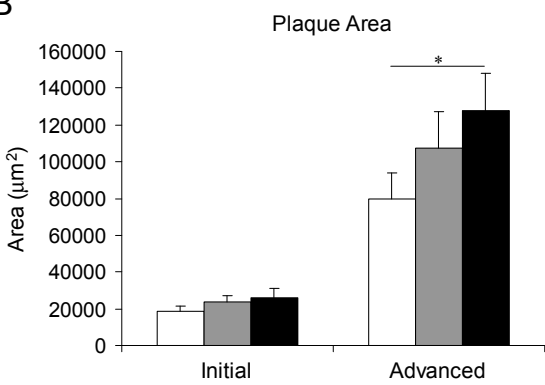

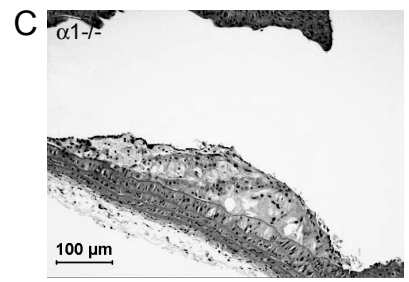

$\square \alpha 1-/-\quad \square \alpha 1+/-$

- $\alpha 1+++$
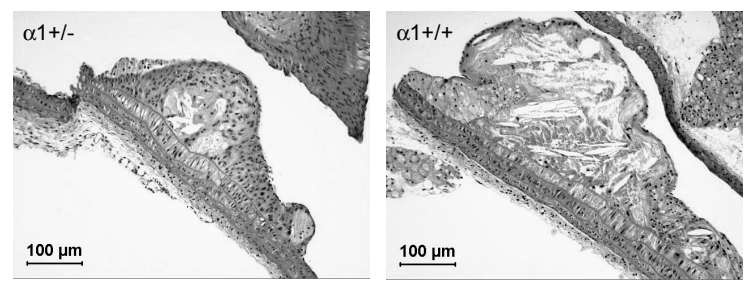

Figure 2. Deficiency in $\alpha 1$ integrin reduced plaque area in aortic arches. (A) Total plaque area of $\alpha 1-/-$ and $\alpha 1+/$ - mice was significantly smaller than those of $\alpha 1+/+$ mice. (B) Average area of individual advanced plaques of $\alpha 1-/-$ mice was smaller compared with those of $\alpha 1+/+$ mice. (C) HE-stained sections of representative advanced atherosclerotic plaques of $\alpha 1-/-, \alpha 1+/-$ and $\alpha 1+/+$ mice showing relative area of plaques. ${ }^{*} \mathrm{P}<0.05$. For full colour figure see page 136 .

\section{Extent of Atherosclerosis}

Complete deletion of $\alpha 1$ integrin reduced total plaque area by $42 \%$ compared with WT mice (figure 2). The decrease in plaque area was due to a $38 \%$ decrease in advanced atherosclerotic plaque area. Absence of one $\alpha 1$ allele was sufficient to significantly reduce the total plaque area as seen in heterozygous mice in which total plaque area was reduced by $37 \%$ and advanced plaque area was reduced by $16 \%$ compared with WT mice $(\mathrm{P}<0.05)$. Plaques representative of the 3 groups of mice are shown in figure $2 \mathrm{C}$, which shows that plaque area was significantly reduced in $\alpha 1$ homozygous and heterozygous mice compared with controls.

\section{Atherosclerotic Plaque Composition}

To further characterize atherosclerosis, the composition of lesions was analyzed. Histological analysis of advanced plaques demonstrated that $\alpha 1$-deficiency resulted not only in a decreased size, but also a dramatic alteration in plaque composition. Lesions from $\alpha 1$-deficient mice were more fibrotic and less lipid-rich than those of WT mice, whereas plaques of $\alpha 1$ heterozygous mice were of an intermediate phenotype (figure 3). Analysis of initial lesions in the aortic arch revealed that the relative number of CD3+ cells, macrophages, collagen, and $\alpha \mathrm{SMA}$ content did not differ in 


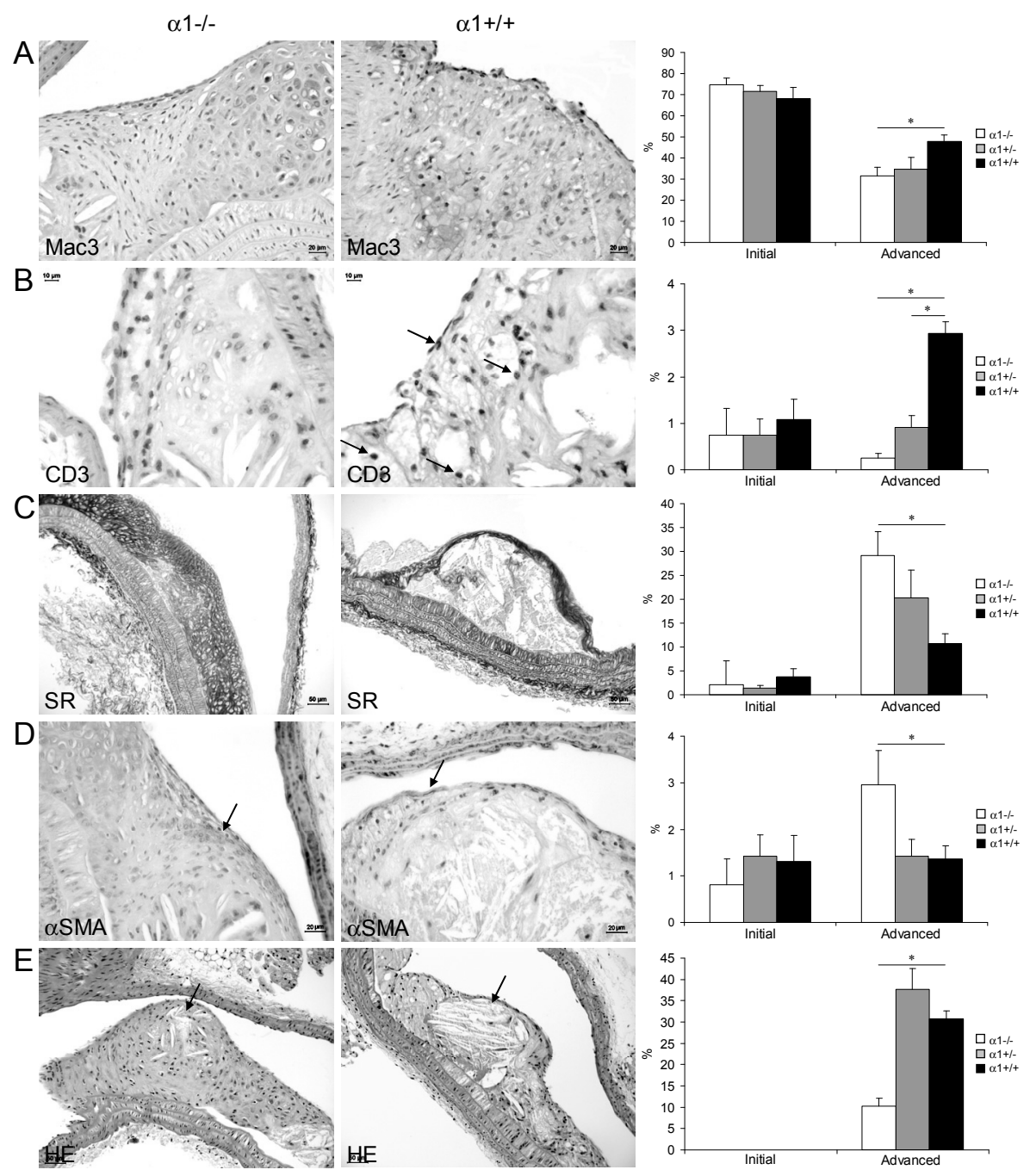

Figure 3. Plaque composition of initial and advanced atherosclerotic plaques in aortic arches of $\alpha 1$-deficient mice. There were significantly less (A) macrophages (Mac3+, red stained cells) and (B) CD3+ cells (arrows) in advanced plaques of $\alpha 1-/-$ compared with $\alpha 1+/+$ mice. There was a significantly higher (C) collagen content (SR+) and (D) SMC content ( $\alpha$ SMA+ cells, arrows) in advanced plaques of $\alpha 1-/-$ compared with $\alpha 1+/+$ mice. (E) Lipid cores were smaller in plaques of $\alpha 1-/-$ compared with $\alpha 1+/+$ mice (arrows). ${ }^{*} \mathrm{P}<0.05$. For full colour figure see page 137. 
initial atherosclerotic plaques. Similarly, initial lesions in heterozygous mice were not altered compared with those in WT mice.

Differences in plaque composition were more pronounced in advanced lesions of homozygous and heterozygous mice. Inflammatory cell content significantly decreased in homozygous mice, reflected by a decrease in the percentage of macrophages and CD3+ cells. Furthermore, lipid cores of plaques were smaller while ECM as measured by collagen and $\alpha \mathrm{SMA}$ content increased. Atherosclerotic plaques of heterozygous mice showed an intermediate plaque phenotype with a significant decrease in CD3+ cells and a trend toward a decrease in macrophage content $(\mathrm{p}=0.07)$ and collagen content $(\mathrm{p}=0.06)$.

The presence of cartilaginous metaplasia observed in advanced plaques of $\alpha 1-$ deficient mice was confirmed with immunohistochemical staining against collagen II, which is the major matrix protein of cartilage tissue, as well as with alcian blue and toluidine blue, which stain chondroid tissue (figure 4). To further identify characteristics of cartilaginous metaplasia, we performed immunohistochemistry using bone markers. The regulators of bone formation OC, ON, OPN, BMP-2, and BMP-4 were present in areas of cartilaginous metaplasia (figure 5). MGP, another protein involved in bone formation, was only present in plaque macrophages. Two regulators of osteoclastogenesis, OPG and OPGL, did not show expression.

\section{Antibody Treatment}

Mice

Average body weight of mice did not differ in the anti- $\alpha 1$ antibody-treated group compared to controls in either of the early or delayed treatment groups. There were no differences in plasma total cholesterol, triglycerides, or LDL, however HDL was slightly elevated in anti- $\alpha 1$ antibody-treated mice compared with controls in the early treatment group (table 1). Autopsy of organs revealed no abnormalities or pathologies.

To ascertain possible systemic effects of antibody treatment on atherosclerotic lesion development, FACS analysis was performed on cells isolated from peripheral blood, spleen, and lymph nodes, as well as on peritoneal macrophages of anti- $\alpha 1$ antibody-treated and control mice. Analysis revealed no differences in the amount of Mac1+ macrophages between the two groups in either blood or peritoneum. Similarly, there were no differences in the amount of CD4+ (helper) or CD8+ (cytotoxic) $\mathrm{T}$ lymphocytes, nor in the activation status of $\mathrm{T}$ lymphocytes (reflected by CD4+/CD8+ ratio and CD4+CD25+ T lymphocytes) between the two groups in any of the tissues. There was however, an increase in the amount of CD3+ T lymphocytes (total $\mathrm{T}$ lymphocytes) in peripheral blood of anti- $\alpha 1$ antibody-treated mice compared with controls in both of the early and delayed treatment groups (figure $6)$. 
A
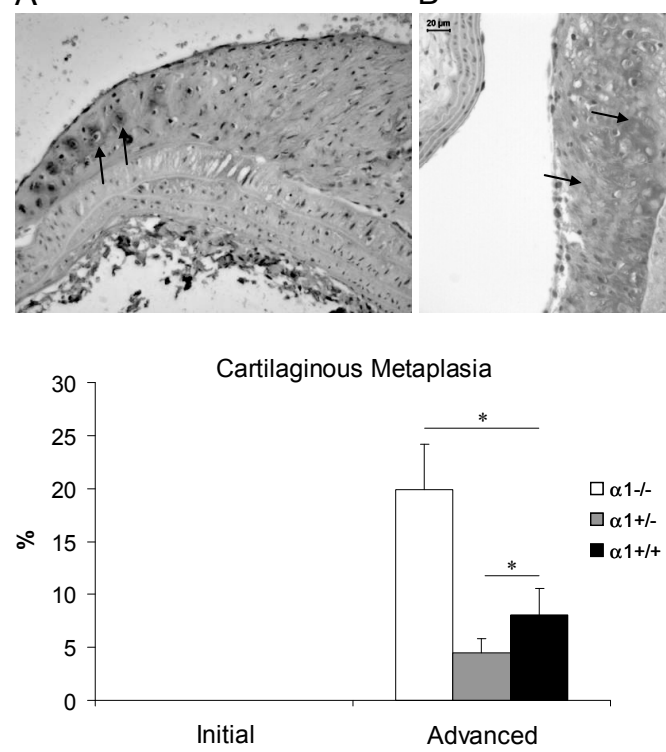

C

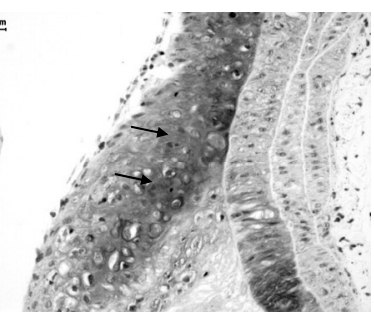

Figure 4. Cartilaginous metaplasia in advanced plaques in aortic arches of $\alpha 1$ deficient mice. (A) Collagen II is expressed in matrix (indicated by arrows) surrounding chondrocyte-like cells. (B) Alcian blue and (C) toluidine blue stainings show chondrocyte-like cells and chondroid matrix (indicated by arrows) in advanced atherosclerotic plaques of $\alpha 1-/-$ mice. ${ }^{*} \mathrm{P}<0.05$. For full colour figure see page 138.
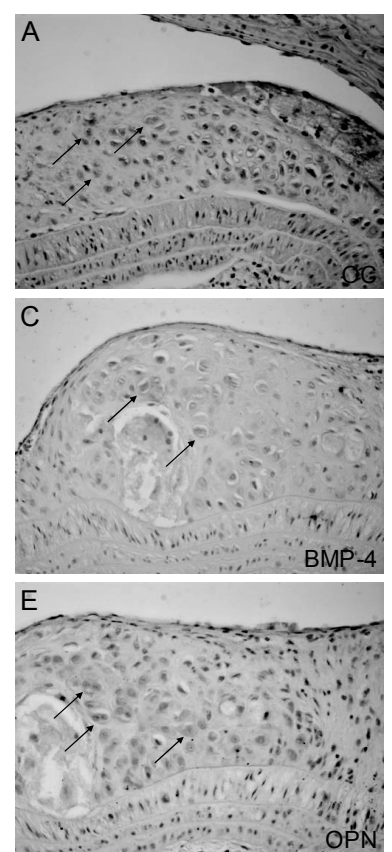
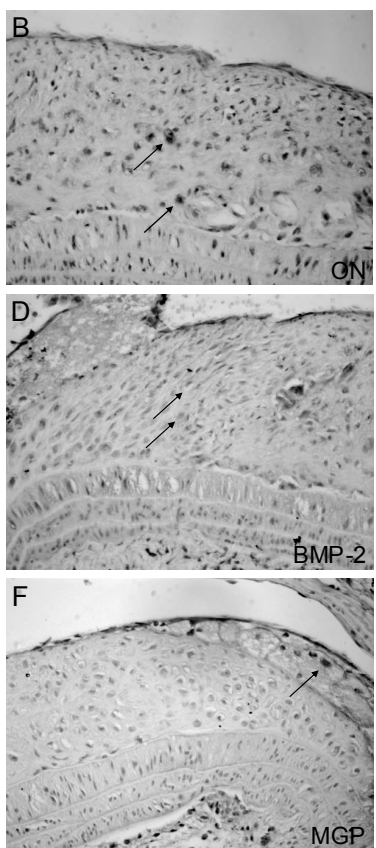

Figure 5. Expression of mediators of bone formation in atherosclerotic plaques in the aortic arch of $\alpha 1$-deficient mice. (A-C) Strong expression of OC, ON and BMP-4 in chondrocyte-like cells (indicated by arrows). Weaker expression of (D) BMP-2 and (E) OPN in chondrocyte-like cells (indicated by arrows). (F) MGP only expressed in macrophages (indicated by arrow). Magnification: 400X. For full colour figure see page 138. 


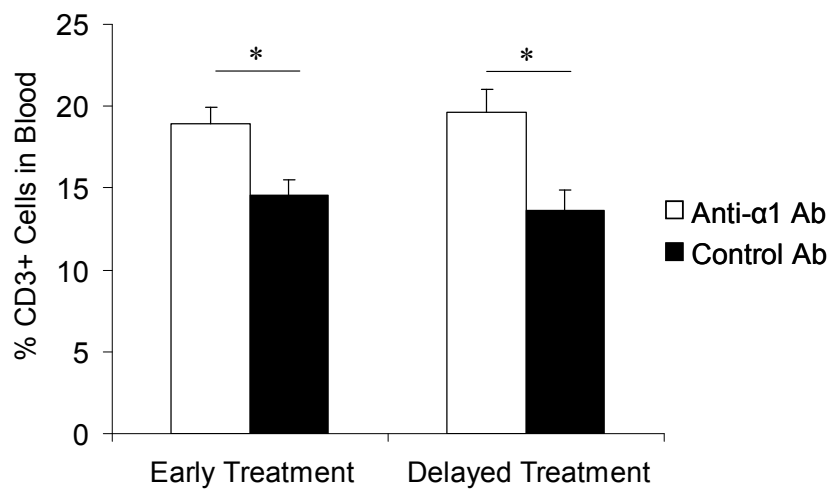

Figure 6. FACS analysis of CD3+ cells in blood revealed an increased number of circulating $\mathrm{T}$ lymphocytes in blood of anti- $\alpha 1$ antibody-treated mice compared with controls. ${ }^{*} \mathrm{P}<0.05$.
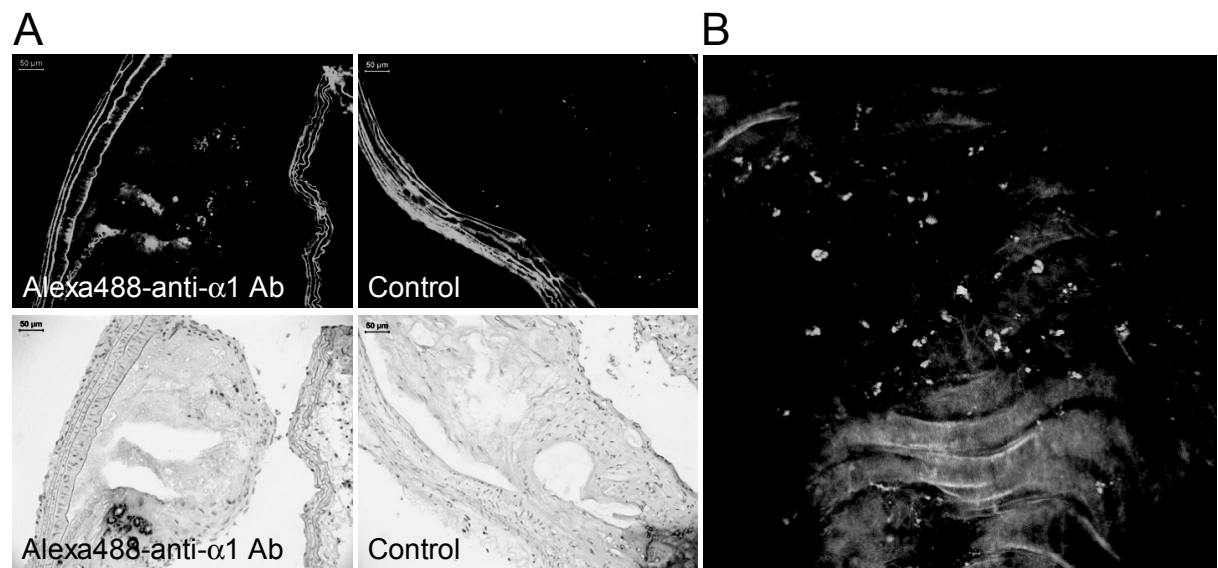

Alexa488-anti- $\alpha 1 \mathrm{Ab}$

Control

Figure 7. Anti- $\alpha 1$ antibody infiltrated atherosclerotic plaques of ApoE-/- mice. (A) Fluorescence and bright field images of atherosclerotic plaques in the aortic arch of ApoE-/- mice injected with Alexa488-labeled anti- $\alpha 1$ antibody or not injected with any antibody (control). Antibody appears as green spots in the plaque and autofluorescence of elastic laminae in the media are shown in green. (B) TPLSM 3D image of an atherosclerotic plaque in the carotid artery of an ApoE-/mouse injected with Alexa488-labeled anti- $\alpha 1$ antibody. Antibody appears as green spots and collagen fibers in the plaque and media are shown in blue. For full colour figure see page 139. 


\section{Antibody Infiltration}

To ascertain whether anti- $\alpha 1$ antibody infiltrated atherosclerotic plaques, we used TPLSM and fluorescence microscopy. Atherosclerotic plaques of mice injected with Alexa488-labeled anti- $\alpha 1$ antibody displayed more fluorescence in plaques of aortic arches compared with control mice, which were not injected with antibody. Similarly, using TPLSM, which combines 3D resolution and large penetration depth ${ }^{19}$ showed a positive signal for antibody labeled with the green fluorescent label Alexa488 in atherosclerotic plaques in carotid arteries (figure 7).

\section{Extent of Atherosclerosis}

There was no significant difference in the individual plaque area between anti- $\alpha 1$ antibody-treated and control mice in either of the early (initial: $14596 \pm 1455$ for anti$\alpha 1 \mathrm{mAb}$ vs. $15761 \pm 1955$ for control, $\mathrm{P}=0.06$; advanced: $49593 \pm 8051$ for anti- $\alpha 1 \mathrm{mAb}$ vs. $91519 \pm 14468$ for control, $\mathrm{P}>0.05$ ) or delayed treatment groups (initial: $45184 \pm 9635$ for anti- $\alpha 1 \mathrm{mAb}$ vs. $31076 \pm 5729$ for control, $\mathrm{P}>0.05$; advanced: $141300 \pm 19809$ for anti- $\alpha 1 \mathrm{mAb}$ vs. $120498 \pm 10671$ for control, $\mathrm{P}>0.05)$.

\section{Atherosclerotic Plaque Composition}

Differences in plaque composition between anti- $\alpha 1$ antibody-treated and control mice were less striking than in $\alpha 1$-deficient mice. Significant differences observed were a decreased macrophage content in initial atherosclerotic plaques of anti- $\alpha 1$ antibody-treated mice compared with controls in both of the early and delayed treatment groups (figure 8A), a decreased CD3+ cell content in advanced plaques of anti- $\alpha 1$ antibody-treated mice of the delayed treatment group compared with controls (figure $8 \mathrm{~B}$ ), and an increased collagen content in initial and advanced plaques of anti- $\alpha 1$ antibody-treated mice compared with controls of the delayed treatment group (figure $8 \mathrm{C}$ ). There were no differences in $\alpha \mathrm{SMA}$ content in any of the groups (early treatment, initial: $3.0 \pm 0.6$ for anti- $\alpha 1 \mathrm{Ab}$ vs. $1.8 \pm 0.4$ for control, $\mathrm{P}>0.05$; early treatment, advanced: $1.9 \pm 1.1$ for anti- $\alpha 1$ Ab vs. $3.7 \pm 0.5$ for control, $P>0.05$; delayed treatment, initial: $0.7 \pm 0.5$ for anti- $\alpha 1$ Ab vs. $2.8 \pm 1.1$ for control, $P>0.05$; delayed treatment, advanced: $3.4 \pm 0.6$ for anti- $\alpha 1 \mathrm{Ab}$ vs. $4.5 \pm 0.4$ for control, $\mathrm{P}>0.05$ ).

\section{Cell Migration Assay}

Because we observed a reduced macrophage content in both $\alpha 1$-deficient and anti$\alpha 1$ antibody-treated mice, we wanted to test the ability of $\alpha 1$-deficient macrophages to migrate on collagen substrata. Cells were allowed to migrate on collagen I and IV monolayers as it has previously been reported that $\alpha 1$ integrin binds these types of collagen. ${ }^{13}$ Following 4 and 12 hours of incubation, significantly less $\alpha 1-/-$ cells had migrated on collagen IV compared to WT cells (figure 9A). There was no significant difference in the number of $\alpha 1$-deficient cells migrating on collagen I compared with WT cells after 4 or 12 hours of migration (figure 9B). Treatment of WT cells 


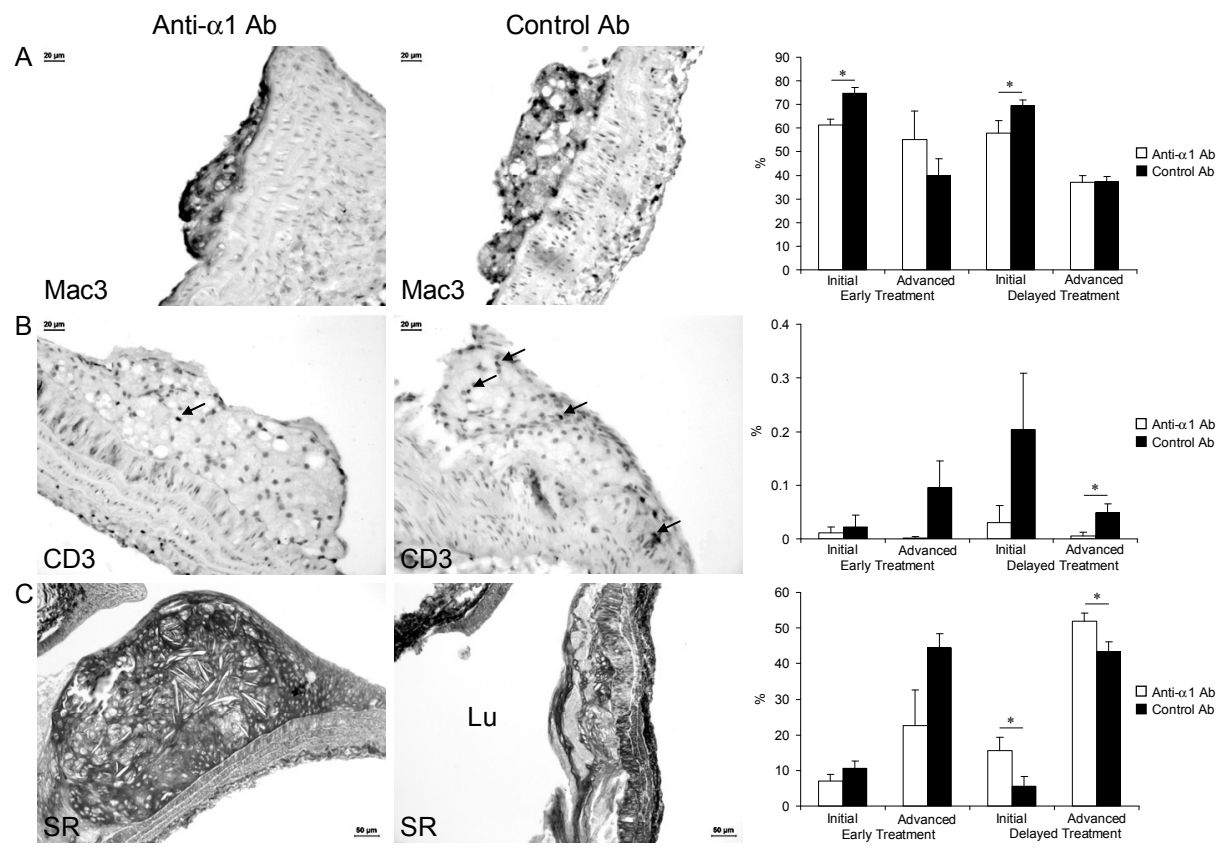

Figure 8. Plaque composition of initial and advanced atherosclerotic plaques in aortic arches of antibody-treated mice. There were significantly less (A) macrophages (Mac3+, red stained cells) and (B) CD3+ cells (brown stained cells, arrows) and a higher (C) collagen content (SR+ areas shown in red) in plaques of anti- $\alpha 1$ antibody-treated compared with control mice (Lu indicates lumen). ${ }^{*} \mathrm{P}<0.05$. For full colour figure see page 140.

with $\alpha 1$-blocking antibody inhibited migration on collagen IV compared with control antibody after 4 and 12 hours of migration (figure 9C).

\section{Collagen IV Expression}

Because $\alpha 1$-deficient macrophages as well as macrophages treated with $\alpha 1$-blocking antibody were inhibited from migrating on collagen type IV, the expression of collagen IV was determined in atherosclerotic plaques. Collagen IV is strongly expressed in the region of endothelial cells (EC) and slightly in areas surrounding cells in both mouse and human atherosclerotic plaques (figure 10). 
A

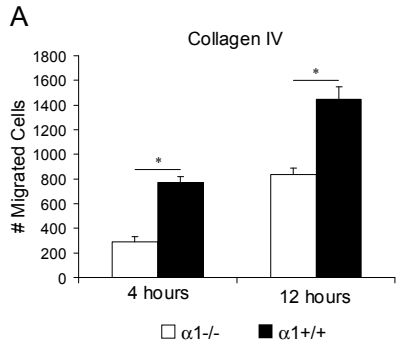

B

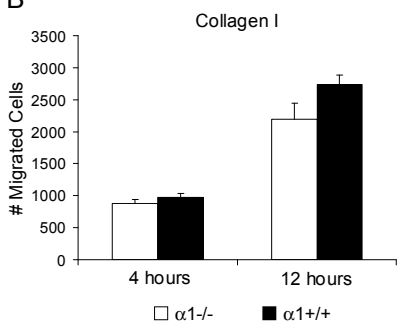

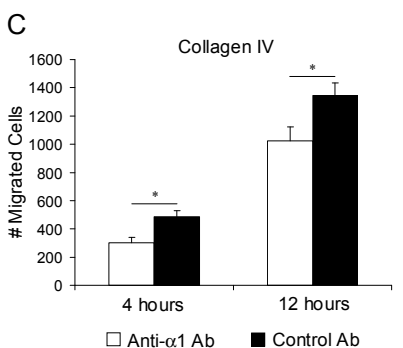

Figure 9. Cells lacking $\alpha 1$ integrin or receiving anti- $\alpha 1$ antibody treatment are deficient in migrating on collagen IV, but not collagen I. (A) Significantly less $\alpha 1-/-$ macrophages migrated on collagen IV compared with $\alpha 1+/+$ after 4 and 12 hours. (B) No significant difference in the number of $\alpha 1-/$ - compared with $\alpha 1+/+$ macrophages migrated on collagen I after 4 and 12 hours. (C) Significantly less anti- $\alpha 1$ antibody-treated compared with control antibody-treated macrophages migrated on collagen IV after 4 and 12 hours. ${ }^{*} \mathrm{P}<0.05$.
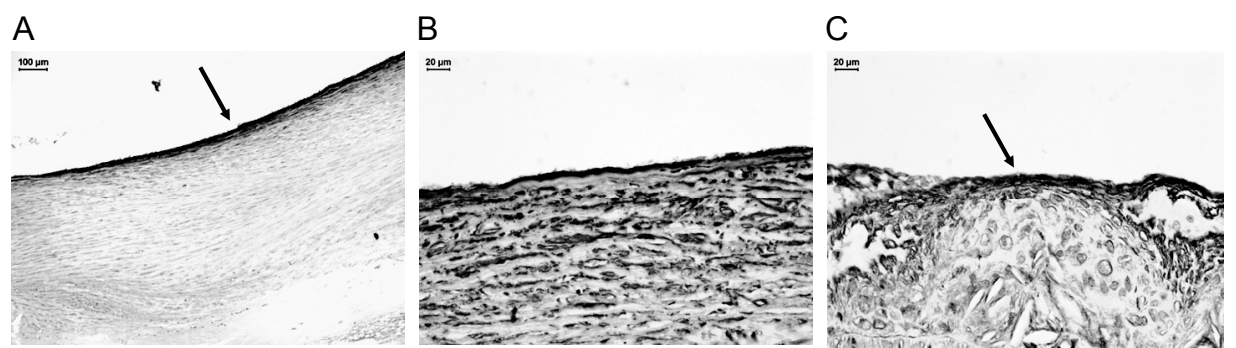

Figure 10. Collagen IV expression in mouse and human atherosclerotic plaques. (A) Advanced atherosclerotic plaque in a human carotid artery expressing collagen IV in the region of endothelial cells (indicated by arrow, magnification 10X) and (B) shown at higher magnification (40X). (C) Advanced atherosclerotic plaque in a mouse aortic arch showing collagen IV expression in the region of endothelial cells and somewhat surrounding cells within the plaque (indicated by arrow, magnification 40X). For full colour figure see page 140. 


\section{Discussion}

To investigate the role of $\alpha 1 \beta 1$ integrin in atherosclerosis we have used $\alpha 1$ integrin, ApoE double knockout mice as well as administered an $\alpha 1$-blocking antibody to normal ApoE knockout mice in an early and delayed treatment setting. Deficiency in $\alpha 1$ integrin did not prevent the initiation of lesion formation, but did reduce the size of advanced atherosclerotic plaques and induced a more stable plaque phenotype as characterized by decreased inflammation and increased ECM content. In both of the early and delayed anti- $\alpha 1$ antibody treatment groups, macrophage content was decreased in initial plaques while collagen content increased in advanced plaques. Furthermore, the CD3+ cell content was decreased in advanced plaques after delayed treatment.

Antibody treatment against $\alpha 1$ integrin was less effective in attenuating atherosclerosis compared to complete genetic deletion, however, the consequences of antibody intervention do not necessarily correlate with the phenotype of corresponding null animals. Knockout animals are deficient in a particular protein from birth, whereas antibody-treated mice receive treatment against the already existing protein beginning at a later time point for a limited period of time. Furthermore, in the present study we sacrificed $\alpha 1$-deficient mice after 26 weeks of age, whereas in the antibody intervention study, mice were sacrificed after 17 or 29 weeks of age in the early and delayed treatment groups, respectively. Previous studies have also demonstrated differences between the effects of using knockout mice and antibody intervention. For instance, complete genetic deletion of CD154 (CD40 ligand) in ApoE-/- mice resulted in smaller advanced plaques, ${ }^{20}$ whereas with anti-CD40 ligand antibody treatment, advanced plaque area was not reduced compared to controls. $^{21}$

Despite differences in the effects of $\alpha 1$-deficiency and anti- $\alpha 1$ antibody treatment, plaque phenotype was altered in both experiments to a more stable phenotype in two important ways, by reducing the macrophage content and increasing the collagen content. Indeed, the two major functions of $\alpha 1 \beta 1$ integrin are the regulation of collagen synthesis and mediating the migration of activated leukocytes into inflamed tissues. ${ }^{7,16}$ In the course of inflammation, leukocytes migrate through the subendothelial basement membrane, ${ }^{7}$ which is rich in collagen type IV. ${ }^{22}$ Central to the migration of cells into inflammatory sites are adhesive interactions between cells and ECM proteins that are widely mediated by the integrin family of adhesion molecules. ${ }^{23} \alpha 1 \beta 1$ is a major collagen-binding integrin with a preference for collagen IV and is expressed on activated leukocytes. It has been demonstrated in vitro that lipopolysaccharide-activated monocytes highly express $\alpha 1 \beta 1$ integrin. ${ }^{24}$ Activated T lymphocytes also express $\alpha 1 \beta 1$ and it has been shown in vivo to be involved in the migration and retention of leukocytes in tissues. ${ }^{25}$

$\mathrm{T}$ lymphocytes found in atherosclerotic plaques express $\alpha 1 \beta 1$ integrin $^{8}$ and we have demonstrated here that macrophages in normal mouse atherosclerotic plaques 
also express this integrin. However, the role of $\alpha 1 \beta 1$ integrin in lesion development has not yet been determined. Our study revealed a reduced inflammatory cell content particularly in lesions of $\alpha 1$-deficient, but also in anti- $\alpha 1$ antibody treated mice, suggesting a role for $\alpha 1 \beta 1$ integrin in the accumulation of leukocytes in atherosclerotic plaques. To shed light on the mechanism by which this occurs we performed migration assays, which demonstrated that $\alpha 1$-deficient and anti- $\alpha 1$ antibodytreated macrophages are inhibited from migrating on collagen IV. The subendothelial basement membrane of vessel walls consists largely of collagen IV, through which leukocytes must migrate to enter the intima during atherogenesis. ${ }^{26}$ In the present study, we have also shown by immunohistochemical staining that collagen IV is expressed in the region of ECs in both human and mouse atherosclerotic plaques. It appears therefore, that $\alpha 1 \beta 1$ integrin is necessary for the infiltration of leukocytes during atherogenesis. Results of the migration assays also suggest that antibody treatment against $\alpha 1 \beta 1$ integrin was successful in blocking its function in vivo.

Furthermore, there was an increase in the level of CD3+ T lymphocytes in the peripheral blood of anti- $\alpha 1$ antibody-treated mice as determined by FACS analysis as well as a significantly reduced CD3+ cell content in advanced plaques after delayed anti- $\alpha 1$ antibody treatment. These findings are consistent with a role of $\alpha 1 \beta 1$ in the migration and/or retention of activated $\mathrm{T}$ lymphocytes in collagen-rich tissues. ${ }^{27}$ By preventing migration and localization of $\alpha 1 \beta 1$-positive $\mathrm{T}$ lymphocytes in tissues such as the vessel wall, antibody treatment against $\alpha 1 \beta 1$ results in an increased circulating $\mathrm{T}$ lymphocyte population.

Our findings are consistent with previous studies on $\alpha 1 \beta 1$ integrin in various models of inflammatory diseases. Monocyte accumulation and activation was found to be reduced in mouse models of colitis in which $\alpha 1$ integrin was deleted or blocked by antibody treatment. ${ }^{11} \mathrm{~A}$ decrease in macrophage accumulation was also observed in a model of kidney fibrosis in which $\alpha 1$ integrin was deleted..$^{10}$ A deficiency in $\alpha 1 \beta 1$ integrin as well as anti- $\alpha 1$ antibody treatment was reported to be protective against experimental murine arthritis, delayed-type hypersensitivity, and contact hypersensitivity as shown by a reduced leukocyte infiltrate. ${ }^{9}$ In addition, in vitro $\alpha 1$-blocking antibody treatment attenuated the proliferation of $\mathrm{T}$ lymphocytes isolated from draining lymph nodes of arthritic rats ${ }^{28}$ and inhibited $\mathrm{T}$ lymphocytes cultured from peripheral blood of arthritic patients from migrating on collagen IV..$^{29}$

Besides its role in mediating activated leukocyte migration to sites of inflammation, $\alpha 1 \beta 1$ integrin regulates collagen synthesis by negative feedback inhibition. This was demonstrated in $\alpha 1$-deficient mice in which steady state collagen synthesis was observed in normal and wounded dermis. ${ }^{16}$ Furthermore, receptor stimulation has been shown to enhance the downregulation of collagen synthesis. ${ }^{15}$ In our study we found an increased collagen content in atherosclerotic plaques of both $\alpha 1-$ deficient and anti- $\alpha 1$ antibody-treated mice. This was particularly evident in advanced plaques, which is to be expected given that initial plaques consist of little or 
no collagen. An increased collagen content in atherosclerotic lesions contributes to their stability as does a thick fibrous cap, which we also observed in $\alpha 1$-deficient mice. Atherosclerotic lesions consist primarily of collagen types I and III and although $\alpha 1 \beta 1$ prefers to bind collagen IV, it is also a receptor for collagen I. It has been reported that $\alpha 1 \beta 1$ integrin downregulates collagen I mRNA levels in cells suspended in collagen gels ${ }^{30}$ and collagen I synthesis was increased in the dermis of $\alpha 1$-deficient mice due to elevated collagen I mRNA levels. ${ }^{16}$ This suggests that negative feedback inhibition of collagen synthesis mediated by $\alpha 1 \beta 1$ integrin occurs in atherosclerosis.

In addition to an increased collagen content, we found an increase in SMC content as revealed by $\alpha \mathrm{SMA}$-positive cells in advanced atherosclerotic plaques of $\alpha 1-$ deficient mice. SMCs are ECM-producing cells that are responsible for the collagens present in atherosclerotic plaques and are particularly involved in the formation of fibrous caps. The abundance of SMCs in atherosclerotic plaques is therefore important to plaque stability, however the role of $\alpha 1 \beta 1$ integrin in SMC proliferation and accumulation in atherosclerotic plaques is unclear.

Along with a change in plaque composition to a more stable plaque phenotype, cartilaginous metaplasia was observed in plaques of $\alpha 1$-deficient mice. Cartilaginous metaplasia may be a pathway by which calcification develops in atherosclerotic lesions, ${ }^{31}$ and increasing morphological and molecular evidence suggests that atherosclerotic calcification shares similarities with bone formation. Several proteins involved in osteogenesis have been identified in human atherosclerotic lesions such as OC, ON, OPN, BMP-2, BMP-4, and MGP and are associated with calcification. ${ }^{32}$ $\mathrm{OC}$ is an osteoblast-specific protein that can also be expressed by macrophages, whereas $\mathrm{ON}$ is a non-collagenous protein that accumulates in the ECM of bone tissue. BMP-2 and BMP-4 are osteogenic factors that trigger osteoblast differentiation. OPG, a member of the TNF receptor superfamily, is expressed on osteoblast-like cells and inhibits their differentiation.

In our study, we observed the expression of all of these bone markers to various degrees in areas of cartilaginous metaplasia, which suggests that the cartilaginous tissue found in these lesions may be a precursor to calcification. It is important to note that although cartilaginous metaplasia was more extensive in lesions of $\alpha 1-$ deficient mice relative to controls, there was no gross difference in the expression pattern of cartilage and bone markers between the two groups. The role of $\alpha 1 \beta 1$ integrin in cartilaginous metaplasia is unknown, however, its occurrence in atherosclerotic plaques may be an indirect effect of $\alpha 1$-deficiency. It has been reported that two of the matrix components known to be important in bone formation, fibronectin and collagen I, are also important in promoting mineralization of vascular cells. ${ }^{33}$ Because collagen type I is abundantly present in atherosclerotic plaques and an increased collagen content was observed in plaques of $\alpha 1$-deficient mice, this may have lead to the formation of cartilaginous metaplasia observed in these plaques. 
These results indicate a role of $\alpha 1 \beta 1$ integrin in atherosclerosis and emphasize the importance of integrin-mediated adhesive interactions in this inflammatory disease. Complete deletion of this integrin was not only able to reduce plaque area, but also altered plaque composition by reducing inflammation and increasing the ECM content, which are crucial features of a stable atherosclerotic plaque. Antibody intervention against $\alpha 1$ integrin, although less effective in attenuating atherosclerosis compared with complete genetic deletion, modulated plaque characteristics in two very important respects by decreasing the leukocyte content and increasing collagen content. It appears that $\alpha 1 \beta 1$ integrin is involved in the inflammatory process of atherosclerosis by mediating the migration of leukocytes to lesions.

\section{Acknowledgements}

E.L. is a post-doctoral fellow of the Dr. E. Dekker program of the Dutch Heart Foundation (2000T41). The authors thank Linda Beckers, Anique Janssen, Ine Middendorp, Mat Rousch, Marjan Smook, Remco Megens and Kim Douma for excellent technical assistance. 


\section{References}

1. Duplaa C, Couffinhal T, Dufourcq P, Llanas B, Moreau C, Bonnet J. The integrin very late antigen-4 is expressed in human smooth muscle cell. Involvement of alpha 4 and vascular cell adhesion molecule-1 during smooth muscle cell differentiation. Circ Res. 1997;80:159-169.

2. Shih PT, Brennan ML, Vora DK, Territo MC, Strahl D, Elices MJ, et al. Blocking very late antigen-4 integrin decreases leukocyte entry and fatty streak formation in mice fed an atherogenic diet. Circ Res. 1999;84:345-351.

3. Barringhaus KG, Phillips JW, Thatte JS, Sanders JM, Czarnik AC, Bennett DK, et al. alpha(4)beta(1) Integrin (VLA-4) Blockade Attenuates both Early and Late Leukocyte Recruitment and Neointimal Growth following Carotid Injury in Apolipoprotein E (-/-) Mice. J Vasc Res. 2004;41:252-260.

4. Sajid M, Stouffer GA. The role of alpha(v)beta3 integrins in vascular healing. Thromb Haemost. 2002;87:187-193.

5. Antonov AS, Kolodgie FD, Munn DH, Gerrity RG. Regulation of Macrophage Foam Cell Formation by alphaVbeta3 Integrin: Potential Role in Human Atherosclerosis. Am J Pathol. 2004;165:247-258.

6. He L, Pappan LK, Grenache DG, Li Z, Tollefsen DM, Santoro SA, et al. The contributions of the alpha 2 beta 1 integrin to vascular thrombosis in vivo. Blood. 2003;102:3652-3657.

7. de Fougerolles AR, Koteliansky VE. Regulation of monocyte gene expression by the extracellular matrix and its functional implications. Immunol Rev. 2002;186:208-220.

8. Stemme S, Holm J, Hansson GK. T lymphocytes in human atherosclerotic plaques are memory cells expressing CD45RO and the integrin VLA-1. Arterioscler Thromb. 1992;12:206-211.

9. de Fougerolles AR, Sprague AG, Nickerson-Nutter CL, Chi-Rosso G, Rennert PD, Gardner H, et al. Regulation of inflammation by collagen-binding integrins alpha1beta1 and alpha2beta1 in models of hypersensitivity and arthritis. J Clin Invest. 2000;105:721-729.

10. Sampson NS, Ryan ST, Enke DA, Cosgrove D, Koteliansky V, Gotwals P. Global gene expression analysis reveals a role for the alpha 1 integrin in renal pathogenesis. J Biol Chem. 2001;276:34182-34188.

11. Krieglstein CF, Cerwinka WH, Sprague AG, Laroux FS, Grisham MB, Koteliansky VE, et al. Collagen-binding integrin alpha1beta1 regulates intestinal inflammation in experimental colitis. J Clin Invest. 2002;110:1773-1782.

12. Belkin VM, Belkin AM, Koteliansky VE. Human smooth muscle VLA-1 integrin: purification, substrate specificity, localization in aorta, and expression during development. J Cell Biol. 1990;111:2159-2170.

13. Gardner H, Kreidberg J, Koteliansky V, Jaenisch R. Deletion of integrin alpha 1 by homologous recombination permits normal murine development but gives rise to a specific deficit in cell adhesion. Dev Biol. 1996;175:301-313.

14. Pozzi A, Wary KK, Giancotti FG, Gardner HA. Integrin alpha1beta1 mediates a unique collagen-dependent proliferation pathway in vivo. J Cell Biol. 1998;142:587-594.

15. Langholz O, Rockel D, Mauch C, Kozlowska E, Bank I, Krieg T, et al. Collagen and collagenase gene expression in three-dimensional collagen lattices are differentially regulated by alpha 1 beta 1 and alpha 2 beta 1 integrins. J Cell Biol. 1995;131:1903-1915.

16. Gardner H, Broberg A, Pozzi A, Laato M, Heino J. Absence of integrin alpha1beta1 in the mouse causes loss of feedback regulation of collagen synthesis in normal and wounded dermis. J Cell Sci. 1999;112 ( Pt 3):263-272.

17. Lutgens E, Gijbels M, Smook M, Heeringa P, Gotwals P, Koteliansky VE, et al. Transforming growth factor-beta mediates balance between inflammation and fibrosis during plaque progression. Arterioscler Thromb Vasc Biol. 2002;22:975-982.

18. Havenith MG, Cleutjens JP, Beek C, vd Linden E, De Goeij AF, Bosman FT. Human specific anti-type IV collagen monoclonal antibodies, characterization and immunohistochemical application. Histochemistry. 1987;87:123-128. 
19. van Zandvoort M, Engels W, Douma K, Beckers L, Oude Egbrink M, Daemen M, et al. Twophoton microscopy for imaging of the (atherosclerotic) vascular wall: a proof of concept study. $J$ Vasc Res. 2004;41:54-63.

20. Lutgens E, Gorelik L, Daemen MJ, de Muinck ED, Grewal IS, Koteliansky VE, et al. Requirement for CD154 in the progression of atherosclerosis. Nat Med. 1999;5:1313-1316.

21. Lutgens E, Cleutjens KB, Heeneman S, Koteliansky VE, Burkly LC, Daemen MJ. Both early and delayed anti-CD40L antibody treatment induces a stable plaque phenotype. Proc Natl Acad Sci U S A. 2000;97:7464-7469.

22. Sukhova GK, Zhang Y, Pan JH, Wada Y, Yamamoto T, Naito M, et al. Deficiency of cathepsin S reduces atherosclerosis in LDL receptor-deficient mice. J Clin Invest. 2003;111:897-906.

23. Hemler ME. VLA proteins in the integrin family: structures, functions, and their role on leukocytes. Anпu Rev Immunol. 1990;8:365-400.

24. Rubio MA, Sotillos M, Jochems G, Alvarez V, Corbi AL. Monocyte activation: rapid induction of alpha 1/beta 1 (VLA-1) integrin expression by lipopolysaccharide and interferon-gamma. Eur J Immunol. 1995;25:2701-2705.

25. Andreasen SO, Thomsen AR, Koteliansky VE, Novobrantseva TI, Sprague AG, de Fougerolles $\mathrm{AR}$, et al. Expression and functional importance of collagen-binding integrins, alpha1beta1 and alpha2beta1, on virus-activated T cells. J Immunol. 2003;171:2804-2811.

26. Newby AC. An overview of the vascular response to injury: a tribute to the late Russell Ross. Toxicol Lett. 2000;112-113:519-529.

27. Ray SJ, Franki SN, Pierce RH, Dimitrova S, Koteliansky V, Sprague AG, et al. The collagen binding alpha1beta1 integrin VLA-1 regulates CD8 $\mathrm{T}$ cell-mediated immune protection against heterologous influenza infection. Immunity. 2004;20:167-179.

28. Ianaro A, Cicala C, Calignano A, Koteliansky V, Gotwals P, Bucci M, et al. Anti-very late antigen-1 monoclonal antibody modulates the development of secondary lesion and T-cell response in experimental arthritis. Lab Invest. 2000;80:73-80.

29. Bank I, Koltakov A, Goldstein I, Chess L. Lymphocytes expressing alpha1beta1 integrin (very late antigen-1) in peripheral blood of patients with arthritis are a subset of $\mathrm{CD} 45 \mathrm{RO}(+) \mathrm{T}$-cells primed for rapid adhesion to collagen IV. Clin Immunol. 2002;105:247-258.

30. Riikonen T, Westermarck J, Koivisto L, Broberg A, Kahari VM, Heino J. Integrin alpha 2 beta 1 is a positive regulator of collagenase (MMP-1) and collagen alpha 1(I) gene expression. J Biol Chem. 1995;270:13548-13552.

31. Qiao JH, Mertens RB, Fishbein MC, Geller SA. Cartilaginous metaplasia in calcified diabetic peripheral vascular disease: morphologic evidence of enchondral ossification. Hum Pathol. 2003;34:402-407.

32. Dhore CR, Cleutjens JP, Lutgens E, Cleutjens KB, Geusens PP, Kitslaar PJ, et al. Differential expression of bone matrix regulatory proteins in human atherosclerotic plaques. Arterioscler Thromb Vasc Biol. 2001;21:1998-2003.

33. Watson KE, Parhami F, Shin V, Demer LL. Fibronectin and collagen I matrixes promote calcification of vascular cells in vitro, whereas collagen IV matrix is inhibitory. Arterioscler Thromb Vasc Biol. 1998;18:1964-1971. 


\section{CHAPTER 6}

TWEAK inhibition reduces fibrosis and alters the macrophage phenotype in atherosclerotic plaques of ApoE-/- mice

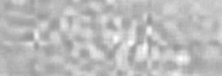

Kitty Schapira, Linda C. Burkly, Timothy S. Zheng, Mark M. Kockx, Mat JA.P. Daemen, Sylvia Heeneman

Submitted 


\begin{abstract}
TWEAK is a multifunctional cytokine belonging to the tumour necrosis factor superfamily and binds to the receptor Fn14. Both TWEAK and Fn14 are expressed in atherosclerotic plaques in areas rich in macrophages and foam cells. We investigated the role of TWEAK/Fn14 interactions in ApoE-/- mice. ApoE-/- mice were treated with TWEAK-inhibiting fusion protein, Fn14:Fc, in an early (5 to 17 weeks of age) and delayed (17 to 29 weeks of age) setting. In the aortic arch, Fn14:Fc resulted in smaller advanced plaques after early treatment. Fn14:Fc also resulted in a low fibrotic content in advanced plaques of both early and delayed treatment groups. Advanced plaques of the delayed treatment group exhibited an increased macrophage content and smaller macrophage size. ApoE-/- bone marrow-derived macrophages and foam cells treated with Fn14:Fc and other TWEAK-blocking reagents did not induce apoptosis, but blocking TWEAK results in less uptake of modified lipids. While TWEAK inhibition did not prevent initiation of lesions, both early and delayed treatment reduced fibrosis in atherosclerotic plaques of ApoE-/- mice. Delayed treatment also induced advanced plaques with a unique macrophage phenotype. These findings suggest that TWEAK/Fn14 interactions play a role in atherosclerosis and may mediate lipid metabolism in macrophages.
\end{abstract}




\section{Introduction}

TNF-like weak inducer of apoptosis (TWEAK) is a recently identified cytokine belonging to the TNF ligand family. It is synthesized as a transmembrane protein with its N-terminus residing in the cytoplasm (type II), that can be cleaved into a soluble form. ${ }^{1}$ Using recombinant soluble TWEAK, a novel receptor for TWEAK was identified and named TWEAKR. ${ }^{2}$ This was found to be identical to the previously described fibroblast growth factor (FGF)-inducible 14 (Fn14), a small type I plasma membrane protein discovered during a search for growth factor-inducible genes..$^{3,4}$

As its name suggests, TWEAK was initially described as a weak inducer of apoptosis. ${ }^{1}$ TWEAK expression on human peripheral blood monocytes induced by IFN $\gamma$ have been shown to contribute to monocyte cytotoxicity against tumor cells. ${ }^{5}$ Studies investigating the molecular mechanism of TWEAK-mediated cell death reported that TWEAK indirectly induces apoptosis in several tumor cell lines via endogenous TNF.5,6 Further studies by Nakayama et al. described additional cell-type specific pathways of TWEAK-induced cell death including caspase-dependent apoptosis and cathepsin B-dependent necrosis.7,8

These multiple pathways of TWEAK-induced cell death are solely mediated by Fn14, ${ }^{8}$, however the signaling pathway remains to be defined. Studies have shown that binding of TWEAK to Fn14 activates the NFKB pathway, which regulates genes involved in inflammation, and that this occurs via TNF receptor associated factors (TRAF). ${ }^{9}$ TWEAK/Fn14 interaction is therefore capable of regulating a variety of cellular processes besides apoptosis, many of which are important in atherosclerosis. TWEAK has been implicated in angiogenesis as it induces the proliferation and migration of ECs and aortic SMCs in vitro and neovascularization when implanted in rat corneas. ${ }^{10,11}$ It has also been shown that TWEAK potentiates the mitogenic activity of FGF-2 and VEGF-A. ${ }^{12}$ In addition, TWEAK can stimulate the expression of proinflammatory cytokines in several cell types, including $\mathrm{ECs}^{13}$ and mesangial cells. ${ }^{14}$

Recently, analysis of human atherosclerotic plaques showed that TWEAK and Fn14 are expressed in areas rich in macrophages and foam cells and TWEAK induces production of proatherogenic mediators such as MCP-1, IL-6, IL-8, MMP-9, 15 and HMGB1 ${ }^{16}$ by a human macrophage-like cell line, however the effects of TWEAK on atherogenic development have not been determined. In the present study, using a TWEAK-blocking protein in a mouse model of atherosclerosis we report that blocking TWEAK inhibits fibrosis and induces a macrophage-rich plaque phenotype with smaller macrophages in vivo and decreases lipid uptake by macrophages in vitro. 


\section{Materials and Methods}

Mice

To study the role of TWEAK/Fn14 interactions in atherosclerosis, male ApoE-/- mice on a $100 \%$ C57Bl6 background were used (obtained from Iffa Credo) and fed normal chow. Mice were injected intraperitoneally twice a week with $100 \mu \mathrm{g}$ of murine Fn14:Fc fusion protein (Fn14:Fc) as previously described ${ }^{14}$ or murine IgG isotype control Ab (P1.17) (American Type Culture Collection). Mice received treatment for 12 weeks beginning at either 5 weeks of age when no atherosclerotic lesions were present in the aortic arch (early treatment: Fn14:Fc, n=15; control, n=15) or 17 weeks of age when advanced lesions began to appear in the aortic arch (delayed treatment: Fn14:Fc, n=14; control, $n=14$ ). This dose level was designed to achieve at least a $20 \mu \mathrm{g} / \mathrm{ml}$ serum level of Fn14:Fc, a level sufficient to inhibit TWEAK based on complete inhibition of TWEAK-induced signaling by $2 \mu \mathrm{g} / \mathrm{ml}$ Fn14:Fc in vitro. ${ }^{14}$ Mice were sacrificed following an 8-hour fast. Approximately $1.0 \mathrm{ml}$ blood was drawn from the caval vein for lipoprotein analysis. Animal experiments were approved by the institutional committee for the care and welfare of laboratory animals of Maastricht University.

\section{Lipid Profiles}

For the assessment of lipid profiles standard enzymatic techniques were used as described previously. ${ }^{17}$

\section{Histology and Morphometry}

The arterial tree was perfused with PBS containing $0.1 \mathrm{mg} / \mathrm{ml}$ sodium nitroprusside (Sigma) followed by 1\% phosphate-buffered paraformaldehyde. Major organs of each mouse were excised and analyzed for abnormalities on $4 \mu \mathrm{m}$-thick paraffin sections stained with HE. The aortic arch was processed and cut as described previously.17,18 Atherosclerotic lesions were classified as initial (AHA type II/III: fatty streaks containing macrophage-derived foam cells) or advanced (AHA type IV/V: containing extracellular lipid, a lipid core, and/or a fibrous cap). Morphometric analysis was performed as described previously. ${ }^{17,18}$

\section{Immunohistochemistry}

Sections were immunolabeled to detect macrophages, T lymphocytes, and SMCs, as described previously.17,18 TUNEL (terminal deoxynucleotidyl transferase biotindUTP nick end labeling) staining was performed with the use of the ApopTag kit (Oncor) for the detection of apoptotic cells in vivo. 


\section{Cell Isolation}

Bone marrow-derived macrophages were isolated from the femur and tibia of ApoE-/- mice and cultured as described previously. ${ }^{18}$

\section{Lipoprotein Isolation and Modification}

Low density lipoprotein (LDL) was isolated from fresh human plasma by density gradient ultracentrifugation. LDL was oxidized with $\mathrm{CuSO}_{4}$ by incubating overnight at $37^{\circ} \mathrm{C}$ followed by dialysis against PBS $+10 \mu \mathrm{M}$ EDTA. Modification of LDL to oxidized LDL (oxLDL) was confirmed by gel electrophoresis. The concentration of lipoprotein samples was determined by the Bradford protein assay.

\section{Fn14 Expression on Macrophages and Foam Cells}

Bone marrow-derived macrophages were incubated on glass cover slips in 24-well plates at approximately 200,000 cells per well and were loaded with $25 \mu \mathrm{g} / \mathrm{ml}$ oxLDL for 24 or 48 hours to generate foam cells. Cells were fixed with acetone and blocked with $4 \%$ normal goat serum in PBS for 30 minutes. Non-specific binding of avidin/biotin reagents was blocked using a blocking kit (Vector Labs, SP-2001) according to the manufacturer's instructions. Cells were incubated overnight at $4^{\circ} \mathrm{C}$ with $4 \mu \mathrm{g} / \mathrm{ml}$ (in PBS) of a purified Ig fraction of rabbit polyclonal anti-mouse Fn14 (Biogen Idec, Inc.) or normal rabbit Ig as a negative control. Biotinylated goat antirabbit Ig (Vector Labs, BA-1000) at 1:200 dilution in 4\% NGS in PBS was added for 30 minutes followed by addition of $10 \mu \mathrm{g} / \mathrm{ml}$ (in PBS) of streptavidin Alexa488 (Molecular Probes, S-11223) and incubated in the dark for 30 minutes. Nuclei were counterstained with 4',6-Diamidino-2-phenylindole, dihydrochloride (DAPI).

\section{Lipid Uptake}

Bone marrow-derived ApoE-/- macrophages were treated overnight with 100ng/ml Fc-TWEAK prepared as previously described, ${ }^{14} 10 \mu \mathrm{g} / \mathrm{ml}$ TWEAK-blocking proteins Fn14:Fc or murine anti-TWEAK mAb P2D10,14 10 $\mu \mathrm{g} / \mathrm{ml}$ Fn14-specific blocking mAb P2D3, 10 $\mu \mathrm{g} / \mathrm{ml}$ MOPC-21 (murine IgG1 isotype control Ab for anti-Fn14 mAb), or 10 $\mu \mathrm{g} / \mathrm{ml}$ P1.17 (murine IgG2a isotype control Ab for Fc-TWEAK, Fn14:Fc, and antiTWEAK mAb) (both isotype controls were from American Type Culture Collection). To demonstrate the specificity of the stimulatory effect of Fc-TWEAK, 100ng/ml FcTWEAK previously determined to be an optimal dose in various assays ${ }^{14}$ was premixed for 30 minutes with 10X excess of TWEAK-blocking agents Fn14:Fc, anti-Fn14 $\mathrm{mAb}$, or anti-TWEAK mAb prior to addition to cells. OxLDL was labeled with the fluorescent dye 1,1'-dioctadecyl-3,3,3',3'-tetramethylindocarbocyanine perchlorate (DiI) (Molecular Probes). Cells (2x106 per sample) were loaded with $25 \mu \mathrm{g} / \mathrm{ml}$ DiIlabeled oxLDL for 10 or 30 minutes. OxLDL uptake by macrophages was assessed by fluorescence-activated cell sorting (FACS) analysis (FACSCalibur, BD Biosciences) 
and analyzed with CellQuest software (BD Biosciences). DiI-labeled oxLDL uptake was determined for a total of 104 cells per sample and expressed as geomeans.

Apoptosis Assay

Bone marrow-derived ApoE-/- macrophages or foam cells (prepared by loading macrophages with $25 \mu \mathrm{g} / \mathrm{ml}$ oxLDL for 24 hours) were treated overnight with the same reagents used for the lipid uptake assay: 100ng/ml Fc-TWEAK, $10 \mu \mathrm{g} / \mathrm{ml}$ Fn14:Fc, $10 \mu \mathrm{g} / \mathrm{ml}$ anti-TWEAK mAb, 10 $\mu \mathrm{g} / \mathrm{ml}$ anti-Fn14 mAb, 10 $\mu \mathrm{g} / \mathrm{ml}$ MOPC-21, $10 \mu \mathrm{g} / \mathrm{ml}$ P1.17, or $20 \mu \mathrm{g} / \mathrm{ml}$ cycloheximide (CHX) (Sigma), which was used as a positive control for apoptosis. To determine the TWEAK-blocking ability of each reagent, 100ng/ml Fc-TWEAK was premixed for 30 minutes with 10× excess of TWEAKblocking agents Fn14:Fc, anti-Fn14 mAb, or anti-TWEAK mAb prior to addition to cells. Apoptosis was determined by FACS analysis using an annexin VFITC apoptosis detection kit (BD Biosciences). Briefly, following antibody treatment, cells were washed with PBS and labeled with annexin VFITC (which stains apoptotic and necrotic cells) and propidium iodide (which stains necrotic cells). Cells that were annexin $\mathrm{V}$-positive and propidium iodide-negative were considered apoptotic.

\section{Statistical Analysis}

Statistical analyses of both the in vivo and in vitro studies were performed using a non-parametric Mann-Whitney $U$ test. Data are expressed as mean \pm SEM and differences were considered statistically significant at $\mathrm{P}<0.05$.

\section{Results}

\section{General}

Average body weight of mice did not differ in Fn14:Fc-treated mice compared with controls in either of the early or delayed treatment groups. There were no differences in plasma total cholesterol, triglycerides, or LDL, however HDL was slightly elevated in Fn14:Fc-treated mice compared with controls in the early treatment group (table 1). Autopsy of organs revealed no abnormalities or pathologies.

\section{Extent of Atherosclerosis}

Fn14:Fc treatment resulted in smaller advanced plaques compared with control antibody treatment in the early treatment group as shown in figure 1A. The number of initial and advanced plaques in the early treatment group did not differ between Fn14:Fc-treated and control mice. In the delayed treatment group, however, there were more initial plaques and fewer advanced plaques in Fn14:Fc-treated mice compared with controls, as shown in figure 1B. Thus, blocking TWEAK starting at 5 
weeks of age, prior to establishment of atherosclerotic lesions, did not inhibit the occurrence of plaques but did significantly limit the size of advanced lesions. Blocking TWEAK at 17 weeks of age, after lesions had begun to appear, resulted in fewer advanced plaques suggesting that plaque progression from the initial to advanced stage as qualified by AHA criteria was inhibited.

Table 1. Plasma lipid profile and body weight of Fn14:Fc-treated and control mice.

\begin{tabular}{ccccccc}
\hline Treatment & $\mathrm{n}$ & $\begin{array}{c}\text { Average } \\
\text { body weight } \\
(\mathrm{g})\end{array}$ & $\begin{array}{c}\text { Plasma total } \\
\text { cholesterol } \\
(\mathrm{mM})\end{array}$ & $\begin{array}{c}\text { Plasma total } \\
\text { triglycerides } \\
(\mu \mathrm{M})\end{array}$ & $\begin{array}{c}\text { Plasma total } \\
\mathrm{HDL} \\
(\mathrm{mM})\end{array}$ & $\begin{array}{c}\text { Plasma total } \\
\mathrm{LDL}\end{array}$ \\
\hline $\begin{array}{c}\text { Early } \\
\text { Fn14:Fc }\end{array}$ & 15 & 30 & $10.7 \pm 0.7$ & $997 \pm 78$ & $0.45 \pm 0.05^{*}$ & $9.96 \pm 0.6$ \\
Control Ab & 14 & 28 & $9.4 \pm 0.6$ & $859 \pm 121$ & $0.28 \pm 0.05$ & $8.84 \pm 0.5$ \\
& & & & & & \\
Delayed & & & & & & \\
Fn14:Fc & 15 & 30 & $12.8 \pm 0.8$ & $1581 \pm 104$ & $0.29 \pm 0.04$ & $11.9 \pm 0.7$ \\
Control Ab & 14 & 30 & $11.3 \pm 0.6$ & $1420 \pm 110$ & $0.31 \pm 0.03$ & $10.5 \pm 0.6$ \\
\hline
\end{tabular}

${ }^{*} \mathrm{P}<0.05$. Fn14:Fc-treated vs. control Ab-treated.

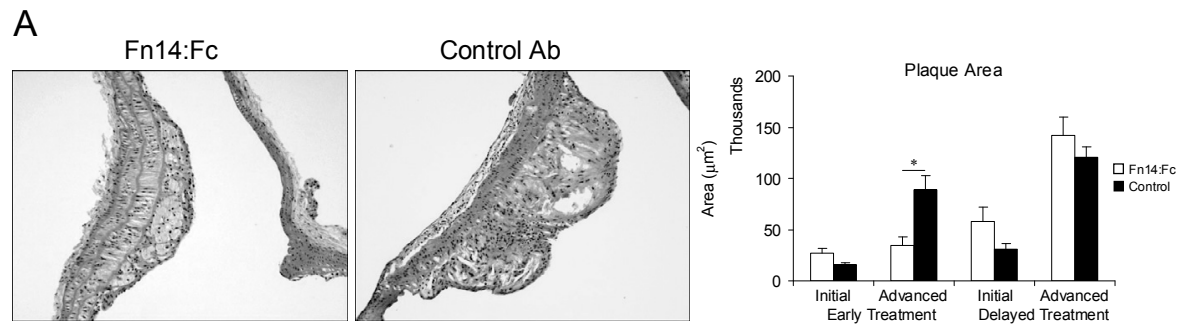

B

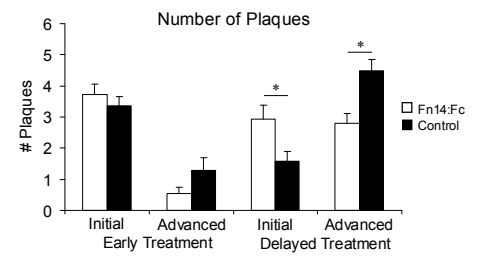

Figure 1. Smaller advanced plaques with early Fn14:Fc treatment and fewer advanced plaques with delayed treatment. (A) Early Fn14:Fc treatment resulted in smaller plaque areas compared with control mice. (B) Delayed Fn14:Fc treatment resulted in more initial plaques and fewer advanced plaques. ${ }^{*} \mathrm{P}<0.05$. For full colour figure see page 141 . 


\section{Atherosclerotic Plaque Composition}

Although Fn14:Fc treatment did not affect plaque size to a great extent, the composition of lesions was altered. Fn14:Fc treatment resulted in less fibrous plaques due to a reduced $\alpha S M A$ content in both initial and advanced lesions compared with control antibody treatment in the delayed treatment group (figure 2A), as well as a reduced collagen content in advanced plaques of Fn14:Fc-treated mice in both the early and delayed treatment groups (figure 2B). Interestingly, there was an increased macrophage content in advanced plaques of the delayed treatment group of Fn14:Fc-treated mice compared with controls (figure 2C). CD45+ cell content was decreased in initial plaques following delayed treatment (data not shown). Lipid core sizes in advanced plaques did not differ between Fn14:Fc-treated mice and controls in the delayed treatment group (figure 2D). No lipid cores were observed in the early treatment group. Thus, both early and delayed anti-TWEAK treatment inhibited fibrosis. Delayed treatment also induced a macrophage-rich plaque phenotype in advanced lesions, but did not change the size of lipid cores.

\section{Lipid Uptake by Macrophages}

In addition to inducing macrophage-rich advanced plaques with delayed Fn14:Fc treatment, the size of macrophage foam cells in vivo was determined and it was found that macrophages in plaques of Fn14:Fc-treated mice were smaller than in controls as shown in figure $3 \mathrm{~A}$. This suggests that TWEAK inhibition might reduce lipid uptake thereby limiting the size of macrophages. This possibility was directly tested in vitro. Bone marrow-derived ApoE-/- macrophages pretreated with TWEAK-blocking reagents took up less DiI-labeled oxLDL compared with cells treated with control antibody after both 10 and 30 minutes of lipid loading. Figure 3B shows results after 30 minutes of lipid loading. Conversely, addition of TWEAK to the culture did not further enhance lipid uptake (data not shown), suggesting there is already sufficient endogenous TWEAK in the culture system. These data indicate that endogenous TWEAK/Fn14 interactions regulate lipid uptake in cultured macrophages and may thereby affect the size of macrophages in vivo.

\section{Fn14 Expression on Macrophages and Foam Cells}

To ascertain whether the receptor Fn14 is expressed by macrophages and foam cells, immunolabeling of Fn14 was performed on ApoE-/- bone marrow-derived macrophages and foam cells generated by treatment with oxLDL. Immunofluorescence images of macrophages (figure 4A) and foam cells treated with oxLDL for 48 hours (figure 4B) show staining with Alexa488-labeled anti-Fn14 Ig as compared with control Ig indicating the expression of Fn14 on these cells. Foam cells generated by treatment with oxLDL for 24 hours showed similar results to those treated with oxLDL for 48 hours (data not shown). 


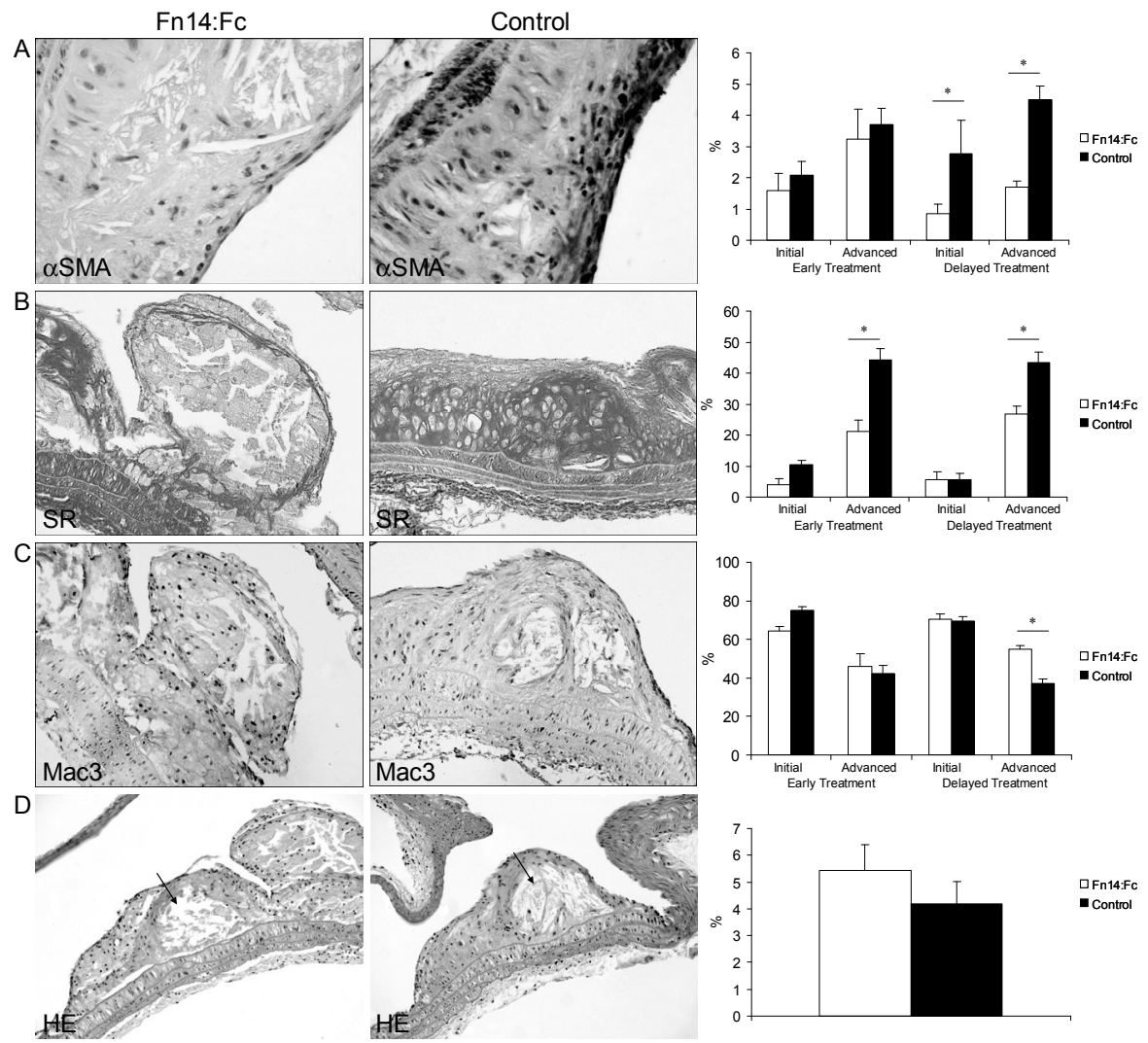

Figure 2. Plaque composition of initial and advanced atherosclerotic plaques. Fibrotic content of atherosclerotic plaques was significantly lower with Fn14:Fc treatment due to (A) a reduced $\alpha$ SMA content in initial and advanced plaques of mice that received delayed Fn14:Fc treatment and (B) a reduced collagen content as shown by SR staining in advanced plaques following both early and delayed Fn14:Fc treatment compared with controls. (C) Macrophage content as shown by Mac3 immunohistochemical staining increased in advanced plaques of Fn14:Fc-treated mice compared with controls. (D) Lipid core content (indicated by arrow) as shown by HE staining in advanced plaques did not differ between Fn14:Fc-treated mice and controls in the delayed treatment group. ${ }^{*} \mathrm{P}<0.05$. For full colour figure see page 142.

Apoptosis of Macrophages and Foam Cells in vivo and in vitro

The increased macrophage numbers might be due to a reduction in apoptosis during Fn14:Fc treatment. Therefore, apoptosis was determined in macrophages and foam cells in vitro after treatment with TWEAK. Since endogenous TWEAK might be affecting the baseline apoptosis under these culture conditions, the effects on apoptosis of various reagents that block TWEAK/Fn14 interactions, including Fn14:Fc, anti-Fn14 antibody, and anti-TWEAK antibody were determined. As 
A

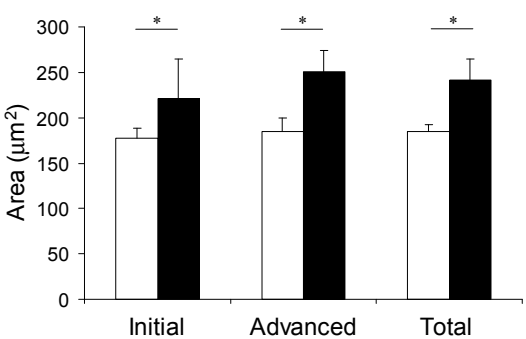

B

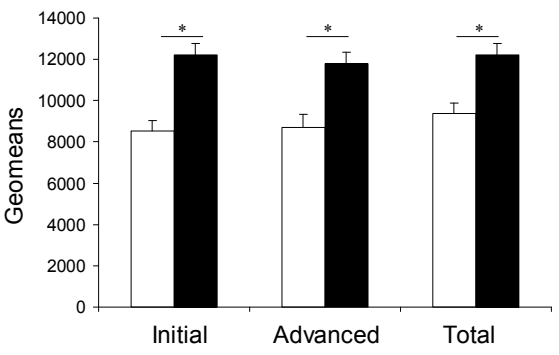

$\square$ Fn14:Fc $\quad$ Control

Figure 3. (A) Macrophages in initial and advanced plaques of Fn14:Fc-treated mice were smaller than in controls. Total refers to all macrophages regardless of whether present in initial or advanced plaques. (B) Bone marrow-derived macrophages treated with TWEAK-inhibiting reagents (Fn14:Fc, anti-Fn14 mAb, and anti-TWEAK mAb) took up less DiI-labeled oxLDL after 30 minutes of lipid loading compared with control antibody treatment. Black bars refer to TWEAK-inhibiting reagents and white bars refer to respective control antibodies. ${ }^{*} \mathrm{P}<0.05$.

A
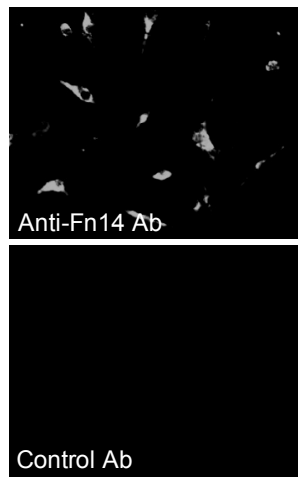
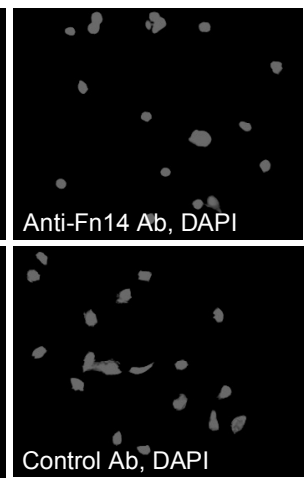

B

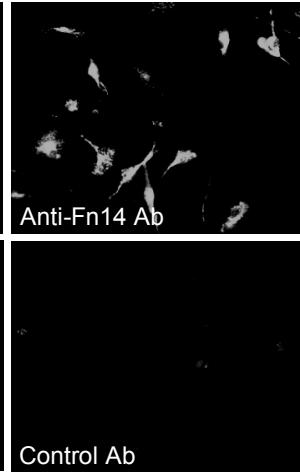

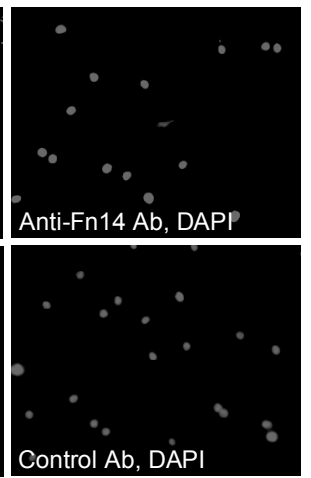

Figure 4. Fn14 is expressed on bone marrow-derived macrophages and foam cells as detected by immunohistochemistry using anti-Fn14 Ab. Fn14 is expressed on (A) macrophages and (B) foam cells treated with oxLDL for 48 hours. Nuclei were counterstained with DAPI. Control cells were stained with Ig isotype Ab. For full colour figure see page 143. 
shown in figure 5A, it was found that neither TWEAK nor TWEAK-blocking reagents had an effect on apoptosis of macrophages and foam cells. To further ascertain the effects of Fn14:Fc on macrophage apoptosis, TUNEL staining was performed in vivo on aortic arch sections containing atherosclerotic plaques. It was found that the number of TUNEL+ cells in Fn14:Fc-treated mice did not differ from those in control mice in neither the early nor delayed treatment groups as shown in figure 5B. These data suggest that TWEAK/Fn14 interactions do not mediate apoptosis of macrophage foam cells in murine atherosclerotic plaques.

A
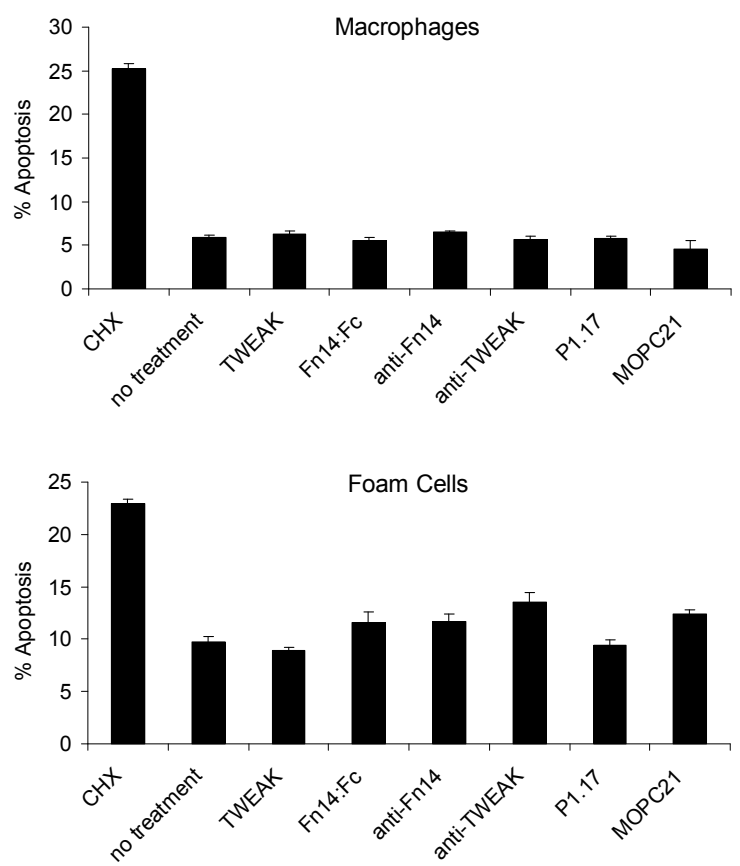

B

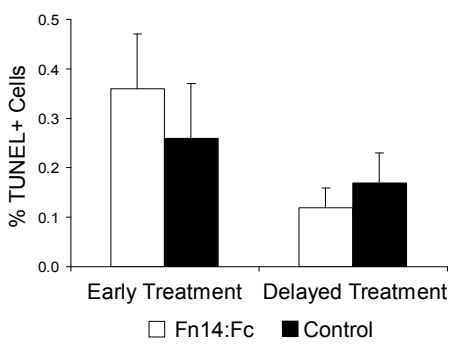

Figure 5. (A) There were no differences in macrophage or foam cell apoptosis between treatment with Fc-TWEAK and TWEAK-blocking reagents (Fn14:Fc, anti-Fn14 mAb, anti- TWEAK $\mathrm{mAb}$ ). CHX refers to positive control. (B) The number of TUNEL+ cells in Fn14:Fc-treated mice did not differ significantly from those in control mice in either of the early or delayed treatment groups. 


\section{Discussion}

TWEAK is a multifunctional cytokine involved in processes that are important in atherosclerosis such as cell proliferation, migration, apoptosis, angiogenesis, and the induction of inflammatory cytokines. In the present study we investigated the effects of blocking TWEAK/Fn14 interactions on lesion development and progression in a mouse model of atherosclerosis. Our novel findings reveal a role for TWEAK in atherosclerosis. TWEAK does not play a role in plaque initiation but regulates atherosclerosis at later stages as evidenced by smaller advanced plaques after early treatment with the TWEAK-blocking fusion protein, Fn14:Fc, and the reduced number of advanced plaques after delayed treatment with Fn14:Fc. TWEAK promotes fibrous plaques, as shown by reduced collagen content in advanced plaques with either early or delayed Fn14:Fc treatment. To our knowledge, this is the first demonstration that blocking TWEAK inhibits fibrosis. Treatment with Fn14:Fc also resulted in a unique macrophage-rich advanced plaque phenotype with delayed treatment. Not only were macrophages in lesions of mice treated with Fn14:Fc more abundant, they were smaller compared with those in lesions of control mice, and took up less modified lipids in vitro. Thus, TWEAK may be involved in regulating macrophage lipid metabolism.

We demonstrate that macrophages and foam cells express Fn14. TWEAK and Fn14 expression have previously been shown in atherosclerotic plaques, particularly in regions rich in macrophages and foam cells, ${ }^{15}$ and TWEAK stimulation of a human monocyte cell line induced the expression of pro-inflammatory mediators such as MMP-9, IL-6, IL-8, and MCP-1 suggesting that TWEAK plays a proatherogenic role in atherosclerosis. Treatment with TWEAK has also been shown to induce proliferation ${ }^{11}$ and migration of SMCs, an effect that was blocked by treatment with Fn14:Fc. ${ }^{19}$ In the present study we found a significantly reduced SMC content in lesions of Fn14:Fc-treated mice of the delayed treatment group suggesting that TWEAK/Fn14 interactions mediate SMC proliferation and migration in atherosclerosis. TWEAK-expressing macrophages may regulate SMC proliferation and migration via autocrine or paracrine-mediated signals since both cell types express the Fn14 receptor. Interestingly, high level expression of Fn14 has been associated with fibroblasts that are induced by mechanical stress to assume a proliferating and synthetic phenotype. ${ }^{20}$ Further investigations are warranted to determine whether TWEAK/Fn14 signaling also promotes collagen synthesis by SMCs.

Blocking the TWEAK/Fn14 pathway may have reduced apoptosis of macrophage foam cells in lesions resulting in their accumulation. TWEAK is known for its ability to induce apoptosis and, therefore, we investigated whether ApoE-/- bone marrow-derived macrophages would undergo apoptosis upon treatment with TWEAK or would be inhibited from undergoing apoptosis by treatment with TWEAK-blocking reagents. Interestingly, neither TWEAK nor TWEAK-blocking reagents had a significant effect on apoptosis in macrophages and foam cells in vi- 
tro. In addition, no differences in the number of apoptotic cells were observed in vivo between FN14:Fc-treated compared with control mice as revealed by TUNEL staining of aortic arch sections. It is also interesting to note that the size of necrotic cores did not differ between Fn14:Fc-treated mice and controls, since lipid core size is determined by the extent of macrophage cell death occurring in an atherosclerotic lesion. As plaques progress, macrophages continue to take up modified lipids until they undergo cell death and release their contents thereby contributing to the formation of a necrotic lipid core. In our mice, no differences in lipid cores sizes were found between Fn14:Fc-treated mice and controls, lending further support to the suggestion that macrophage apoptosis is not altered by blocking TWEAK/Fn14 interactions. Had TWEAK inhibition by Fn14:Fc treatment resulted in reduced apoptosis of macrophages, smaller lipid cores would be expected in lesions of Fn14:Fctreated mice, which was not the case. Taken together, these observations suggest that TWEAK does not mediate macrophage apoptosis in murine atherosclerotic lesions.

In the majority of studies that have reported TWEAK-mediated apoptosis, cell death occurred indirectly or required co-incubation with sensitization agents. ${ }^{21}$ TWEAK was shown to induce cell death in Kym-1 rhabdomyosarcoma cells indirectly via endogenous TNF. ${ }^{6}$ This was later confirmed by Nakayama et al. ${ }^{7}$ who further characterized mechanisms of TWEAK-induced cell death in various tumour cell lines and found that HT-29 colon carcinoma cells and KATO-III gastric adenocarcinoma cells are sensitive to TWEAK, but only in the presence of IFN $\gamma$. Direct induction of apoptosis by TWEAK only occurred in HSC3 oral squamous carcinoma cells. ${ }^{7}$ In addition, monocyte apoptosis in systemic lupus erythematosus was shown to occur via increased TWEAK expression in activated T cells. ${ }^{22}$ These findings indicate that TWEAK does possess proapoptotic activity, but its effects may be indirect and cell-type dependent. In the context of atherosclerosis, TWEAK does not appear to induce apoptosis in macrophages and foam cells.

Having ruled out the possibility of inhibiting macrophage apoptosis by Fn14:Fc treatment, the increased macrophage content observed in lesions of Fn14:Fc-treated mice, and in particular the smaller size of these cells, lead us to investigate the effects of TWEAK on lipid uptake by macrophages. Blocking the TWEAK/Fn14 pathway with the reagents Fn14:Fc, anti-Fn14 antibody, and anti-TWEAK antibody resulted in decreased oxLDL uptake compared with control antibody treatment. This suggests that TWEAK/Fn14 interactions modulate lipid uptake and/or efflux in macrophages. Since TWEAK/Fn14 interactions regulate innate immune responses in macrophages, including cytokine and chemokine production, we speculate that they may also regulate lipid uptake through expression of scavenger receptors. In addition, it is plausible that, as in the case of apoptosis, TWEAK regulation of lipoprotein metabolism may require stimulation with another mediator.

The advanced plaque phenotype induced by delayed treatment with the TWEAK-blocking agent is fairly unique. Like delayed treatment with Fn14:Fc, de- 
layed treatment with a TGF $\beta$ inhibitor resulted in less fibrous plaques with increased inflammatory cells compared with controls. ${ }^{17}$ However, in the case of TGF $\beta$ inhibition, the plaques exhibited an increased CD3+ cell content, as well as macrophage content, and larger lipid cores; macrophage size was not reported to be smaller and there was no difference in the number of $\alpha \mathrm{SMA}+$ cells. Thus, inhibition of TGF $\beta$ appears to increase plaque instability. Whether or not TWEAK may be a useful therapeutic target in atherosclerosis remains to be determined. Though TWEAK inhibition reduces the number of advanced AHA lesions, the consequences of a macrophage-rich plaque phenotype, albeit small macrophages with reduced lipid uptake, is unknown. Regardless, inhibition of fibrosis by TWEAK blockade in other disease contexts may be of therapeutic value.

In summary, we have demonstrated that TWEAK inhibition in ApoE-/- mice induces plaques with reduced SMC and collagen content. Thus, TWEAK may induce SMC proliferation and migration in atherosclerotic lesions. Amongst the advanced lesions, which are reduced in number by delayed Fn14:Fc as compared with control treatment, TWEAK inhibition also induces a macrophage-rich phenotype. TWEAK may regulate lipid metabolism in macrophages since Fn14:Fc treatment resulted in smaller macrophages in vivo and TWEAK-blocking reagents resulted in less lipid uptake by macrophages in vitro. Given these findings, TWEAK/Fn14 interactions play a role in atherosclerosis, however the mechanisms by which they exert their effects remain to be elucidated. 


\section{References}

1. Chicheportiche Y, Bourdon PR, Xu H, Hsu YM, Scott H, Hession C, et al. TWEAK, a new secreted ligand in the tumor necrosis factor family that weakly induces apoptosis. J Biol Chem. 1997;272:32401-32410.

2. Wiley SR, Cassiano L, Lofton T, Davis-Smith T, Winkles JA, Lindner V, et al. A novel TNF receptor family member binds TWEAK and is implicated in angiogenesis. Immunity. 2001;15:837-846.

3. Feng SL, Guo Y, Factor VM, Thorgeirsson SS, Bell DW, Testa JR, et al. The Fn14 immediate-early response gene is induced during liver regeneration and highly expressed in both human and murine hepatocellular carcinomas. Am J Pathol. 2000;156:1253-1261.

4. Meighan-Mantha RL, Hsu DK, Guo Y, Brown SA, Feng SL, Peifley KA, et al. The mitogeninducible Fn14 gene encodes a type I transmembrane protein that modulates fibroblast adhesion and migration. J Biol Chem. 1999;274:33166-33176.

5. Nakayama M, Kayagaki N, Yamaguchi N, Okumura K, Yagita H. Involvement of TWEAK in interferon gamma-stimulated monocyte cytotoxicity. J Exp Med. 2000;192:1373-1380.

6. Schneider P, Schwenzer R, Haas E, Muhlenbeck F, Schubert G, Scheurich P, et al. TWEAK can induce cell death via endogenous TNF and TNF receptor 1. Eur J Immunol. 1999;29:1785-1792.

7. Nakayama M, Ishidoh K, Kayagaki N, Kojima Y, Yamaguchi N, Nakano H, et al. Multiple pathways of TWEAK-induced cell death. J Immunol. 2002;168:734-743.

8. Nakayama M, Ishidoh K, Kojima Y, Harada N, Kominami E, Okumura K, et al. Fibroblast growth factor-inducible 14 mediates multiple pathways of TWEAK-induced cell death. J Immunol. 2003;170:341-348.

9. Saitoh T, Nakayama M, Nakano H, Yagita H, Yamamoto N, Yamaoka S. TWEAK induces NFkappaB2 p100 processing and long lasting NF-kappaB activation. J Biol Chem. 2003;278:3600536012.

10. Jakubowski A, Browning B, Lukashev M, Sizing I, Thompson JS, Benjamin CD, et al. Dual role for TWEAK in angiogenic regulation. J Cell Sci. 2002;115:267-274.

11. Lynch CN, Wang YC, Lund JK, Chen YW, Leal JA, Wiley SR. TWEAK induces angiogenesis and proliferation of endothelial cells. J Biol Chem. 1999;274:8455-8459.

12. Donohue PJ, Richards CM, Brown SA, Hanscom HN, Buschman J, Thangada S, et al. TWEAK is an endothelial cell growth and chemotactic factor that also potentiates FGF-2 and VEGF-A mitogenic activity. Arterioscler Thromb Vasc Biol. 2003;23:594-600.

13. Harada N, Nakayama M, Nakano H, Fukuchi Y, Yagita H, Okumura K. Pro-inflammatory effect of TWEAK/Fn14 interaction on human umbilical vein endothelial cells. Biochem Biophys Res Commun. 2002;299:488-493.

14. Campbell S, Burkly LC, Gao HX, Berman JW, Su L, Browning B, et al. Proinflammatory effects of TWEAK/Fn14 interactions in glomerular mesangial cells. J Immunol. 2006;176:1889-1898.

15. Kim SH, Kang YJ, Kim WJ, Woo DK, Lee Y, Kim DI, et al. TWEAK can induce pro-inflammatory cytokines and matrix metalloproteinase-9 in macrophages. Circ J. 2004;68:396-399.

16. Kalinina N, Agrotis A, Antropova Y, DiVitto G, Kanellakis P, Kostolias G, et al. Increased expression of the DNA-binding cytokine HMGB1 in human atherosclerotic lesions: role of activated macrophages and cytokines. Arterioscler Thromb Vasc Biol. 2004;24:2320-2325.

17. Lutgens E, Gijbels M, Smook M, Heeringa P, Gotwals P, Koteliansky VE, et al. Transforming growth factor-beta mediates balance between inflammation and fibrosis during plaque progression. Arterioscler Thromb Vasc Biol. 2002;22:975-982.

18. Schapira K, Lutgens E, de Fougerolles A, Sprague A, Roemen A, Gardner H, et al. Genetic deletion or antibody blockade of alpha1beta1 integrin induces a stable plaque phenotype in ApoE-/mice. Arterioscler Thromb Vasc Biol. 2005;25:1917-1924.

19. Han S, Yoon K, Lee K, Kim K, Jang H, Lee NK, et al. TNF-related weak inducer of apoptosis receptor, a TNF receptor superfamily member, activates NF-kappa B through TNF receptorassociated factors. Biochem Biophys Res Commun. 2003;305:789-796.

20. Kessler D, Dethlefsen S, Haase I, Plomann M, Hirche F, Krieg T, et al. Fibroblasts in mechanically stressed collagen lattices assume a "synthetic" phenotype. J Biol Chem. 2001;276:3657536585. 
21. Wiley SR, Winkles JA. TWEAK, a member of the TNF superfamily, is a multifunctional cytokine that binds the TweakR/Fn14 receptor. Cytokine Growth Factor Rev. 2003;14:241-249.

22. Kaplan MJ, Lewis EE, Shelden EA, Somers E, Pavlic R, McCune WJ, et al. The apoptotic ligands TRAIL, TWEAK, and Fas ligand mediate monocyte death induced by autologous lupus T cells. J Immunol. 2002;169:6020-6029. 


\section{CHAPTER 7}

\section{General discussion}
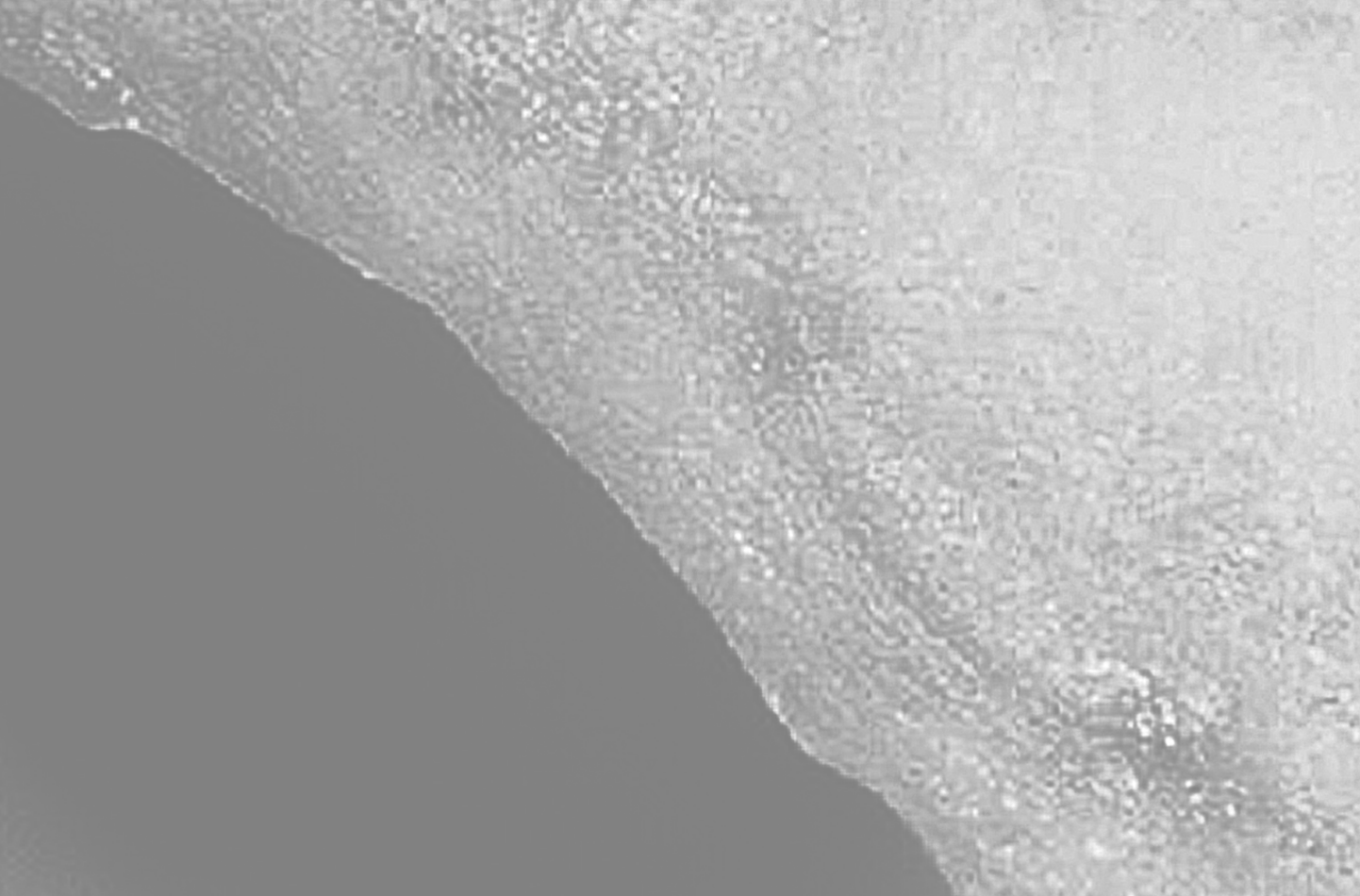

cisict 
In this thesis the role of several mediators involved in plaque development and progression in mouse models of atherosclerosis are described. Identification of mediators at various stages of atherosclerosis is key to gaining insight into the atherogenic process. Once mediators are identified, they can be manipulated in animal models of atherosclerosis such that their effects are inhibited or enhanced in order to demonstrate their specific role in the disease and/or evaluate their therapeutic potential.

We hypothesized that in a mouse model of atherosclerosis, the ApoE-/- mouse, the various stages of atherogenesis are accompanied by a specific expression pattern of genes. To test this hypothesis, microarray technology was used to analyze gene expression in the various stages of atherosclerosis in ApoE-/- mice (chapter 3). The gene expression profile during plaque progression revealed upregulation of genes involved in inflammation, namely the small inducible cytokines, as well as genes involved in protein and matrix degradation. These findings were validated by inhibiting the small inducible cytokines MCP-1 and MCP-5 in an early and delayed treatment setting and it was found that atherosclerotic lesions were attenuated and exhibited a stable phenotype.

Using a different approach to stabilize lesions, the effects of inhibiting neovascularization using angiogenesis inhibitors was determined in a collar-induced mouse model of atherosclerosis. It was found that atherosclerotic lesion size was reduced with early, but not delayed treatment with the angiogenesis inhibitors anginex and endostatin (chapter 4 ).

The role of a novel mediator not previously described in atherosclerosis, VLA-1, and a mediator gaining attention in the field of atherosclerosis, TWEAK, was investigated in apoE-/- mice in an early and delayed treatment setting. Inhibition of VLA1 by antibody blockade, and by complete genetic deletion in particular, attenuated atherosclerosis and induced stable lesions characterized by a reduced leukocyte content and increased ECM. In addition, a role for this integrin in the extravasation of leukocytes to lesions was revealed (chapter 5). Blocking the cytokine TWEAK resulted in lesions rich in macrophages and a reduced ECM content (chapter 6).

\section{Targeting Macrophages}

While the composition of human atherosclerotic plaques prone to thrombus formation is continually being defined (chapter 2), it has been established that inflammation is detrimental to atherosclerosis. Central to inflammatory processes occurring in atherosclerotic plaques are leukocytes. Monocyte-derived macrophages in particular play a prominent role throughout the life of a lesion, exerting proinflammatory effects at all stages of atherogenesis. ${ }^{1}$ In the present thesis we showed that treatment against the cytokines MCP-1 and MCP-5 and the integrin VLA-1 changed the composition of lesions to a more stable phenotype characterized by a 
reduced macrophage content. Inhibiting TWEAK/Fn14 interactions also altered plaque phenotype, notably the number of macrophages, which was increased. It is, therefore, apparent that intervention against diverse targets, whether they are chemokines, cytokines, or adhesion molecules, affects macrophage content in atherosclerotic lesions.

\section{Chemokines}

Indeed, given their significant role in atherosclerotic plaque development and progression, monocyte-derived macrophages are emerging as targets of therapeutic strategies and various approaches to suppress macrophage accumulation and function have been explored. ${ }^{2}$ Common targets in the initial stages of atherosclerosis are the proinflammatory chemokines. Well-described chemokines that are largely responsible for the recruitment of monocytes to the vessel wall are MCP-1 and RANTES. ${ }^{3}$ Inhibition of RANTES by administration of an antagonist to its receptor reduced macrophage infiltration, reduced the number of atherosclerotic lesions and induced a more stable plaque phenotype in ApoE-/- mice. ${ }^{4}$ A deficiency in MCP-15-7 or its receptor CCR-2, ${ }^{8}$ which is highly expressed on monocytes, ${ }^{9}$ has been shown to reduce the macrophage infiltrate thereby reducing atherosclerosis. In the present thesis we used a novel approach to target $\mathrm{MCP}-1$, which was to use an inhibiting antibody. Treatment with this antibody reduced the macrophage content in both early and advanced lesions and reduced the overall atherosclerotic burden.

\section{Adhesion Molecules}

Beyond monocyte recruitment to the vessel wall, options for intervention include inhibiting the adhesion of monocytes to the endothelium or their infiltration through the subendothelial basement membrane. Leukocyte adhesion and transmigration into tissue are mediated by integrins and members of the immunoglobulin superfamily. ${ }^{10}$ For instance, antibody blockade of vascular cell adhesion molecule-1 (VCAM-1), an immunoglobulin highly expressed on activated ECs that bind monocytes through the integrin VLA- $4,{ }^{11}$ was shown to attenuate atherosclerosis in ApoE/- mice by reducing the leukocyte infiltrate. ${ }^{12}{ }^{13}$ Similar effects were achieved by blocking VLA-4 in animal models of atherosclerosis. ${ }^{14,15}$

In this thesis, we showed that antibody blockade of VLA-1 integrin reduced the macrophage content in initial lesions. VLA- 1 binds collagen IV, which is abundantly present in the subendothelial basement membrane. ${ }^{16}$ Activated monocytes are known to express VLA-17 and we showed that macrophages in atherosclerotic plaques of ApoE-/- mice also express this integrin. Furthermore, we found that macrophages deficient in VLA-1 or treated with an anti- $\alpha 1$ antibody do not migrate 
on collagen IV. Given these findings we suggest that VLA-1 mediates the extravasation of monocyte-derived macrophages to atherosclerotic lesions. VLA-1 may, therefore, be considered among the various adhesion molecules that play a role in atherosclerosis as a novel potential therapeutic target.

\section{Angiogenesis}

Among the potential targets in the accumulation of macrophages, neovascularization has gained increasing attention. Neovascularization has been implicated in the progression of atherosclerosis by providing a pathway for leukocyte entry into lesions. ${ }^{18,19}$ Inhibition of neovascularization by endostatin treatment has been reported to reduce macrophage accumulation and reduce advanced atherosclerotic lesion progression in ApoE-/- mice. ${ }^{20}$ This is in contrast to our study in which we found a reduced size of initial, but not advanced, lesions in ApoE-/- mice upon treatment with the angiogenesis inhibitors endostatin and anginex, and this was not accompanied by a reduction in macrophage content. Our findings are also in contrast to the effects of anti-angiogenesis therapy in the treatment of cancer, particularly with respect to leukocyte infiltraton. Treatment with several anti-angiogenesis agents including endostatin, anginex and angiostatin has been shown to not only reduce microvessel density in tumours, but to increase the leukocyte infiltrate. ${ }^{21}$ There is an apparent discrepancy in the effects of endostatin and anginex treatment in cancer and atherosclerosis. Nevertheless, anginex, which has not previously been studied in atherosclerosis, appears to be as effective in reducing atherosclerosis progression as endostatin.

\section{Cytokines}

Instrumental to the progression of atherosclerosis are cytokines that have also been explored as potential targets of intervention. Cytokines differentially mediate atherogenesis in that some exert pro-inflammatory processes whereas others play an anti-inflammatory role. Among the cytokines that perpetuate inflammation in atherosclerosis, members of the TNF superfamily such as TNF $\alpha$ and CD40L are well described. Blocking CD40L in ApoE-/- mice by administration of an inhibiting antibody induced a stable plaque phenotype, which included a reduced macrophage content. $^{22}$ In this thesis we showed that blocking the cytokine TWEAK, a member of the TNF superfamily, increased macrophage accumulation in plaques of ApoE-/mice. These results along with those of a previous study in which it was shown that TWEAK and its receptor Fn14 are expressed in atherosclerotic lesions ${ }^{23}$ suggest a role for TWEAK/Fn14 interactions in atherosclerosis. 
However, these findings are too preliminary to consider TWEAK a potential therapeutic target in the treatment of atherosclerosis. Because TWEAK inhibition increased macrophage accumulation in plaques, it would be interesting to determine the effects of TWEAK overexpression and whether the number of macrophages would be reduced. Furthermore, recent studies suggest a pro-inflammatory role for TWEAK as it has been shown to induce the expression of inflammatory mediators such as MCP-1, IL-6, IL-8, and MMP-9.23 Because we observed an unfavourable plaque phenotype characterized by an increased macrophage content and decreased fibrosis upon TWEAK inhibition, it does not appear likely that inflammation was reduced. In addition, TWEAK inhibition resulted in smaller macrophages in vivo and a reduced lipid uptake by macrophages in vitro suggesting that TWEAK may mediate lipid metabolism. To lend further support to this possibility, the effects of TWEAK on lipid uptake and efflux, as well as on the expression of mediators involved in lipid metabolism would need to be determined.

Although additional studies are required to shed more light on the role of TWEAK in atherosclerosis before it can be considered a potential target of intervention, information thus far warrants further investigation. A recent study identified reduced levels of TWEAK in the plasma of atherosclerosis patients compared to healthy subjects and it was suggested that TWEAK may serve as a biomarker for subclinical atherosclerosis. ${ }^{24}$

\section{Targeting Atherosclerosis}

Atherosclerosis is a complex multifactorial disease, and as such, a multitude of mediators play a role that is not unique to atherosclerosis. This presents the challenge of developing therapies that target atherosclerotic lesions without affecting other organ systems and essential biological processes. None of the targets described in this thesis are specific to atherosclerosis. Both MCP- 1 and VLA- 1 mediate immune mechanisms, therefore inhibition of leukocyte recruitment, adhesion and/or migration should occur specifically in atherosclerotic lesions without the side-effect of general immunosuppression. Similarly, angiogenesis is essential to processes such as wound healing, therefore when inhibiting neovascularization it is important to target the intended vascular bed. However, as mentioned above, anti-angiogenesis therapy exerts opposite yet favourable effects in terms of leukocyte infiltration in tumours and atherosclerotic lesions. The increased leukocyte infiltration in tumours as a result of anti-angiogenesis agents is beneficial in the treatment of cancer, whereas the same treatment reduces macrophage infiltration in lesions, which is beneficial in the treatment of atherosclerosis. This suggests that targeting a particular mediator may not necessarily produce the same effect in different tissues. With respect to TWEAK, given that it is a multifunctional cytokine inducing various 
processes from cell proliferation to apoptosis, a large number of side effects could potentially arise from targeting this cytokine.

The quest for atherosclerosis-specific mediators is ongoing and the use of technologies such as microarrays has allowed for the identification of genes involved in atherogenesis. Techniques such as laser capture microdissection is being applied to isolate cells from atherosclerotic plaques to determine their unique atherosclerosisspecific gene expression profile as compared to the same cell types in other organ systems. Recently, the transcription factor TWIST1, not previously linked to atherosclerosis, was found to be highly expressed in macrophage foam cells microdissected from human atherosclerotic plaques compared to macrophages in nonatherosclerotic tissues such as spleen ${ }^{25}$ and is a potential atherosclerosis-specific target of intervention. Although it is unclear whether TWIST regulates atherosclerosis or is simply a marker of the disease, it has been shown that TWIST reduces the expression of proinflammatory cytokines by inhibiting NFKB activity, ${ }^{26}$ suppresses apoptosis, ${ }^{27}$ and induces cell migration and differentiation. ${ }^{28}$ Given that TWIST is upregulated in macrophage foam cells of atherosclerotic plaques and mediates processes important in atherosclerosis, this transcription factor is a promising atherosclerosis-specific target.

Until mediators specific to atherosclerosis are identified, local drug delivery in the treatment of atherosclerosis is ideal. Examples of local treatment modalities are percutaneous coronary intervention, drug-eluting stents and viral gene transfer to target specific cell types. ${ }^{3}$ A novel drug delivery system currently being explored is nanoparticle technology in which a therapeutic agent is conjugated with a carrier that specifically binds to the site of interest. Originally applied to imaging techniques, nanoparticles conjugated to the angiogenesis inhibitor fumagillin have been shown to reduce angiogenesis in atherosclerotic rabbits. ${ }^{29}$ However, currently applied therapies do not necessarily target atherosclerosis directly. Statins for instance are widely used as therapy for atherosclerosis and they exhibit pleiotropic effects. The clinical benefits of statin therapy were originally attributed to its lipid-lowering effects, however, a decade ago it was found that statins possess anti-inflammatory and anti-oxidant properties, decrease the propensity for thrombosis, reduce SMC proliferation and inhibit angiogenesis. ${ }^{30}$

\section{Atherosclerosis Prevention or Regression?}

Besides identifying and selecting mediators to target atherosclerosis, it is important to consider whether therapy should be aimed at the prevention or regression of the disease. In the present thesis, intervention studies in mice were performed in both early and delayed treatment settings to investigate whether treatment would prevent the development of atherosclerotic lesions or reduce the extent of pre-existing lesions, respectively. 
Because chemokines and adhesion molecules play a large role in early atherogenesis, inhibition of MCP-1 and VLA-1 would be expected to prevent lesion development. Microarray results revealed that MCP-1 is expressed throughout atherogenesis and inhibiting this chemokine reduced the size of initial and advanced lesions as well as induced a stable phenotype with both early and delayed treatment. This suggests that therapy against MCP-1 may be applied to prevent and regress atherosclerotic lesions.

Although complete genetic deletion of VLA-1 attenuated atherosclerosis at all stages, antibody inhibition was only able to induce a stable plaque phenotype. However, inhibition of VLA-1 did reduce the macrophage content of initial lesions, which is important given that VLA-1 is involved in the migration of macrophages through the subendothelial basement membrane. This suggests that VLA-1 may serve as a therapeutic target in atherosclerosis prevention.

With respect to angiogenesis, it is generally considered to occur in advanced stages of atherosclerosis, however, some studies revealed that neovascularization is also associated with early lesions. . $^{31,32}$ Neovascularization was shown in early carotid artery lesions of human subjects undergoing endarterectomy ${ }^{32}$ as well as in coronary arteries of pigs within the first weeks of experimental hypercholesterolemia. ${ }^{31}$ Using angiogenesis inhibitors, we found reduced lesion sizes with early treatment suggesting that anti-angiogenesis therapy may also be used against atherosclerotic lesion prevention.

Because TWEAK inhibition produced an unfavourable phenotype rich in macrophages and a reduced fibrotic content, it is unclear whether targeting this cytokine should be aimed at atherosclerosis prevention or regression. The role of TWEAK in atherosclerosis would need to be further elucidated such as by determining the effects of TWEAK overexpression.

Of the treatments that had a positive effect on atherosclerosis (inhibition of MCP-1 and VLA-1; anginex and endostatin treatment), none prevented the development of atherosclerotic lesions. At best, lesion sizes were reduced and acquired a more stable phenotype. It appears that atherogenesis is inevitable regardless of the treatment and that the aim of potential therapeutic strategies should be to prevent the progression of atherosclerosis and/or stabilize lesions. The only currently effective therapeutic strategy to prevent atherosclerosis appears to be nonpharmacological intervention such as diet and exercise. ${ }^{33}$ Because atherosclerosis develops silently over a long period of time before it is clinically manifest, most treatment options focus on lesion regression, and some therapeutic strategies have shown promising results. For instance, because HDL is inversely associated with cardiovascular disease as it mediates reverse cholesterol transport, increasing HDL levels by manipulating its metabolism is gaining attention as potential therapy in atherosclerosis. ${ }^{34,35}$ Upon administration of ApoA-I, a major protein component of HDL, plaque resorption and significantly reduced atheromas were shown in animal models of atherosclerosis. ${ }^{36-38}$ Currently, clinical trials are being conducted to test the 
therapeutic potential of ApoA-I peptide mimetics in the treatment of atherosclerosis patients. ${ }^{39}$ Statin therapy has also been shown to regress atherosclerotic lesions, which was attributed to its HDL-elevating properties..$^{40}$

\section{Concluding Remarks}

While mouse models of atherosclerosis do not reflect the human condition in its entirety, they are invaluable tools in intervention studies in which regulators of atherosclerosis and potential therapies can be studied. In the present thesis we investigated the role of several mediators of atherosclerosis in mouse models. The chemokine MCP-1, known to play a central role in the recruitment of leukocytes to lesions, was found to be expressed throughout all stages of atherogenesis in ApoE-/mice. Inhibiting this chemokine reduced atherosclerosis and stabilized lesions. Deficiency of the integrin VLA-1, a novel mediator not previously linked to atherosclerosis, attenuated lesions and induced a stable plaque phenotype. Antibody inhibition of VLA-1 produced similar results, particularly with respect to lesion stabilization, confirming this integrin to be a potential therapeutic target. VLA- 1 was further found to mediate the migration of monocyte-derived macrophages to lesions by adhesion to collagen IV, which is highly expressed in the subendothelial basement membrane. The process of angiogenesis, which is involved in the progression of atherosclerosis, was targeted by administration of angiogenesis inhibitors in ApoE/- mice and it was found that the size of initial atherosclerotic lesions was reduced. Inhibition of the multifunctional cytokine TWEAK, previously shown to be expressed in human atherosclerotic lesions, induced a macrophage-rich plaque phenotype and reduced fibrosis.

The mechanism of action of VLA-1 and TWEAK would need to be further elucidated, as well as investigated in human atherosclerosis, however, our intervention studies in mice reveal that these mediators, along with MCP-1 and angiogenesis, play a role in atherosclerosis. As such, they may be considered potential therapeutic targets. Despite having an affect on the content of macrophages - the very cells that play a central role in atherosclerotic lesions - these targets are not specific to atherosclerosis. Therapeutic targeting of these mediators would have to be applied locally in lesions in order to prevent adverse side effects. On the other hand, the pleiotropic effects of statins suggest that drug efficacy in atherosclerosis may not be related to target and/or lesion specificity. 


\section{References}

1. Takahashi K, Takeya M, Sakashita N. Multifunctional roles of macrophages in the development and progression of atherosclerosis in humans and experimental animals. Med Electron Microsc. 2002;35:179-203.

2. Choudhury RP, Lee JM, Greaves DR. Mechanisms of disease: macrophage-derived foam cells emerging as therapeutic targets in atherosclerosis. Nat Clin Pract Cardiovasc Med. 2005;2:309-315.

3. Braunersreuther V, Mach F. Leukocyte recruitment in atherosclerosis: potential targets for therapeutic approaches? Cell Mol Life Sci. 2006;63:2079-2088.

4. Veillard NR, Kwak B, Pelli G, Mulhaupt F, James RW, Proudfoot AE, et al. Antagonism of RANTES receptors reduces atherosclerotic plaque formation in mice. Circ Res. 2004;94:253-261.

5. Ni W, Egashira K, Kitamoto S, Kataoka C, Koyanagi M, Inoue S, et al. New anti-monocyte chemoattractant protein-1 gene therapy attenuates atherosclerosis in apolipoprotein E-knockout mice. Circulation. 2001;103:2096-2101.

6. Inoue S, Egashira K, Ni W, Kitamoto S, Usui M, Otani K, et al. Anti-monocyte chemoattractant protein-1 gene therapy limits progression and destabilization of established atherosclerosis in apolipoprotein E-knockout mice. Circulation. 2002;106:2700-2706.

7. Gu L, Okada Y, Clinton SK, Gerard C, Sukhova GK, Libby P, et al. Absence of monocyte chemoattractant protein-1 reduces atherosclerosis in low density lipoprotein receptor-deficient mice. Mol Cell. 1998;2:275-281.

8. Boring L, Gosling J, Cleary M, Charo IF. Decreased lesion formation in CCR2-/- mice reveals a role for chemokines in the initiation of atherosclerosis. Nature. 1998;394:894-897.

9. Phillips RJ, Lutz M, Premack B. Differential signaling mechanisms regulate expression of CC chemokine receptor-2 during monocyte maturation. J Inflamm (Lond). 2005;2:14.

10. Blankenberg S, Barbaux S, Tiret L. Adhesion molecules and atherosclerosis. Atherosclerosis. 2003;170:191-203.

11. Elices MJ, Osborn L, Takada Y, Crouse C, Luhowskyj S, Hemler ME, et al. VCAM-1 on activated endothelium interacts with the leukocyte integrin VLA-4 at a site distinct from the VLA4/fibronectin binding site. Cell. 1990;60:577-584.

12. Oguchi S, Dimayuga P, Zhu J, Chyu KY, Yano J, Shah PK, et al. Monoclonal antibody against vascular cell adhesion molecule-1 inhibits neointimal formation after periadventitial carotid artery injury in genetically hypercholesterolemic mice. Arterioscler Thromb Vasc Biol. 2000;20:17291736.

13. Barringhaus KG, Phillips JW, Thatte JS, Sanders JM, Czarnik AC, Bennett DK, et al. alpha(4)beta(1) Integrin (VLA-4) Blockade Attenuates both Early and Late Leukocyte Recruitment and Neointimal Growth following Carotid Injury in Apolipoprotein E (-/-) Mice. J Vasc Res. 2004;41:252-260.

14. Lumsden AB, Chen C, Hughes JD, Kelly AB, Hanson SR, Harker LA. Anti-VLA-4 antibody reduces intimal hyperplasia in the endarterectomized carotid artery in nonhuman primates. $J$ Vasc Surg. 1997;26:87-93.

15. Shih PT, Brennan ML, Vora DK, Territo MC, Strahl D, Elices MJ, et al. Blocking very late antigen-4 integrin decreases leukocyte entry and fatty streak formation in mice fed an atherogenic diet. Circ Res. 1999;84:345-351.

16. Bank I, Koltakov A, Goldstein I, Chess L. Lymphocytes expressing alpha1beta1 integrin (very late antigen-1) in peripheral blood of patients with arthritis are a subset of CD45RO(+) T-cells primed for rapid adhesion to collagen IV. Clin Immunol. 2002;105:247-258.

17. Rubio MA, Sotillos M, Jochems G, Alvarez V, Corbi AL. Monocyte activation: rapid induction of alpha 1/beta 1 (VLA-1) integrin expression by lipopolysaccharide and interferon-gamma. Eur J Immunol. 1995;25:2701-2705.

18. O'Brien KD, McDonald TO, Chait A, Allen MD, Alpers CE. Neovascular expression of Eselectin, intercellular adhesion molecule-1, and vascular cell adhesion molecule-1 in human atherosclerosis and their relation to intimal leukocyte content. Circulation. 1996;93:672-682. 
19. Moreno PR, Purushothaman KR, Fuster V, Echeverri D, Truszczynska H, Sharma SK, et al. Plaque neovascularization is increased in ruptured atherosclerotic lesions of human aorta: implications for plaque vulnerability. Circulation. 2004;110:2032-2038.

20. Moulton KS, Vakili K, Zurakowski D, Soliman M, Butterfield C, Sylvin E, et al. Inhibition of plaque neovascularization reduces macrophage accumulation and progression of advanced atherosclerosis. Proc Natl Acad Sci U S A. 2003;100:4736-4741.

21. Dirkx AE, oude Egbrink MG, Castermans K, van der Schaft DW, Thijssen VL, Dings RP, et al. Anti-angiogenesis therapy can overcome endothelial cell anergy and promote leukocyteendothelium interactions and infiltration in tumors. FASEB J. 2006;20:621-630.

22. Lutgens E, Cleutjens KB, Heeneman S, Koteliansky VE, Burkly LC, Daemen MJ. Both early and delayed anti-CD40L antibody treatment induces a stable plaque phenotype. Proc Natl Acad Sci U $S$ A. 2000;97:7464-7469.

23. Kim SH, Kang YJ, Kim WJ, Woo DK, Lee Y, Kim DI, et al. TWEAK can induce pro-inflammatory cytokines and matrix metalloproteinase-9 in macrophages. Circ J. 2004;68:396-399.

24. Blanco-Colio LM, Martin-Ventura JL, Munoz-Garcia B, Orbe J, Paramo JA, Michel JB, et al. Identification of Soluble Tumor Necrosis Factor-Like Weak Inducer of Apoptosis (sTWEAK) as a Possible Biomarker of Subclinical Atherosclerosis. Arterioscler Thromb Vasc Biol. 2007.

25. Jamnongluk W, Kisters N, Cleutjens K, Ofledderus J, Volger OL, Daemen MJ, et al. The transcription factor TWIST1 is specifically expressed in macrophage-derived foam cells. Circulation Abstract Supplement. 2006;114.

26. Sosic D, Richardson JA, Yu K, Ornitz DM, Olson EN. Twist regulates cytokine gene expression through a negative feedback loop that represses NF-kappaB activity. Cell. 2003;112:169-180.

27. Maestro R, Dei Tos AP, Hamamori Y, Krasnokutsky S, Sartorelli V, Kedes L, et al. Twist is a potential oncogene that inhibits apoptosis. Genes Dev. 1999;13:2207-2217.

28. Yang J, Mani SA, Donaher JL, Ramaswamy S, Itzykson RA, Come C, et al. Twist, a master regulator of morphogenesis, plays an essential role in tumor metastasis. Cell. 2004;117:927-939.

29. Winter PM, Neubauer AM, Caruthers SD, Harris TD, Robertson JD, Williams TA, et al. Endothelial alpha(v)beta3 integrin-targeted fumagillin nanoparticles inhibit angiogenesis in atherosclerosis. Arterioscler Thromb Vasc Biol. 2006;26:2103-2109.

30. Almuti K, Rimawi R, Spevack D, Ostfeld RJ. Effects of statins beyond lipid lowering: potential for clinical benefits. Int J Cardiol. 2006;109:7-15.

31. Herrmann J, Lerman LO, Rodriguez-Porcel M, Holmes DR, Jr., Richardson DM, Ritman EL, et al. Coronary vasa vasorum neovascularization precedes epicardial endothelial dysfunction in experimental hypercholesterolemia. Cardiovasc Res. 2001;51:762-766.

32. Jeziorska M, Woolley DE. Neovascularization in early atherosclerotic lesions of human carotid arteries: its potential contribution to plaque development. Hum Pathol. 1999;30:919-925.

33. Gattone M, Giannuzzi P. Interventional strategies in early atherosclerosis. Monaldi Arch Chest Dis. 2006;66:54-62.

34. Cuchel M, Rader DJ. Macrophage reverse cholesterol transport: key to the regression of atherosclerosis? Circulation. 2006;113:2548-2555.

35. Kawashiri MA, Maugeais C, Rader DJ. High-density lipoprotein metabolism: molecular targets for new therapies for atherosclerosis. Curr Atheroscler Rep. 2000;2:363-372.

36. Tangirala RK, Tsukamoto K, Chun SH, Usher D, Pure E, Rader DJ. Regression of atherosclerosis induced by liver-directed gene transfer of apolipoprotein A-I in mice. Circulation. 1999;100:18161822.

37. Navab M, Anantharamaiah GM, Hama S, Garber DW, Chaddha M, Hough G, et al. Oral administration of an Apo A-I mimetic Peptide synthesized from D-amino acids dramatically reduces atherosclerosis in mice independent of plasma cholesterol. Circulation. 2002;105:290-292.

38. Valenta DT, Ogier N, Bradshaw G, Black AS, Bonnet DJ, Lagrost L, et al. Atheroprotective potential of macrophage-derived phospholipid transfer protein in low-density lipoprotein receptor-deficient mice is overcome by apolipoprotein AI overexpression. Arterioscler Thromb Vasc Biol. 2006;26:1572-1578.

39. Navab M, Anantharamaiah GM, Reddy ST, Fogelman AM. Apolipoprotein A-I mimetic peptides and their role in atherosclerosis prevention. Nat Clin Pract Cardiovasc Med. 2006;3:540-547. 
40. Nicholls SJ, Tuzcu EM, Sipahi I, Grasso AW, Schoenhagen P, Hu T, et al. Statins, high-density lipoprotein cholesterol, and regression of coronary atherosclerosis. JAMA. 2007;297:499-508.

41. Cullen P, Baetta R, Bellosta S, Bernini F, Chinetti G, Cignarella A, et al. Rupture of the atherosclerotic plaque: does a good animal model exist? Arterioscler Thromb Vasc Biol. 2003;23:535-542.

42. Faber BC, Cleutjens KB, Niessen RL, Aarts PL, Boon W, Greenberg AS, et al. Identification of genes potentially involved in rupture of human atherosclerotic plaques. Circ Res. 2001;89:547554. 


\section{Summary}

Atherosclerosis continues to be the leading cause of illness and death in western society. It is a progressive inflammatory disease of the large and medium-sized arteries in which lipids, cells, and extracellular matrix accumulate in the inner lining of the vessel wall leading to the formation of an atherosclerotic plaque. Plaque progression may cause arterial stenosis, however clinical complications such as myocardial infarction or stroke mostly occur as a result of plaque rupture and subsequent thrombus formation. Although the exact triggers of plaque rupture and thrombosis are unknown, it is thought that the composition of an atherosclerotic plaque is important to its stability: the more stable, the less likely it is to disrupt. Stable plaques are generally considered to be fibrotic, have a low inflammatory infiltrate, and a small necrotic lipid core.

In this thesis, key players in atherosclerotic development and progression were identified and investigated in mouse models to gain further insight into the pathogenesis of atherosclerosis as well as to determine their therapeutic potential in the stabilization of plaques. The primary hypothesis was that the various stages of atherogenesis in the ApoE-/- mouse model exhibit a unique expression pattern of genes. Once key regulators were identified, they were validated in ApoE-/- mice to determine their effects on atherosclerotic plaque composition and stability.

The various animal models used to study plaque stability or vulnerability are described in chapter 2. The definition of a vulnerable plaque prone to rupture and thrombus formation is highly disputed as the characteristic composition of such plaques is unclear. The current concepts and generally accepted features of vulnerable plaques that are thought to contribute to clinical complications are described. Studies that have reported vulnerable plaque characteristics such as plaque rupture and thrombosis in animal models of atherosclerosis are summarized and evaluated based on their ability to represent the human condition. Although animal models are invaluable in elucidating the mechanisms of atherogenesis, their use in studying vulnerable plaques remains limited as there is currently no standard animal model of plaque rupture.

In chapter 3, the gene expression profile of the various stages of atherosclerosis in ApoE-/- mice as determined by microarray analysis is described. The gene expression profile during plaque progression revealed upregulation of genes involved in inflammation, such as the small inducible cytokines MCP-1 and MCP-5, as well as genes involved in matrix degradation. MCP-1 in particular is a well-known chemokine that mediates the migration of monocytes to inflamed tissue and is 
known to promote atherosclerotic plaque progression. The role of MCP-1 and MCP5 was validated using a novel monoclonal antibody against these cytokines, which was found to attenuate atherogenesis and induce plaque stability in ApoE-/- mice. More specifically, antibody treatment resulted in smaller atherosclerotic plaques with a reduced macrophage and $\mathrm{T}$ cell content, and increased fibrosis as characterized by a reduced collagen and SMC content. Given the positive effects of blocking MCP-1 on atherosclerotic lesion development and progression, this chemokine may be a potential therapeutic target in the treatment of atherosclerosis.

Angiogenesis has been implicated in the development and progression of atherosclerotic plaques and is thought to contribute to their destabilization. In chapter 4, preliminary studies are described in which the role of angiogenesis was investigated in atherogenesis using a collar-induced model of atherosclerosis in ApoE-/mice. Mice were treated with the angiogenesis inhibitors anginex or endostatin, both of which were found to reduce the development of initial atherosclerotic lesions, whereas no effects were found on advanced lesions. Histological analysis revealed that plaque phenotype was not affected by anginex or endostatin treatment, and neovascularization was not observed in lesions. Treatment with anginex or endostatin appears to reduce early, but not advanced lesions in collar-induced atherosclerotic plaques of ApoE-/- mice, partly via an angiogenesis-independent manner.

Among the factors involved in atherosclerotic plaque stability, adhesive interactions between cells and extracellular matrix components play an important role. Chapter 5 focuses on the collagen-binding integrin $\alpha 1 \beta 1$ or VLA-1, which was either genetically deleted or inhibited using an $\alpha 1$-blocking antibody in ApoE-/- mice. Mice deficient in this integrin in particular, as well as those receiving antibody treatment exhibited stable plaques characterized by an increased collagen content and a reduced macrophage infiltrate. Further investigation revealed that VLA-1 integrin is expressed on macrophages and binds to collagen IV - a type of collagen abundantly expressed in the basement membrane of the vessel wall through which leukocytes must migrate to enter atherosclerotic plaques. Macrophages deficient in $\alpha 1$ integrin are inhibited from migrating on collagen IV substrata, which suggests that this integrin mediates the migration of macrophages to lesions. This study indicates a role for VLA-1 in atherosclerosis and inhibiting this integrin may be considered an approach in the treatment of atherosclerosis.

Investigation of the role of a recently discovered cytokine, TWEAK, in atherosclerosis is described in chapter 6. TWEAK is a multifunctional cytokine that mediates various processes important in atherosclerosis such as cell proliferation, migration, apoptosis, and neovascularization, and has recently been identified along with its receptor, Fn14, in atherosclerotic plaques. Treatment of ApoE-/- mice with a TWEAK-blocking fusion protein, Fn14:Fc, resulted in a macrophage-rich advanced plaque phenotype and reduced fibrosis. In addition, macrophages treated with reagents that block TWEAK/Fn14 interactions were found to take up less modified 
lipids. These data suggest that TWEAK plays a role in atherosclerosis that may involve lipid metabolism in macrophages.

In chapter 7 , the findings of this thesis are discussed. Because atherosclerosis is a complex, multifactorial disease, the various processes and regulators that may potentially be targeted in the treatment of atherosclerosis are considered. Macrophage content in particular is often affected in atherosclerotic plaques by intervention studies whether they target chemokines, cytokines, or adhesion molecules. The mediators investigated in this thesis are evaluated based on their potential as therapeutic targets. Based on the findings in this thesis, we conclude that MCP-1 is the most promising therapeutic target as its role has been well-documented in the field of atherosclerosis, and blocking this chemokine as reported in the present thesis resulted in a stable plaque phenotype. Given that a deficiency in or blocking of VLA-1 also resulted in a more stable plaque phenotype, this integrin may be considered a potential target, however, the mechanism of action of this integrin in atherosclerosis would need to be further elucidated. Although the role of TWEAK and the process of angiogenesis in atherosclerosis are as yet unclear, the findings in this thesis suggest a role for these mediators in atherosclerosis that warrants further investigation. 
124 


\section{Samenvatting}

Atherosclerose is de belangrijkste doodsoorzaak in de westerse samenleving. Het is een progressieve inflammatoire ziekte van de grote slagaders waarbij lipiden, cellen en extracellulaire matrix in de vaatwand ophopen en uiteindelijk leidt tot de vorming van een atherosclerotische plaque. De progressie van een plaque kan stenose van het vat veroorzaken, echter clinische complicaties zoals hart- en herseninfarcten onstaan meestal door het openscheuren van een plaque (plaque ruptuur) en de hierop volgende vorming van een bloedstolsel (thrombose). Alhoewel de precieze aanleiding voor de ruptuur van een plaque niet bekend is, denkt men dat de samenstelling van een atherosclerotische plaque een belangrijke factor is in het wel of niet ruptureren van een plaque. Over het algemeen wordt aangenomen dat een plaque die weinig kans heeft op ruptuur (ook wel genoemd een stabiele plaque) een dikke overliggende bindweefsel laag heeft, een kleine kern van weefsel-debris (necrotische kern) en weinig ontsteking. Een plaque die een hoog risico heeft op ruptureren heeft een dunne overliggende bindweefsellaag, veel ontsteking en een grote necrotische kern.

In dit proefschrift zijn een aantal belangrijke regulerende processen in de ontwikkeling en progressie van atherosclerotische plaques nader onderzocht in muizenmodellen. Dit is gedaan om meer inzicht te krijgen in de mechanismen die ten grondslag liggen aan ontstaan en ontwikkeling van atherosclerotische plaques. Ook is gekeken of door het ingrijpen in deze regulerende processen een mogelijke behandeling bewerkstelligd kon worden. Nadat de belangrijkste regulerende processen waren vastgesteld, is in een serie experimenten onderzocht in hoeverre door in te grijpen in deze processen de samenstelling van atherosclerotische plaques of te wel de plaque stabiliteit beinvloed kon worden.

De verschillende muizenmodellen die gebruikt worden voor het bestuderen van plaque stabiliteit zijn in hoofdstuk 2 beschreven. De definitie van een ruptuurgevoelige oftewel instabiele plaque met hoge kans tot ruptuur en thrombusvorming is onderwerp van discussie, omdat de precieze samenstelling en eigenschappen van deze plaques niet bekend zijn. De huidige gedachten en in het algemeen geaccepteerde kenmerken van een instabiele plaque waarvan men denkt dat die leiden tot clinische complicaties zoals hart en herseninfarcten worden beschreven. Ook worden studies waarin melding werd gemaakt van plaque ruptuur en thrombose in muizenmodellen voor atherosclerose samengevat en geëvalueerd op hun bruikbaarheid als voorspeller voor de humane situatie. Alhoewel dierenmodellen van onschatbare waarde zijn voor het onderzoeken van de onderliggende mechanismen 
van atherosclerose, is de toepasbaarheid voor het bestuderen van instabiele plaques beperkt, omdat er op dit moment geen gestandaardiseerd diermodel van instabiele plaques bestaat.

In hoofdstuk 3, werd tijdens de verschillende stadia van atherosclerose veranderingen in gen-expressie van de atherosclerotische vaten van Apolipoprotein E knockout muizen (ApoE-/-) bepaald. Dit profiel werd bepaald door het gebruik van microarray. Veranderingen in het genexpressieprofiel tijdens plaque progressie liet zin dat genen die te maken hebben met inflammatie verhoogd tot expressie kwamen. Opvallend hierin waren de bepaalde ontstekingsmediatoren ("small inducible cytokines" MCP-1 en MCP-5), en ook genen betrokken bij afbraak van het bindweefsel (de extracellulaire matrix). Met name het bekende chemokine MCP-1 is een regulator in het proces van transport van bepaalde ontstekingscellen (monocyten) naar ontstoken weefsels en dit zou zo de ontwikkeling van atherosclerotische plaques kunnen bevorderen. De rol van MCP-1 en MCP-5 in de ontwikkeling van plaques in een muizenmodel is bevestigd door gebruik van een antilichaam tegen MCP-1/5. Dit antilichaan blokkeert de werking van MCP-1/5. In het muizenmodel verminderde het antilichaam de ontwikkeling en progressie van plaques en zorgde voor stabielere plaques met minder ontstekingscellen en meer bindweefsel. Gezien de positieve aspecten van het blokkeren van MCP-1, is deze chemokine een potentieel therapie-doel in de behandeling van atherosclerose.

Angiogenese is het proces waarbij nieuwe, kleine bloedvaten worden gevormd, die groeiend/actief weefsel voorzien van zuurstof en voedingsstoffen. Angiogenese wordt gezien als en mogelijk bijdrage aan de ontwikkeling and progressie van atherosclerotische plaques en men denkt dat het bijdraagt aan het minder stabiel worden van de plaque. In hoofdstuk 4, werden preliminaire studies beschreven naar de rol van angiogenese in atherosclerose. Met gebruik van ApoE-/- muizen werd de ontwikkeling van atherosclerotische plaques versneld door een plastic buisje (collar) om beide carotiden te plaatsen. De muizen werden vervolgens behandeld met 2 angiogeneseremmers (anginex en endostatin). Beide remmers bleken de ontwikkeling van vroege plaques te verminderen, maar er waren geen effecten te zien als de behandeling werd gestart als vergevorderde plaques zich al gevormd hadden. Histologische analyse toonde aan dat het samenstelling van de plaque (qua ontsteking en bindweefsel) niet was veranderd door behandeling met anginex of endostatin. Ook kon er geen vorming van nieuwe bloedvaatjes in de plaque aangetoond worden. Behandeling met anginex of endostatin in collar-geïnduceerde ApoE-/- muizen blijkt vroege plaques te reduceren in grootte, maar heeft geen effect op vergevorderde plaques. Dit lijkt te gebeuren op een wijze die onafhankelijk is van angiogenese.

Een van de relevante factoren voor de stabiliteit van atherosclerotiche plaques is de adhesie tussen cellen en componenten van de extracellulaire matrix. Integrines zijn structuren op cellen die ervoor zorgen dat cellen in weefsels verbinding met elkaar houden. Hoofdstuk 5 richt zich op integrine $\alpha 1 \beta 1$ (ook bekend als VLA-1) dat 
zich bindt aan collageen. Dit integrine werd genetisch uitgeschakeld dan wel geremd door het toedienen van een $\alpha 1$-blokkerende antilichaam in ApoE-/- muizen. Zowel in muizen die deficient waren voor dit integrine als in muizen die behandeld waren met het antilichaam werden stabielere plaques aangetoond met een verhoogde hoeveelheid collageen (bindweefsel) en verminderd aantal macrofagen. Verder werd aangetoond dat VLA-1 aanwezig is op macrofagen en zich bindt aan collageen IV. Collageen IV is een belangrijke bestanddeel van de vaatwand en een barriere die monocyten moeten overbruggen om atherosclerotische plaques binnen te kunnen komen. Macrofagen die deficient zijn voor $\alpha 1$-integrin kunnen zich niet voortbewegen op een ondergrond van collageen IV, wat suggereert dat dit integrine een rol speelt in de voortbeweging van macrofagen in en naar plaques. Deze studie laat zien dat VLA-1 een rol speelt in atherosclerose en de inhibitie ervan zou een strategie kunnen zijn om atherosclerose te behandelen.

De rol van het recent ontdekte ontstekingsmediator of cytokine TWEAK in atherosclerose is beschreven in hoofdstuk 6. TWEAK is een multifunctioneel cytokine die een rol speelt in meerdere processen die belangrijk zijn in atherosclerose, zoals celdeling, voortbeweging van cellen, celdood en het vormen van nieuwe vaatjes. Bovendien werd TWEAK en zijn receptor Fn14 onlangs aangetoond in menselijke atherosclerotische plaques. Behandeling van ApoE-/- muizen met een eiwit dat TWEAK remt (Fn14:Fc) resulteerde in vergevorderde plaques die rijk waren aan macrofagen en weinig bindweefsel hadden. Verder was er minder vet opgenomen door macrofagen die behandeld waren met stoffen die de interactie tussen TWEAK en Fn14 blokkeren. Deze data suggereren dat de manier waarop TWEAK een rol speelt in atherosclerose te maken heeft met het vet metabolisme in macrofagen.

De bevindingen in dit proefschrift werden in hoofdstuk 7 bediscussiëerd. Omdat atherosclerose een complexe ziekte is, zijn de verschillende processen en regulatoren overwogen die mogelijk een aangrijpingspunt kunnen zijn in het behandelen van atherosclerose. De hoeveelheid macrofagen in atherosclerotische plaques kan beïnvloed worden door in te grijpen in processen waarbij ontstekingsmediatoren en matrix-cel interacties betrokken zijn. De mediatoren bestudeerd in dit proefschrift werden geëvalueerd op basis van hun mogelijke therapeutische waarde. Gebaseerd op de bevindingen in dit proefschrift, concluderen we dat MCP-1 het meest veelbelovende aangrijpingspunt is, omdat de rol van deze chemokine goed bekend is in atherosclerose, en blokkeren ervan zoals beschreven in dit proefschrift resulteerde in stabielere plaques. VLA-1 kan ook een mogelijk aangrijpingspunt zijn in het behandelen van atherosclerose, omdat een deficiëntie of het blokkeren van deze integrine tot stabielere plaques leidde, hoewel het mechanisme van dit proces in atherosclerose verder onderzocht moet worden. Alhoewel zowel de rol van TWEAK als het proces van angiogenese in atherosclerose tot nu toe nog niet duidelijk zijn, suggereren de bevindingen in dit proefschrift een rol voor deze mediatoren in atherosclerose. 


\section{Full colour figures}
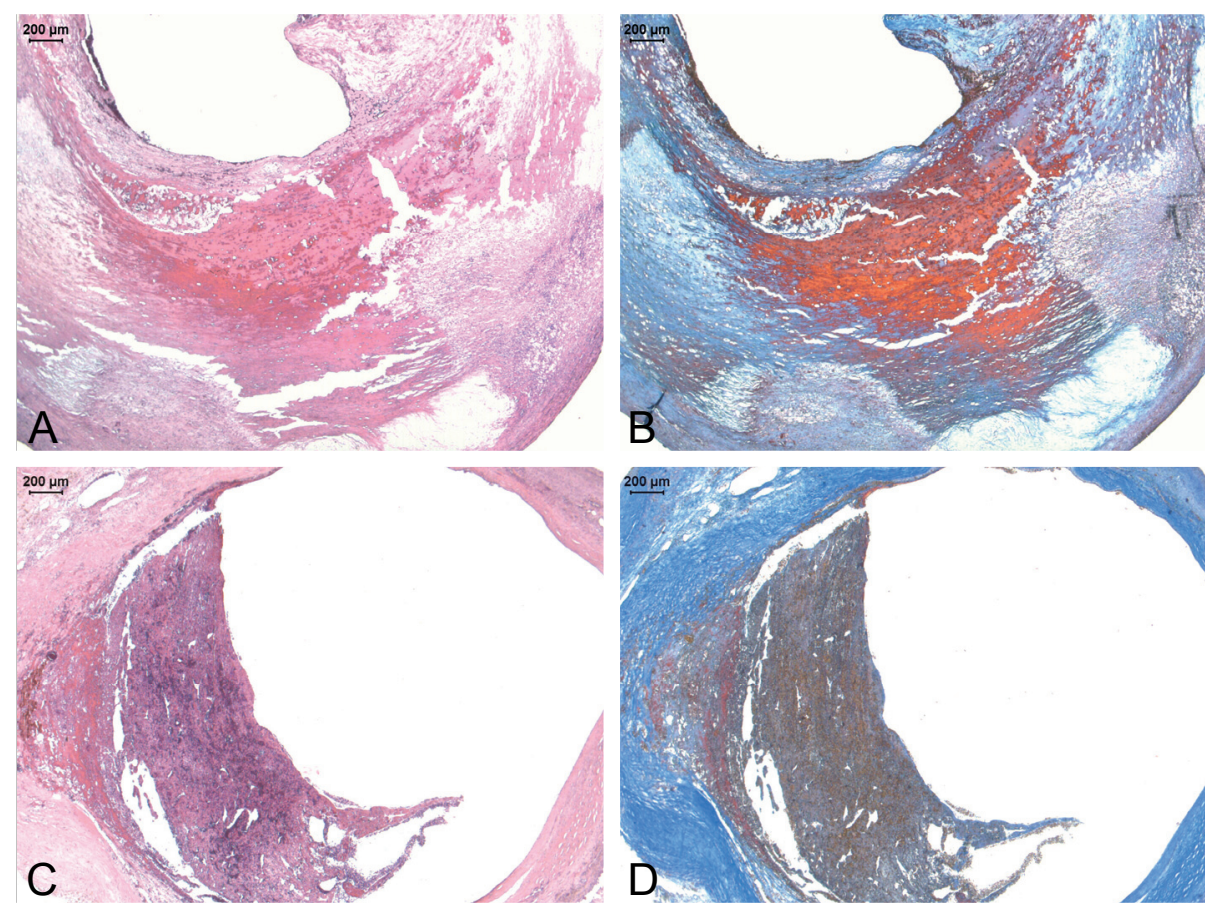

Figure 1. Human atherosclerotic lesions with intraplaque hemorrhage or non-occlusive luminal thrombus. (A) Hematoxylin and eosin (HE)-stained section of a carotid artery atherosclerotic plaque with intraplaque hemorrhage. (B) Martius, scarlet and blue (MSB)-stained section of the same plaque as in A, with fibrin deposition shown in red. (C) HE-stained section of a carotid artery atherosclerotic plaque associated with a nonocclusive luminal thrombus. (D) MSB-stained section of the same plaque as in $\mathrm{C}$ showing fibrin deposits in red and components of fresh thrombus (erythrocytes) shown in yellow. 


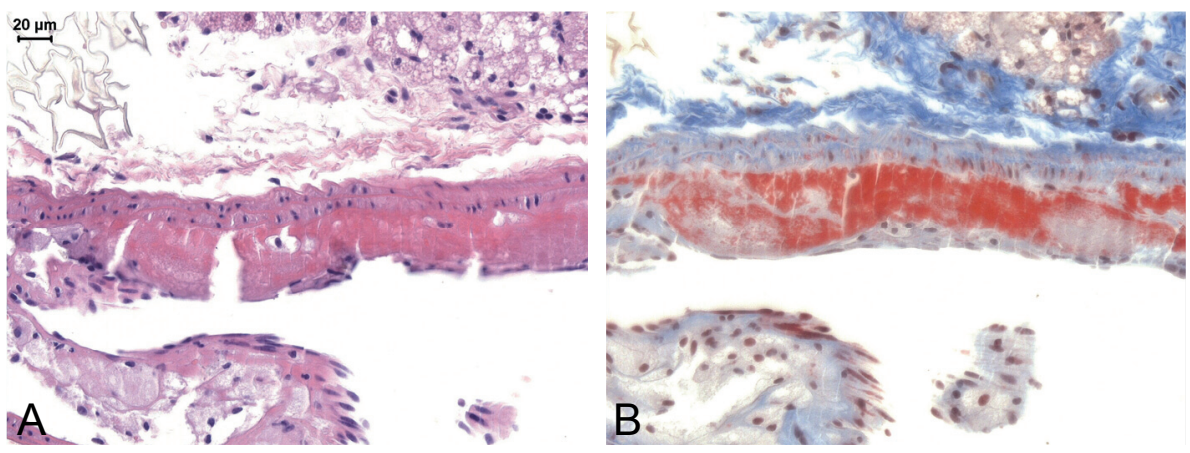

Figure 2. Mouse atherosclerotic lesion with intraplaque hemorrhage. (A) HE-stained section of an aortic arch atherosclerotic plaque with intraplaque hemorrhage. (B) MSB-stained section of the same plaque as in A showing fibrin deposition in red.

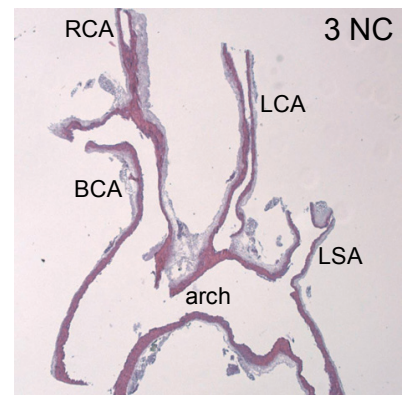

Plaque area: $26 \pm 21 \mu \mathrm{m}^{2 *}$

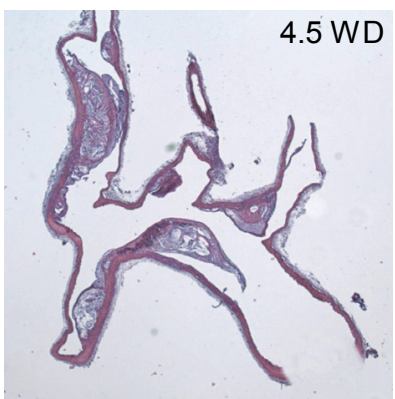

Plaque area: $668 \pm 142 \mu \mathrm{m}^{2 *}$

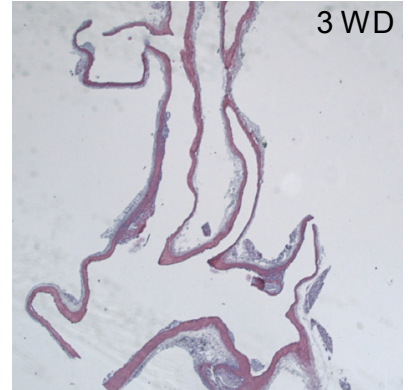

Plaque area: $106 \pm 26 \mu \mathrm{m}^{2 *}$

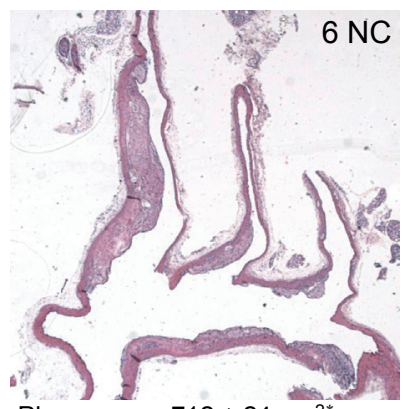

Plaque area: $712 \pm 24 \mu \mathrm{m}^{2 *}$

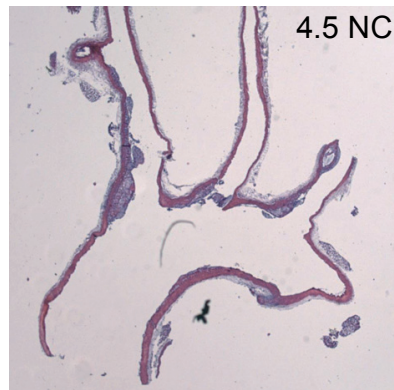

Plaque area: $162 \pm 42 \mu \mathrm{m}^{2 *}$

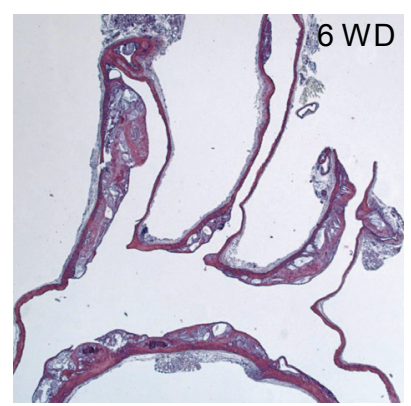

Plaque area: $1807 \pm 188 \mu \mathrm{m}^{2 *}$

Figure 1. HE-stained sections of aortic arches (arch) of ApoE-/- mice including the brachiocephalic artery (BCA), right common carotid artery (RCA), left common carotid artery (LCA), and left subclavian artery (LSA). ${ }^{*}$ Per $10^{3} \mu \mathrm{m}^{2}$ 

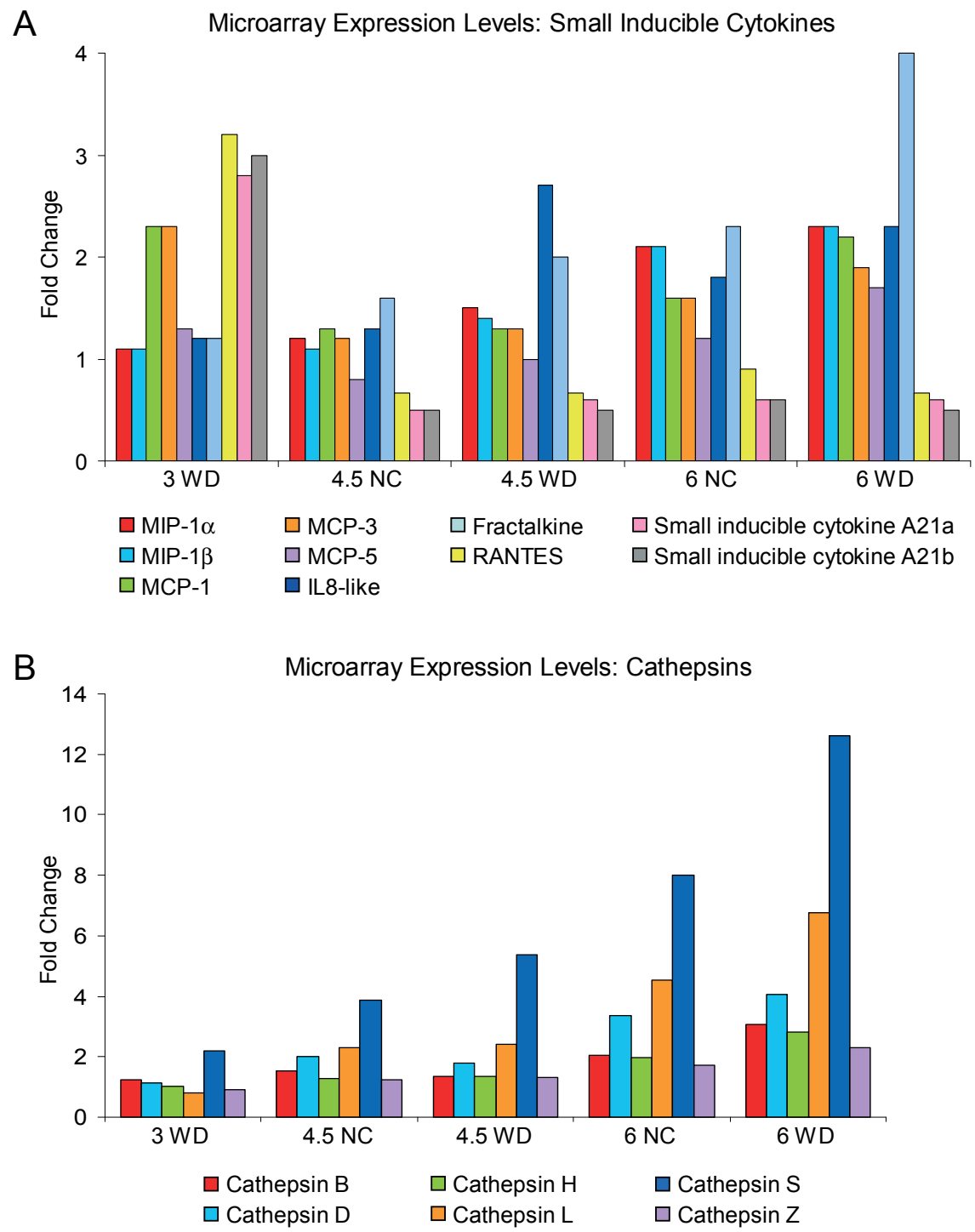

Figure 2. Microarray expression levels of members of the two most abundant clusters: the small inducible cytokines (A) and the cathepsins (B). 

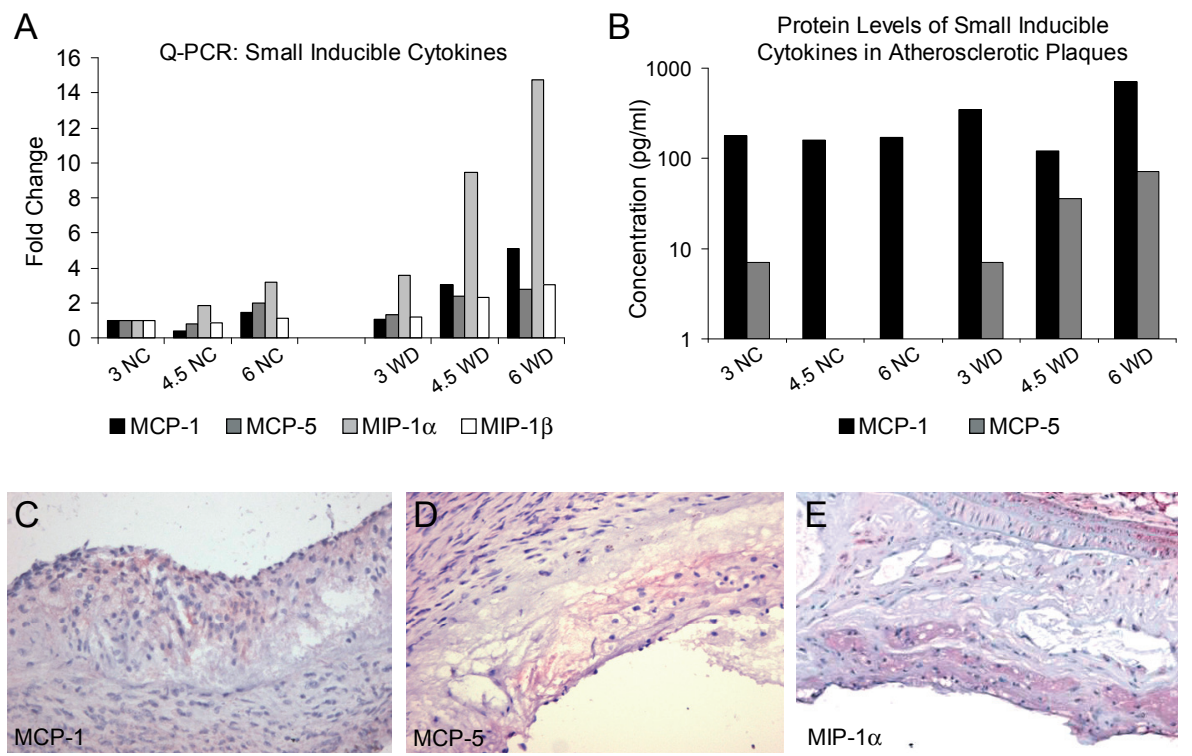

Figure 3. Validation experiments. (A) Quantitative PCR and (B) ELISA show that both RNA and protein levels of several members of the small inducible cytokine family (MCP-1, MCP-5, MIP-1 $\alpha$, and MIP-1 $\beta$ ) increase with disease progression. Immunohistochemistry for (C) MCP-1, (D) MCP-5 and (E) MIP- $1 \alpha$ show that these proteins are predominantly expressed in macrophages of advanced atherosclerotic lesions (magnification 400X).

\section{A}
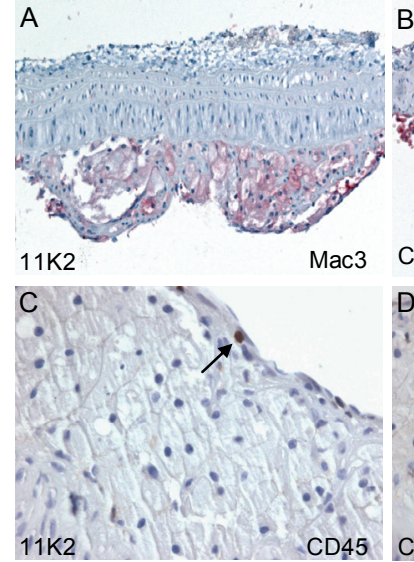

$\mathrm{E}$

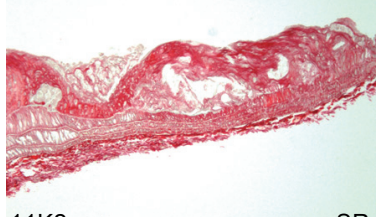

$11 \mathrm{~K} 2$

\section{B}

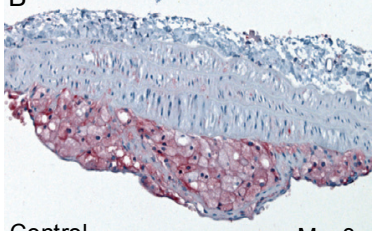

Control Mac3

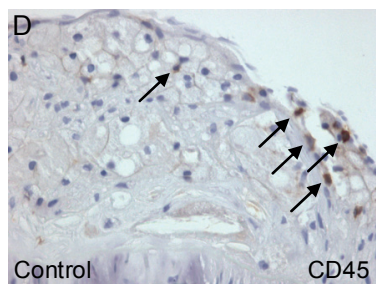

$\mathrm{F}$

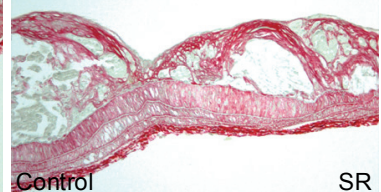

Figure 6. The relative amount of Mac3+ macrophages (200X) is decreased after (A) $11 \mathrm{~K} 2$ treatment compared with (B) control treatment. CD45 staining (400X) of advanced atherosclerotic lesions (shoulder region) revealed that $(C) 11 \mathrm{~K} 2$ treatment decreased the percentage of CD45+ leukocytes (indicated by arrows) compared with (D) control treatment. Sirius Red (SR) staining (100X) of advanced atherosclerotic plaques revealed an increase in collagen content after (E) $11 \mathrm{~K} 2$ treatment compared with (F) control treatment. 
A

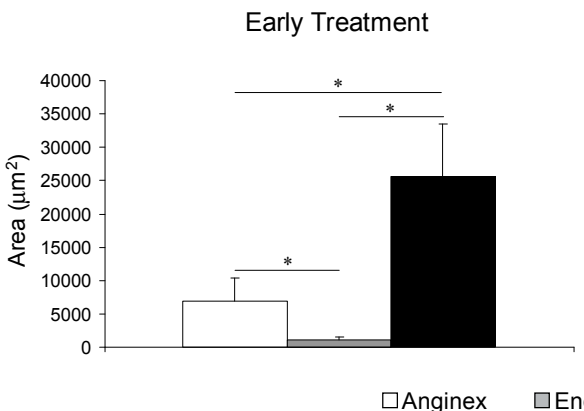

Early Treatment
B

\author{
Delayed Treatment
}

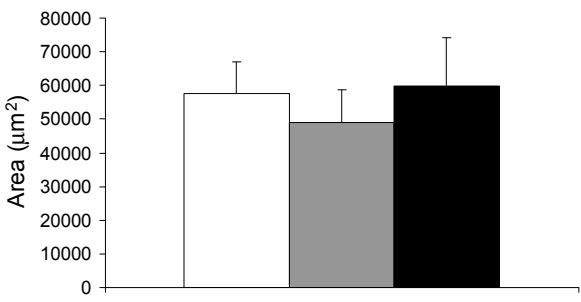

acontrol
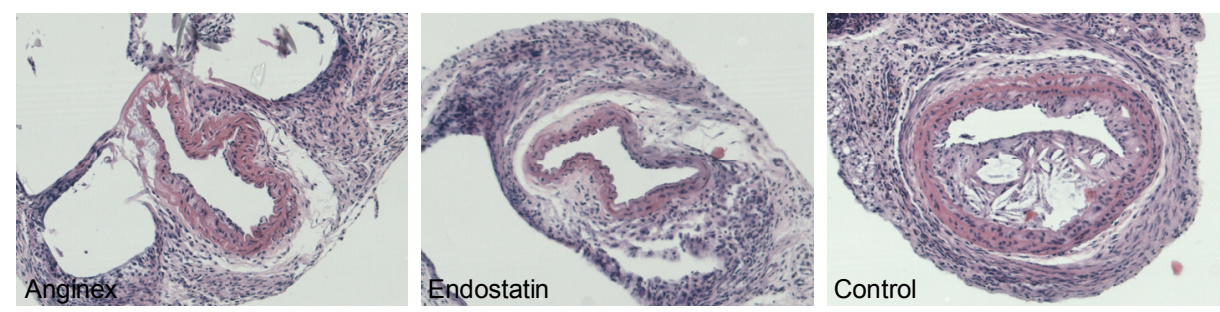

Figure 1. Reduced plaque area with early anginex or endostatin treatment. (A) Plaques of anginex or endostatin-treated mice of the early treatment group were smaller compared with controls. (B) No difference in plaque area between anginex or endostatin treatment compared with controls. ${ }^{*} \mathrm{P}<0.05$. Images are representative of carotid artery plaques of the early treatment group. 

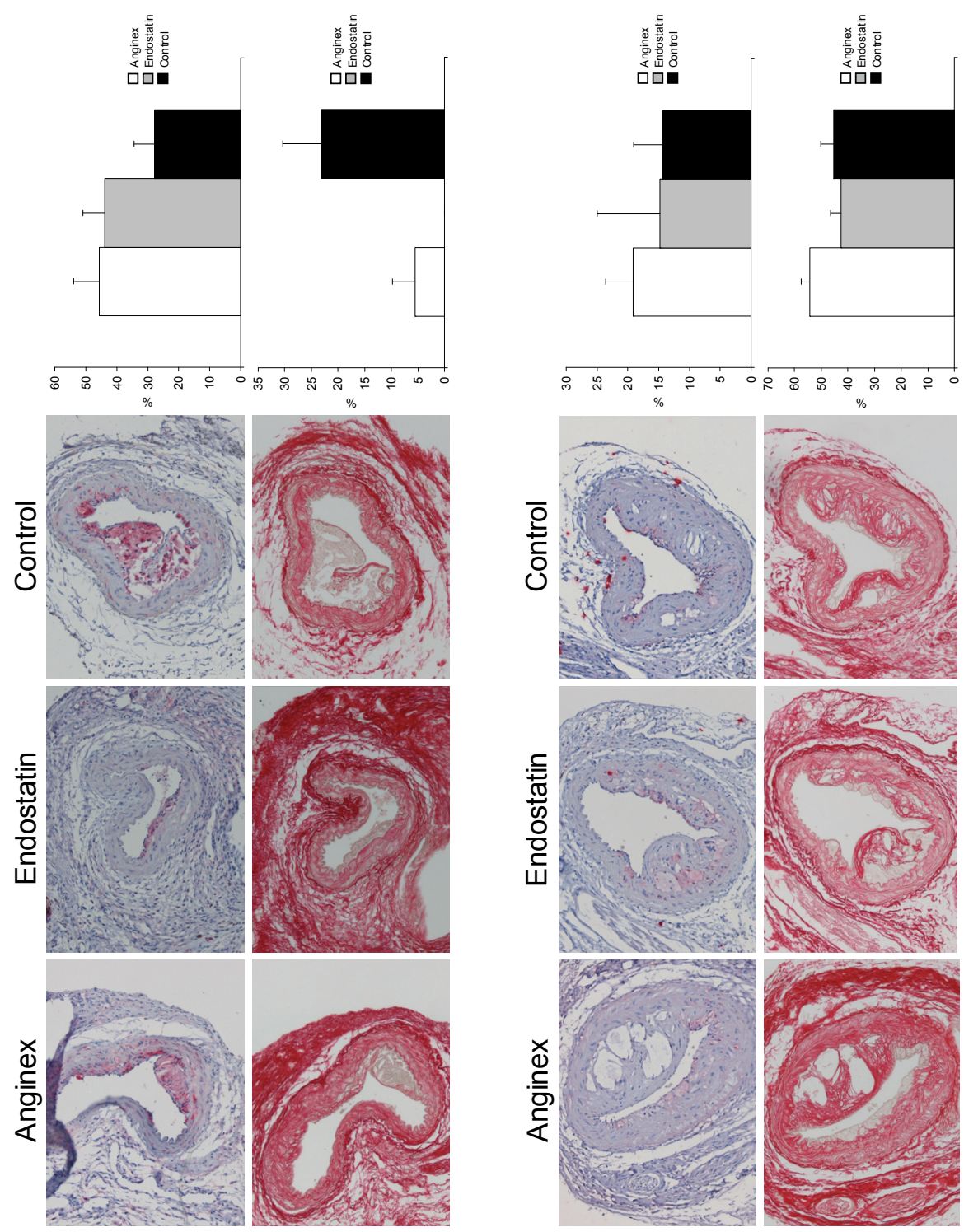

$\varangle$

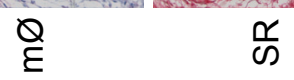

$\stackrel{Q}{\varepsilon}$

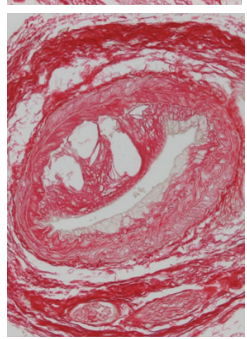

$m$

$\frac{x}{\infty}$

Figure 2. No change in plaque composition with anginex or endostatin treatment. There was no change in macrophage content $(\mathrm{m} \phi)$ or collagen content (SR, indicating Sirius Red staining) in either of the (A) early or (B) delayed treatment groups compared with controls. 


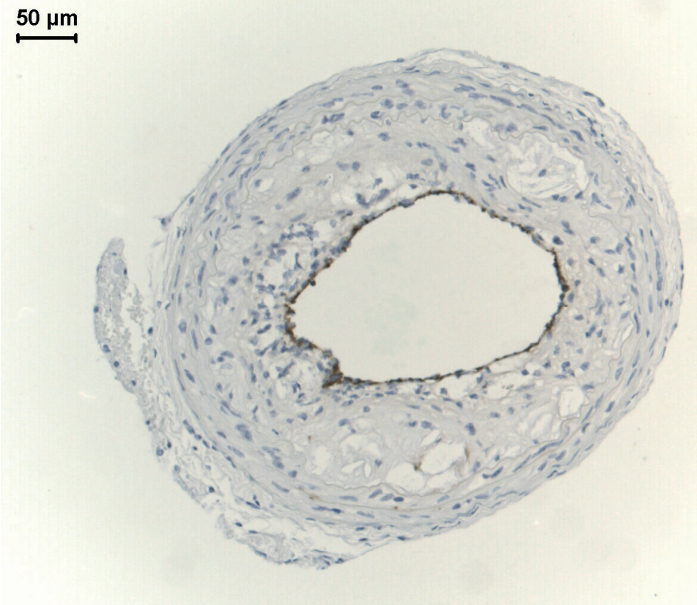

Figure 4. CD31 immunostaining of a carotid artery atherosclerotic plaque reveals positively stained luminal ECs.
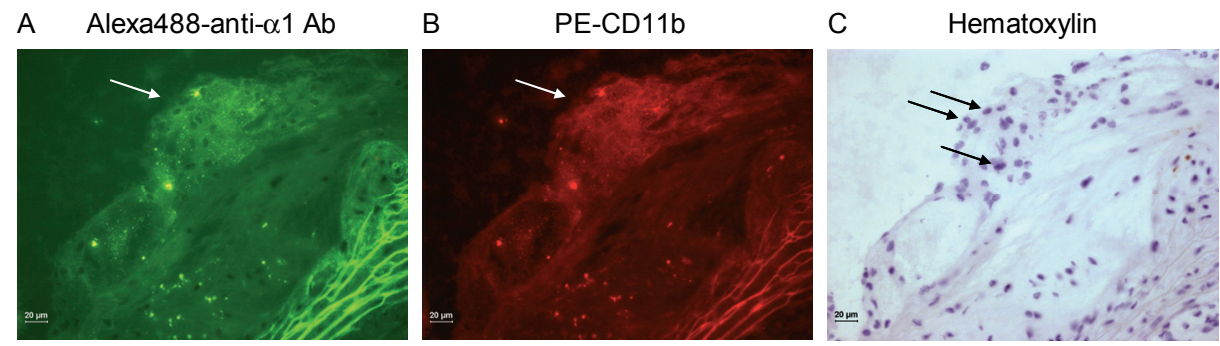

Figure 1. Fluorescence immunohistochemical staining showing expression of (A) $\alpha 1$ integrin (Alexa488-labeled anti- $\alpha 1 \mathrm{Ab}$, green, indicated by arrow) in (B) macrophages (PE-CD11b, red, indicated by arrow) in an advanced atherosclerotic plaque in the aortic arch of an ApoE-/- mouse. (C) Hematoxylin counterstaining of the same plaque showing macrophages (indicated by arrows). 
A

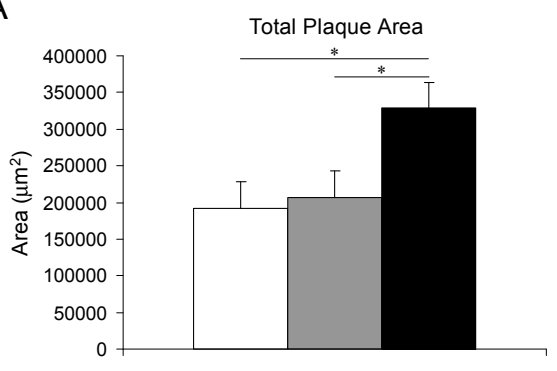

B

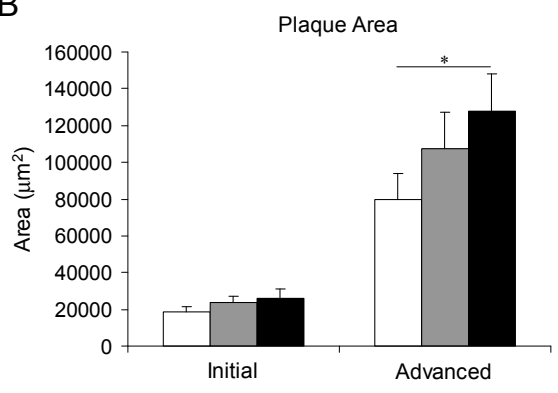

$\square \alpha 1-/-\quad \square \alpha 1+/-\quad \square \alpha 1+/+$
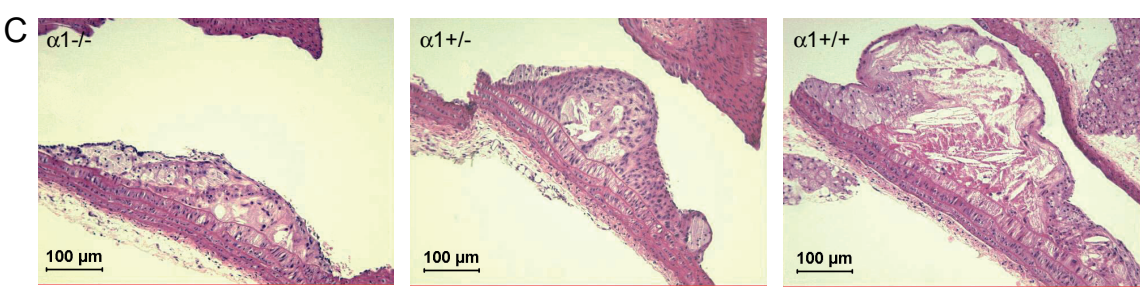

Figure 2. Deficiency in $\alpha 1$ integrin reduced plaque area in aortic arches. (A) Total plaque area of $\alpha 1-/-$ and $\alpha 1+/-$ mice was significantly smaller than those of $\alpha 1+/+$ mice. (B) Average area of individual advanced plaques of $\alpha 1-/-$ mice was smaller compared with those of $\alpha 1+/+$ mice. (C) HE-stained sections of representative advanced atherosclerotic plaques of $\alpha 1-/-, \alpha 1+/-$ and $\alpha 1+/+$ mice showing relative area of plaques. ${ }^{*} \mathrm{P}<0.05$. 


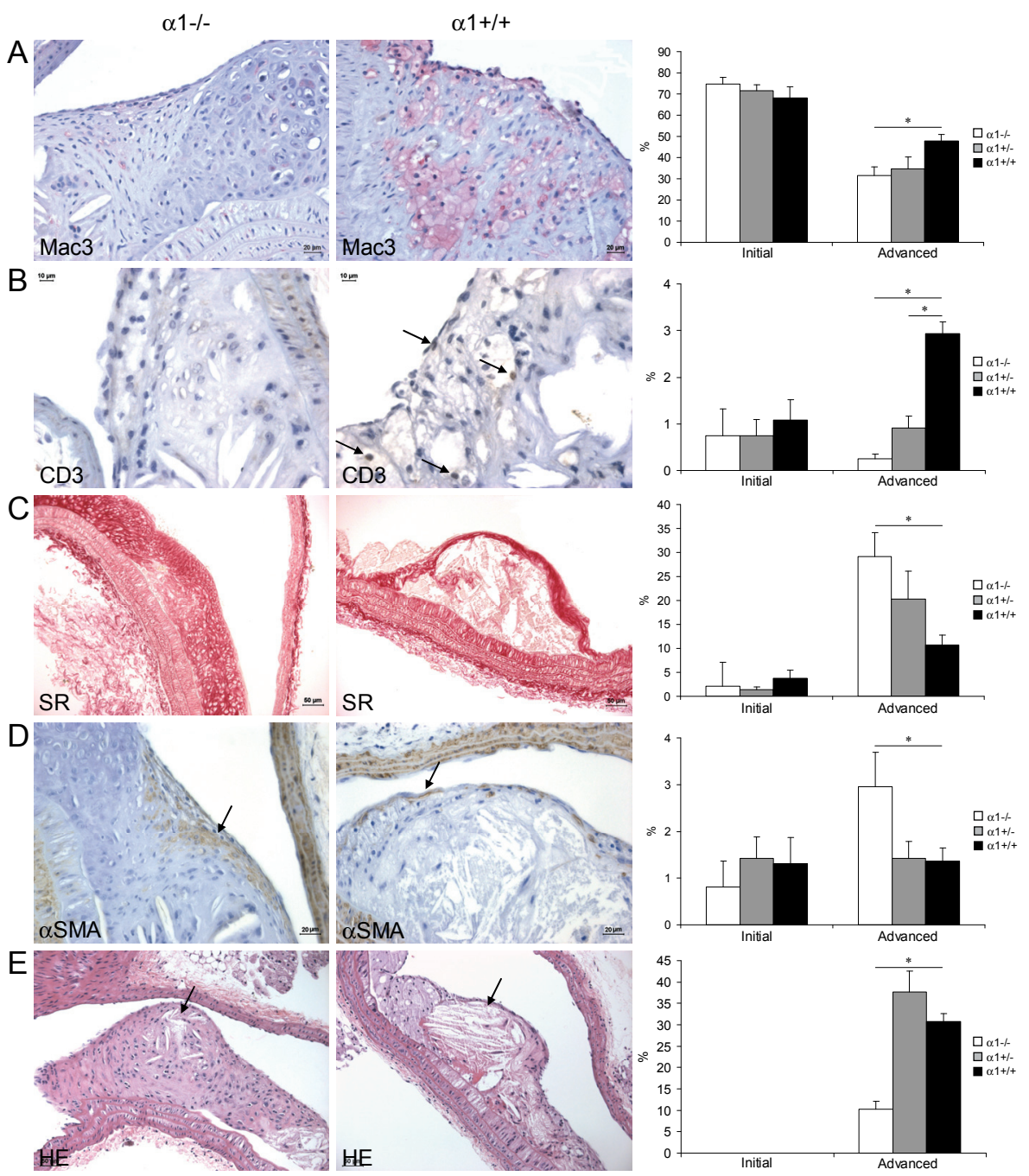

Figure 3. Plaque composition of initial and advanced atherosclerotic plaques in aortic arches of $\alpha 1$-deficient mice. There were significantly less (A) macrophages (Mac3+, red stained cells) and (B) CD3+ cells (arrows) in advanced plaques of $\alpha 1-/$ - compared with $\alpha 1+/+$ mice. There was a significantly higher (C) collagen content (SR+) and (D) SMC content ( $\alpha \mathrm{SMA}+$ cells, arrows) in advanced plaques of $\alpha 1-/$ - compared with $\alpha 1+/+$ mice. (E) Lipid cores were smaller in plaques of $\alpha 1-/$ - compared with $\alpha 1+/+$ mice (arrows). ${ }^{*} \mathrm{P}<0.05$. 
A
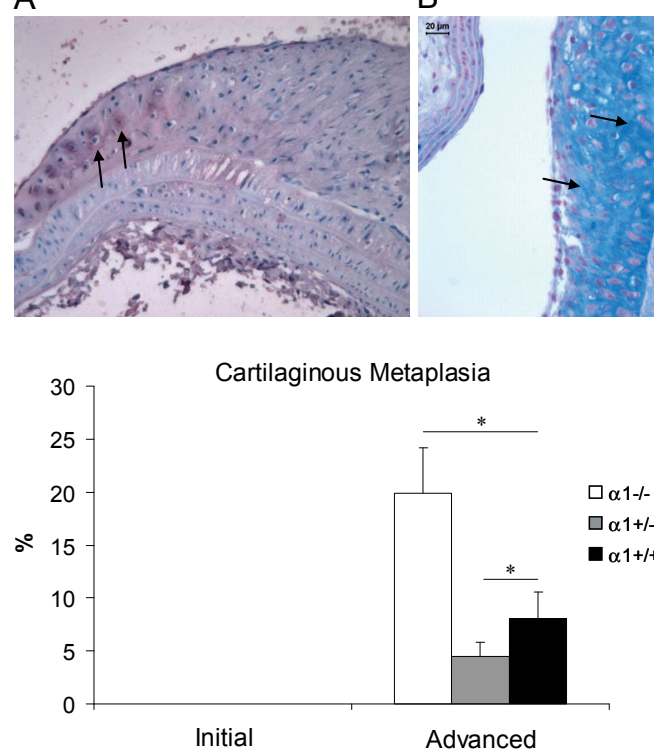

B

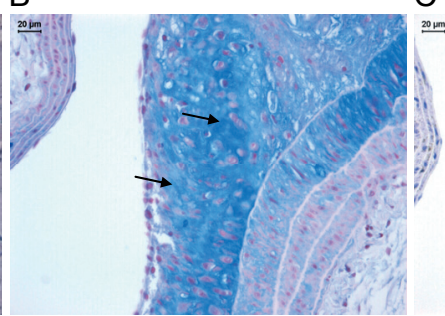

C

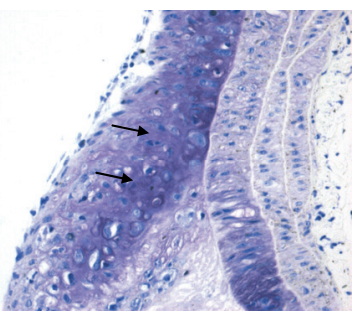

Figure 4. Cartilaginous metaplasia in advanced plaques in aortic arches of $\alpha 1$ deficient mice. (A) Collagen II is expressed in matrix (indicated by arrows) surrounding chondrocyte-like cells. (B) Alcian blue and (C) toluidine blue stainings show chondrocyte-like cells and chondroid matrix (indicated by arrows) in advanced atherosclerotic plaques of $\alpha 1-/-$ mice. ${ }^{*} \mathrm{P}<0.05$.
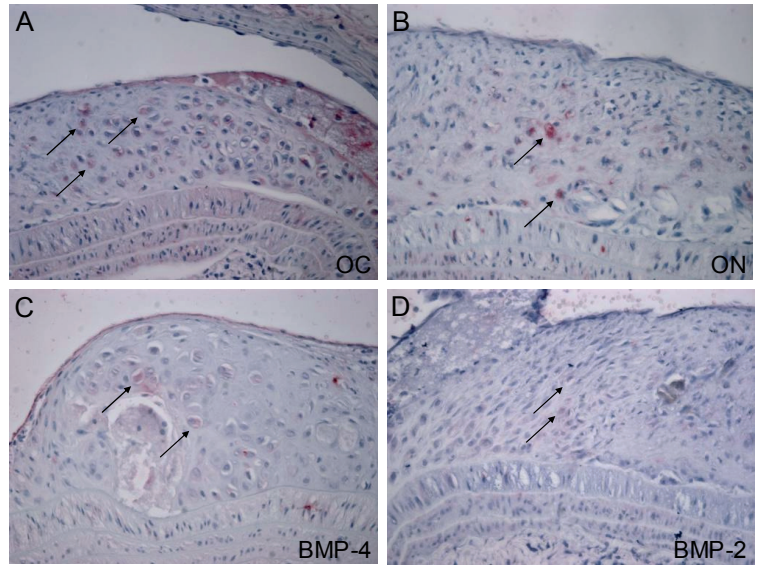

E

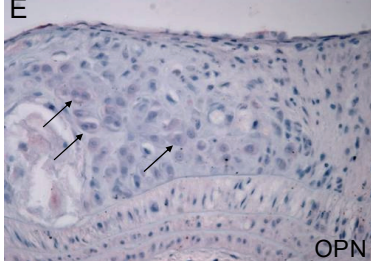

Figure 5. Expression of mediators of bone formation in atherosclerotic plaques in the aortic arch of $\alpha 1$-deficient mice. (A-C) Strong expression of OC, ON and BMP-4 in chondrocyte-like cells (indicated by arrows). Weaker expression of (D) BMP-2 and (E) OPN in chondrocyte-like cells (indicated by arrows). (F) MGP only expressed in macrophages (indicated by arrow). Magnification: $400 \mathrm{X}$ 


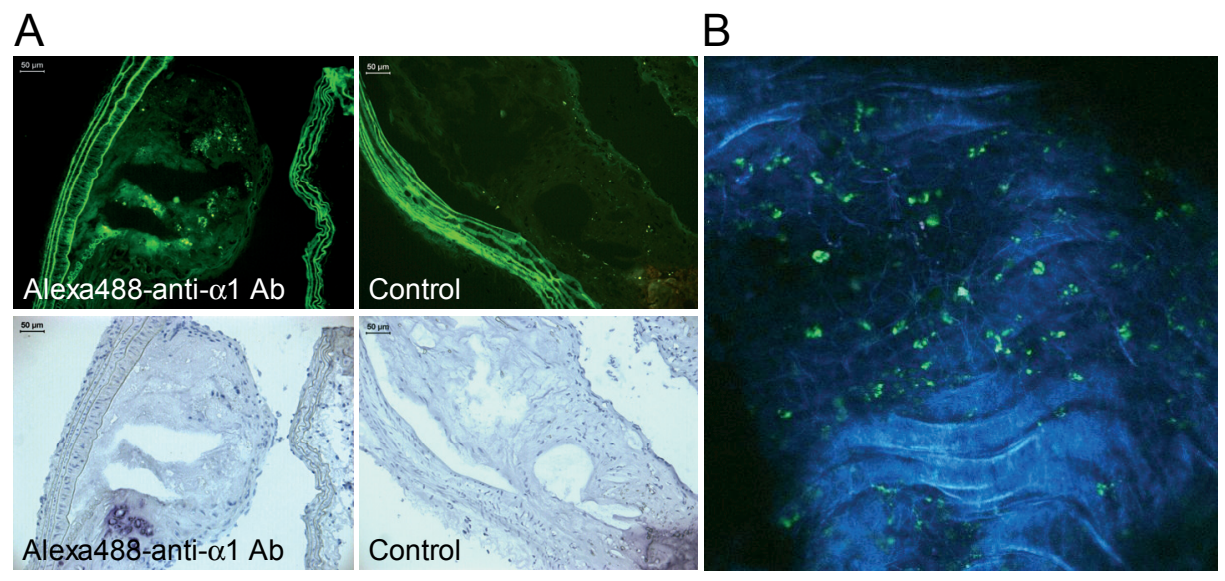

Figure 7. Anti- $\alpha 1$ antibody infiltrated atherosclerotic plaques of ApoE-/- mice. (A) Fluorescence and bright field images of atherosclerotic plaques in the aortic arch of ApoE-/- mice injected with Alexa488-labeled anti- $\alpha 1$ antibody or not injected with any antibody (control). Antibody appears as green spots in the plaque and autofluorescence of elastic laminae in the media are shown in green. (B) TPLSM 3D image of an atherosclerotic plaque in the carotid artery of an ApoE-/mouse injected with Alexa488-labeled anti- $\alpha 1$ antibody. Antibody appears as green spots and collagen fibers in the plaque and media are shown in blue. 


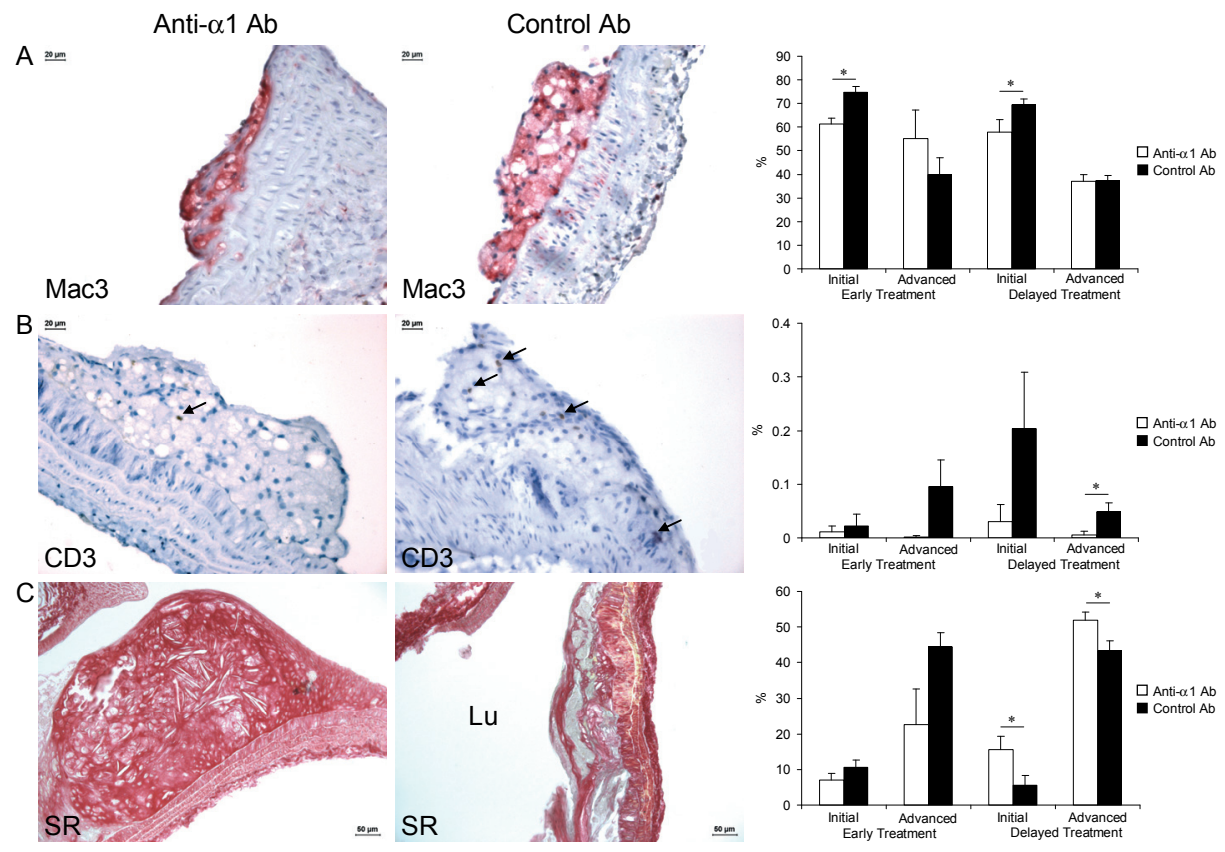

Figure 8. Plaque composition of initial and advanced atherosclerotic plaques in aortic arches of antibody-treated mice. There were significantly less (A) macrophages (Mac3+, red stained cells) and (B) CD3+ cells (brown stained cells, arrows) and a higher (C) collagen content (SR+ areas shown in red) in plaques of anti- $\alpha 1$ antibody-treated compared with control mice (Lu indicates lumen). ${ }^{*} \mathrm{P}<0.05$.

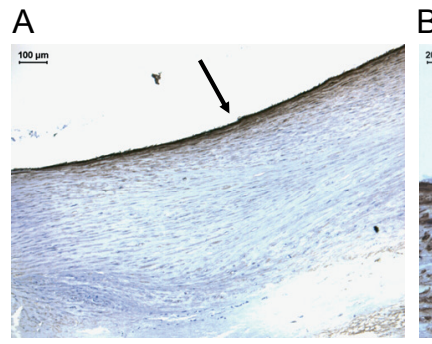

B

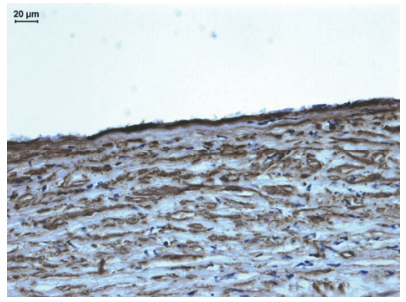

C

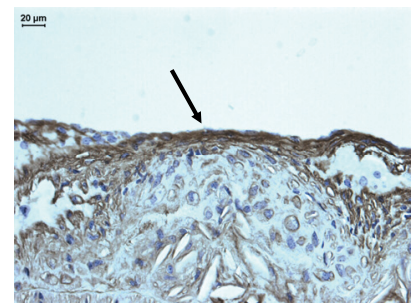

Figure 10. Collagen IV expression in mouse and human atherosclerotic plaques. (A) Advanced atherosclerotic plaque in a human carotid artery expressing collagen IV in the region of endothelial cells (indicated by arrow, magnification 10X) and (B) shown at higher magnification (40X). (C) Advanced atherosclerotic plaque in a mouse aortic arch showing collagen IV expression in the region of endothelial cells and somewhat surrounding cells within the plaque (indicated by arrow, magnification 40X). 
A

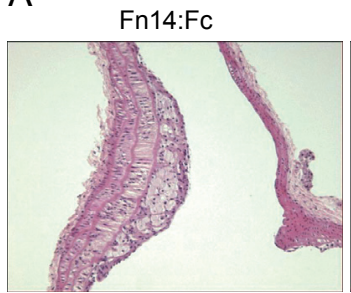

Control $\mathrm{Ab}$
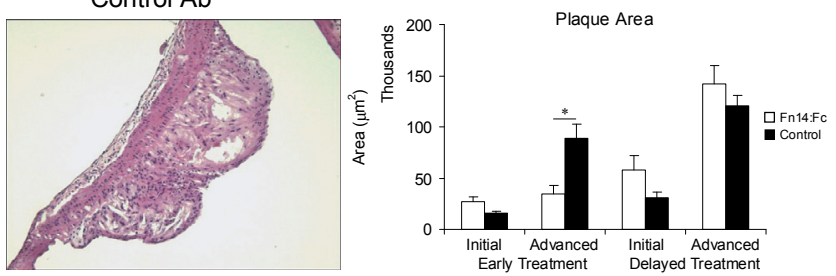

B

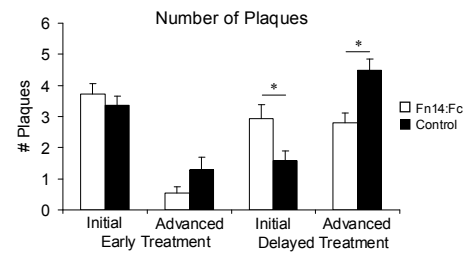

Figure 1. Smaller advanced plaques with early Fn14:Fc treatment and fewer advanced plaques with delayed treatment. (A) Early Fn14:Fc treatment resulted in smaller plaque areas compared with control mice. (B) Delayed Fn14:Fc treatment resulted in more initial plaques and fewer advanced plaques. ${ }^{*} \mathrm{P}<0.05$. 


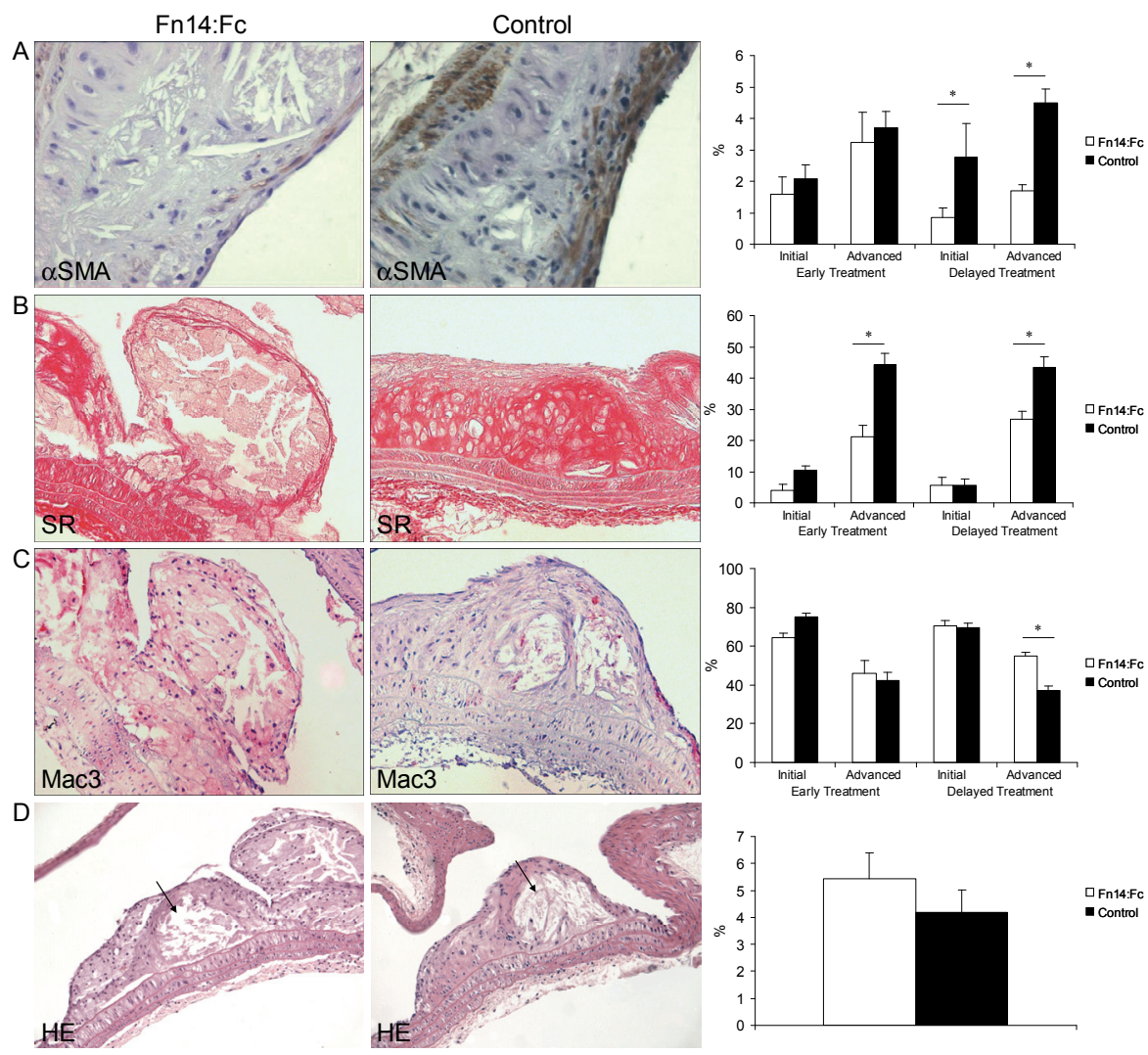

Figure 2. Plaque composition of initial and advanced atherosclerotic plaques. Fibrotic content of atherosclerotic plaques was significantly lower with Fn14:Fc treatment due to (A) a reduced $\alpha$ SMA content in initial and advanced plaques of mice that received delayed Fn14:FC treatment and (B) a reduced collagen content as shown by SR staining in advanced plaques following both early and delayed Fn14:Fc treatment compared with controls. (C) Macrophage content as shown by Mac3 immunohistochemical staining increased in advanced plaques of Fn14:Fc-treated mice compared with controls. (D) Lipid core content (indicated by arrow) as shown by HE staining in advanced plaques did not differ between Fn14:Fc-treated mice and controls in the delayed treatment group. ${ }^{*} \mathrm{P}<0.05$. 

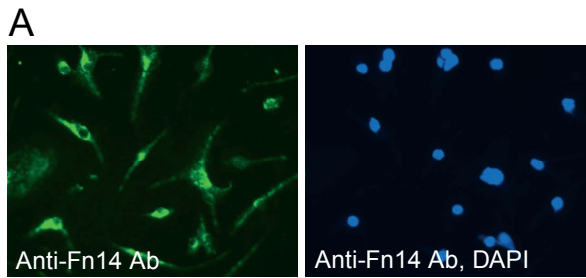

B
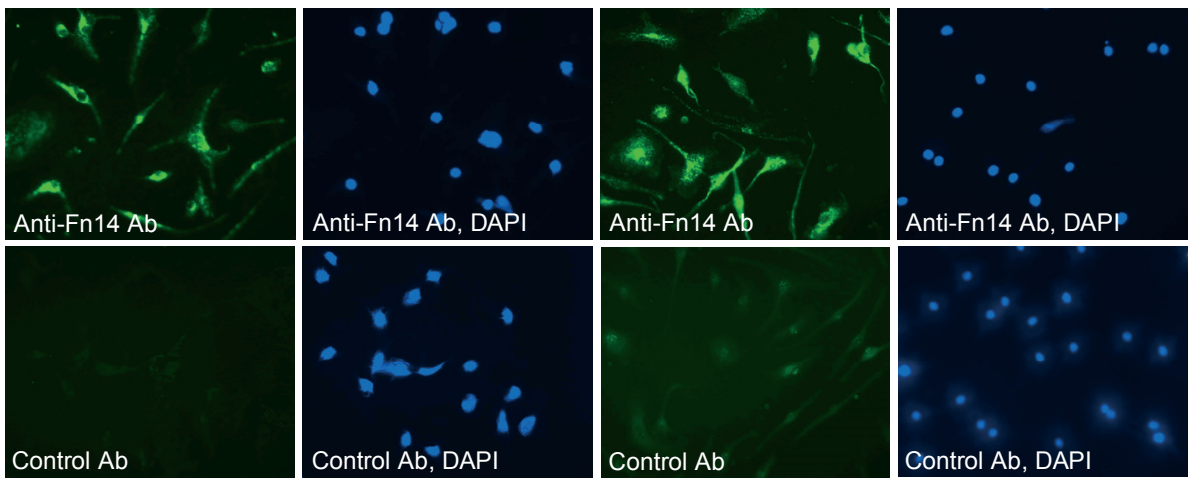

Figure 4. Fn14 is expressed on bone marrow-derived macrophages and foam cells as detected by immunohistochemistry using anti-Fn14 Ab. Fn14 was expressed on (A) macrophages and (B) foam cells treated with oxLDL for 48 hours. Nuclei were counterstained with DAPI. Control cells were stained with Ig isotype Ab. 


\section{Acknowledgements / Dankwoord}

In de eerste plaats wil ik mijn promotor Mat Daemen bedanken, mijn allereerste baas en werkgever in Nederland. Mat, ik heb 7 jaar geleden bij jou gesolliciteerd toen ik naar Nederland kwam. Ik was maar net een paar maanden in Nederland en ik had toen al via via gehoord dat ik absoluut bij Mat Daemen moest gaan solliciteren als ik in de onderzoekswereld wilde gaan werken. Ik wist toen eigenlijk niet wie je was, had nooit eerder van je gehoord, maar terugkijkend ben ik heel blij dat ik mijn promotieonderzoek bij jou heb gedaan. Ik heb ontzettend veel van je geleerd, niet alleen over atherosclerose, maar ook over de Nederlandse werkcultuur en mijn opstelling daarin. Dank je wel voor je steun. Tot slot wil ik je ook nog bedanken voor het opsporen van mijn (engelstalige) spelfouten!

Sylvia, mijn copromotor, we hebben nauw met elkaar samengewerkt. Ik kon altijd bij je terecht als ik het nodig had, maar je hebt me ook de ruimte gegeven om zelfstandig te werken. Je rustige manier van begeleiden heb ik erg op prijs gesteld en je feedback en suggesties waren altijd heel waardevol. Ik had geen betere promotieteam kunnen wensen met jou en Mat! Dank je wel voor je hulp en steun.

Linda, my friend, colleague, roommate, labmate, witness, workout buddy, and now paranimf. We've become great friends since we bonded over "coupes snijden". There are too many inside jokes and things to mention where you're concerned, I'd need another book. Just to name a few...DDD, toeds, and B-A-N-A-N-A-S! (We've shared so much, we've even developed our own language). Thanks man for always being there... and bringing cake!

Anouk, ook mijn paranimf, met jou heb ik heel snel een goede band gevormd, waarvoor het FACSen een goede gelegenheid was. Ik zal voor altijd PBS-AAA met jou associëren! Ik vond het heel gezellig om met jou te werken en op stap gaan. Je hebt een belangrijke bijdrage geleverd aan hoofdstuk 5, heel veel bedankt voor je hulp. En ook bedankt dat je mijn paranimf wilt zijn!

Cardio-kipjes (collega AIO's), we hebben heeeeeel veel samen gedeeld tijdens onze AIOschap, en ik heb ontzettend veel lol gehad in onze "kippenhok". Ook buiten het hok hebben we goed gefeest. Linda, over jou heb ik het al hierboven gehad, maar je krijgt een "honorary mention" aangezien je één van de zes "chicks" bent. Marjo, je bent altijd heel lief en sympathiek geweest. Bedankt voor je advies en het opbeuren 
van iedereen als het een keer minder goed ging. Suus, je hebt me heel vaak aan het lachen gemaakt. Je hebt altijd voor een goede sfeer gezorgd met je speciale humor, en chocolade natuurlijk! Heel veel succes met je promotie binnenkort. Natasja, je bent tijdens het hele AIOschap mijn kamergenoot geweest, ook toen we naar een andere kamer zijn verhuisd. Bedankt dat je er altijd was als ik even iets kwijt wilde, en voor het leren van de belangrijkste Nederlandse scheldwoorden! Jij ook veel succes met je promotie en met post-doc-en in Brussel. Judith, ik ben altijd onder de indruk geweest van je assertiviteit. Jij ook veel succes met de laatste loodjes als laatste der Mohica(IO)nen (jouw woord)! Jullie waren het beste inburgeringsprogramma die een buitenlander zich kan wensen! ( $\mathrm{Nu}$ moet ik alleen die k\#\&!\% scheldwoorden zien af te leren nu ik een moeder ben...)

Esther, we hebben veel samengewerkt aan de hoofdstukken in dit boekje. Bedankt voor alle hulp met de muizen en dat ik altijd bij je terecht kon om even iets te vragen (en dat was best vaak). Ik vond het leuk om samen te werken en ook dat we tegelijkertijd zwanger waren en onze ervaringen konden delen!

Kitty, jij was mijn eerste begeleider bij pathologie toen ik als lab assistent was begonnen. Bedankt dat je altijd enthousiast en geïnteresseerd bent geweest in mijn projecten, en voor je altijd beschikbare advies.

Zonder de mensen op het lab zou dit boekje zeker niet zijn ontstaan. Anique, Ine en Petra, dank je wel voor de talloze coupes die jullie hebben gesneden en gekleurd. Het heeft mooie figuren opgeleverd! Mat, je hebt veel uren achter de FACS gezeten voor mijn experimenten. Dank je wel dat je altijd tijd voor me heb gemaakt, zelfs als ik je hulp last minute nodig had, wat best vaak het geval was! Jack, quantimetten is nooit mijn grootste hobby geworden, maar dankzij jou programma's was het een stuk makkelijker vol te houden. Barry, dank je wel voor je EHBO bij computerongelukken...zonder jou had ik mijn computer al lang uit de raam gegooid!

Elly, Cor, en het overige secretariaat, bedankt voor alle administratieve ondersteuning...zonder jullie hulp was ik absoluut verdwaald in het woud van alle regeltjes! Robert-Jan, je was mijn kruiwagen voor een sollicitatiegesprek met Mat, dank je wel daarvoor. Het was ook altijd leuk om op de gang over Toronto te kletsen. Carine, bedankt voor je interesse in mijn projecten, en tips voor het borstkolven op het werk! De rest van de clinische kant wil ik ook bedanken voor de gezellige gesprekjes, meestal in de koffiekamer.

Er zijn nog een aantal mensen die ik de afgelopen jaren bij pathologie heb zien komen en gaan. Cherida, bedankt voor het advies die je me vroeg in mijn AIOschap hebt gegeven. Birgit, ik heb erg genoten van je kunst om een verhaal met droge humor te vertellen! Ann-Pascale, bedankt voor het uitleggen hoe het nou allemaal zit 
met die microarrays. Veronica and Wanwisa, it was fun sharing our experiences as foreigners in the Netherlands! De nieuwe generatie AIO's en analysten, Dirk, Wouter, Erwin en Chantal heb ik pas in mijn laatste jaar leren kennen en het was al snel gezellig. Succes met jullie onderzoek en verdere carriere! Lily, I also wish you lots of luck and success with your $\mathrm{PhD}$ thesis.

Mensen bij de angiogenese groep, Arjan, Victor en Daisy, bedankt voor jullie hulp met het anginex project. Het wordt vast nog een mooie publicatie. Femke, mijn gezellige kamergenootje in het laatste jaar. Bedankt voor je luisterend oor, ook voor al mijn zwangerschapskwaaltjes! Edith, dank je wel voor je hulp met de cellen. Ik kon er altijd op rekenen dat je medium klaar had staan. De anderen AIO's, post-docs en analysten bij deze groep, bedankt voor de gezellige gesprekjes op de gang!

I would like to thank several people at Biogen Idec with whom we collaborated on three of the projects in this book. Linda Burkly, thank you for all your great advice and suggestions for the TWEAK project, as well as for quickly providing TWEAK reagents whenever we needed them. Tony de Fougerolles and Victor Koteliansky (currently at Alnylam Pharmaceuticals) and Humphrey Gardner - the VLA experts, thank you for all your help and input into the VLA project.

Buiten pathologie zijn er verschillende afdelingen die me hun onderzoeksfaciliteiten en expertise beschikbaaar hebben gesteld. Met de mensen van de afdeling farmacologie heb ik veel gewerkt en ik heb me daar altijd welkom gevoeld. In het bijzonder wil ik Agnieska bedanken voor het inspuiten van de muizen voor bijna alle projecten in dit boek. Nicole en Jack, dank jullie wel voor jullie hulp met de muizen en het leren van technieken. Ik vond het altijd gezellig om bij farmaco te komen werken! Een andere afdeling die veel samenwerkt met pathologie is moleculaire genetica. Marion, Menno, Danielle, Inge en Matthijs, dank jullie wel voor jullie hulp als ik het nodig had en vooral voor het mogen lenen van materialen en protocollen. Bij biofysica wil ik Remco en Kim bedanken voor het uitvoeren van de imaging studies voor hoofdstuk 5. Hans te Poele en Fiona Stewart bij de NKI, bedankt voor het mogen gebruiken van jullie lab en materialen. Marjan Smook die bij immunologie werkte, ook jij bedankt voor je hulp met de FACS. Chris Reutelingsperger bij biochemie, dank u wel voor het voorzien van Annexin V. De mensen bij de CPV...Rik, heel veel bedankt voor het opereren van de muizen. Nadine, Peter en Richard, bedankt voor jullie goede zorgen voor al mijn muisjes.

Mom and dad, now you get to see what I've been doing "across the pond" all this time. Nem vertem a seggemet a földhöz! Thank you for your unconditional love and support of everything I've ever wanted to do! 
Han, you of all people have been there through all the ups and downs of producing this thesis. I am immensely grateful for all the support and encouragement you've given me. I promise now that this book is finished, I'll have more time to go on vacation...I'll even go camping!

My baby girl, Simone, thank you for being the easiest, most cheerful baby a new mom in her last year as a PhD student could ever ask for!

Verder alle vrienden, familie en buren, bedankt voor jullie belangstelling de afgelopen jaren!!! 


\section{Curriculum Vitae}

Kitty Schapira was born on April 25, 1975 in Oradea, Romania. After having moved to Israel and then Greece at a young age with her parents, they settled in Toronto, Canada in 1982. She obtained her Ontario Secondary School Diploma in 1994 from Don Mills Collegiate Institute. That same year she began studies at York University in Toronto and obtained a Bachelor of Science degree in biology in 2000. After graduating from York University, she immigrated to the Netherlands where she began Dutch language courses at the Maastricht University Language Center in September 2001. During this time, she also worked as a research assistant at the Department of Pathology, Maastricht University under the supervision of Dr. Kitty Cleutjens, PhD. In 2002, she obtained her Dutch as a Second Language (NT2) certificate. From September 2002 until the present, she worked as a PhD student at the Department of Pathology, Maastricht University where she investigated regulators of atherosclerotic plaque stability under the supervision of Dr. Sylvia Heeneman, $\mathrm{PhD}$ and Dr. Mat J.A.P. Daemen, MD, PhD. 


\section{Publications}

Schapira K, Heeneman S, Daemen MJAP. Animal models to study plaque vulnerability. Current Pharmaceutical Design 2007;13(10):1013-1020.

Schapira K, Lutgens E, de Fougerolles A, Sprague A, Roemen A, Gardner H, Koteliansky V, Daemen MJAP, Heeneman S. Genetic deletion or antibody blockade of $\alpha 1 \beta 1$ integrin induces a stable plaque phenotype in ApoE-/- mice. Arteriosclerosis, Thrombosis and Vascular Biology 2005;25:1917-1924.

Lutgens E, Faber B, Schapira K, Evelo CTA, van Haaften R, Heeneman S, Cleutjens KBJM, Bijnens AP, Beckers L, Porter JG, Mackay CR, Rennert P, Bailly V, Jarpe M, Dolinski B, Koteliansky V, de Fougerolles T, Daemen MJAP. Gene profiling in atherosclerosis reveals a key role for small inducible cytokines: validation using a novel monocyte chemoattractant protein monoclonal antibody. Circulation 2005;111 (25):3443-3452.

Schapira K, Burkly LC, Zheng TS, Kockx MM, Daemen MJAP, Heeneman S. TWEAK inhibition reduces fibrosis and alters the macrophage phenotype in atherosclerotic plaques of ApoE-/- mice. Submitted.

Schapira K, Heeneman S, Donners MMPC, van der Schaft DWJ, Thijssen VL, Mayo $\mathrm{KH}$, Daemen MJAP, Griffioen AW. Anti-angiogenesis treatment with anginex or endostatin inhibits early lesion development in collar-induced atherosclerotic lesions of ApoE-/- mice. In preparation.

Dhore CR, Geusens PPMM, van Rietbergen B, Schapira K, Gijbels M, Cleutjens JPM, Daemen MJAP. A third generation biphosphonate, Risedronate, has no effect on the development of atherosclerosis in ApoE-/- mice in doses that affect bone density. Submitted. 